\title{
CONSTRUYENDO LA ENERGÍA SOSTENIBLE EN COLOMBIA
}

Recopilación de artículos científicos Cuarto Congreso de Energía Sostenible 



\section{CONSTRUYENDO LA ENERGÍA SOSTENIBLE}

EN COLOMBIA

Recopilación de artículos científicos, Cuarto Congreso de Energía Sostenible 


\section{Construyendo la Energía Sostenible en Colombia}

\section{Recopilación de artículos científicos Cuarto Congreso de Energía Sostenible}

Congreso de Energía Sostenible, 2018

Bogotá, Colombia

www.congresoenergiasostenible.org

(c) Todos los derechos reservados.

Se permite la reproducción total

o parcial de esta obra citando la fuente.

\section{Comite científico}

Dr. Camilo Monroy

Universidad ECCI

Ph.D. Luisa Marina Gómez

Universidad Manuela Beltrán

cPh.D. Jair Alexander Ladino

Universidad del Valle

Ph.D. Dionisio Malagón

Universidad Santo Tomás

M.Sc. Javier Bonilla

Universidad ECCl

M.Sc. Laura Carolina Hernández

Universidad Nacional de Colombia

\section{Comité Organizador}

Ph.D. Dionisio Humberto Malagón

Universidad Santo Tomás

M.Sc. Diana Fajardo

Universidad el Bosque

Carlos Pachón

Organización Akkuaippa

Ph.D. Marco Velasco

SENA - Centro de Metalmecánica

Esp. Bolívar Monroy

Acaire

M.Sc. Benedexa Maldonado

SENA - Centro de Transporte Automotriz
Diseño de portada

Carlos E. Pachón

Asociación Akuaippa

\section{Diagramación}

Carlos E. Pachón

Elizabeth Abril Pulido

Asociación Akuaippa

Corrección de estilo

M.Sc. Laura Carolina Hernández

\section{ISBN versión digital}

En trámite

\section{Editorial}

Asociación Akuaippa

Bogotá, Colombia 


\section{CONTENIDO}

PAG. TÍTULO

$7 \quad$ PRÓLOGO

9 COMPUTATIONAL SIMULATION OF THE HYDRAULIC PERFORMANCE OF A HORIZONTAL AXIS HYDROCYNETIC TURBINE

15 ANÁLISIS DEL CICLO DE VIDA DE LA PRODUCCIÓN DE VAPOR UTILIZADO EN LAS ZONAS HÚMEDAS DEL UMB GOLF CLUB

22 LA INFLUENCIA DEL EMBALSE EL PEÑOL-GUATAPÉ, ANTIOQUIA EN LOS PATRONES CLIMÁTICOS Y METEOROLÓGICOS A ESCALA LOCAL Y REGIONAL

APLICACIÓN DE LAS ENERGÍAS RENOVABLES AL INTERIOR DE LA UNIVERSIDAD ECCI

CELLULOLYTIC ENZYMES PRODUCTION BY Trichoderma asperellum USING CHRYSANTHEMUM WASTE

ACTIVATION ENERGY FOR PYROLYSIS OF MACADAMIA SHELLS

EMPLOYING NON-ISOTHERMAL ISOCONVERSIONAL METHODS

GENERACIÓN CATALÍTICA DE HIDRÓGENO A PARTIR DE BIODONANTES

HIDROGENACIÓN DE ACEITE DE PALMA POR TRANSFERENCIA CATALÍTICA

68 ACCIÓN CATALÍTICA DE METALES NOBLES EN EL HIDROTRATAMIENTO DE ACEITE DE PALMA

74 DISEÑO Y CONSTRUCCIÓN DE UN PIROLIZADOR A ESCALA LABORATORIO PARA LA OBTENCIÓN DE COMBUSTIBLE

78 TRATAMIENTO DE ACEITES USADOS DE MOTOR DIÉSEL PARA SU EVALUACIÓN COMO POSIBLE COMPUESTO REUTILIZABLE EN DIFERENTES PROCESOS DEL CENTRO DE TECNOLOGÍAS DEL TRANSPORTE DEL SENA

EVALUACIÓN DE LA CALIDAD DE ENERGÍA EN SISTEMAS FOTOVOLTAICOS MEDIANTE INTELIGENCIA COMPUTACIONAL HIDRODINÁMICA PARA LA PRODUCCIÓN DE BIODIESEL 



\section{PRÓLOGO}

Las políticas energéticas nacionales han sido enfocadas hacia el desarrollo sostenible, lo que ha permitido generar procesos de colaboración e integración de distintos sectores tanto académicos como industriales, este aporte ha logrado construir y consolidar alianzas estratégicas.

Este libro constituye un aporte a la construcción de dichas alianzas, donde la investigación y la academia se ponen en contacto y en un contexto nacional en la búsqueda de soluciones a problemáticas energéticas actuales, reforzando la integración de sectores Colombianos.

Históricamente el aprovechamiento de la energía ha estado ligado al crecimiento económico y social promoviendo de ese modo el desarrollo de la humanidad. Conforme la tasa de crecimiento poblacional se ha acelerado, el consumo de energía ha incrementado. En los últimos años la canasta energética se ha visto ensanchada por el uso de energías renovables, principalmente de tipo solar, con lo cual el impacto en el ambiente podría disminuir en el corto plazo. Es de esperarse que el impulso dado por la Ley $\mathbf{1 7 1 5}$ de $\mathbf{2 0 1 4}$ contribuya a la generación de nuevas alternativas energéticas que contribuyan con la sostenibilidad.

Finalmente, el aporte que cada uno realiza al sostenimiento energético termina siendo un aporte a la supervivencia propia y del resto de la especie. De no lograrse el sostenimiento energético, el calentamiento global y el aumento dela contaminación ambiental cobrarán la existencia como especie de la más débil de ellas: la humana. 



\title{
COMPUTATIONAL SIMULATION OF THE HYDRAULIC PERFORMANCE OF A HORIZONTAL AXIS HYDROCYNETIC TURBINE
}

\author{
Rodríguez Amaya, Alejandro ${ }^{1}$ \\ Sierra Alarcón, Adriana Fernanda ${ }^{1}$ \\ Universidad Santo Tomás \\ alejandro.rodriguez@usantotomas.edu.co \\ adriana.sierra@usantotomas.edu.co
}

\section{THEMATIC AREA}

Alternative Energies: Solar, wind, hydro, geothermal and tidal energy

\section{SUMMARY}

The GEAMEC research group of the Santo Tomás University designed a hydrokinetic turbine to study its viability in Colombia, considering its performance conditions. Next to this project arises the need to simulate this turbine by computational fluid dynamics (CFD) using ANSYS Workbench, to analyze its operating characteristics. The purpose of this simulation is to reduce costs and times associated with experimentation, as the results are going to be validated by another experimental study of the scale hydrokinetic turbine. Additionally, it seeks to reduce the risk of error once you want to implement the results in a real system and, finally, use the research as a source of information that allows not only improving what we understand of the technology studied, but also expand its use and deepen in the investigative process. Before using computational tools, a different design of the blades based on the moment theory of the blade element is proposed. Stationary simulations are performed using the turbulence model $k-\omega$ SST. The domain has a truncated cone shape with a distance downstream of 6 times the radius of the rotor. The results indicate that a power coefficient of 0.36 is generated at the most efficient point, considering that the velocity of the fluid remains constant. The power generated by the turbine is $153.52 \mathrm{~W}$, enough to supply the energy required for a day in remote regions with rivers as water supply.

Keywords: Horizontal axis hydrokinetic turbine, Computational Fluid Dynamics CFD, ANSYS, Computational simulation, renewable energies, energy microgeneration, Power coefficient, Tip speed ratio, hydro energy 


\section{INTRODUCTION}

Colombia is a country rich in natural resources and has great water potential. The largest contribution in the generation of energy is made by hydroelectric power plants, with about $84.93 \%$ of the total electricity generated, that is, 4,709.10 GWh [1]. This means that, among renewable energy sources, water sources are the ones with the highest production, evidencing the country's potential. One method to extract this type of energy is to capture the kinetic energy directly from the flow velocity of a water source using hydrokinetic turbines [2]. This type of technology does not need large constructions, so they are suitable for the generation of energy in remote areas. Compared with wind turbines, they have a better performance due to the density of the fluid [3]. Although they have a maximum theoretical limit on their efficiency, there are different options to increase the generation of energy, either by the implementation of a group of turbines, or the use of diffusers around them, to increase the speed of the fluid.

Based on this information, it becomes necessary to evaluate this type of technology in Colombia, promote its commercialization and extend the information about it for future studies and advances in energy microgeneration technology. The GEAMEC research group of the Santo Tomás University designed a hydrokinetic turbine to study its viability in Colombia [4]. Together with this project, there is a need to simulate that turbine by means of computational fluid dynamics (CFD), to analyze its operating characteristics. For this, it is worth highlighting the use of computational tools and techniques in the aforementioned field. These have been widely used and successfully applied in the study of the performance and flow characteristics of the hydro-energetic system. It can be used as a tool to analyze, design, and optimize turbine blades, by providing more accurate data on flow characteristics, compared to other models [5]. Among its advantages is the reduction of costs and times associated with experimentation, in addition to reducing the risk of error once you want to implement the results in a real system. Additionally, the practice of the same is a source of information that allows not only improving the understanding of the technology studied, but also to expand its use and deepen the investigative process, and may emerge as a new line of research within the Santo Tomas University.

Regarding the previous works studied, they have been classified into three different groups, that is, an evaluation of the technology, different studies in terms of design, materials, analysis and flow characteristics among others, and specific hydrokinetic turbine simulations, with different types of applications. Daskiran et al. [6] conducts transient simulations to characterize a simple turbine and an array of turbines in line and in staggered order, using the turbulence model k- $\omega$ shear-stress transport (SST). Riglin et al. [7] designed the prototype based on numerous blade characterizations and optimization analysis carried out with dynamic computational flow simulations (CFD). Tampier et al. [8] presents a new alternative to evaluate the effects of interaction in a hydrokinetic turbine of diffuser increased (DAHT). Muratoglu et al. [9] uses a three-dimensional finite volume multi-phase solver (VOF) to capture the effects resulting from the interaction of the free surface.

Due to the similarity with wind turbines, these references are also used. Wang et al. [10], exposes the problem of the increase in the size and flexibility of wind turbine blades, which introduces considerable elastic Aero-effects, caused by the interaction between the structures of the FSI fluid. Additionally Giahi and Dehkordi [11], study the influence of scaling wind turbines, arguing the use of the experience of large turbines, in smaller ones. Vucina et al. [12] performs a computational study on the optimization of shape of the blades of a wind turbine, under operating conditions dependent on the distributions of the local wind speed.

\section{MATERIALS AND METHODS}

To develop the proposed computer simulations, the software ANSYS 18 is used. Specifically, it works with the computational fluid dynamics CFD (FLUENT). Ansys, Inc. is an American public company based in Canonsburg, Pennsylvania. It develops and markets engineering simulation software and was founded in 1970 by John Swanson.

The process of carrying out a CFD simulation is divided into four components. As a first stage of pre-processing, it is sought to produce a mesh for the input variables. Before being able to generate the mesh, a closed geometric solid is required. The basic procedure involves defining the geometry of the region of interest, creating regions for fluid flow, solid regions and boundary conditions, to finish establishing the properties of the mesh [13]. 


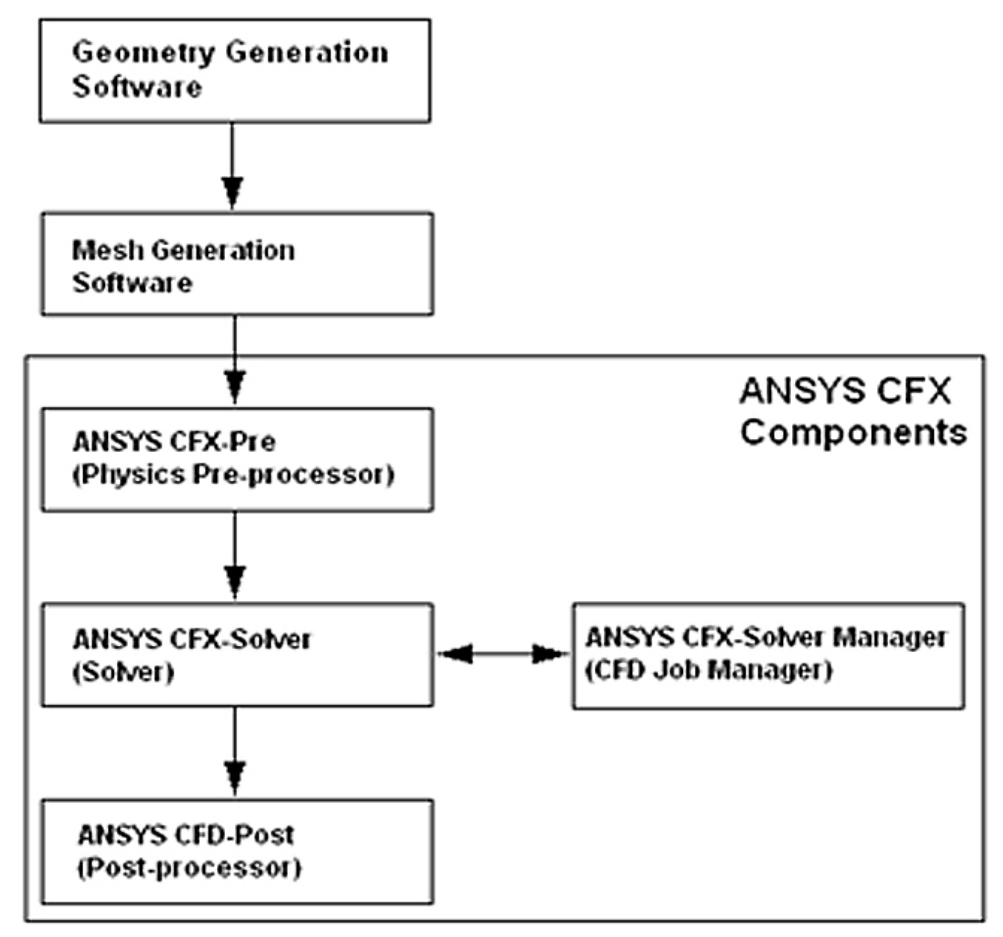

Figure 1: CFD Methodology [13]

The second stage of pre-processing consists of defining the physics of the model, that is, creating the input variables that the program needs. The physical models that are going to be included in the simulation are selected, as well as the properties of the fluid and the boundary conditions [13].

The third stage is the component that solves the CFD problem through three steps: first partial differential equations are integrated on all the control volumes in the region of interest (equivalent to applying basic conservation laws), then the equations are converted to a system of algebraic equations, generating a number of approximations for their respective terms [13].

Finally, the algebraic equations are solved iteratively. An iterative process is required due to the non-linear nature of the equations; Additionally, as the solution approaches an exact solution, it is said to converge. For each iteration, an error or residue is reported, as a measure of the conservation properties of the flow. How close you are to the final result of the exact solution depends on a number of factors, including the size and shape of the control volumes or the final size of the residuals. Finally, the results are displayed in the post-processor. The post-process is the component used to analyze, visualize and present the results, this includes results such as the visualization of the geometry and control volumes, vector graphs showing the direction and magnitude of the flow, scalar variables through the domain, calculations, animations, graphs, etc. [13].

\section{RESULTS AND DISCUSSION}

The first value to analyze is the tangential speed of the blades. As can be seen in Fig 2, this speed varies along the radius of the turbine, being greater at the tip of the blades. Its expected value of $5.5 \mathrm{~m} / \mathrm{s}$ is reflected in the results. As for the pressure, it can be seen, that the region of greater value and red color in front has approximately the same magnitude as the green region behind the blade, although this is a negative value. The entire pressure distribution is the cause of the lift force, whose components are distributed in the direction of the Z-axis and in the direction of the rotation or the $X Y$ plane. However, a large part of this force contributes to the deformation and mechanical stress of the blade.
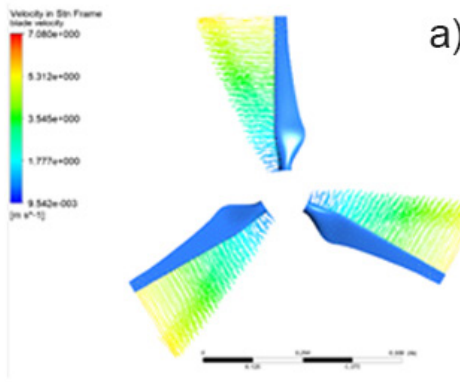

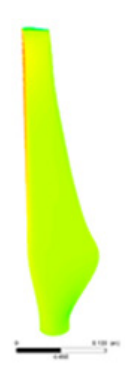

b)

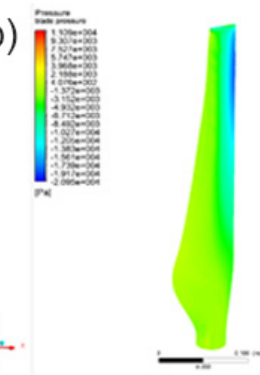

c)

Figure 2: a) Blade tangential speed and Pressure contour on the blade: b) front view, c) back view

In Fig 3 it is verified a drop in the speed behind the turbine, an expected behavior due to the wake left by it. There is a slight acceleration of the fluid around the wake of the turbine, which obey the conservation of mass and momentum. For the domain, the pressure tends to increase as it approaches the turbine, this is because it slows the incoming fluid and therefore, more particles gather in front of the rotor. Once the fluid interacts with the blades, the value of the pressure drops, because the energy from the fluid is being extracted. After this, the pressure gradually returns to the same value of atmospheric pressure, as specified as a boundary condition at the output of the domain. The difference between the pressures in front and behind the turbine gives us the thrust force.
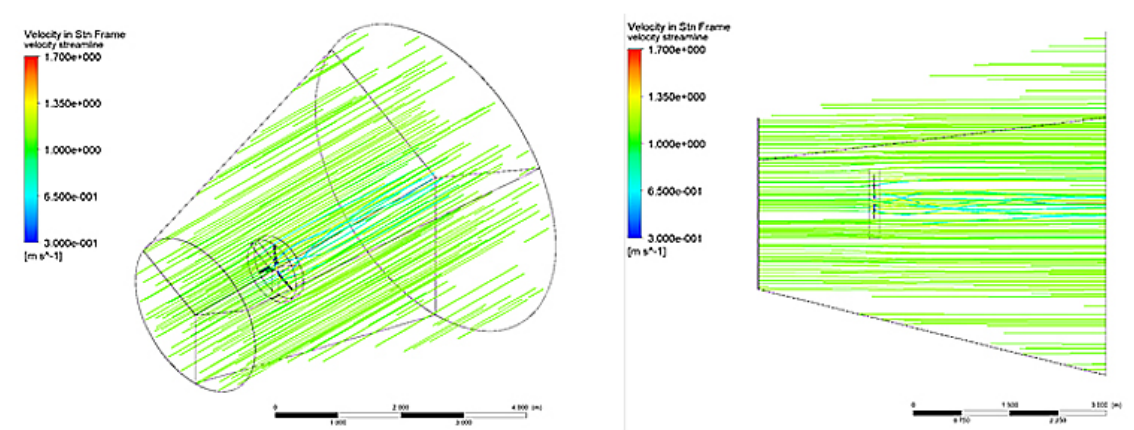

Figure 3: Fluid velocity streamlines 
In order to fulfill the main objective of this document, that is, to analyze the operating characteristics of a hydrokinetic turbine with a horizontal axis, the blades of the same are designed together with the domain through which the fluid will pass. Having a computational mesh over the aforementioned domain, a convergence analysis is carried out to determine with how many elements we must work. Once this procedure is completed, the performance curve and main objective of this document is developed. This curve is a function of the Tip speed ratio or TSR, which in turn is a function of the speed of the fluid and the angular velocity of the turbine. This is why these values were parameterized in the FLUENT configuration. By varying these values, different TSRs are obtained, and with it different power coefficients. The purpose of this practice is to determine which point of design of the hydrokinetic turbine, is the most efficient. The points to evaluate are shown below.

Table 1: Tip speed ratio

\begin{tabular}{|c|c|c|c|}
\hline $\mathbf{U}[\mathrm{m} / \mathrm{s}]$ & $\omega[\mathrm{rad} / \mathrm{s}]$ & $\omega[\mathrm{rpm}]$ & TSR \\
\hline 1,1 & 7,33 & 70,03 & 3 \\
\hline 1,1 & 9,78 & 93,37 & 4 \\
\hline 1,1 & 12,22 & 116,71 & 5 \\
\hline 1,1 & 14,67 & 140,06 & 6 \\
\hline 1,1 & 17,11 & 163,40 & 7 \\
\hline 1,1 & 19,56 & 186,74 & 8 \\
\hline
\end{tabular}

When determining the power coefficient for each of these points, the turbine performance curve is obtained.

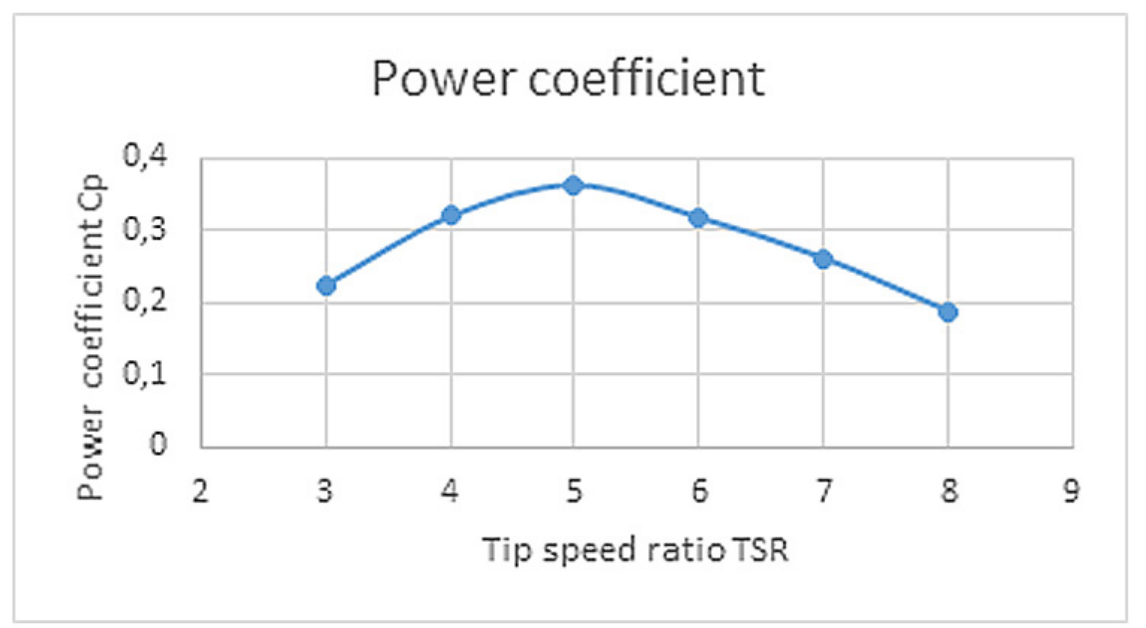

Figure 4: Power coefficient of the hydrokinetic turbine

In summary, the final results of the simulation are shown below:
Table 2: Final results of the CFD simulation

\begin{tabular}{|c|c|c|c|c|c|c|c|}
\hline $\mathrm{U}[\mathrm{m} / \mathrm{s}]$ & $\begin{array}{c}\omega \text { [ra- } \\
\text { d/s] }\end{array}$ & $\omega$ [rpm] & TSR & Cp & $\mathrm{T}[\mathrm{Nm}]$ & $P[W]$ & $\begin{array}{l}\text { Mass flow } \\
\text { rate }[\mathrm{Kg} / \mathrm{s}]\end{array}$ \\
\hline 1.1 & 12.22 & 116.71 & 5 & 0.36379 & 4.1878 & 153.52 & 0.00028013 \\
\hline
\end{tabular}

In order to analyze the results, it must be verified that they are within the expected range, that is, that the parameters chosen in the document, in which this work is based [4], where the right ones and that the objectives have been achieved.

Table 3: Results comparison

\begin{tabular}{|c|c|c|c|}
\hline Variable & Previous work & Results & Error [\%] \\
\hline Blade tip speed [m/s] & 5.5 & 5.50688 & 0.12 \\
\hline Power Coefficient & 0.35 & 0.36379 & 3.94 \\
\hline
\end{tabular}

It can be seen that there is no significant difference between the results. Additionally, it is known that with the proposed design, the desired energy production of 2 $\mathrm{KWh}$ /day with $153.52 \mathrm{~W}$ is achieved to supply energy to a home in remote areas. This value also represents the point of greatest efficiency against a speed of $1.1 \mathrm{~m} / \mathrm{s}$ of the river, as predicted with a power coefficient of 0.36 .

On the other hand, it is possible to compare the behavior of the hydrokinetic turbine performance curve with other studies, to verify that the tendency of the efficiency as a function of the TSR is similar. This works as an additional measure to corroborate that the results are valid. Next, the results of the works with greater contribution to the present document are shown. Of these, it can be seen that the behavior of the power coefficient as a function of the tip speed ratio is similar to that of a parabola. The efficiency of the turbine depends on the design of the turbine and the operating conditions. Being the curve of Cp more concave, in front of greater efficiencies. In comparison, most designs exceed an efficiency of $40 \%$.

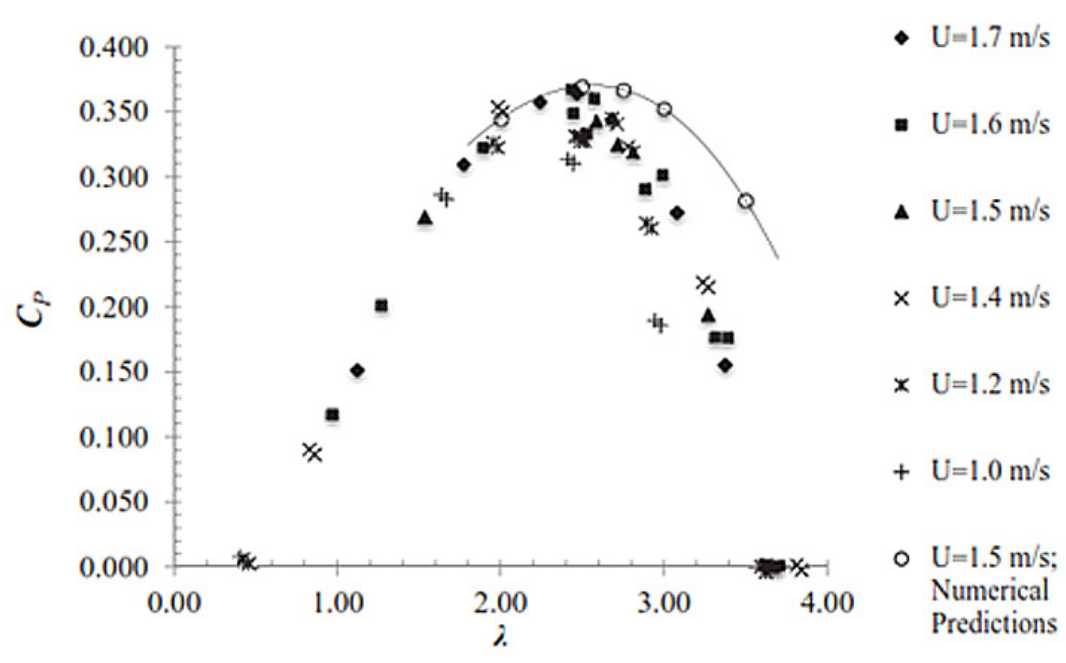

Figure 5: Power coefficient as a function of the TSR for experimental tests and numerical predictions [7] 


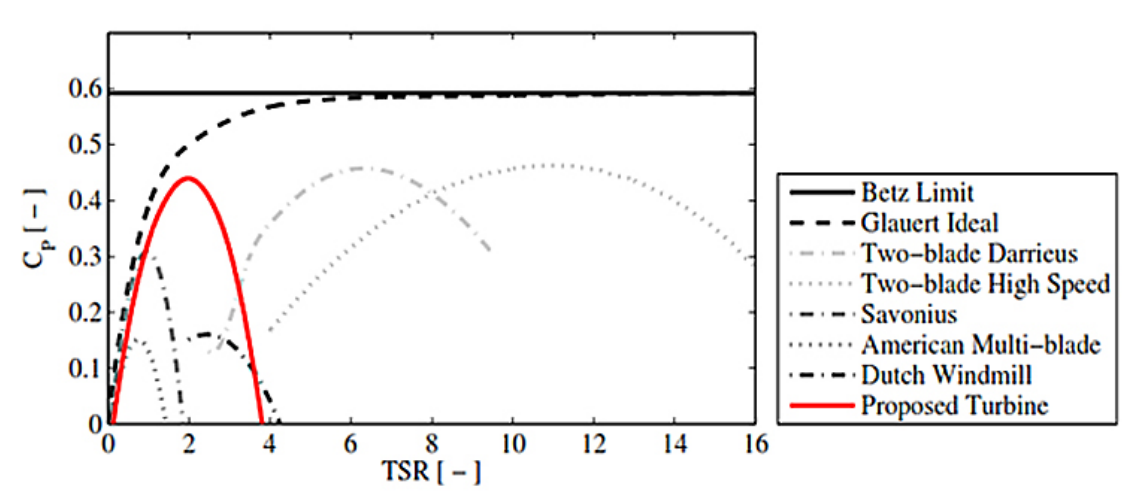

Figure 6: Cp vs. TSR. Comparison between preliminary designs and the proposed turbine [14]

\section{CONCLUSIONS}

It took 2500 iterations for the residuals to converge, with a limit of $1 \times 10^{-06}$. The solver uses a coupled system based on pressure, which increases this possibility. Regarding the criterion to determine the convergence of the mesh, the relative error is less than 3 $\%$, which gives us very similar results compared with those dictated by the theory. In order to solve a system of approximately 4,500,000 elements, which means solving 27,000,000 algebraic equations, a computer with a minimum of 16 GB of RAM is required. From the short review above, key findings emerge: The form of the domain was considered pertinent because of how much is demonstrated in the bibliographic references that there is an expansion of the wake for wind turbines. However, although an expansion is evident, it is small and does not occur conically. It is possible to ask the feasibility of using a cylindrical domain, saving time and computational cost. This is an important finding in the understanding of the fluid behavior and how could we use this information for experimental purposes. A further finding is that, since the system has rotational symmetry, only a representative portion of the model was modeled. Being able to use a mobile reference frame, the flow around the elements in motion, could be studied as a stationary problem with respect to the frame of reference. As a result, an advantage was obtained from the mathematical point of view. Specifically, the conservation equations for mass and momentum are simplified. Additionally, the number of elements in the mesh was reduced considerably and with this, the cost and computational time.

This section summarises the findings and contributions made. For a fluid velocity of $1.1 \mathrm{~m} / \mathrm{s}$, it was found that the turbine generates a power of $153.52 \mathrm{~W}$ with a power coefficient of 0.36 . This being the highest effi- ciency when the rotor is rotating at $12.22 \mathrm{rad} / \mathrm{s}$, with a specific speed of five. This analysis was made considering a constant fluid velocity. From these results it is clear that most of the hydrodynamic power is generated between 60 and $95 \%$ of the radial distance of the blade. This is due to the high values of the relative speed in that area, and also because in this region we can find the profiles with the highest performance. Recall that the thickness at the root of the blade was increased to provide greater structural strength. On the other hand, taking into account that in the area described the bending moment is less than at the base, it is possible to use thinner profiles. It is also important to emphasize that the last $5 \%$ of the blade suffers losses at the tip, as explained in the blade element momentum method.

\section{REFERENCES}

[1] Unidad de planeación Minero Energética (UPME), "Informe Mensual de Variables de Generación y del Mercado Eléctrico Colombiano - Diciembre de 2016," Subdirección Energía Eléctrica - Grup. Generación, no. 69, p. 15, 2016.

[2] P. J. Ginter VJ, "Robust gain scheduled control of a hydrokinetic turbine," Control Syst Technol IEEE Trans, no. 19:805-17, 2011.

[3] M. I. Yuce and A. Muratoglu, "Hydrokinetic energy conversion systems: A technology status review," Renew. Sustain. Energy Rev., vol. 43, pp. 72-82, 2015.

[4] E. D. Roberto Ortiz, "Diseño de una turbina hidrocinética de eje horizontal para microgeneración de energía eléctrica," Universidad Santo Tomás, 2017.

[5] M. Ghasemian, Z. N. Ashrafi, and A. Sedaghat, "A review on computational fluid dynamic simulation techniques for Darrieus vertical axis wind turbines," Energy Convers. Manag., vol. 149, pp. 87-100, 2017.

[6] C. Daskiran, J. Riglin, W. Schleicher, and A. Oztekin, "Transient analysis of micro-hydrokinetic turbines for river applications," Ocean Eng., vol. 129, no. November 2016, pp. 291-300, 2017.

[7] J. Riglin, F. Carter, N. Oblas, W. C. Schleicher, C. Daskiran, and A. Oztekin, "Experimental and numerical characterization of a full-scale portable hydrokinetic turbine prototype for river applications," Renew. Energy, vol. 99, pp. 772-783, 2016.

[8] G. Tampier, C. Troncoso, and F. Zilic, "Numerical analysis of a diffuser-augmented hydrokinetic turbine," Ocean Eng., vol. 145, no. September, pp. 138-147, 2017. 
[9] A. Muratoglu and M. Ishak Yuce, "Design of a River Hydrokinetic Turbine Using Optimization and CFD Simulations," J. Energy Eng., vol. 143, no. Muratoglu 2014, pp. 1-11, 2017.

[10] L. Wang, R. Quant, and A. Kolios, "Fluid structure interaction modelling of horizontal-axis wind turbine blades based on CFD and FEA," J. Wind Eng. Ind. Aerodyn., vol. 158, pp. 11-25, 2016.

[11] M. H. Giahi and A. Jafarian Dehkordi, "Investigating the influence of dimensional scaling on aerodynamic characteristics of wind turbine using CFD simulation," Renew. Energy, vol. 97, pp. 162-168, 2016.
[12] D. Vučina, I. Marinić-Kragić, and Z. Milas, "Numerical models for robust shape optimization of wind turbine blades," Renew. Energy, vol. 87, pp. 849-862, 2016.

[13] ANSYS 18 Theory guide, "ANSYS, A." Ansys Inc., U.S.A., 2017.

[14] W, Schleicher. D. Riglin, A. Oztekin, "'N Numerical characterization of a preliminary portable microhydrokinetic turbine rotor design," renew Energy, vol. 76, pp. 234-241, 2015. 


\title{
ANÁLISIS DEL CICLO DE VIDA DE LA PRODUCCIÓN DE VAPOR UTILIZADO EN LAS ZONAS HÚMEDAS DEL UMB GOLF CLUB
}

\author{
Ortiz Castillo, Daniela ${ }^{1}$ \\ Garzón Cortés, Giovanna ${ }^{1}$ \\ Gaona-Corral, Luis Andrés ${ }^{1}$ \\ Gómez-Torres, Luisa Marina² \\ ${ }^{1}$ Universidad Manuela Beltrán, Vicerrectoría de investigaciones, Grupo de Sistemas \\ y Recursos Ambientales Sostenibles (Syras) \\ ${ }^{2}$ Instituto Técnico Central \\ giovanna.garzon@docentes.umb.edu.co
}

\section{ÁREA TEMÁTICA}

Eficiencia y auditoría energética

\section{RESUMEN}

El Club de Golf de la Universidad Manuela Beltrán, tiene espacios de esparcimiento (zonas húmedas), que deben mantener condiciones de temperatura óptimas; a partir de un sistema generador de vapor, que se abastece con ACPM. Se hicieron visitas in situ a las instalaciones del club para realizar el diagrama de procesos y posteriormente, el balance de masa y energía. Para el análisis de ciclo de vida se utilizó la herramienta Simapro para identificar y evaluar los impactos de la caldera y de las zonas húmedas del club. El vapor de agua es un gas efecto invernadero, que representa importantes efectos sobre el calentamiento global. El cambio climático y el agotamiento de recursos fueron las condiciones de mayor impacto en el ciclo, además se encontró carencia de normatividad referente a la temperatura con que son emitidos los gases.

Palabras claves: Vapor; Ciclo de vida; Temperatura; Cambio Climático. 


\section{INTRODUCCIÓN}

Los Gases de Efecto Invernadero (GEI) son los principales causantes del calentamiento global [1] entre éstos los principales son el vapor de agua y el dióxido de carbono $\left(\mathrm{CO}_{2}\right)$, seguidos por el metano $\left(\mathrm{CH}_{4}\right)$, óxido nitroso $\left(\mathrm{N}_{2} \mathrm{O}\right)$ y ozono $\left(\mathrm{O}_{3}\right)$. Varios estudios indican, que en el último siglo, aumentó la temperatura con mayor rapidez desde $1,1^{\circ} \mathrm{C}$ hasta $6,4^{\circ} \mathrm{C}$ [2] y con este aumento de temperatura, se presume un incremento del $1,2 \%$ del vapor de agua en la atmósfera, lo que trae como consecuencia precipitaciones severas, impredecibles y localizadas, además del derretimiento de las zonas polares, el incremento del nivel del mar y la extinción de gran parte de la biodiversidad a nivel global [3] [4].

Los GEl son generados en gran medida por las industrias; sin embargo, centros prestadores de servicios (p.ej., hoteles, clubes, spas) también liberan vapor de agua durante su funcionamiento, contribuyendo al calentamiento global [5]. Estos centros demandan vapor en las zonas húmedas (p.ej., piscina, turco, jacuzzi), el cual comúnmente es suministrado por las calderas.

Las calderas son máquinas térmicas diseñadas para generar vapor saturado, estas máquinas se pueden clasificar según el contenido de los tubos en acuatubulares y pirotubulares. La caldera de tipo pirotubular es muy común en aplicaciones pequeñas, como calefacción a baja presión o vapor a presión relativamente baja, por su menor costo inicial y exigencia en la calidad de agua [6], [7]. La caldera de tipo pirotubular del UMB Golf Club, está compuesta por las siguientes partes principales: hogar o cámara de combustión, quemador, haces de tubos, carcaza, chimenea, válvulas de seguridad y tablero de control.

Cuando se genera vapor a partir de calderas se realiza un proceso de recirculación, sin embargo, siempre se van a crean pérdidas a través de las paredes y las tuberías [8]. El vapor de agua carece de reglamentación clara en cuanto a temperaturas para emisión atmosférica en Colombia, únicamente se encuentra la Resolución 909 del 2008 expedida por el Ministerio de Ambiente Vivienda y Desarrollo Territorial, por la cual se establecen las normas y estándares de emisión admisibles de contaminantes a la atmósfera por fuentes fijas y se dictan otras disposiciones [9], pero no se establecen parámetros relacionados con la temperatura a la que deben salir los gases de combustión, lo que conlleva al aumento del calentamiento global.

Una de las herramientas de la gestión ambiental más completas es el análisis de ciclo de vida (ACV).
El ACV identifica y evalúa los impactos ambientales de un producto o servicio durante todas las etapas de su existencia: extracción, producción, distribución, uso y fin de vida (reutilización, reciclaje, valorización y eliminación o disposición de los residuos) [10]. En este artículo se propone efectuar un ACV de la generación de vapor en el UMB Golf Club para identificar los procesos de mayor impacto ambiental y posteriormente plantear alternativas de mitigación tanto ambientales como económicas. Es preciso conocer los procesos, las materias primas e insumos requeridos, además de los equipos necesarios para satisfacer los requerimientos de las zonas húmedas, para con esa información determinar los balances de masa y energía, así como las alternativas de solución y búsqueda de opciones que minimicen el impacto ambiental atmosférico.

\section{MATERIALES Y MÉTODOS}

El UMB Golf Club es un lugar de recreación, ubicado en el municipio de Tocancipá Cundinamarca, el cual cuenta con un campo de 37 hectáreas para prácticas de golf, canchas de squash, canchas de tenis, zonas de diversión y relajación como las zonas húmedas (spa, sauna, turco, jacuzzi y piscina), además de contar con área de restaurante y café bar. El club presta servicio de miércoles a domingo y festivos, frecuentado aproximadamente por 100 personas al día.

La metodología para llevar a cabo el ACV comprende cuatro fases: definición de objetivos y alcance, análisis de inventario, evaluación de impactos y análisis de mejoras [10].

\section{Fase 1. Análisis del sistema de generación de vapor para la calefacción de las zonas húmedas del UMB Golf Club}

El objetivo del estudio es evaluar el desempeño ambiental de una caldera pirotubular para la generación de vapor que se utiliza en las zonas húmedas del UMB Golf Club. El siguiente paso es definir la función del sistema, que es la producción de vapor para el funcionamiento de las zonas húmedas del club. Por tanto, la unidad funcional es $1 \mathrm{~kg}$ de vapor de agua. Se realizó una visita a las instalaciones para poder representar los procesos de generación de calor y de calefacción y definir las fronteras correspondientes. 


\section{Fase 2: Balances de masa y energía para el sistema}

Siguiendo las etapas del ciclo de vida del proceso de generación de vapor, se identifican y cuantifican las entradas y las salidas del sistema. A partir de la Figura 1 se procedió al cálculo de balances de masa del sistema de calefacción (caldera, tubería, turco y piscina).

Para hacer el balance en la caldera se identificaron los insumos y materiales de entrada y salida. La caldera cuenta con una capacidad de 6000 L, está compuesta por un quemador, abastecido por ACPM, el cual direcciona los gases hacia la tubería de la cámara de combustión a temperaturas entre 180 y $200{ }^{\circ} \mathrm{C}$; la cámara de combustión está compuesta por 64 tubos internos de $1.6 \mathrm{~m}$ de largo con diámetro de 1/4 pulgada cada uno, que al paso de los gases provenientes del quemador son conectados con el ducto de desfogue de gases; un hogar que protege la cámara de combustión; un tablero de control de funciones tiempos y niveles y una chimenea que es el ducto donde evacuan los gases de combustión. Se realizó también el balance de energía en la caldera, tubería, turco y piscina. A partir de estas ecuaciones se analiza el ciclo de vida del vapor. El balance de masa se realizó teniendo en cuenta los requerimientos energéticos y las pérdidas de cada uno de los componentes del sistema de generación de vapor y calefacción del club UMB.

Tabla 1. Balance de energía del sistema de generación de vapor y calefacción del club UMB. Fuente: Los autores.

\begin{tabular}{|c|c|c|}
\hline Elemento & Ecuación & Observación \\
\hline Caldera & $\begin{array}{l}\text { Calor suministrado por la caldera } \\
\qquad \mathrm{Q}=\mathrm{m}_{\mathrm{H} 2 \mathrm{O}}{ }^{*} \mathrm{Cp}\left(\mathrm{T}_{2}-\mathrm{T}_{1}\right)+\mathrm{m}_{\mathrm{H} 2 \mathrm{O}}{ }^{\star} \Delta \mathrm{H}\end{array}$ & $\begin{array}{c}\mathrm{Q}=\text { Calor suministrado, } \mathrm{W} \\
\mathrm{m}_{\mathrm{H} 20}=\text { Flujo del agua evaporada, } \mathrm{kg} / \mathrm{s} \\
\mathrm{Cp}=\text { Calor específico agua, } \mathrm{J} / \mathrm{kg} . \mathrm{K} \\
\mathrm{T}_{2}: \text { Temperatura de trabajo de la caldera, } \mathrm{K} \\
\mathrm{T}_{1}: \text { Temperatura de ingreso de agua de alimentación a la caldera, } \mathrm{K} \\
\Delta \mathrm{H}: \text { Calor latente de evaporación del agua, } \mathrm{J} / \mathrm{kg}\end{array}$ \\
\hline Tuberías & $\begin{array}{l}\text { Pérdidas de calor por las tuberías } \\
\qquad Q=\frac{\pi(\Delta T)}{\frac{2,3}{2 K_{1}} \log \left(\frac{D_{2}}{D_{1}}\right)+\frac{1}{h_{o} D_{2}}}\end{array}$ & $\begin{array}{c}\Delta \mathrm{T}=\text { Diferencia de temperaturas, } \mathrm{K} \\
\mathrm{K}_{1}=\text { Conductividad térmica material } \mathrm{A}, \mathrm{W} /\left(\mathrm{m}^{\left.2 *^{\circ} \mathrm{C}\right)}\right. \\
\mathrm{D}_{2}=\text { Diámetro externo de la tubería, } \mathrm{m} \\
\mathrm{D}_{1}=\text { Diámetro interno de la tubería, } \mathrm{m} \\
\mathrm{h}_{0}=\text { Coeficiente global de transferencia, } \mathrm{W} /\left(\mathrm{m}^{2 *} \mathrm{~K}\right)\end{array}$ \\
\hline \multirow[b]{2}{*}{ Turco } & $\begin{array}{c}\text { Calor sensible } \\
Q_{s}=\frac{\left(V_{\text {aire }} \cdot \delta \cdot C_{P} \cdot \Delta T\right)}{t}\end{array}$ & $\begin{array}{c}\mathrm{Q}_{\mathrm{s}}=\text { Calor Sensible, } \mathrm{kW} \\
\mathrm{V}_{\text {aire }}=\text { Volumen del aire, } \mathrm{m}^{3} \\
\delta=\text { Densidad del aire, } \mathrm{kg} / \mathrm{m}^{3} \\
\mathrm{C}_{\mathrm{P}}=\text { Calor especifico del aire, } \mathrm{kJ} /(\mathrm{kg} * \mathrm{~K}) \\
\Delta \mathrm{T}=\text { Diferencia de temperaturas, } \mathrm{K} \\
\mathrm{t}=\text { Tiempo, } \mathrm{s}\end{array}$ \\
\hline & $\begin{array}{l}\text { Pérdida de calor a través de las paredes } \\
\qquad Q_{L}=\frac{\Delta T}{\left[\left(\frac{1}{h_{\infty t}}\right)+\left(\frac{L_{A}}{k_{A}}\right)+\left(\frac{L_{B}}{k_{B}}\right)\right] * \frac{1}{A}}\end{array}$ & $\begin{array}{c}\mathrm{Q}_{\mathrm{L}}=\text { Calor Latente, } \mathrm{W} \\
\Delta \mathrm{T}=\text { Diferencia de temperaturas, } \mathrm{K} \\
\mathrm{h}_{\infty \mathrm{t}}=\text { Coeficiente convectivo, } \mathrm{W} /\left(\mathrm{m}^{2 *} \mathrm{~K}\right) \\
\mathrm{L}_{\mathrm{A}}=\text { Longitud material } \mathrm{A}, \mathrm{m} \\
\mathrm{L}_{\mathrm{B}}=\text { Longitud material } \mathrm{B}, \mathrm{m} \\
\mathrm{k}_{\mathrm{A}}=\text { Conductividad térmica material } \mathrm{A}, \mathrm{W} /\left(\mathrm{m}^{\left.2 *^{\circ} \mathrm{C}\right)}\right) \\
\mathrm{k}_{\mathrm{B}}=\text { Conductividad térmica material } \mathrm{B}, \mathrm{W} /\left(\mathrm{m}^{\left.2 *^{\circ} \mathrm{C}\right)}\right. \\
\mathrm{A}=\text { Área, } \mathrm{m}^{2}\end{array}$ \\
\hline
\end{tabular}




\begin{tabular}{|c|c|c|}
\hline Elemento & Ecuación & Observación \\
\hline \multirow{6}{*}{ Piscina } & $\begin{array}{l}\text { Pérdidas por evaporación } \\
\qquad Q_{E}=M_{e}{ }^{*} C_{v}\end{array}$ & $\begin{array}{c}\mathrm{Q}_{\mathrm{E}}=\text { Pérdidas por evaporación, } \mathrm{W} \\
\mathrm{M}_{\mathrm{e}}=\text { Masa de evaporación, } \mathrm{kg} / \mathrm{h} \\
\mathrm{C}_{\mathrm{v}}=\text { Calor latente de evaporización, } \mathrm{J} / \mathrm{kg}\end{array}$ \\
\hline & $\begin{array}{c}\text { Pérdidas por radiación } \\
Q_{R}=\sigma * \varepsilon *\left(T_{P}^{4}-T_{a m b}^{4}\right) * A\end{array}$ & $\begin{array}{c}\mathrm{Q}_{\mathrm{R}}=\text { Pérdidas por radiación, } \mathrm{W} \\
\sigma=\text { Constante de Stefan Boltzman, } \mathrm{W} /\left(\mathrm{m}^{2}\left(\mathrm{~K}^{4}\right)\right) \\
\varepsilon=\text { Emisividad de la superficie } \\
\mathrm{T}_{\mathrm{p}}=\text { Temperatura del agua de la piscina, } \mathrm{K} \\
\mathrm{T}_{\text {amb }}=\text { Temperatura ambiente, } \mathrm{K} \\
\mathrm{A}=\text { Área, } \mathrm{m}^{2}\end{array}$ \\
\hline & $\begin{array}{l}\text { Pérdidas por convección } \\
\mathrm{Q}_{\mathrm{C}}=0,6246(\Delta \mathrm{T})^{4 / 3 *} \mathrm{~A}\end{array}$ & $\begin{array}{c}\mathrm{Q}_{\mathrm{RE}}=\text { Pérdidas por renovación, } \mathrm{kW} \\
\mathrm{M}_{\mathrm{e}}=\text { Masa de evaporación, } \mathrm{kg} / \mathrm{s} \\
\mathrm{C}_{\mathrm{e}}=\text { Calor específico del agua, } \mathrm{kJ} /\left(\mathrm{kg}^{\star} \mathrm{K}\right) \\
\Delta \mathrm{T}=\text { Diferencia de temperaturas, } \mathrm{K}\end{array}$ \\
\hline & $\begin{array}{l}\text { Pérdidas por renovación } \\
\mathrm{Q}_{\mathrm{RE}}=\left(\mathrm{M}_{\mathrm{e}}\right)\left(\mathrm{C}_{\mathrm{e}}\right)(\Delta \mathrm{T})\end{array}$ & $\begin{array}{c}\mathrm{Q}_{\mathrm{RE}}=\text { Pérdidas por renovación, } \mathrm{kW} \\
\mathrm{M}_{\mathrm{e}}=\text { Masa de evaporación, } \mathrm{kg} / \mathrm{s} \\
\mathrm{C}_{\mathrm{e}}=\text { Calor específico del agua, } \mathrm{kJ} /\left(\mathrm{kg}^{\star} \mathrm{K}\right) \\
\Delta \mathrm{T}=\text { = Diferencia de temperaturas, } \mathrm{K}\end{array}$ \\
\hline & $\begin{array}{l}\text { Pérdidas por conducción } \\
Q_{T}=\left(C_{T}\right)(A) \frac{(\Delta T)}{L}\end{array}$ & $\begin{array}{c}\mathrm{Q}_{\mathrm{T}}=\text { Pérdidas por conducción o transmisión, } \mathrm{W} \\
\mathrm{C}_{\mathrm{T}}=\text { Coeficiente de transmisión del material, } \mathrm{W} /(\mathrm{m} * \mathrm{~K}) \\
\mathrm{A}=\text { Área, } \mathrm{m}^{2} \\
\Delta \mathrm{T}=\text { Diferencia de temperaturas, } \mathrm{K} \\
\mathrm{L}=\text { Espesor del material, } \mathrm{m}\end{array}$ \\
\hline & $\begin{array}{l}\text { Pérdidas calentamiento piscina } \\
\qquad \mathrm{Q}_{\text {calent }}=V_{p}^{*} \delta^{*} C p_{p}^{*}(\Delta T)\end{array}$ & $\begin{array}{c}\mathrm{Q}_{\text {calent }}=\text { Pérdidas por calentamiento piscina, } \mathrm{kW} \\
V_{\mathrm{p}}=\text { Volumen piscina, } \mathrm{m}^{3} \\
\mathrm{C}_{\mathrm{p}}=\text { Calor específico del agua, } \mathrm{kJ} /\left(\mathrm{kg}^{\star} \mathrm{K}\right) \\
\Delta \mathrm{T}=\text { Diferencia de temperaturas, } \mathrm{K}\end{array}$ \\
\hline
\end{tabular}

\section{Fase 3. Uso de herramienta computacional SimaPro}

En esta etapa se ingresaron los datos obtenidos del análisis de inventario (balance de materia y energía) al software SimaPro 8.2.3.0. Esta herramienta desarrollada por Pré Consultants permitió realizar un análisis de ciclo de vida completo del vapor con múltiples métodos para la evaluación de impactos siguiendo las recomendaciones de las normas ISO 14040 [11].

\section{Fase 4: Análisis de resultados}

La última etapa es donde se hacen los análisis de los resultados arrojados por el programa, comparando cada una de las categorías que se evalúan y observando en cuáles fases del ciclo se producen mayores impactos negativos sobre el ambiente. 


\section{RESULTADOS Y Y ANÁLISIS DE RESULTADOS}

\section{Fase 1: Análisis del sistema de generación de vapor para la calefacción de las zonas húmedas del UMB Golf Club.}

El club de golf de la Universidad Manuela Beltrán (UMB Golf Club) está ubicado en el municipio de Tocancipá, en la sabana de Bogotá (Colombia), tiene una piscina y un Jacuzzi que funcionan a $25^{\circ} \mathrm{C}$ y un turco a $38^{\circ} \mathrm{C}$. El gasto energético del calentamiento del agua es alto, y la distancia entre las zonas húmedas y la caldera es de $100 \mathrm{~m}$, lo que ocasiona pérdidas de calor y mayor liberación de vapor de agua. A partir de la visita de reconocimiento de la caldera y las zonas húmedas se logró el levantamiento del diagrama de proceso ( Figura 1). Se identificaron la zona de la generación de vapor en el club de golf, y las entradas (ACPM y agua), las cuales alimentan la caldera para obtener el vapor requerido para ser distribuido por tuberías de acero inoxidable, hasta llegar a la zona húmeda, donde una parte del vapor de agua es recirculado

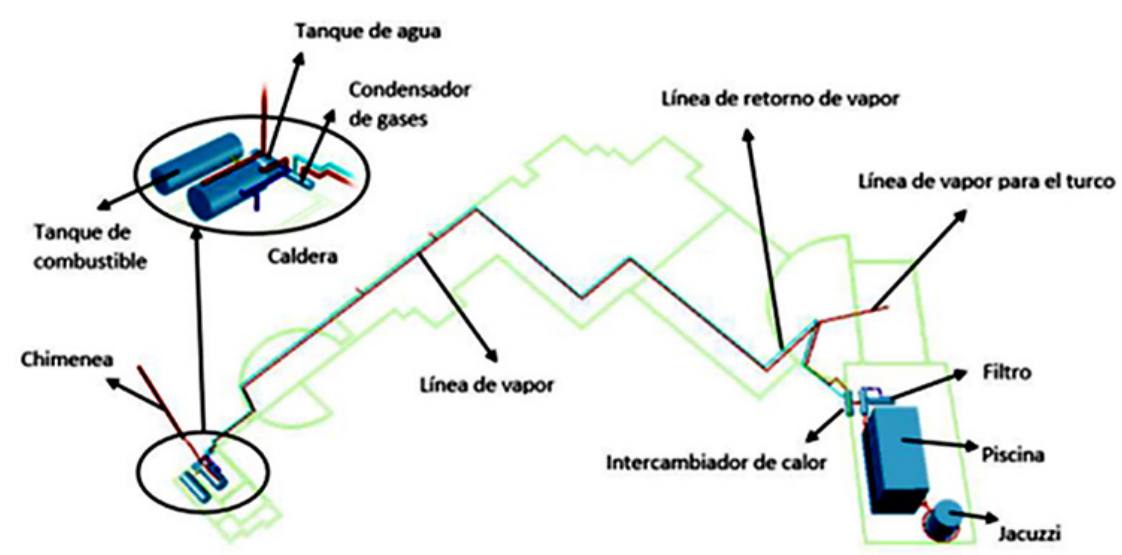

Figura 1: Diagrama del proceso de calefacción de la zona húmeda UMB Golf Club. Fuente: Autores

\section{Fase 2: Balances de masa y energía para el sistema de calefacción de las zonas húmedas del UMB Golf Club.}

Teniendo en cuenta el diagrama de procesos en la caldera en la UMB se realizó el balance de materia y energía para calcular las entradas y salidas de la caldera y se calculan las pérdidas a través de la tubería, el turco y la piscina con las ecuaciones establecidas en la Tabla 1. La Tabla 2 muestra el flujo másico de ACPM que entra a la caldera $(10,25 \mathrm{gal} / \mathrm{h})$, se tiene en cuenta la composición del aire para conocer los datos de kilogramos de entrada. A partir de las entradas se generan las salidas de gases por medio del proceso de combustión que realiza la caldera. La Tabla 2 también muestra las pérdidas de agua que se generan las cuales son necesarias para completar el proceso de salida. También se identificaron las necesidades de energía eléctrica $(14,5$ kWh) necesarias para suministrar vapor de agua en dicha zona húmeda, a partir de los catálogos de calderas de $6000 \mathrm{~L}$ de capacidad (Tabla 2).

Tabla 2: Balances de masa y energía (entradas y salidas) sistema de calefacción. Fuente. Autores.

\begin{tabular}{|c|c|c|c|c|}
\hline \multirow{6}{*}{ Caldera } & Cantidad & \multicolumn{3}{|c|}{ Cantidad (kg) } \\
\hline & ACPM & 3879.62 & \multirow{2}{*}{ Vapor } & \multirow{2}{*}{65000.00} \\
\hline & 02 & 80669.44 & & \\
\hline & N2 & 265536.88 & $\mathrm{O} 2$ & 64535.68 \\
\hline & $\mathrm{H} 2 \mathrm{O}$ & 65000.00 & N2 & 265536.88 \\
\hline & $\begin{array}{c}\text { Electricidad } \\
\text { (kWh) }\end{array}$ & 14.50 & $\mathrm{CO} 2$ & 14970.12 \\
\hline \multirow{2}{*}{ Tubería } & \multirow{2}{*}{ Vapor } & \multirow{2}{*}{4684.83} & $\begin{array}{c}\text { Pérdidas de } \\
\text { calor }(\mathrm{W})\end{array}$ & 27336.00 \\
\hline & & & $\begin{array}{c}\text { Condensado } \\
\text { kg }\end{array}$ & 4684.83 \\
\hline \multirow{2}{*}{ Turco } & \multirow{2}{*}{ Vapor } & \multirow{2}{*}{163.8552} & $\begin{array}{c}\text { Pérdidas de } \\
\text { calor }(\mathrm{W})\end{array}$ & 956.09 \\
\hline & & & Condensado & 163.86 \\
\hline \multirow{3}{*}{ Piscina } & Vapor & 61668.83 & Condensado & 61668.83 \\
\hline & Agua & 358000.00 & \multirow{2}{*}{$\begin{array}{c}\text { Pérdidas de } \\
\text { calor }(\mathrm{W})\end{array}$} & \multirow[b]{2}{*}{359837.60} \\
\hline & $\begin{array}{c}\text { Electricidad } \\
(\mathrm{kWh})\end{array}$ & 0.001 & & \\
\hline
\end{tabular}

\section{Fase 3: Ciclo de vida programa SimaPro}

Después de introducir los datos del balance de masa y energía al software SimaPro, el programa arrojó los resultados en un diagrama de Sankey (Figura 2). Éstos se usan para visualizar flujos de materia y energía en muchas aplicaciones, para ayudar a comprender las pérdidas y las ineficiencias, planificar los procesos de producción y dar una sensación de escala en un sistema (la anchura de las flechas se muestra proporcional a la cantidad de flujo). El agua potable es la entrada más importante para la producción de vapor, seguida de la electricidad utilizada para el funcionamiento de la caldera y el sistema de calefacción y por último la cantidad de combustible requerido para su funcionamiento 


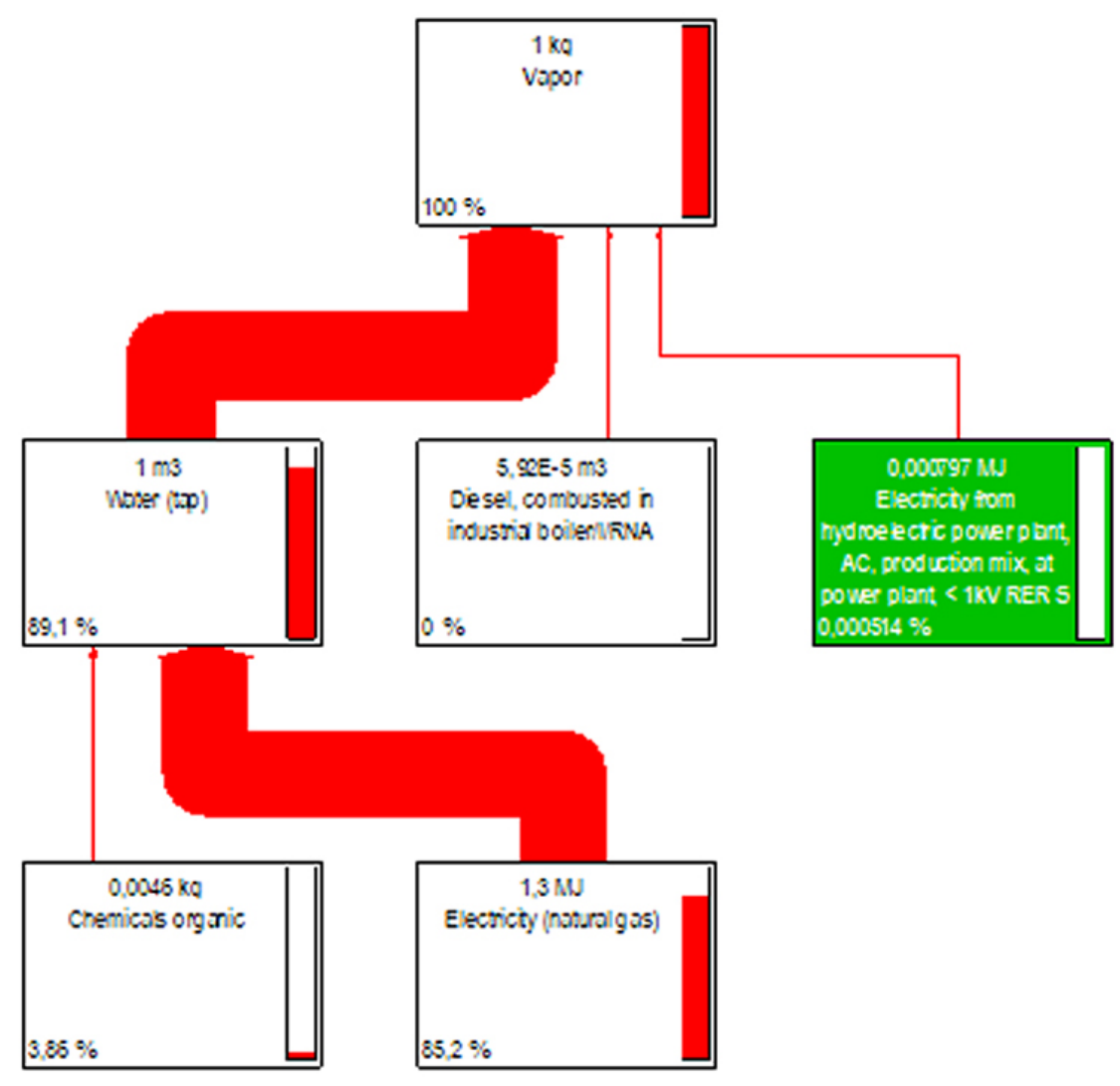

Figura 2: Diagrama resultados ciclo vapor de agua. Datos obtenidos de los cálculos a partir de la información suministrada por el UMB Golf Club, haciendo uso del programa Simapro. Fuente: Autores.

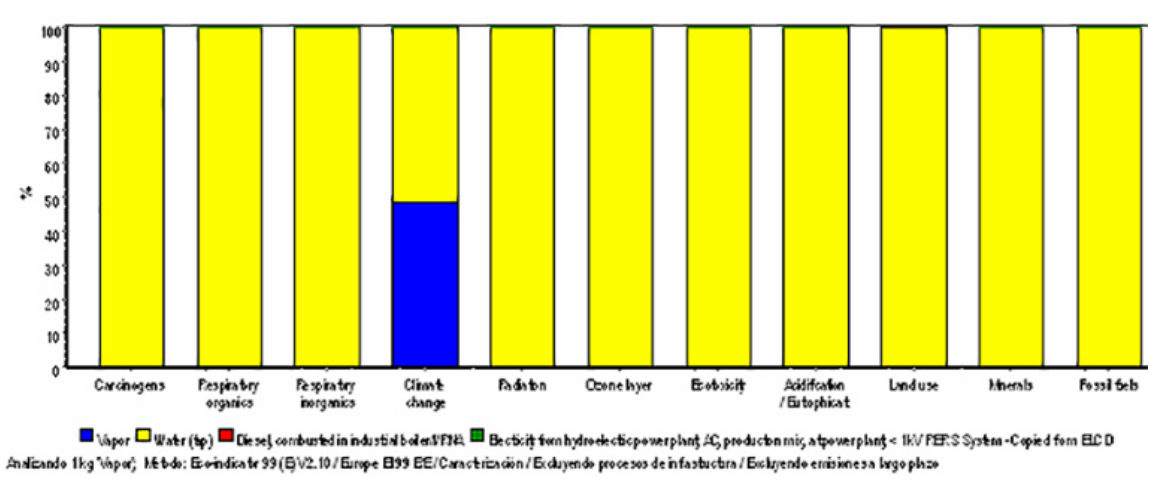

Figura 3. Caracterización del proceso de generación de vapor. Fuente: Autores

Los ecoindicadores son números que expresan el impacto ambiental total de un proceso o producto y con esa información los diseñadores de productos pueden analizar las cargas ambientales de diferentes productos durante su ciclo de vida. El método LCA se ha desarrollado para incluir un método de coeficientes de ponderación. Esto permite calcular un solo valor para el impacto ambiental total basado en los efectos calculados [12]

Las categorías de impacto en la Figura 3, se muestra la caracterización del proceso de generación de vapor con el método Eco-indicador 99, a partir de los datos asignados a cada categoría de impacto, observando que todas las categorías tienen valores positi- vos (perjudiciales) para el ambiente. Estas categorías están asociadas a las emisiones al aire, al agua y al suelo, de sustancias químicas orgánicas e inorgánicas usadas en el proceso de potabilización de agua (color amarillo), el proceso de producción de energía eléctrica para la potabilización de agua, emisiones de vapor de agua (color azul) y dióxido de carbono, etc. Los impactos generados por el diésel y electricidad usados para el proceso de generación de vapor en el club no son significativos.

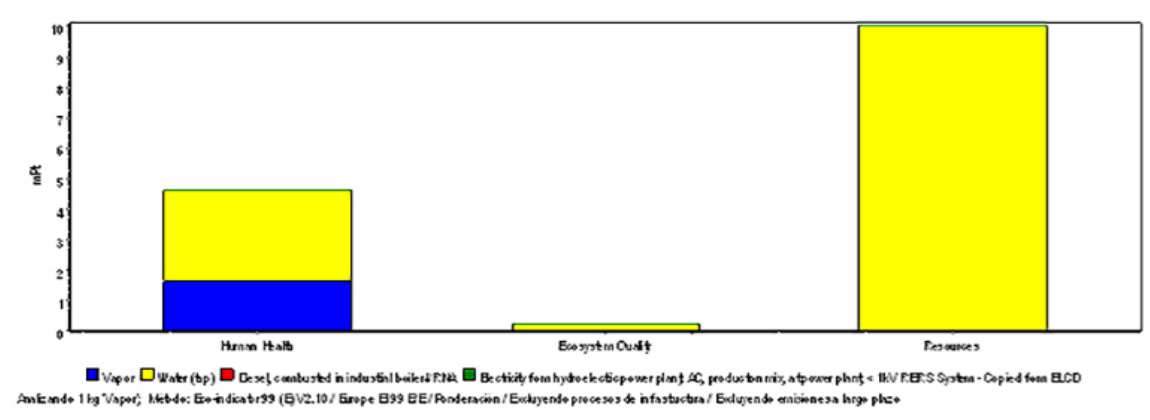

Figura 4. Ponderación del proceso de generación de vapor. Fuente: Autores.

Los valores estándar de los ecoindicadores son cifras sin dimensión. En las listas de ecoindicadores se emplea normalmente la unidad de milipuntos ( $\mathrm{mPt}), \mathrm{y}$ el valor absoluto de los puntos no es muy relevante ya que el objetivo principal es comparar las diferencias relativas entre productos o componentes. La escala se ha elegido de forma que el valor de 1 Pt represente la centésima parte de la carga ambiental anual de un ciudadano europeo medio [12].

La Figura 4, muestra el impacto que produce el proceso de generación de vapor en el club en las tres categorías de impacto (daño a la salud humana, a la calidad del ecosistema y los recursos). En este caso se reafirma como productos más agresivos al ambiente, el consumo de agua potable (daño a la salud humana, calidad del ecosistema y recursos naturales principalmente, en color amarillo) y la producción de vapor (salud humana, en color azul).

\section{Fase 4. Análisis de resultados.}

A partir de los resultados obtenidos en la evaluación del impacto del ciclo de vida, se concluye, que la mayor parte de las cargas contaminantes que afectan a la salud humana, la calidad del ecosistema y el agotamiento de los recursos están generadas en primer lugar por la energía requerida por el proceso de potabilización de agua y en segundo lugar por la emisión de gases efecto invernadero producto de la generación de vapor en el sistema de las zonas húmedas del UMB golf club. 
Entre las medidas de prevención y mitigación del impacto ambiental podría tenerse en cuenta una disminución de las distancias entre la caldera y las zonas húmedas, sin dejar de lado las normas de seguridad industrial. Podría también implementarse un combustible alternativo para la caldera, dado que la combustión de combustibles alternativos como el gas natural, produce menores emisiones de material particulado o gases como los SOx o NOx, comparado con el ACPM, disminuyendo los respectivos impactos ambientales. Podrían realizarse adiciones en la infraestructura para mejorar la recirculación de vapor de agua y así disminuir las pérdidas de vapor a la atmósfera.

\section{CONCLUSIONES}

El consumo de agua potable es el que más incide en las 11 categorías de impacto ambientales.

La aplicación de la metodología del ACV permite conocer las áreas y flujos que más inciden en los impactos ambientales objeto de estudio y por consiguiente posibilita establecer medidas de mejoras para minimizar los daños al ambiente; en el estudio realizado están dirigidas sobre el consumo de agua potable y la emisión de vapor a la atmósfera.

\section{AGRADECIMIENTOS}

A la Universidad Manuela Beltrán por su programa de prácticas empresariales.

\section{REFERENCIAS}

[1] I. S. Stachlewska, M. Costa-Surós, y D. Althausen, «Raman lidar water vapor profiling over Warsaw, Poland», Atmospheric Res., vol. 194, pp. 258-267, sep. 2017.

[2] C. Landeros-Sánchez, A. García-Saldaña, I. Nikolskii-Gavrilov, M. del R. Castañeda-Chávez, J. M. Hernández-Pérez, y G. Sánchez-Ocaña, Tendencias del cambio climático: una revisión. 2016.
[3] J. A. Santiago-Lastra, M. López, y S. López, Tendencias del cambio climático global y los eventos extremos asociados. 2018.

[4] J. L. D. Quesada y A. E. de N. y Certificación, Huella ecológica y desarrollo sostenible. AENOR-Asociación Española de Normalización y Certificación, 2009.

[5] A. Michopoulos, I. Ziogou, M. Kerimis, y T. Zachariadis, «A study on hot-water production of hotels in Cyprus: Energy and environmental considerations», Energy Build., vol. 150, pp. 1-12, sep. 2017.

[6] Consejería de Economía y Hacienda, Guía Básica de Calderas Industriales Eficientes. Gráficas Arias Montano. S.A., 2012.

[7] H. P. Nielsen, F. J. Frandsen, K. Dam-Johansen, y L. L. Baxter, «The implications of chlorine-associated corrosion on the operation of biomass-fired boilers», Prog. Energy Combust. Sci., vol. 26, n.o 3, pp. 283-298, jun. 2000.

[8] R. Saidur, E. A. Abdelaziz, A. Demirbas, M. S. Hossain, y S. Mekhilef, «A review on biomass as a fuel for boilers», Renew. Sustain. Energy Rev., vol. 15, n.o 5, pp. 2262-2289, jun. 2011.

[9] Colombia Ministerio de Medio Ambiente y Desarrollo Territorial, «Resolución 909 de 2008 por la cual se establecen las normas y estándares de emisión admisibles de contaminantes a la atmósfera por fuentes fijas y se dictan otras disposiciones.» [En línea]. Disponible en: http://www.minambiente.gov.co/images/normativa/app/resoluciones/f0-Resoluci\%C3\%B3n\%20 909\%20de\%202008\%20\%20-\%20Normas\%20y\%20estandares\%20de\%20emisi\%C3\%B3n\%20Fuentes\%20 fijas.pdf. [Accedido: 10-jul-2018].

[10] C. Cardona, D. Sánchez, y O. Sánchez, Análisis de ciclo de vida y su aplicación a la producción de bioetanol: Una aproximación cualitativa, vol. 43. 2007.

[11] ISO, «ISO 14040. Environmental management-Life cycle assessment-Principles and framework.», Environ. Manag.-Life Cycle Assess.-Princ. Framew. Eur. Comm. Stand., 2006.

[12] IHOBE, S.A. Sociedad Pública de Gestión Ambiental, Manual práctico de ecodiseño. Operativa de implantación en 7 pasos. 2000. 


\title{
LA INFLUENCIA DEL EMBALSE EL PEÑOL- GUATAPÉ, ANTIOQUIA EN LOS PATRONES CLIMÁTICOS Y METEOROLÓGICOS A ESCALA LOCAL Y REGIONAL
}

\author{
Marín Martínez, Diego Alejandro
}

\author{
${ }^{1}$ Universidad El Bosque \\ diegomarin.m@hotmail.com
}

\author{
ÁREA TEMÁTICA \\ Energías Alternativas: Energía hidráulica o hidroeléctrica
}

\section{RESUMEN}

El clima y su variabilidad representan un factor imprescindible en los procesos de regulación y almacenamiento del recurso hídrico en los embalses, incidiendo directamente en el desarrollo de la industria hidroeléctrica de Colombia. Es por esta razón que el propósito de este estudio de caso, es analizar el papel del embalse El Peñol-Guatapé, Antioquia en posibles cambios del clima local circundante y los patrones meteorológicos locales y regionales para el periodo de 1970-2017; teniendo como referencia el vacío de información y políticas en el marco nacional e internacional. La metodología del presente trabajo de investigación consiste en caracterizar el clima de inmediaciones al embalse, a partir de la información local de la red de estaciones meteorológicas del IDEAM del periodo 1973-2017, y datos de climatología global y regional del Reanálisis Japonés (JRA-55) del periodo 1970-2013, de variables de mesoescala con una frecuencia de datos trihorarios integrados a datos mensuales y establecer la influencia de ENOS en cada variable climatológica, de forma comparativa entre el periodo previo y posterior al inicio de operación del embalse, utilizando estadísticas descriptivas y normales climatológicas. Los resultados evidencian que la dinámica atmosférica del embalse El Peñol-Guatapé está relacionada a la topografía y variables de mesoescala como la convección.

La contribución del trabajo radica en que se presenta la base técnico - científica que fundamenta la importancia y utilidad de vincular estudios climáticos al sector hidroenergético, como media de prevención y contingencia frente en escenarios de gestión del riesgo, frente a la adaptación y mitigación del cambio climático.

Palabras claves: Clima, Convección, Dinámica Atmosférica, Embalse El Peñol-Guatapé, Patrón meteorológico. 


\section{INTRODUCCIÓN}

La generación de energía eléctrica a partir de fuentes renovables es cada vez mayor en el mundo. Según Renewable Energy Policy Network for the 21st Century (REN21, por sus siglas en inglés), se estima que el 80,8 \% de la energía eléctrica consumida en el planeta, proviene de fuentes fósiles, mientras que el 19,2\% de fuentes renovables. Actualmente, en Colombia el 69,9 $\%$ de la energía eléctrica consumida proviene de fuentes renovables y el 30,1 \% restante procede de fuentes fósiles [1], un porcentaje sobresaliente al mundial y altamente significativo en el país, pues el total de energía que se consume en este, se debe gracias a los Sistemas de Interconexión Nacional (SIN) [2]. Lo anterior se atribuye a los más de 18 proyectos hidráulicos o hidroeléctricos ubicados en toda la extensión del territorio, especialmente sobre la región Andina [3], siendo el departamento de Antioquia una de las primeras regiones del país en desarrollar la capacidad de instalación y generación de energía [4]. Estos proyectos de hidroenergía cuentan con espacios de almacenamiento de recurso hídrico proveniente de fuentes cercanas y las áreas de almacenamiento dependen de la capacidad de generación de energía, estas áreas son llamadas embalses, cuyo papel es fundamental y necesario dentro de todos los procesos hidráulicos [5] como el caso del embalse El Peñol-Guatapé, ubicado en el oriente de Antioquia y caracterizado por ser el de mayor regulador hídrico del país [4].

Sin embargo, pese a todas las cifras que favorecen no solamente al sector económico, sino también, hacia la prestación del servicio eléctrico, con fines de garantizar una mejor calidad de vida, este tipo de proyectos han sido controvertidos a lo largo de los años por generar una serie de impactos sociales y ecológicos [6]. Ello no es una situación alejada en el país, y es precisamente ahí donde se encuentra el problema de investigación en el cuál se basa este trabajo investigativo, ya que los impactos ambientales directos e indirectos usualmente trascienden en aspectos intrínsecamente relacionados al desarrollo social en escenarios de educación, infraestructura, comunicación, empleo, prestación de servicios, etc., que en general subyace en la búsqueda de un progreso íntegro de la sociedad, muchas veces fracasado por la sobreposición económica en medio de la vulnerabilidad social [7] [8]; Todo esto es representado en un trasfondo, por los indicadores de crecimiento o decrecimiento poblacional; y es entonces en donde se tienen que desa- rrollar alternativas de prevención o remediación, que permitan que los proyectos hidroeléctricos no se conviertan en un costo social, económico y ecológico para el territorio, sino un beneficio integral mancomunado [9].

Motivo por el cual se tomó como objeto de estudio el embalse El Peñol-Guatapé, por su importante papel en Colombia y la región, como se mencionó anteriormente.

Por consiguiente, el presente se desarrolla bajo la hipótesis de que los embalses pertenecientes a hidroeléctricas generan alteraciones en los patrones meteorológicos y climatológicos locales y regionales, pues es un tema poco investigado en toda esta industria [10] y uno de los principales factores es la falta de políticas que permitan establecer lineamientos de evaluación de impacto ambiental, con lo cual coinciden diversos expertos [11]. Alrededor del mundo, la información del tema es limitada y casi que desconocida; uno de los pocos países que cuenta con investigaciones es los Estados Unidos, cuyos estudios son liderados por Roger A. Pielke en diversas presas y embalses del país americano; en estos se establecen análisis direccionados a la cobertura del suelo y uso del suelo y las interacciones con la atmosfera, obteniendo resultados correlaciónales entre sí, para generar estimaciones de alteraciones en los patrones climáticos. El factor común de los estudios realizados del año 2010 al 2014, indican que en estas regiones los embalses han alterado los patrones de precipitación extrema, principalmente y de temperaturas, considerándose entonces la formación de microclimas en cercanías de estos proyectos [8] [10] [12] [13].

Otros de los estudios con mayor impacto se desarrollaron en China y en India, ratificando en ambos casos, cambios significativos en las diferencias de temperatura, lo que podría revelar diferencias en el microclima de la región aún más claramente [14] [15]. En Colombia, no se tiene un marco de referencia respecto a estudios bajo el contexto de dinámica atmosférica dentro del sector energético, pero la actividad si esta regida legalmente. La norma encargada de los proyectos de generación de energía hidroeléctrica en el país, es la Resolución 1519 de 2017 [16], en ella se establecen los términos de referencia para la elaboración del estudio de impacto ambiental (EIA), los cuales son requeridos para el trámite de la licencia ambiental en los proyectos de construcción, operación y se toman otras determinaciones. En los EIA las componentes climáticas - meteorológicas son caracterizadas, diag- 
nosticadas y evaluadas a la par de muchos otros factores y aspectos que se solicitan en los requerimientos [16]. Sin embargo, una vez estando el proyecto en la fase de operación, no se vuelve a conocer a fondo las implicaciones que pueden llegar a ejercer en este caso, los embalses o hidroeléctricas sobre los componentes específicamente mencionados, inclusive la norma no puntualiza de forma explícita la realización de análisis o evaluaciones aplicadas de la dinámica atmosférica dentro de la formulación de los Planes de Manejo Ambiental (PMA), planes de seguimiento y monitoreo y planes de gestión del riesgo (Capítulos 8.2 y 10 de la norma) [16]. No obstante, la mayoría de los otros aspectos como: aire, agua, suelo, flora, fauna, paisaje y economía, principalmente, si son evaluados posteriormente como medida de beneficio, contingencia e investigación [16]. De manera que los programas que se establecen en los planes emitidos, deben estar para mitigar, prevenir y compensar todo tipo de impacto, establecido o no establecido y ofrecer garantías a las poblaciones aledañas [7].

\section{MATERIALES Y MÉTODOS}

\section{Bases de Información}

El desarrollo del análisis de la investigación contó con dos fuentes de información de calidad, con series de tiempo superior a los 30 años, garantizando así, un mejor acercamiento en la variación del clima circundante, además de adoptar las recomendaciones que propone la Organización Meteorológica Mundial (OMM) [17]. Los datos de las variables climatológicas provienen de dos fuentes de información; Por un lado, se recopila información de cinco estaciones con series de 44 años (1973-2017) de la red de estaciones meteorológicas de la zona de estudio, operadas por el Instituto de Hidrología, Meteorología y Estudios Ambientales (IDEAM); y de otro lado, datos de bases de información climática global y regional en sistema gaussiano de cuadrícula, Japanese Reanalysis (JRA-55) de la Agencia Meteorológica Japonesa, con series de 43 años (1970-2013). Toda la información es ejecutada en herramientas computacionales de alto desempeño, como GRADS y RSTUDIO [18] [19].

Tabla 1. Características de la información tomada de las bases del modelo.

\begin{tabular}{|c|c|c|c|c|c|c|}
\hline \multirow[b]{2}{*}{$\begin{array}{c}\text { Fuentede } \\
\text { Información }\end{array}$} & \multirow[b]{2}{*}{$\begin{array}{c}\text { Nombre-de } \\
\text { Estación }\end{array}$} & \multicolumn{2}{|c|}{ Resolución-Temporal } & \multirow[b]{2}{*}{$\begin{array}{l}\text { Frecuenciade } \\
\text { toma-dedatos }\end{array}$} & \multirow[b]{2}{*}{$\begin{array}{c}\text { Nivele } \\
\text { verticales }\end{array}$} & \multirow[b]{2}{*}{ Variables-de-análisis } \\
\hline & & \begin{tabular}{|c|}
$\begin{array}{c}\text { Periodo Previo ala } \\
\text { Construcción }\end{array}$ \\
\end{tabular} & \begin{tabular}{|c|} 
Periodo-Posteriora \\
la-Construcción
\end{tabular} & & & \\
\hline \multirow{8}{*}{$\begin{array}{c}\text { Reanálisis } \\
\text { Japonés(JRA-55) }\end{array}$} & & \multirow{8}{*}{ 1970-1981 } & \multirow{8}{*}{ 1982-2013 } & \multirow{8}{*}{$\begin{array}{c}\text { Trihorarios } \\
\text { integradosa-datos } \\
\text { mensuales }\end{array}$} & \multirow{5}{*}{$\begin{array}{c}\text { Superficie-del } \\
\text { suelo-o-agua } \\
\text { (1000-hpa) }\end{array}$} & Precipitaciôn-Total \\
\hline & & & & & & Precipitación-Convectiva \\
\hline & & & & & & $\begin{array}{c}\text { Precipitación. Estratiforme- } \\
\text { no-convectiva }\end{array}$ \\
\hline & & & & & & $\begin{array}{c}\text { Frecuenciade-convección } \\
\text { profunda }\end{array}$ \\
\hline & & & & & & $\begin{array}{l}\text { Frecuencia-de-convección } \\
\text { superficial }\end{array}$ \\
\hline & & & & & $\begin{array}{c}\text { Nivel-híbrido-9 } \\
(919 \cdot \mathrm{hpa} \approx \cdot \cdot 1 \\
\mathrm{km})\end{array}$ & $\begin{array}{c}\text { Razón de calentamiento } \\
\text { convectivo }\end{array}$ \\
\hline & & & & & \multirow{2}{*}{$\begin{array}{l}2 \text { metros dela } \\
\text { superficie }\end{array}$} & Temperaturadel-aire \\
\hline & & & & & & Humedad-Especifica \\
\hline & & & & & & \\
\hline \multirow{5}{*}{$\begin{array}{l}\text { Estaciones } \\
\text { Meteorológicas } \\
\text { - IDEAM }\end{array}$} & E1·Peñol & 1973-1981 & $1982-2017$ & & & \multirow{5}{*}{$\begin{array}{c}\text { Precipitación, -Número- } \\
\text { dâts con-lluvia, Temperatur } \\
\text { y·Humedad-relativa. }\end{array}$} \\
\hline & Corrientes & $1975-1981$ & $1982-2017$ & & & \\
\hline & Alejandría & $1973-1981$ & $1982-2017$ & & & \\
\hline & Tejar & 1959-1981 & 1982-1993 & & & \\
\hline & Violetas & $\begin{array}{l}\text { Noreporta } \\
\text { Información }\end{array}$ & $1982-2011$ & & & \\
\hline
\end{tabular}




\section{MÉTODOS}

Las series de datos de cada variable climatológica, fueron tratadas con estadísticas descriptivas y normales climatológicas. La conformación de todas las series se realizó con la aplicación de la media aritmética, soportado en la ecuación (1), para estimar los valores característicos o promedios mensuales y multianuales.

$$
\bar{X}=\frac{\sum_{i=1}^{n} X_{i}}{N}
$$

Dónde $\overline{\mathbf{X}}$ es el promedio o media aritmética de la variable correspondiente, $i$ hace referencia al año inicial de los datos, $n$ es el año final de los datos, $X_{i}$ son los datos mensuales o multianuales de la variable a evaluar y $N$ es el total de datos de cada variable.

También se representa los cambios positivos o negativos de un periodo a otro entre meses y temporadas seca y húmeda, mediante la ecuación (2).

$$
\text { Diferencia }=\quad \sum_{i=1}^{N}\left(\bar{X}_{f}-\bar{X}_{i}\right)
$$

Dónde $\bar{X}_{f}$ es el promedio o media aritmética del periodo posterior a la construcción del embalse y $\overline{\mathbf{X}}_{i}$ es el promedio o media aritmética del periodo previo a la construcción del embalse.

Finalmente, con la ecuación (3) se calcula un patrón compuesto de anomalías acumulado para cada año seleccionado por estación (Seca y Húmeda) para determinar la influencia de ENOS, con referencia a los años atípicos o anómalos de El Niño y La Niña.

$$
\overline{\boldsymbol{Z}}=\frac{\sum_{j}^{n} X_{i}}{N}-\frac{\sum_{i}^{m} W_{i}}{M}
$$

Dónde $\bar{Z}$ es el patrón compuesto de anomalías acumulado para cada año seleccionado por estación, j es el año inicial de los datos (Desde el año 1959 para estación seca y desde el año 1958 para estación húmeda), $n$ es el año final de los datos (El año 2010 para estación seca y el año 2009 para estación húmeda), $X_{i}$ hace referencia a los datos estacionales de cada año seleccionado (seca con diciembre, enero y febrero, y húmeda de abril a noviembre), $N$ es el total de datos de cada variable (13 años para estación seca y 8 años para estación húmeda), i es el año inicial de los datos (1981), m es el año final de los datos (2010), W son los datos estacionales de la variable a evaluar (seca con diciembre, enero y febrero, y húmeda de abril a noviembre) y finalmente, $M$ es el total de datos de cada variable (30 años).

\section{RESULTADOS Y ANÁLISIS DE RESULTADOS}

Los datos de series históricas procedentes del IDEAM, evidencian un comportamiento estable de la precipitación en cuatro de las cinco estaciones meteorológicas analizadas. La estación Violetas es la única con tendencia a crecimiento paulatino a lo largo de los años (Figura 1). Todo esto está asociado a un patrón de aumento de la temperatura que supera $1{ }^{\circ} \mathrm{C}$ en el caso de las estaciones El Peñol y Corrientes. Así mismo se presenta un aumento pronunciado de la variable en el resto de estación, exceptuando la estación Violetas, en donde la correlación con los aumentos de precipitación han influido en el decrecimiento de la temperatura desde el año 2000 hasta el año 2017 (Figura 2).

Para poder comprender este comportamiento, es importante mencionar que la altura en esta zona disminuye de oeste a este (2200 (m.s.n.m) y 900 (m.s.n.m)), siendo entonces la estación Tejar y Violetas las más bajas en altura a nivel del mar en el este, y El Peñol y Corrientes las más altas en el oeste; esto es algo que permite inferir en el desplazamiento de una corriente de aire con los vientos alisios del noreste, que ejercen una importante interacción con la configuración orográfica, en la activación del forzamiento orográfico, que básicamente consiste en el ascenso de corrientes cálidas y húmedas sobre los frentes montañosos (Barlovento), condicionando a que el aire cálido se enfrié en la altura, retenga el vapor de agua presente en el aire, se condense y generare precipitación en este caso hacia el lado este [20].

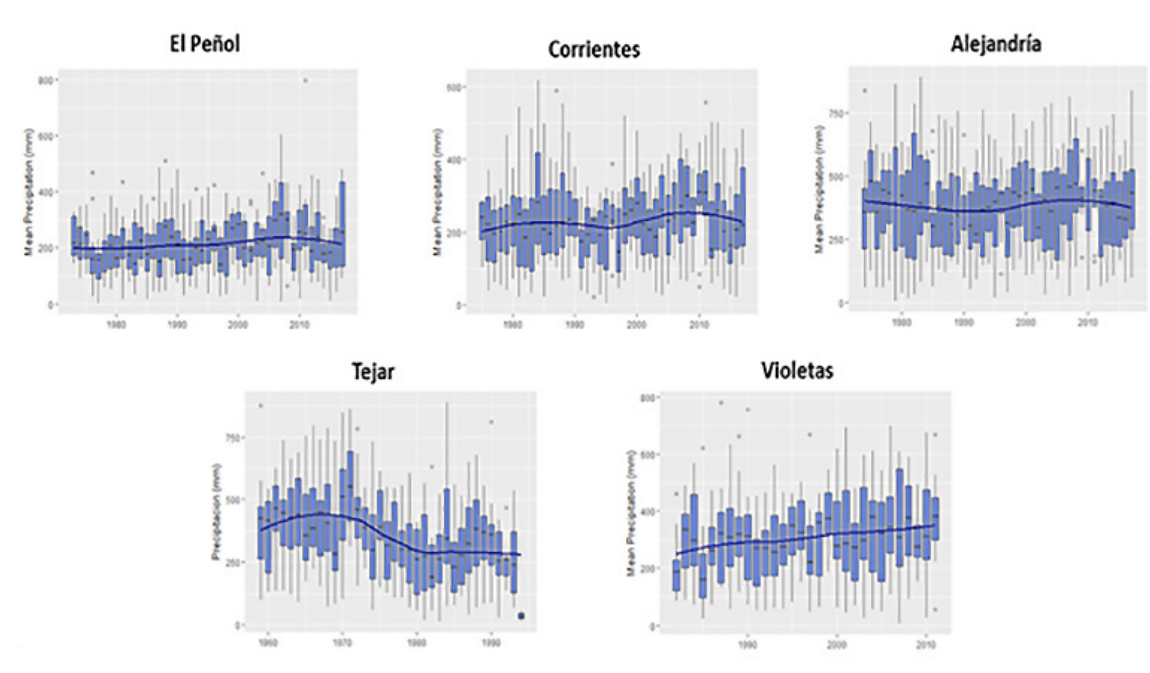

Figura 1. Patrones de precipitación interanuales del periodo 1973-2017; Radicado estaciones de análisis, IDEAM. 

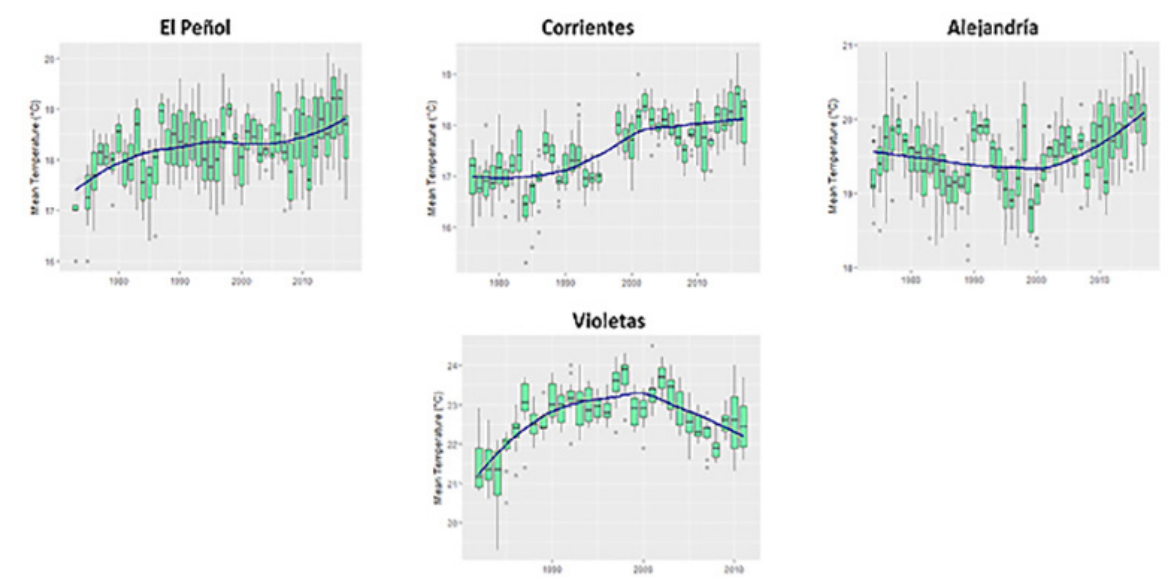

Figura 2. Patrones de temperatura interanuales del periodo 1973-2017: Radicado estaciones de análisis, IDEAM.

Al lado oeste, la corriente de viento desciende cálido y seco (Sotavento), por lo que se esperaría una temperatura superior a la del lado este; y es precisamente esta interacción la que se presenta en inmediaciones del embalse El Peñol-Guatapé (Figura 2). Adicionalmente, a este fenómeno de aumento de temperatura del aire por lluvia orográfica, se suma el calor que irradia el embalse de forma vertical y horizontal [21], facilitando aumentos de temperatura de hasta $1,3{ }^{\circ} \mathrm{C}$ entre 1973 y 2017 (Figura 2) y por ende incidiendo en procesos termodinámicos de transporte de alta humedad [22].
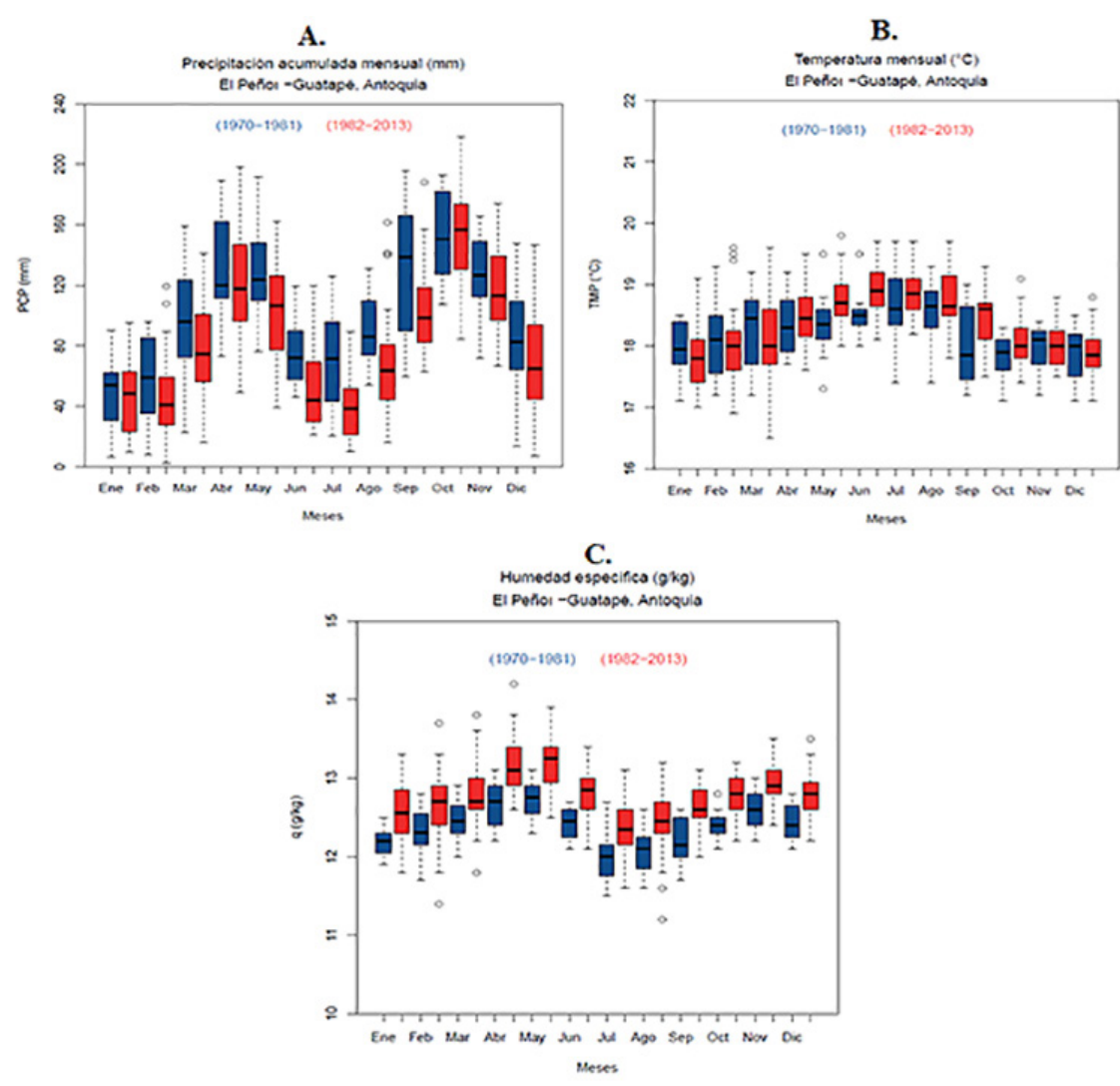

Figura 3. Promedios mensuales multianuales de variables meteorológicas (1970-1981) y (1982-2013). A. Precipitación (mm)

B. Temperatura $\left({ }^{\circ} \mathrm{C}\right)$ y C. Humedad especifica $(\mathrm{g} / \mathrm{kg})$

Para evidenciar de manera explícita las variaciones climáticas, se analiza cada variable de manera compa- rativa entre los periodos 1970-1981 y 1982-2013 sobre el embalse El Peñol-Guatapé (Lat. 6.288 N, Lon. 75.188 $\left.W^{\circ}\right)$. La variable de precipitación no muestra cambios significativos entre los periodos (Gráfica 3, A.), En tanto a las variables de temperatura en el aire y humedad específica; se constata un aumento en el periodo 19822013, respecto a 1970-1981, ratificando entonces que el comportamiento de los patrones de estabilidad de las estaciones meteorológicas del IDEAM a una escala regional y local (Figura 3, B.) (Figura 3, C.).
A.

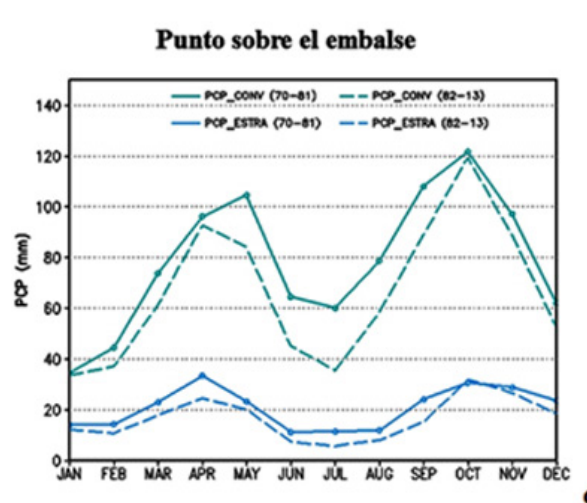

B.

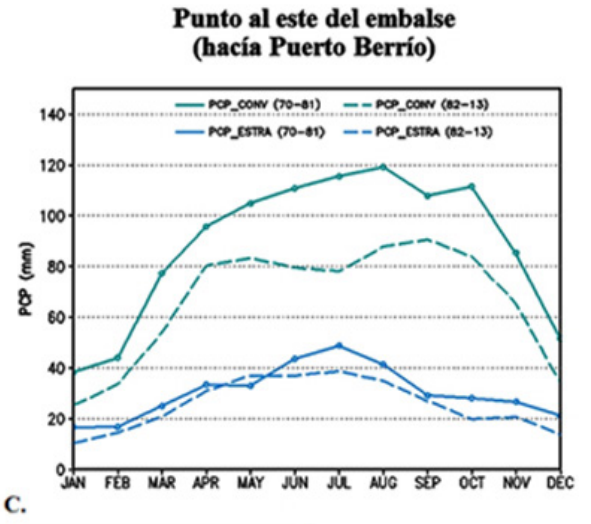

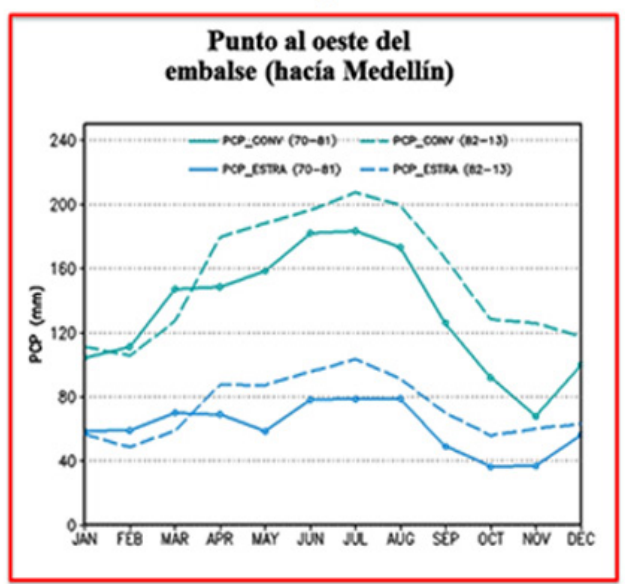

Figura 4. Diferencia mensual multianual de precipitación ( $\mathrm{mm}$ ) convectiva y estratiforme entre periodo (1970-1981) y (19822013). A. Punto sobre el embalse. B. Punto al este del embalse y C. Punto al oeste del embalse; Japanese Reanalysis (JRA-55).

De otro lado, se determinó la precipitación convectiva por tratarse de un proceso asociado a mesoescala que permite determinar la actividad de convección regional en el marco del embalse El Peñol-Guatapé. Así mismo, se analizó la precipitación estratiforme (no convectiva), la cual está asociada a procesos de gran escala o escala sinóptica; La suma de estas, representa la precipitación total [23]. Estas variables fueron determinadas en tres puntos para los periodos de 1970-1981 y 1982-2013. Los resultados muestran una disminución en la precipitación convectiva y estratiforme para el periodo 1982-2013, respecto a 19701981, en los puntos hacia el este (Figura 4, B.) y en el punto sobre el embalse (Figura 4, A.), con una mayor marcación de régimen bimodal sobre el embalse y régimen monomodal hacia el este. El punto hacia el oeste, mostró un patrón inverso a los otros puntos, pues 
en este punto, la precipitación convectiva aumenta en el periodo de 1982-2013, respecto a 1970-1981 (Figura 4, C.); dando indicios de que posiblemente existe una migración de corrientes de aire caliente y húmedo, efecto del calentamiento del aire en la superficie y contribuciones de otras corrientes inducidas por forzamiento orográfico proveniente del este. Al presentarse un calentamiento del aire, este disminuye su densidad, favoreciendo el ascenso y la dilatación que permite la retención de grandes cantidades de vapor de agua en el aire, para luego condensarse y generar nubes de tipo cumulonimbus. Este tipo de nubes por lo general tienen una forma vertical y generan fuertes precipitaciones [24]. Esto es un factor importante que puede incurrir en el proceso de escorrentía superficial a los cuerpos hídricos circundantes sobre la región montañosa del oeste. Favoreciendo entonces los niveles del recurso hídrico (eventualidad de riesgo) en el embalse El Peñol-Guatapé y compensando la disminución parcial de precipitación (evidente en las estaciones del IDEAM), a causa de del forzamiento orográfico en el este, que lleva a que la zona del embalse presencie aumentos en la temperatura del aire [20].
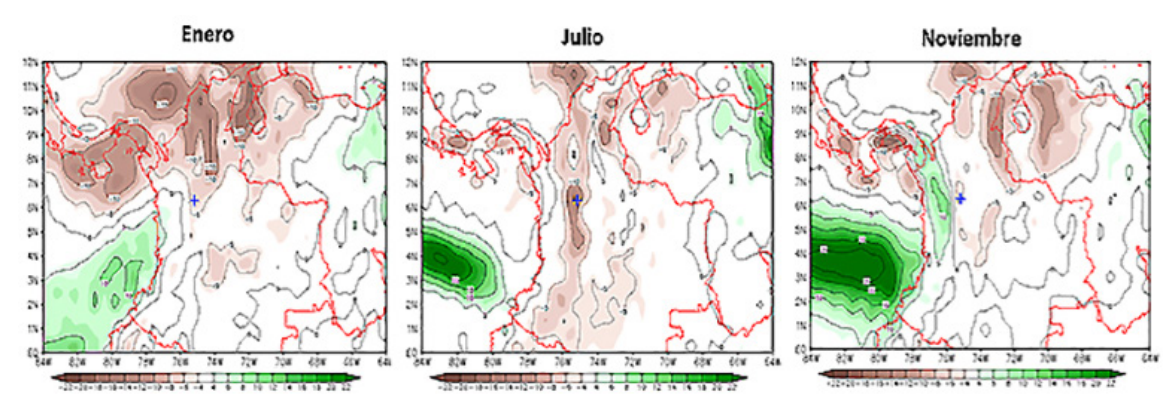

Figura 5. Frecuencia de convección profunda (\%), diferencia (1981-2011) - (1970-1981). De izquierda a derecha el mes de enero, julio y noviembre. Japanese Reanalysis (JRA-55).

Al evidenciar un aumento en la precipitación convectiva hacia el oeste del embalse, se estableció necesario entender la frecuencia de los episodios de convección. Para esto es pertinente comprender la frecuencia de convección profunda y somera. La frecuencia de convección profunda demuestra sistemáticamente, que existe una menor activación de la convección profunda durante la época o estación seca y evidencia un déficit desde el norte de Colombia para el periodo actual (1982-2013) y este patrón se extiende aproximadamente hasta la latitud de $5 \mathrm{~N}^{\circ}$, en donde se encuentra la región de estudio (Figura 5, Julio). Para la segunda época o estación seca del año, el déficit toma una distribución espacial diferente, prácticamente meridional siguiendo más o menos la orografía de la región (Figura 5, Enero). Sin embargo, para los meses de la estación húmeda de abril, mayo, agosto, septiembre, octubre y noviembre (Figura 5, Noviembre), en la región oeste respecto al embalse (hacía Medellín) se activa la convección entre un $5 \%$ y $10 \%$ para el periodo actual (1982-2013); ese patrón es consistente en las diferencias de precipitación convectiva y precipitación total.

Finalmente, para dar coherencia a la explicación del incremento de la precipitación convectiva en el punto oeste del embalse, fue necesario analizar la razón de calentamiento convectivo en un corte zonal (Norte-Sur, $\left.5 \mathrm{~N}^{\circ}-7 \mathrm{~N}^{\circ}\right)$, paralelo al embalse. Este corte facilita la explicación de la migración del régimen húmedo al oeste y seco al este en la zona de estudio (Latitud 6.288 ${ }^{\circ}$, Longitud $84 W^{\circ}-64 W^{\circ}$ ) (Figura 6).

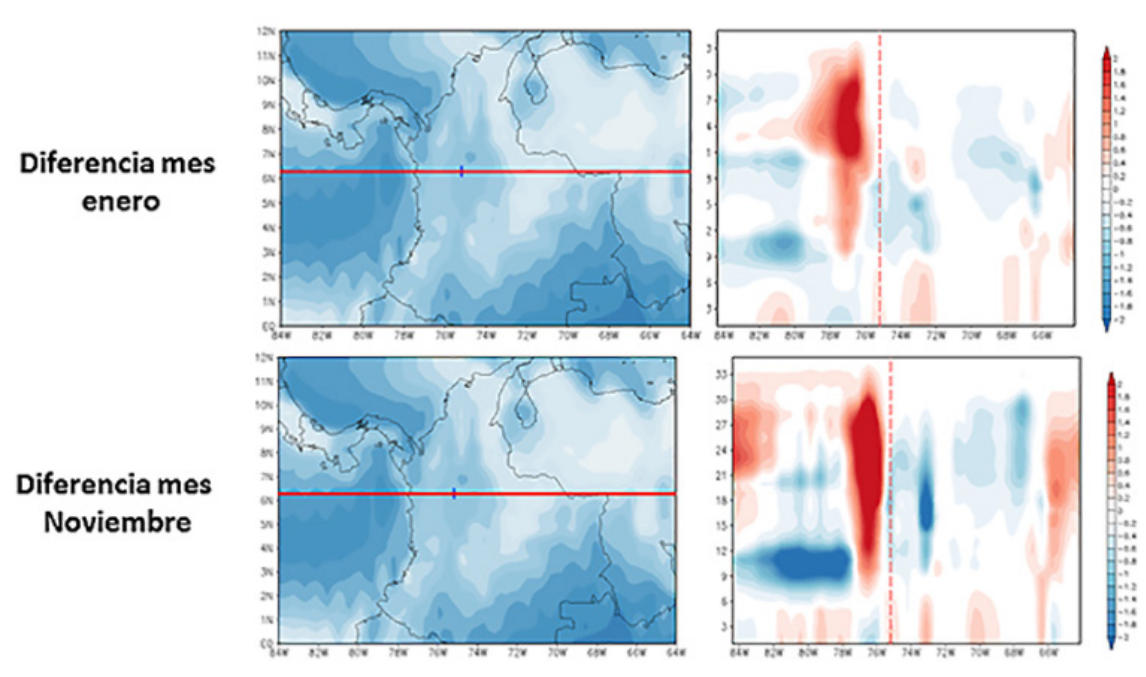

Figura 6. Corte zonal (Lat. 6.288 ${ }^{\circ}$, Lon. $\left.84 W^{\circ}-64 W^{\circ}\right)$, diferencia (K/día) para el periodo (1982-2013) - (1970-1981). Arriba mes enero y abajo mes de Noviembre. Japanese Reanalysis (JRA55).

La razón de calentamiento convectivo se realiza para todos los meses del año, expresada como la diferencia entre periodos establecidos para el análisis, sin embargo, se toman como referentes los meses de enero y noviembre, por tratarse de los meses donde se presenta respectivamente la menor y mayor diferencia de precipitación convectiva para el periodo más actual (1982-2013). En el mes de enero, se presenta una transferencia de calor negativa sobre el embalse, la cual varía entre -0,2 y -0,6 kelvin por día (K/día); En el mes de noviembre, se presenta la mayor diferencia entre periodos de precipitación convectiva, debido a la transición de la estación húmeda a seca que se presenta en el costado izquierdo u oeste de la figura 6, como una mancha roja con elongación extensa de calor sobre todo el oeste del embalse, llegando a un valor de 2 (K/día) (Figura 6). Esto es un indicador crucial en la explicación del papel del embalse El Peñol-Guatapé en el contexto climático, debido a las interacciones tierra-atmósfera que se presentan a lo largo de este territorio. 


\section{CONCLUSIONES}

El análisis climatológico realizado en el embalse El Peñol-Guatapé para el periodo 1973-2017, permitió conocer que en la zona el patrón con mayor predominancia es la temperatura, al mostrar incrementos de hasta $1,3{ }^{\circ} \mathrm{C}$ hacia el oeste, posiblemente relacionado a un efecto de forzamiento orográfico, cuyo significado radica en corrientes de aire frio y húmedo al este (mayor precipitación convectiva) y el flujos de aire caliente en el oeste. En tanto, a excepción de la temperatura, las otras variables presentan patrones de estabilidad y decrecimiento leve no significativo.

La aproximación de la variabilidad climática, indica que el embalse ha tenido cambios en el clima entre el periodo 1970-1981 y 1982-2013, presentándose una relación intrínseca con procesos más específicos de mesoescala a nivel local, circulación atmosférica y transferencia de masas de aire húmedo por parte del embalse. Todo esto infiere en la generación de un efecto o impacto positivo en contribución de recurso hídrico al embalse, lo que puede ser un garante de seguridad energética; Pero de otro lado, puede representar un factor de riesgo por la posibilidad de la intensificación de precipitación que trae consigo episodios de inundación, movimientos de masa y en general un impacto negativo a la población y en general a todos los procesos económicos de la región.

Finalmente se concluye que el conocimiento de la compleja dinámica atmosférica de inmediaciones al embalse El Peñol-Guatapé es una herramienta que contribuye a las bases de posibles escenarios de variabilidad climática, cambio climático y gestión del riesgo, con la incorporación en políticas nacionales e internacionales, en estudios de impacto ambiental, planes de manejo ambiental y en la gestión y planificación ambiental territorial desde el contexto de desarrollo sostenible y mejoramiento de la calidad de vida de los habitantes del territorio, bajo el marco del sector hidroenergético.

\section{AGRADECIMIENTOS}

Al ingeniero David Felipe Beltrán Gómez por las asesorías prestadas para el desarrollo del proyecto, en representación de la Universidad El Bosque.

Al Dr. Ernesto Dos Santos Caetano Neto y Luis Clemente López Bravo, investigadores expertos en dinámica atmosférica, asociados a la Universidad Nacional Autónoma de México (UNAM); por facilitar herramien- tas necesarias para la investigación y brindar apoyo técnico durante la estructuración y desarrollo del proyecto.

\section{REFERENCIAS}

[1] REN21. (2016). Renewables 2016 Global Status Report. Obtenido de http://www.ren21.net/wp-content/ uploads/2016/05/GSR_2016_Full_Report_lowres.pdf

[2] UPME. (2015). Atlas Potencial Hidroenergético de Colombia. Obtenido de http://www1.upme.gov.co/ Documents/Atlas/Atlas_p25-36.pdf

[3] Palacios Sierra, R. A. (2013). Inventario Documentado de Represas en Colombia. Obtenido de Repositorio Universidad Militar Nueva Granada: http://repository.unimilitar.edu.co/bitstream/10654/11360/1/ PalaciosSierraRicardoAndres2013.pdf

[4] MME \& UPME. (2017). Registro de Proyectos de Generación Inscripción según requisitos de las Resoluciones UPME No. 0520, No. 0638 de 2007 y No. 0143 de 2016. Obtenido de http://www.siel.gov.co/Generacion_sz/Inscripcion/2017/Registro_Proyectos_Generacion_Mayo2017.pdf

[5] UCA. (2000). Centrales Hidroeléctricas. Obtenido de Universidad Centroamericana José Simeón Cañas: http://www.uca.edu.sv/facultad/clases/ing/ m200018/doc1.pdf

[6] Goldsmith, E., \& Hildyard, N. (1984). The social and environmental effects of large dams. Camelford, Cornwall: Wadebridge Ecological Centre.

[7] Úsuga Montolla, E. (2014). Impactos sociales y económicos de la hidroeléctrica en Ituango. Obtenido de Univesridad de Medellín, Facultad de Ciencias Económicas, Administrativas y Contables: http://repository.udem.edu.co/bitstream/handle/11407/2154/ TG_AE_3.pdf?sequence=1\&isAllowed=y

[8] Pielke Sr. et al. (2011). Land use/land cover changes and climate: modeling analysis and observational evidence. WIREs Clim Change, 2: 828-850.

[9] Iglesias Carvajal, S. (2011). Guía de Impacto Ambiental Para Centrales Hidroeléctricas. Obtenido de Universidad Tecnológica de Pereira, Facultad de Tecnología: http://repositorio.utp.edu.co/dspace/bitstream/handle/11059/2314/3337932I24.pdf;jsessioni$d=F 2029 B 5631750 D 535 E B B 673 F 32390 C F 3 ?$ sequen$\mathrm{ce}=1$ 
[10] Hossain, F., Jeyachandran, I., \& Pielke Sr., R. (2010). Dam safety effects due to human alteration of extreme precipitation. WATERRESOURCESRESEARCH, VOL. 46, W03301, doi: 10.1029/2009WR007704.

[11] World Commission on Dams. (2000). Dams and Development: A New Framework for Decision-Making. London and Sterling, VA: Earthscan Publications Ltd. Obtenido de https://www.internationalrivers.org/ sites/default/files/attached-files/world_commission_ on_dams_final_report.pdf

[12] Degu et al. (2011). The influence of large dams on surrounding climate and precipitation patterns. Geophysical Research Letters, 38, L04405, doi:10.1029/2010GL046482.

[13] Woldemichael, A., Hossain, F., \& Pielke Sr., R. (2014). Evaluation of surface properties and atmospheric disturbances caused by post-dam alterations of land use/land cover. Hydrology and Earth System Sciences, 18, 3711-3732.

[14] Tullos D. et al. (2010). Perspectives on the Salience and Magnitude of Dam Impacts for Hydro Development Scenarios in China. Water Alternatives, 3(2): 71-90.

[15] Kum, Gülşen. (2016). The Influence of Dams on Surrounding Climate: The Case of Keban Dam - Barajların Çevre İklime Etkisi: Keban Barajı Örneği. Gaziantep University Journal of Social Sciences, 15(1):193204.

[16] MinAmbiente. (26 de Julio de 2017). Resolución 1519 del 2017. Obtenido de Términos de referencia EIA: http://www.minambiente.gov.co/images/normativa/app/resoluciones/39RES\%201519\%20de\%20 2017.pdf

[17] Arango, C., Dorado, J., Guzmán, D., \& Ruiz, J. F. (Diciembre de 2012). CAMBIO CLIMÁTIO MÁS PROBA-
BLE PARA COLOMBIA A LO LARGO DELSIGLO XXI RESPECTO AL CLIMA PRESENTE. Obtenido de Grupo de Modelamiento de Tiempo, Clima y Escenarios de Cambio Climático; Subdirección de Meteorología - IDEAM: http://www.ideam.gov.co/documents/21021/21138/ Escenarios+Cambio+Climatico+\%28Ruiz\%2C+Guzman\%2C+Arango+y+Dorado\%29.pdf/fe5d64fb-3a824909-a861-7b783d0691cb

[18] R Core Team. (2017). R: A language and environment for statistical computing. Obtenido de $\mathrm{R}$ Foundation for Statistical Computing, Vienna, Austria: https://www.R-project.org/.

[19] COLA. (2017). The Grid Analysis and Display System (GrADS). Obtenido de Version 2.2.0: http:// cola.gmu.edu/aboutcola.php

[20] Poveda Jaramillo, G. (2006). El Clima de Antioquia. Escuela de Geociencias y Medio Ambiente Facultad de Minas, Universidad Nacional de Colombia, Sede Medellín, 1-17.

[21] CORNARE. (Febrero de 2006). Actualización del Plan de Manejo y Ordenamiento de la Cuenca Pozo, Municipios de El Peñol y Marinilla, Antioquia. Obtenido de https://www.cornare.gov.co/POMCAS/Documentos/El-Pozo.pdf

[22] Chow, V., Maidment, R., \& Mays, L. (1994). Hidrología aplicada. Bogotá: McGrawHill

[23] Houze, R. A. (1997). Stratiform precipitation in regions of convection. Bull. Amer. Meteor. Soc. Vol 78, 2179-95.

[24] Sarochar, R. H., Ciappesoni, H. H., \& Ruiz, N. E. (2005). Precipitaciones convectivas y estratiformes en la Pampa Húmeda: una aproximación a su separación y aspectos climatológicos de ambas. Meteorológica Vol. $30,77-88$ 


\title{
APLICACIÓN DE LAS ENERGÍAS RENOVABLES AL INTERIOR DE LA UNIVERSIDAD ECCI
}

\author{
Castiblanco Garzón, Cristian Leonardo ${ }^{1}$ \\ Ortiz Yepes, Nathalie ${ }^{1}$ \\ Luque Bernal, Gabriel Santiago ${ }^{1}$ \\ Ospina Molina Jonathan ${ }^{1}$ \\ Medina Gamba, Andrés Felipe ${ }^{1}$ \\ Guevara Umaña, Andrés Ricardo ${ }^{1}$ \\ Aparicio Gallo, Andrea ${ }^{1}$
}

${ }^{1}$ Universidad ECCI, Grupo de investigación Innovación Pedagógica (IP) aapariciog@ecci.edu.co

\section{ÁREA TEMÁTICA}

Energías Alternativas: Energía solar, eólica, hidráulica, geotérmica y mareomotriz

\section{RESUMEN}

La utilización de energías limpias en este momento es una preocupación a nivel mundial, de tal forma que la Universidad ECCI, de acuerdo con su proyecto educativo institucional no es ajeno a la apropiación de las nuevas tecnologías, ni a la problemática que alarma en este momento a todo el mundo, la contaminación ambiental debida a las emisiones causadas por el uso de la energía convencional. Es por esto que el semillero de investigación UERSIS (Utilización de Energías Renovables Sostenibles para la Industrial y la Sociedad), perteneciente al grupo de investigación IP (Innovación Pedagógica), quiere apostarle a hacer de ésta institución, una universidad totalmente amigable con el medio ambiente, que sirva de pilar a otras instituciones para desarrollar prototipos que contribuyan con la optimización del recurso energético a través de la utilización de energías renovables no convencionales: eólica y solar. El proyecto a desarrollar pretende implementar este tipo de energía no sólo con el fin de reducir el valor económico en el consumo de la energía convencional optimizando los recursos, sino también, disminuir el porcentaje de emisión de radiación eléctrica en los diferentes ambientes de la institución, limpiando un poco el ecosistema en el cual se encuentra la comunidad educativa. Además se requiere generar una conciencia y conocimiento de todos los conceptos e implementaciones que se pueden llevar a cabo con las energías renovables no convencionales a través de una cartilla conceptual que presenta definiciones, ejercicios prácticos y evaluaciones para que pueda ser utilizada como ayuda didáctica en las asignaturas que así lo requieran.

Palabras claves: Energía solar, energía eólica, implementación, ayuda didáctica 


\section{INTRODUCCIÓN}

La capa más importante que envuelve la tierra es la atmósfera, encargada de proteger al planeta de las radiaciones solares, conteniendo gases que permiten mantener la vida y tiene además la capacidad de ser un sistema que se adapta a los cambios de temperatura, vientos y acumulación de gases, capacidad que se está viendo afectada debido a los gases emitidos por: aerosoles, refrigerantes, extintores, contaminantes derivados de procesos industriales los cuales han hecho que se acidifique el ambiente generando el llamado efecto invernadero debilitando la atmósfera, dando como resultado la pérdida considerable de ozono, una mayor incursión de los rayos ultravioleta sobre la superficie terrestre, entre otros.[1]

Debido a lo anterior inicia la preocupación mundial por el agotamiento de los recursos naturales y se empieza a pensar en generar avances y desarrollos que sean permanentes sin agotarlos al máximo, por esto, se conforma la Comisión Mundial sobre Medio Ambiente y Desarrollo (informe Brundtland) en agosto de 1987, donde uno de sus puntos se refiere al desarrollo duradero: "Está en manos de la humanidad hacer que el desarrollo sea sostenible, duradero, o sea, asegurar que satisfaga las necesidades del presente sin comprometer la capacidad de las futuras generaciones para satisfacer las propias...."[2]. Los acuerdos inician con la Convención Marco de las Naciones Unidas firmada en la cumbre de Rio de 1992 que entra en vigencia en el año 1994, luego en el año 1997, el protocolo de Kyoto está dedicado a los países desarrollados que deben propender por la reducción de gases de efecto invernadero, este proceso debía llevarse a cabo en el período correspondiente entre el 2008-2012. Para el 2011 se firma el acuerdo de París, tratado internacional que entra en vigencia en 2015 y su objetivo principal es brindar apoyo a la amenaza del cambio climático a través del desarrollo sostenible[3].

Después de estos acuerdos inician las grandes implementaciones en la parte eólica y fotovoltaica. En la parte eólica internacionalmente algunas de las más destacadas son: Parque Eólico Shepherds Flat: situado cerca de Arlington, al este de Oregón, en Estados Unidos, el Parque Eólico Fantanele-Cogealac: Iocalizado en la provincia de Dobruja en Rumania.[4] En cuanto a energía solar fotovoltaica internacionalmente sobresalen algunas de las plantas fotovoltáicas más grandes del mundo: Kurnool Ultra Mega Solar Park. Ubicado en el distrito de Kurnool, el Longyangxia Hydro- Solar PV Station: situado en la provincia china de Qinghai. [4]
En Colombia por su gran cantidad de ríos, la principal fuente de energía proviene de las hidroeléctricas y en segundo lugar de la energía térmica generada a través de fuentes de gas, ambos recursos no renovables y que por diferentes factores climáticos y ambientales, están disminuyendo considerablemente, por esto, el país está comenzando gradualmente a darle importancia al uso de energías limpias[5]. Hoy, el 70 \% de la energía generada proviene de las hidroeléctricas (producida en los embalses); además al ubicarse en la zona ecuatorial y contar con climas y ecosistemas variados, cuenta con un gran potencial para desarrollar energías limpias a partir del agua, el viento, el sol y de los residuos de biomasa como los de la caña de azúcar, aceite de palma, arroz y plátano[6]. "Los recursos disponibles, como una irradiación solar promedio de 194 $\mathrm{W} / \mathrm{m}^{2}$ para el territorio nacional, vientos de velocidades medias en el orden de los 9 metros por segundo (a 80 metros de altura) en La Guajira, y potenciales energéticos del orden de 450.000 TJ por año en residuos de biomasa representan un atractivo importante comparados con los de países ubicados en otras latitudes del planeta"[7]. Para la Asociación de Energías Renovables (Ser Colombia), resulta necesario complementar la generación de energía con alternativas independientes -eólica, solar, geotérmica, mareomotriz y de biomasa- para cubrir la demanda. En esto coincide Daniel Fernández, presidente de Siemens para Suramérica, quien considera que el país cuenta con potencial en casi todos los recursos energéticos, pero "se requiere actualizar la política energética del Gobierno para que defina de forma clara cuánto debe ser la participación de cada una de ellas en la matriz energética y aprovechar la complementariedad de las mismas".

Colombia tiene suficientes recursos de Energía solar por su ubicación en la zona ecuatorial; la radiación media es de $4,5 \mathrm{kWh} / \mathrm{m}^{2}$, y el área con mejor recurso solar es la Península de la Guajira, con $6 \mathrm{kWh} / \mathrm{m}^{2}$ de radiación; adicional a esto de los $6 \mathrm{MW}$ de energía solar instalados en el país (equivalente a aproximadamente 78.000 paneles solares), el $57 \%$ está distribuido para aplicaciones rurales y $43 \%$ para torres de comunicación y señalizaciones de tránsito, pudiéndose generar en mayor escala en las zonas del Magdalena, La Guajira, San Andrés y Providencia [7]. La evaluación del potencial solar y eólico de Colombia se ha realizado empleando principalmente información de estaciones meteorológicas del IDEAM (Instituto de Estudios Ambientales)[8].

De acuerdo con el Atlas de radiación solar y vientos, se evidencia que en varias localidades de la ciudad de Bogotá se cuenta con buen indice de radiación solar 
y velocidad de los vientos, una de ellas la localidad de Teusaquillo[8] en la cual se encuentra ubicada la Universidad ECCl. Al ser ésta un espacio que cuenta con un sin número de laboratorios especializados, salas de computo, entre otros, que debido a las diferentes actividades que se realizan no sólo emiten diferentes tipos de radiación, o gases de forma controlada al entorno, sino que también hacen muy costoso el consumo de energía eléctrica; se quiere generar una conciencia de energía limpia y promover la optimización del recurso energético al interior de la Institución, contribuir al mejoramiento ambiental de la zona y aprovechar la ubicación estratégica de algunos de los edificios de la institución que son favorables para la implementación del proyecto.

Para lograr lo mencionado anteriormente se realiza una búsqueda de bibliografía al interior de la institución, con el fin de conocer si se han elaborado proyectos con esta temática, encontrando que se han desarrollado algunos trabajos de grado, los que más se acercan a lo que se quiere hacer son los siguientes: "Diseño, cálculo y elaboración de un sistema de energia térmica solar para agua caliente sanitaria con instalación en el edificio de ECCI"; sistema implementado en la sede de posgrados (Sede P) de la Universidad $\mathrm{ECCl}$, y que actualmente se encuentra alimentando la iluminación de las baterías de baños que se encuentran en esta sede. Por otro lado esta: "Propuesta técnica de implementación de un sistema para el ahorro de energía eléctrica a partir de energías renovables en la sede principal de la Universidad ECCI, en la ciudad de Bogotá", este proyecto realizó un estudio del consumo eléctrico en la sede principal de la Universidad y generó como propuesta la utilización de energías limpias por medio de la colocación de baldosas piezoeléctricas a la entrada de la institución con el fin de convertir la energía mecánica en energía eléctrica y mostrando además un análisis de costo/beneficio con la implementación del proyecto,

Para el desarrollo del proyecto también se debe tener en cuenta la legislación Colombiana para el manejo de las energías renovables, algunas de las cuales se mencionan a continuación:

La Ley de Servicios Públicos (Ley 142) y la Ley Eléctrica (Ley 143 de 1994), definieron los lineamientos generales para la prestación del servicio público domiciliario de energía eléctrica y el marco legal para el desarrollo de la regulación sectorial por parte de la Comisión de Regulación de Energía y Gas (CREG). [9][10][11]

Colombia se adhirió al Protocolo de Kyoto de la Convención Marco de las Naciones Unidas sobre el Cam- bio Climático (Ley 629 de 2000). El objetivo de este Protocolo era reducir las emisiones de Gases Efecto Invernadero (GEI), por lo cual las energías renovables se convirtieron en una opción estratégica para Colombia.[12] [11]

La Ley 697 de 2001 declaró el Uso Racional y Eficiente de la Energía (URE) como un asunto de conveniencia nacional. Además, creó el Programa Nacional de URE (PROURE), en el que se promueven la eficiencia energética y otras formas de energías no convencionales.[13][11]

La Ley 788 de 2002 estableció una exención al impuesto de renta sobre los ingresos derivados de la venta de energía eléctrica generada a partir de residuos agrícolas, fuentes eólicas y biomasa. Esta Ley exige el cumplimiento de 2 requisitos: tramitar certificados de emisión de $\mathrm{CO}_{2}$ y, que al menos 50,0 \% de los recursos obtenidos por la venta de dichos certificados se inviertan en obras de beneficio social en la región donde opera el generador.[14][11]

A finales de 2013, Colombia aprobó el estatuto de la Agencia Internacional de Energías Renovables (IRENA, por sus siglas en inglés) (Ley 1665 de 2013), el cual promueve el uso sostenible de las energías renovables. Finalmente en mayo de 2014 se aprobó la Ley 1715, que desarrolla una política pública para la integración de las energías renovables no convencionales al Sistema energético nacional. Esta ley se desarrollará más adelante.[15][16][11]

A partir de esta información se inicia el proyecto al interior del semillero donde el primer paso es actualizar lo que se tiene respecto a la cantidad de radiación solar y velocidad de los vientos en la localidad de Teusaquillo, especialmente en el punto donde se encuentra ubicada la universidad, en seguida se indaga en la institución si se cuenta con formación en este tipo de temáticas, evidenciando que a través del departamento de Educación Continuada se imparte un curso de energía fotovoltaica lo cual permite una base de conocimiento fuerte, sobre la cual construir todo un curso acerca de las aplicaciones e implementaciones de las energías renovables: eólica y solar; permitiendo un intercambio de conocimientos que se evidenciará en la Cartilla de Conceptos e implementación de Energías Renovables y diferentes tipos de eventos que se pueden llevar a cabo tanto con otras instituciones, a nivel empresarial y local.

La implementación de los prototipos permitirá que la universidad $\mathrm{ECCl}$, se ponga a la vanguardia de las instituciones educativas amigables con el ambiente a 
través de la utilización de energías alternativas, inicialmente instaladas en la sede principal y un programa de concienciación de qué son y cómo utilizar e implementar las energías alternativas para la reducción de costos y optimización de los recursos energéticos de la Institución.

\section{MATERIALES Y MÉTODOS}

\section{El proyecto cuenta con tres fases:}

Fase 1: Búsqueda de información referente a la implementación de energías renovables específicamente en Bogotá. Realización de la Cartilla de Conceptos e implementación de Energías Renovables.

Fase 2: Ampliación de la cobertura energética de la Sede $\mathrm{P}$ a través de la optimización de los paneles ya existentes y la implementación de otros u otro sistema de energía alternativa que permita la alimentación de las luminarias de toda la sede.

Fase 3: Generar un prototipo que evidencie el funcionamiento del dispositivo piezoeléctrico para la sede principal con el fin de lograr su implementación a mediano plazo.

Fase 4: Generar un prototipo que evidencie el funcionamiento de un dispositivo eólico que alimente la sede B con el fin de lograr su implementación a mediano plazo y la reducción de consumo en las salas de sistemas.

\section{RESULTADOS Y ANÁLISIS DE RESULTADOS}

De las cuatro fases de las que consta el proyecto se está finalizando la primera, a través de la cual se aprendió a leer los mapas de radiación solar y de viento que están consignados en los atlas que presenta el IDEAM, de los cuales se evidencia que Bogotá aunque no cuenta con la geografía para una radiación solar con una eficiencia del $100 \%$, en la localidad de Teusaquillo, cuenta con una radiación solar alta que entre las 10:00 am y la 1:00 pm puede alcanzar hasta un 38 $\%$ de eficiencia permitiendo acceder a ella para generar de 3,5 a 4,2 KWh/m² diariamente, estos valores también dependen de la época del año ya que los meses donde se presenta mayor radiación es de diciembre a marzo. Junto con los mapas de radiación solar se estudiaron los mapas de vientos encontrando que los vientos al interior del departamento de Cundinamarca, son muy débiles aproximadamente de 2,2 m/s la gran parte del año, y que pueden alcanzar hasta $5 \mathrm{~m} / \mathrm{s}$ en los meses de enero, julio y agosto entre la 1:00 y las 4:00 pm. Esta información nos ha permitido delimitar la búsqueda en las características de los edificios con que cuenta la universidad, con el fin de saber si realmente la implementación puede hacerse directamente en la sede principal de la Universidad ECCI.

En segunda instancia se está culminando la cartilla: Energías Renovables sostenibles, la cual cuenta con cuatro capítulos: el primero dedicado a la parte conceptual, el segundo hace énfasis a la parte de energía solar, el tercero presenta las características de la energía eólica y por último el cuarto capítulo está dedicado a la implementación de las energías eólica y solar. Esto con el fin de generar conciencia de la utilización de las energías renovables de forma sostenible no solo al interior de la universidad sino que puede ser utilizada en cualquier lugar que cuente con las condiciones mínimas para la implementación de las mismas. Cada capítulo al final cuenta con diferentes actividades de tipo didáctico que permita al lector realizar una verdadera apropiación del conocimiento en este tipo de energías.

Para el desarrollo de la fase 2 y 4 se está realizando la verificación del funcionamiento de los paneles solares y el aerogenerador que se encuentran en la sede $P$ y $\mathrm{J} 2$, respectivamente, con el fin de realizar mediciones y llevar un registro de cuánto potencial están generando, si se encuentran en buen estado o deben ser reparados o cambiados, con esto poder ampliar la cobertura energética actual o diseñar un nuevo sistema de paneles o implementar un nuevo aerogenerador.

La fase 3 lleva un poco más de tiempo debido a que deben realizarse pruebas con las baldosas piezoeléctricas de tal forma que se verifique exactamente cuál sería su aporte energético en las horas donde hay más afluencia de personas en la entrada de la sede principal.

\section{CONCLUSIONES}

Con el trabajo realizado hasta el momento se tiene una caracterización de vientos y radiación solar sobre la ubicación de la Universidad ECCl, evidenciando que puede ser un buen lugar para la implementación de energías alternativas.

Se encontró que los paneles que alimentan la sede $P$, se encuentran en buen estado, pero no se aprovecha al máximo la energía que entrega ya que en este 
momento alimenta solamente 24 luminarias de $12 \mathrm{~W}$ cada una correspondiente a las 6 baterías de baños con que cuenta el edificio (una por piso).

La realización de la cartilla tiene como objetivo principal dar a conocer a toda la comunidad de la Universidad ECCl, qué son, cómo se pueden utilizar y para qué sirven las energías alternativas haciendo que se despierte el interés por este tipo de proyectos y se tome conciencia de la aplicabilidad de este tipo de energía en diversos escenarios.

\section{REFERENCIAS}

[1] H. Oswaldo, B. Ballesteros, G. Esperanza, and L. Aristizabal, "Información Técnica sobre gases de efecto invernadero y el cambio climático," 2007.

[2] Naciones Unidas-Asamblea General, "ONU.Informe Brundtland. (Ago 1987).Informe de la Comisión Mundial sobre Medio Ambiente y Desarrollo," 1987. [Online]. Available: https://es.scribd.com/doc/105305734/ ONU-Informe-Brundtland-Ago-1987-Informe-de-la-Comision-Mundial-sobre-Medio-Ambiente-y-Desarrollo. [Accessed: 28-Aug-2018].

[3] Naciones Unidas, "Report of the World Commission on Environment and Development: Our Common Future - A/42/427 Annex - UN Documents: Gathering a body of global agreements," 1987. [Online]. Available: http://www.un-documents.net/wced-ocf.htm. [Accessed: 28-Aug-2018].

[4] E. Alternasindd, "Energías Alternas: Propuesta de Investigación y Desarrollo Tecnológico para México," 2010.

[5] AméricaFotovoltaica, "Energías Renovables Archivos - La Guía Solar," 2015. [Online]. Available: http:// www.laguiasolar.com/energia-solar/energias-renovables/. [Accessed: 27-Aug-2018].

[6] Portafolio, "energias renovables en colombia | Innovación | Portafolio," 2016. [Online]. Available: http://www.portafolio.co/innovacion/energias-renovables-en-colombia-502061. [Accessed: 27-Aug-2018].

[7] Unidad de planeación minero energética, "Informe de Gestión UPME 2017," 2017.
[8] U. De Planeación and M. Energética, "INSTITUTO DE HIDROLOGÍA, METEOROLOGIA Y ESTUDIO AMBIENTALES."

[9] "LEY 142 DE 1994, Por la cual se establece el régimen de los servicios públicos domiciliarios y se dictan otras disposiciones" Congreso de la República, Santafé de Bogotá, D.C. Diario Oficial No. 41.433 de 11 de julio de 1994.

[10] “LEY 143 DE 1994, Por la cual se establece el régimen para la generación, interconexión, transmisión, distribución y comercialización de electricidad en el territorio nacional, se conceden unas autorizaciones y se dictan otras disposiciones en materia energética." Congreso de la República, Santafé de Bogotá, D.C. Diario Oficial No. 41.434, de 12 de julio de 1994.

[11] Cámara de Comercio de Cali, "Informes Económicos - Bioenergía Iniciativa Cluster," 2016.

[12] "LEY 629 DE 2000, Por medio de la cual se aprueba el "Protocolo de Kyoto de la Convención Marco de las Naciones Unidas sobre el Cambio Climático", hecho en Kyoto el 11 de diciembre de 1997." Congreso de la República, Bogotá, D.C., Publicada en el Diario Oficial 44.272 de diciembre 27 de 2000.

[13] "LEY 697 DE 2001, Mediante la cual se fomenta el uso racional y eficiente de la energía, se promueve la utilización de energías alternativas y se dictan otras disposiciones." Congreso de la República, Bogotá, D.C., Diario Oficial No. 44.573, de 05 de octubre de 2001.

[14] "LEY_0788_2002, Por la cual se expiden normas en materia tributaria y penal del orden nacional y territorial; y se dictan otras disposiciones." Congreso de la República, Bogotá, D.C., Diario Oficial No. 45.046 de 27 de diciembre de 2002.

[15] "LEY 1665 DE 2013, por medio de la cual se aprueba el "Estatuto de la Agencia Internacional de Energías Renovables (Irena )", hecho en Bonn, Alemania, el 26 de enero de 2009." Congreso de la República, Bogotá D.C., Diario Oficial 48.853, julio 16 de 2013.

[16] "LEY 1715 DE 2014. Por medio de la cual se regula la integración de las energías renovables no convencionales al Sistema Energético Nacional" Congreso de la República, Bogotá, D.C., Diario Oficial 49.150, mayo 13 de 2014. 


\title{
CELLULOLYTIC ENZYMES PRODUCTION BY Trichoderma asperellum USING CHRYSANTHEMUM WASTE
}

\author{
Suesca Díaz, Adriana ${ }^{1}$ \\ Quevedo Hidalgo, Balkys Esmeralda² \\ Velásquez Lozano, Mario Enrique ${ }^{3}$ \\ ' Universidad ECCI, GIDMYM; Universidad Nacional de Colombia, \\ Grupo de Procesos Químicos y Bioquímicos \\ ${ }^{2}$ Pontificia Universidad Javeriana, Grupo de Biotecnología Ambiental e Industrial (GBAI) \\ ${ }^{3}$ Universidad Nacional de Colombia sede Bogotá, Grupo de Procesos Químicos y Bioquímicos \\ asuescad@ecci.edu.co
}

\section{THEMATIC AREA}

Biomass, Bioenergy and Biofuels

\begin{abstract}
Cellulolytic enzymes were produced by a strain of Trichoderma asperellum using milled carnation stalks as a carbon source in flask scale. Endoglucanase activity was evaluated on CMC and exocelulase activity on Avicel®. The effects of macro and microelements in the culture medium were studied using a central composite design; it was found that a reduction in the concentration of urea, peptone, $\mathrm{Ca}^{+2}, \mathrm{Mg}^{+2}, \mathrm{Fe}^{2+}$ and $\mathrm{Co}^{2+}$ enhances the production of enzymes, because they exhibit a negative effect on the adjusted model. This could happen due to the addition of these elements from the biomass waste which can reach the concentration need for the cellulases' production. The cellulose inductor compounds were Tween 80, $\mathrm{Mn}^{2+}, \mathrm{Zn}^{2+}$ and $\mathrm{K}^{1+}$, which are known for their positive effect on cellulolytic enzymes production. The best enzymatic activities found in this study were $413 \mathrm{U} / \mathrm{L}$ in $\mathrm{CMC}$ and $132 \mathrm{U} / \mathrm{L}$ in Avicel®.
\end{abstract}

Keywords: Cellulolytic enzymes, Trichoderma asperellum, chrysanthemum waste 


\section{INTRODUCTION}

The energy used in the world is mainly derived from non-renewable sources such as oil, natural gas and coal with an $84 \%$ of participation in the world primary energy consumption for the year 2017 [1]. Due to the decrease in oil reserves and the need to meet energy requirements, the emergence of new technologies for the production of energy from renewable sources has been encouraged, with the production of compounds such as ethanol, biodiesel, hydrogen among others, which show a favorable outlook to partially replace conventional energy sources and generate a lower environmental impact.

Ethanol is produced mainly by the United States and Brazil, with a production of 14,806 million gallons and 7,093 million gallons respectively for the year 2007[2] , it is synthesized catalytically from ethylene and biologically by fermentation using different microorganisms as yeasts, using sugarcane as source of carbon. To significantly reduce the cost of these fermentation products and make this alternative more economically viable, it is necessary to reduce the costs of sugars. Hence, the future and importance of the fermentation industry will depend on the cost and supply of accessible and low-cost sugary raw materials.

Biomass is one of the most abundant natural resources on the planet. By using a biorefinery system through the integration of processes and equipment, chemicals, liquid fuels, and energy can be obtained [3]. Composed of cellulose, hemicellulose, lignin, among others, lignocellulosic biomass constitutes a promising route for industrial use[4], as a raw material for hydrolysis and biochemical reactions to produce compounds such as proteins, enzymes, flavorings, dyes, carbohydrates, among others [3].

The use of lignocellulosic materials such as agroindustrial and forest residues as a feedstock is characterized by the fact that they do not require additional land use for their production and do not represent a negative effect in the food safety, but the economic, ecological and social effects of these need to be evaluated before extending their program to a large scale [5] [6]. One example is found in floriculture, an industry that has stood out at a national level for its innovation and its important contribution to Colombian economy[7]. Currently, this type of waste does not have a defined use, but it has been used for the production of reducing sugars and its accumulation in the flower production fields generates a negative environmental impact [8].
The enzymatic hydrolysis of biomass with cellulases and other enzymes for the production of carbohydrates presents a viable alternative where their conditions not only save energy but also avoid the generation of toxic and corrosive chemicals produced by the acid hydrolysis[9]. The enzymes used in this process are obtained from microorganisms with the ability to degrade macromolecules such as cellulose. One of the producer species is Trichoderma, which contains an enzymatic system with three classes of enzymes which act synergistically to degrade cellulose to glucose [10].

Different substrates have been used in the production of cellulases. Its production from cellulose, pretreated corn stover, hard and soft pretreated wood, willow and fir have been investigated[11]. In submerged cultures fermentation willow wood has been used as raw material[10], cellulose [12]; glucose, CMC and corn seed [13]; bagasse of cane and rice straw [14], beet pulp [15] at different production scales. Studies on the influence of the composition of the culture medium on the production of enzymes have focused on the addition of inductors like Tween 80 [16],[17] and the effect of microelements when biomass is used instead of a source of purified carbon [18], [19].

The goal of the study was to produce cellulolytic enzymes from Trichoderma asperellum, a strain used for biological control and enzyme production [21][22] and the predominant species of Trichoderma in Colombia[20]. To evaluate the nutritional requirements of $T$. asperellum using chrysanthemum waste as the main carbon source, a design effect experiment is proposed to determine the effect of the macro and micro elements in the culture medium on the cellulolytic activity of $T$. asperellum, using a central composite design.

\section{MATERIALS AND METHODS}

\section{Microorganism and inoculation}

Two fungal strains, Trichoderma asperellum C1 and Trichoderma reesei Simmons NRRL 3652 ATCC 56763. The $T$. reesei was used in this study as a positive control of the production of cellulolytic enzymes. T. reesei was obtained from the crop collection of the Agricultural Research Service (ARS) of the Department of Agriculture of the U.S. Activation of the strain was carried out by placing the contents of the tube containing the strain in $8 \mathrm{~mL}$ of a $0.1 \%$ Tween 80 solution, and then sowing in nutritious broth and in a solid medium PDA (Papa Dextrose Agar). T. asperellum C1 was provided 
by the Universidad Jorge Tadeo Lozano culture collection.

\section{Biomass}

The lignocellulosic biomass used was carnation stem, obtained from the waste of flower crops of the Sabana de Bogotá, Flor América, which were previously dried and then processed in a hammer mill with a 0.5 $\mathrm{mm}$ diameter sieve. The composition of the biomass used was $5.3 \%$ lignin, $34.7 \%$ cellulose, and $12.2 \%$ hemicellulose.

\section{Inoculum}

The inoculum was prepared following the procedures described in [13], [15], [23]. The fungal culture was maintained on PDA medium agar slants at $30^{\circ} \mathrm{C}$. Spores suspension was prepared by adding $8 \mathrm{ml}$ of sterile Tween $800.1 \%$ to 7-day grown slants. The concentration used in all experiments was $3^{*} 10^{4}$ spores $/ \mathrm{ml}$. To carry out the fermentation tests, $250 \mathrm{~mL}$ flasks were used, with $50 \mathrm{~mL}$ of work volume. The tests were carried out in an orbital shaker with a speed of $150 \mathrm{rpm}$, at $28 \pm 1^{\circ} \mathrm{C}$ in dark. As positive control, an experimental unit was used, inoculated with a spore solution of T. reesei at the same concentration. As an abiotic control and contamination control, an experimental unit was used in each experiment assembly, adding $0.1 \%$ Tween 80 solution to the inoculation process. No microorganism growth was found in any abiotic control after incubation.

\section{Production media}

A Packet-Bruman design was used with the help of Design Expert $\AA^{\circledR}$, with four central points. The variables were evaluated in a concentration range from zero to maximum, using the compounds given in the Mandels medium [11], [12], [24]-[28] which are shown in Table 1. The maximum concentration of the supplements was maintained as Mandel's medium for urea supplement, due to its negative effect at high concentrations observed in the previous experiments (data not shown), for $\mathrm{Mg}^{2+}$ and for $\mathrm{Fe}^{2+}$ because no record has been found that higher concentrations of this factor improve the production of enzymes. The other compounds of the culture medium were increased in their proportion in the design, doubling the concentration of the calcium source, which is a stimulator of sporulation; Tween 80[16], manganese, cobalt and potassium.
Table 1. Description of the factors concentration used

\begin{tabular}{|c|c|c|c|}
\hline Factor concentration & Variable & Lower limit & Upper limit \\
\hline Urea $[\mathrm{g} / \mathrm{L}]$ & $\mathrm{A}$ & 0 & 0.3 \\
\hline $\mathrm{CaCl}_{2}{ }^{*} 2 \mathrm{H}_{2} \mathrm{O}[\mathrm{g} / \mathrm{L}]$ & $\mathrm{B}$ & 0 & 0.8 \\
\hline $\mathrm{MgSO}_{4}{ }^{*} 7 \mathrm{H}_{2} \mathrm{O}[\mathrm{g} / \mathrm{L}]$ & $\mathrm{C}$ & 0 & 0.3 \\
\hline Peptone $[\mathrm{g} / \mathrm{L}]$ & $\mathrm{D}$ & 0 & 1.5 \\
\hline Tween $80[\mathrm{~mL} / \mathrm{L}]$ & $\mathrm{E}$ & 0 & 2.0 \\
\hline Yeast extract [g/L] & $\mathrm{F}$ & 0 & 1.0 \\
\hline $\mathrm{FeSO}_{4}{ }^{*} 7 \mathrm{H}_{2} \mathrm{O}[\mathrm{mg} / \mathrm{L}]$ & $\mathrm{G}$ & 0 & 10.0 \\
\hline $\mathrm{MnSO}_{4}{ }^{*} \mathrm{H}_{2} \mathrm{O}[\mathrm{mg} / \mathrm{L}]$ & $\mathrm{H}$ & 0 & 4.0 \\
\hline $\mathrm{ZnSO}_{4}{ }^{*} 7 \mathrm{H}_{2} \mathrm{O}[\mathrm{mg} / \mathrm{L}]$ & $\mathrm{J}$ & 0 & 4.0 \\
\hline $\mathrm{CoCl}_{2}{ }^{*} 6 \mathrm{H}_{2} \mathrm{O}[\mathrm{mg} / \mathrm{L}]$ & $\mathrm{K}$ & 0 & 8.0 \\
\hline $\mathrm{KH}_{2} \mathrm{PO}_{4}[\mathrm{~g} / \mathrm{L}]$ & $\mathrm{L}$ & 0 & 2.0 \\
\hline
\end{tabular}

Additionally, yeast extract and peptone were evaluated, since they are two sources of organic nitrogen used for the production of cellulases [13]. The medium was prepared using a carnation concentration of $4.00 \%$ (3.64 \% in dry base) and an ammonium sulfate concentration of $0.5 \mathrm{~g} / \mathrm{L}$, together with the addition of the other compounds at the concentration defined for each test; the $\mathrm{pH}$ was adjusted in each medium before sterilizing to a value of 5.0.

To compare the effect on the parameters in the response, an experiment was proposed which used the production of acivelase and CMCase with a waste concentration of $4 \mathrm{~g} / 100 \mathrm{ml}$ of media, $0.5 \mathrm{~g} / \mathrm{L}$ of ammonium sulfate, $\mathrm{C} / \mathrm{N}$ relation 15.2 and the rest of the compounds used in the Mandel's Medium (per litter):

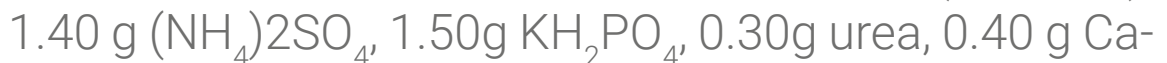
$\mathrm{Cl}_{2} * 2 \mathrm{H}_{2} \mathrm{O}, 0.30 \mathrm{~g} \mathrm{MgSO}_{4} * 7 \mathrm{H}_{2} \mathrm{O}, 0.75 \mathrm{~g}$ peptone, $1.00 \mathrm{ml}$ Tween $80,1.00 \mathrm{ml}$ microelements $\left(9.3 \mathrm{mg} \mathrm{FeSO}_{4} * 7 \mathrm{H}_{2} \mathrm{O}\right.$, $1.9 \mathrm{mg} \mathrm{MnSO}{ }_{4} \mathrm{H}_{2} \mathrm{O}, 3.5 \mathrm{mg} \mathrm{ZnSO}{ }_{4} * 7 \mathrm{H}_{2} \mathrm{O}, 3.6 \mathrm{mg} \mathrm{Co}-$ $\mathrm{Cl}_{2} * 6 \mathrm{H}_{2} \mathrm{O}$ per litter).

\section{Analytical methods}

The medium was centrifuged at $4000 \mathrm{rpm}$ for 10 min. the supernatant was used for determinate Carboxy methyl cellulase (CMC) activity and Avicel ${ }^{\circledR}$ activity, using the method described in [13], [28], [29]. A 2 $\%(\mathrm{w} / \mathrm{v})$ solution of carboxy methyl cellulose and Avicel in a $50 \mathrm{mM}$ acetate buffer with $\mathrm{pH}$ of 5 was used as a substrate. After incubation at $50{ }^{\circ} \mathrm{C}$ for $60 \mathrm{~min}$, the reducing sugar liberated in the reaction mixture was measured using the dinitrosalicylic acid (DNS) method adapted from literature [30]; calibration curves were used to determine the reducing sugars concentration. Every determination was realized by duplicate. Enzyme activity was reported in $U / L$ where $U$ is one unit of enzyme activity calculated as the amount of enzyme that produce $1 \mu \mathrm{mol}$ reducing sugars equivalent to glucose per min at $50{ }^{\circ} \mathrm{C}$ during the hydrolysis reaction. 


\section{Statistical analysis}

Confidence interval analysis were performed with an alpha of 0.05 (95\% confidence). The experiments were analyzed according to the results of the ANOVA. The experimental designs were analyzed using Design Expert® 7.0.0. The significances were examined measuring the F-value at a probability $(P)$ of 0.05 . Regression coefficients were used to make the statistical calculations. The significance of each coefficient considered using the Student's t-test, at 0.05 probability values.

\section{RESULTS AND DISCUSSION}

The results obtained from the design are presented in Table 2. The central points present all the compounds to an intermediate composition of the two levels studied, showed the highest enzymatic activity. Run 3 shows the highest enzymatic activity in CMC, with $424 \mathrm{U} / \mathrm{L}$. Run 7 showed the highest activity in Avicel ${ }^{\circ}$, with $157 \mathrm{U} / \mathrm{L}$. Run 6 presented enzymatic activities with a value of zero, and the lowest concentration of protein with a value of $151 \mu \mathrm{g} / \mathrm{mL}$; this experiment did not have the addition of peptone, Tween 80, yeast extract and $\mathrm{KH}_{2} \mathrm{PO}_{4}$, which means that some of these compounds have a direct and essential effect on the growth of the fungus, and / or on the development of enzymes. The experiment realized with Mandel's medium get CMC Activity $265 \mathrm{U} / \mathrm{L}$ and 92 Avicel ${ }^{\circledR}$ activity.

Table 2. Design layout and results of the Central Composite Design

Factor concentration Results

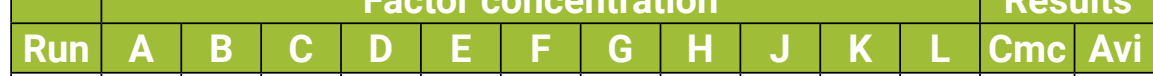
\begin{tabular}{|c|c|c|c|c|c|c|c|c|c|c|c|c|c|c|}
\hline 1 & 0.30 & 0.80 & 0.00 & 0.00 & 0.00 & 1.00 & 0.00 & 4.00 & 4.00 & 0.00 & 2.00 & 367 & 103 \\
\hline 2 & 0.00 & 0.00 & 0.30 & 0.00 & 2.00 & 1.00 & 0.00 & 4.00 & 4.00 & 8.00 & 0.00 & 393 & 138 \\
\hline
\end{tabular} \begin{tabular}{|l|l|l|l|l|l|l|l|l|l|l|l|l|l|}
\hline 2 & 0.00 & 0.00 & 0.30 & 0.00 & 2.00 & 1.00 & 0.00 & 4.00 & 4.00 & 8.00 & 0.00 & 393 & 138 \\
\hline
\end{tabular}

\begin{tabular}{|c|c|c|c|c|c|c|c|c|c|c|c|c|c|}
\hline & \multicolumn{10}{|c|}{ Factor concentration } & \multicolumn{1}{c|}{ Results } \\
\hline Run & A & B & C & D & E & F & G & H & J & K & L & Cmc & Avi \\
\hline 3 & 0.15 & 0.40 & 0.15 & 0.75 & 1.00 & 0.50 & 5.00 & 2.00 & 2.00 & 4.00 & 1.00 & 424 & 143 \\
\hline 4 & 0.00 & 0.80 & 0.30 & 0.00 & 2.00 & 1.00 & 10.00 & 0.00 & 0.00 & 0.00 & 2.00 & 392 & 142 \\
\hline 5 & 0.15 & 0.40 & 0.15 & 0.75 & 1.00 & 0.50 & 5.00 & 2.00 & 2.00 & 4.00 & 1.00 & 404 & 118 \\
\hline 6 & 0.30 & 0.80 & 0.30 & 0.00 & 0.00 & 0.00 & 10.00 & 0.00 & 4.00 & 8.00 & 0.00 & 0 & 0 \\
\hline 7 & 0.15 & 0.40 & 0.15 & 0.75 & 1.00 & 0.50 & 5.00 & 2.00 & 2.00 & 4.00 & 1.00 & 406 & 157 \\
\hline 8 & 0.15 & 0.40 & 0.15 & 0.75 & 1.00 & 0.50 & 5.00 & 2.00 & 2.00 & 4.00 & 1.00 & 374 & 115 \\
\hline 9 & 0.30 & 0.00 & 0.30 & 1.50 & 0.00 & 1.00 & 10.00 & 4.00 & 0.00 & 0.00 & 0.00 & 177 & 23 \\
\hline 10 & 0.30 & 0.80 & 0.00 & 1.50 & 2.00 & 1.00 & 0.00 & 0.00 & 0.00 & 8.00 & 0.00 & 163 & 15 \\
\hline 11 & 0.00 & 0.80 & 0.30 & 1.50 & 0.00 & 0.00 & 0.00 & 4.00 & 0.00 & 8.00 & 2.00 & 335 & 93 \\
\hline 12 & 0.00 & 0.00 & 0.00 & 1.50 & 0.00 & 1.00 & 10.00 & 0.00 & 4.00 & 8.00 & 2.00 & 419 & 139 \\
\hline 13 & 0.00 & 0.00 & 0.00 & 0.00 & 0.00 & 0.00 & 0.00 & 0.00 & 0.00 & 0.00 & 0.00 & 422 & 90 \\
\hline 14 & 0.00 & 0.80 & 0.00 & 1.50 & 2.00 & 0.00 & 10.00 & 4.00 & 4.00 & 0.00 & 0.00 & 375 & 76 \\
\hline 15 & 0.30 & 0.00 & 0.00 & 0.00 & 2.00 & 0.00 & 10.00 & 4.00 & 0.00 & 8.00 & 2.00 & 403 & 98 \\
\hline 16 & 0.30 & 0.00 & 0.30 & 1.50 & 2.00 & 0.00 & 0.00 & 0.00 & 4.00 & 0.00 & 2.00 & 413 & 95 \\
\hline \multicolumn{10}{|c|}{ Cmc: Cmc activity (U/L) ; Avi: Avicel activity (U/L) } & \\
\hline
\end{tabular}

Table 3 shows that the variables that have a significant effect on the $\mathrm{CMC}$ and Avicel ${ }^{\circledR}$ activity response are those with a P-value lower than 0.05. It is then found that the variables $A, L, B, C, K, E, G$ and $H$ present a significant effect on the activity in $\mathrm{CMC}$, which correspond to the concentration of urea, $\mathrm{KH}_{2} \mathrm{PO}_{4}, \mathrm{CaCl}_{2} * 2 \mathrm{H}_{2} \mathrm{O}$ $\mathrm{MgSO}_{4} * 7 \mathrm{H}_{2} \mathrm{O}, \mathrm{CoCl}_{2} * 6 \mathrm{H}_{2} \mathrm{O}$, Tween $80, \mathrm{FeSO}_{4} * 7 \mathrm{H}_{2} \mathrm{O}$ and $\mathrm{MnSO}_{4} * \mathrm{H}_{2} \mathrm{O}$. Among those that do not provide a significant effect on the response are the variables $\mathrm{D}, \mathrm{J}$ and $\mathrm{F}$, which correspond to the concentration of peptone, $\mathrm{ZnSO}_{4} * 7 \mathrm{H}_{2} \mathrm{O}$ and addition of yeast extract.

Regarding the effect of the variables on the activity in Avice ${ }^{\circledR}$, which correspond to the urea concentration and $\mathrm{KH}_{2} \mathrm{PO}_{4}$ respectively have a significant effect on activity. The other variables do not represent a significant effect on the response. The proposed factorial model is significant, with a probability of $0.54 \%$ that the model occurs only due to noise for CMC Activity and $2.98 \%$ for Avicelß

Table 3. Analysis of variance (ANOVA) for the effect of the variables regression coefficient, from experimental results, CMC activity and Avicelß Activity.

\begin{tabular}{|c|c|c|c|c|c|c|c|c|c|c|}
\hline \multirow[t]{2}{*}{ Source } & \multicolumn{2}{|c|}{ Sum of squares } & \multicolumn{2}{|c|}{ DF } & \multicolumn{2}{|c|}{ Mean square } & \multicolumn{2}{|c|}{ F-value } & \multicolumn{2}{|c|}{ P-value } \\
\hline & CMC & Avicel & CMC & Avicel & CMC & Avicel & CMC & Avicel & CMC & Avicel \\
\hline Model & 199237.4 & 25440.2 & 11 & 10 & 18112.5 & 2544.0 & 41.18 & 8.02 & 0.0054 & 0.0298 \\
\hline A-Urea & 54999.7 & 9728.6 & 1 & 1 & 54999.7 & 9728.6 & 125.03 & 30.67 & 0.0015 & 0.0052 \\
\hline $\mathrm{B}-\mathrm{CaCl} 2 * 2 \mathrm{H} 2 \mathrm{O}$ & 29538.8 & 1975.7 & 1 & 1 & 29538.8 & 1975.7 & 67.15 & 6.23 & 0.0038 & 0.0671 \\
\hline C-MgSO4*7H2O & 16128.1 & & 1 & & 16128.1 & & 36.66 & & 0.0090 & \\
\hline D-Peptone & 745.5 & 1403.5 & 1 & 1 & 745.5 & 1403.5 & 1.69 & 4.42 & 0.2839 & 0.1032 \\
\hline E-Tween 80 & 14504.6 & 1104.3 & 1 & 1 & 14504.6 & 1104.3 & 32.97 & 3.48 & 0.0105 & 0.1355 \\
\hline F-yeast extract & 112.0 & 1008.0 & 1 & 1 & 112.0 & 1008.0 & 0.25 & 3.18 & 0.6486 & 0.1492 \\
\hline G-FeSO4*7H2O & 8951.5 & 279.6 & 1 & 1 & 8951.5 & 279.6 & 20.35 & 0.88 & 0.0204 & 0.4010 \\
\hline
\end{tabular}




\begin{tabular}{|c|c|c|c|c|c|c|c|c|c|c|}
\hline \multirow{2}{*}{ Source } & \multicolumn{2}{|c|}{ Sum of squares } & \multicolumn{3}{c|}{ DF } & \multicolumn{2}{c|}{ Mean square } & \multicolumn{2}{c|}{ F-value } & \multicolumn{2}{c|}{ P-value } \\
\hline & CMC & Avicel & CMC & Avicel & CMC & Avicel & CMC & Avicel & CMC & Avicel \\
\hline H-MnSO4*H2O & 4790.4 & 213.3 & 1 & 1 & 4790.4 & 213.3 & 10.89 & 0.67 & 0.0457 & 0.4583 \\
\hline J-ZnSO4*7H2O & 493.9 & 677.8 & 1 & 1 & 493.9 & 677.8 & 1.12 & 2.14 & 0.3671 & 0.2176 \\
\hline K-CoCl2*6H2O & 15647.9 & 177.8 & 1 & 1 & 15647.9 & 177.8 & 35.57 & 0.56 & 0.0094 & 0.4956 \\
\hline L-KH2PO4 & 53324.9 & 8871.6 & 1 & 1 & 53324.9 & 8871.6 & 121.23 & 27.97 & 0.0016 & 0.0061 \\
\hline Curvature & 19417.6 & 7285.0 & 1 & 1 & 19417.6 & 7285.0 & 44.13 & 22.97 & 0.0070 & 0.0087 \\
\hline Pure error & 1319.6 & 1197.1 & 3 & 3 & 439.9 & 399.0 & & & & \\
\hline Total & 219968.7 & 33994.0 & 15 & 14 & & & & & & \\
\hline R2 & 0.9934 & 0.9525 & & & & & & & & \\
\hline Precision & 22.32 & 9.175 & & & & & & & & \\
\hline
\end{tabular}

To predict CMC activity and Avicel ${ }^{\circledR}$ activity an estimated regression model were built using actual values, presented in equations 1 and 2 respectively.

Actividad $C M C[U / L]=422.0-451.3 A-124.0 B-244.4 C-$ $10.5 \mathrm{D}+34.8 \mathrm{E}-6.1 \mathrm{~F}-5.5 \mathrm{G}+10.0 \mathrm{H}+3.2 \mathrm{~J}-9.0 \mathrm{~K}+66.7 \mathrm{~L}$

Actividad avicel[U/L] $=87.37-189.8 \mathrm{~A}-32.1 \mathrm{~B}-$ 14.4D+9.6E+18.3F-1.0G+2.1H+3.8J-1.0K+27.2L

To confirm the validity of the model for predicting the maximum enzyme activities an additional experiment was performed, using the following optimum operation conditions: Urea [g/L] 0.02, $\mathrm{CaCl}_{2} * 2 \mathrm{H}_{2} \mathrm{O}[\mathrm{g} / \mathrm{L}]$ $0.12, \mathrm{MgSO}_{4} * 7 \mathrm{H}_{2} \mathrm{O}[\mathrm{g} / \mathrm{L}] 0.04$, peptone $[\mathrm{g} / \mathrm{L}] 1.31$, Tween $80[\mathrm{~mL} / \mathrm{L}] 1.99$, yeast extract $[\mathrm{g} / \mathrm{L}] 0.27, \mathrm{FeSO}_{4} * 7 \mathrm{H}_{2} \mathrm{O}$ $[\mathrm{mg} / \mathrm{L}]$ 9.63, $\mathrm{MnSO}_{4}{ }^{*} \mathrm{H}_{2} \mathrm{O}[\mathrm{mg} / \mathrm{L}]$ 1.50, $\mathrm{ZnSO}_{4} * 7 \mathrm{H}_{2} \mathrm{O}$ $[\mathrm{mg} / \mathrm{L}] 2.17, \mathrm{CoCl}_{2}{ }^{*} 6 \mathrm{H}_{2} \mathrm{O}[\mathrm{mg} / \mathrm{L}] 0.51, \mathrm{KH}_{2} \mathrm{PO}_{4}[\mathrm{~g} / \mathrm{L}] 0.24$. The CMC activity was $413 \pm 1 \mathrm{U} / \mathrm{L}$ and Avicel $\circledast$ activity was $132 \pm 2 \mathrm{U} / \mathrm{L}$. Enzymatic activity in Avicel ${ }^{\circledR}$ was predicted by the model with an error of $2 \%$ and Avicel ${ }^{\circledR}$ activity with an error of $30 \%$. The productivity of CMC activity and Avicel ${ }^{\circledR}$ activity was $4.3 \mathrm{U} /\left(L^{*} h\right)$ and $1.4 \mathrm{U} /$ $(\mathrm{L}$ औh) respectively.

The average production obtained of enzymes by $T$. asperellum $\mathrm{C} 1$ have values similar to experiments realized with cellulose, sugar beet pulp $0.45 \mathrm{U} / \mathrm{ml}$ endoglucanase activity and $1.2 \mathrm{U} / \mathrm{ml}$ exoglucanase activity[15]; using $A$. annua as a substrate obtained 0.164 $\mathrm{U} / \mathrm{ml}$ endoglucanase activity[19]. Upper values of enzymatic activity were obtained using pure substrates, pretreatment or flask experiments with $\mathrm{pH}$ control[11], [15], [19], [26].

\section{CONCLUSIONS}

With the Packett-Burman design, it was determined that urea, $\mathrm{Ca}^{+2}, \mathrm{Mg}^{+2}, \mathrm{Fe}^{2+}$ and $\mathrm{Co}^{2+}$ present a significant negative effect on the production of cellulolytic enzymes and Tween $80, \mathrm{Mn}^{2+}$, and $\mathrm{KH}_{2} \mathrm{PO}_{4}$ show a significant positive effect, which allowed to develop a cultivation medium more in line with the nutritional requirements of $T$. asperellum for the production of cellulases. The proposed improved medium, with low concentrations of urea and magnesium source and a high concentration of Tween, provides an activity of $413 \mathrm{U} / \mathrm{L}$ in $\mathrm{CMC}$, $132 \mathrm{U} / \mathrm{L}$ in Avicel ${ }^{\circledR}$, higher than the values for the ceIlulolytic activities obtained in the previous stage by 56 $\%$ and $43 \%$ respectively. Due to the cellulase activity achieved with the T. asperellum, it appears as a promising microorganism for the production of hydrolytic enzymes on a larger scale.

\section{REFERENCES}

[1] BP, "Statistical Review of World Energy 2018," pp. $1-53,2018$.

[2] RFA, "Industry Statistics," 2017. [Online]. Available: https://ethanolrfa.org/resources/industry/statistics/. [Accessed: 16-Sep-2018].

[3] S. Fernando, S. Adhikari, C. Chandrapal, and N. Murali, "Biorefineries: Current status, challenges, and future direction," Energy and Fuels, vol. 20, no. 4, pp. 1727-1737, 2006.

[4] M. G. Papatheofanous, D. P. Koullas, E. G. Koukios, H. Fuglsang, J. R. Schade, and B. Löfqvist, "Biorefining of agricultural crops and residues: Effect of pilot-plant fractionation on properties of fibrous fractions," Biomass and Bioenergy, vol. 8, no. 6, pp. 419-426, 1995.

[5] M. O'Hare, A. E. Farrell, R. J. Plevin, and B. T. Turner, "Creating markets for green biofuels: Measuring and improving environmental performance.," UC Ber- 
keley: Transportation Sustainability Research Center, Berkeley, California, 2007.

[6] F. Serna, L. Barrera, and H. Montiel, "Impacto Social y Económico en el Uso de Biocombustibles," J. Technol. Manag. Innov., vol. 6, no. 1, pp. 100-114, 2011.

[7] L. N. Manrique-Ramírez et al., "Floricultura colombiana en contexto: experiencias y oportunidades en Asia pacífico," Online J. Mundo Asia Pacifico, vol. 3, no. 5, pp. 52-79, 2014.

[8] B. Quevedo-Hidalgo, P. C. Narvaéz-Rincón, A. M. Pedroza-Rodríguez, and M. E. Velásquez-Lozano, "Degradation of chrysanthemum (dendranthema grandiflora) wastes by pleurotus ostreatus for the production of reducing sugars," Biotechnol. Bioprocess Eng., 2012.

[9] S. Larsson et al., "The generation of fermentation inhibitors during dilute acid hydrolysis of softwood," Enzyme Microb. Technol., vol. 24, no. (3-4), pp. 151-159, 1999.

[10] K.Reczey, Zs.Szengyel, R.Eklund, and G.Zacchi, "Cellulase production by T.reesei," Bioresour. Technol., vol. 57, pp. 25-30, 1996.

[11] T. Juhász, Z. Szengyel, K. Réczey, M. Siika-Aho, and L. Viikari, "Characterization of cellulases and hemicellulases produced by Trichoderma reesei on various carbon sources," Process Biochem., vol. 40, no. 11, pp. 3519-3525, 2005.

[12] A. Ahamed and P. Vermette, "Culture-based strategies to enhance cellulase enzyme production from Trichoderma reesei RUT-C30 in bioreactor culture conditions," Biochem. Eng. J., vol. 40, no. 3, pp. 399407, 2008.

[13] A. Ahamed and P. Vermette, "Effect of culture medium composition on Trichoderma reesei's morphology and cellulase production," Bioresour. Technol., vol. 100, no. 23, pp. 5979-5987, 2009.

[14] R. K. Sukumaran, R. R. Singhania, G. M. Mathew, and A. Pandey, "Cellulase production using biomass feed stock and its application in lignocellulose saccharification for bio-ethanol production," Renew. Energy, vol. 34, no. 2, pp. 421-424, 2009.

[15] L. Olsson, T. M. I. E. Christensen, K. P. Hansen, and E. A. Palmqvist, "Influence of the carbon source on production of cellulases, hemicellulases and pectinases by Trichoderma reesei Rut C-30," Enzyme Microb. Technol., vol. 33, no. 5, pp. 612-679, 2003.

[16] J. Liu, X. Yuan, G. Zeng, J. Shi, and S. Chen, "Effect of biosurfactant on cellulase and xylanase production by Trichoderma viride in solid substrate fermentation," Process Biochem., vol. 41, no. 11, pp. 2347-2351, 2006.

[17] F. C. Domnigues, J. a. Queiroz, J. M. S. Cabral, and L. P. Fonseca, "The influence of culture conditions on mycelial structure and cellulose production by Trichoderma reeseiRut C-30," Enzym. Microb. Technol, vol. 26, pp. 394-401, 2000.

[18] Z. Wen, W. Liao, and S. Chen, "Production of ceIlulase by Trichoderma reesei from dairy manure," Bioresour. Technol., vol. 96, no. 4, pp. 491-499, 2005.

[19] M. Chandra, A. Kalra, P. K. Sharma, H. Kumar, and R. S. Sangwan, "Optimization of cellulases production by Trichoderma citrinoviride on marc of Artemisia annua and its application for bioconversion process," Biomass and Bioenergy, vol. 34, no. 5, pp. 805-811, 2010.

[20] L. Hoyos-Carvajal, S. Orduz, and J. Bissett, "Genetic and metabolic biodiversity of Trichoderma from Colombia and adjacent neotropic regions," Fungal Genet. Biol., vol. 46, no. 9, pp. 615-631, 2009.

[21] C. M. Marcello, A. S. Steindorff, S. P. da Silva, R. do N. Silva, L. A. Mendes Bataus, and C. J. Ulhoa, "Expression analysis of the exo- $\beta-1,3-$ glucanase from the mycoparasitic fungus Trichoderma asperellum," Microbiol. Res., vol. 165, no. 1, pp. 75-81, 2010.

[22] M. F. Ibrahim, M. N. A. Razak, L. Y. Phang, M. A. Hassan, and S. Abd-Aziz, "Crude cellulase from oil palm empty fruit bunch by trichoderma asperellum UPM1 and aspergillus fumigatus UPM2 for fermentable sugars production," Appl. Biochem. Biotechnol., vol. 170, no. 6, pp. 1320-1335, 2013.

[23] C. Aiello, A. Ferrer, and A. Ledesma, "Effect of alkaline treatments at various temperatures on cellulase and biomass production using submerged sugarcane bagasse fermentation with Trichoderma reesei QM 9414," Bioresour. Technol., vol. 57, no. 1, pp. 13-18, 1996.

[24] L. Xia and P. Cen, "Cellulase production by solid state fermentation on lignocellulosic waste from the xylose industry," Process Biochem., vol. 34, no. 9, pp. 909-912, 1999.

[25] I. Rodríguez and Y. Piñeros, "Producción de complejos enzimáticos celulolíticos mediante el cultivo de fase sólida de Trichoderma sp. sobre los racimos vacíos de palma de aceite como sustrato," Rev. la Fac. Química Farm., no. 22, pp. 35-42, 2007. 
[26] Q. Zhang, C. M. Lo, and L. K. Ju, "Factors affecting foaming behavior in cellulase fermentation by Trichoderma reesei Rut C-30," Bioresour. Technol., vol. 98, no. 4, pp. 753-760, 2007.

[27] C. M. Lo, Q. Zhang, N. V. Callow, and L. K. Ju, "Cellulase production by continuous culture of Trichoderma reesei Rut C30 using acid hydrolysate prepared to retain more oligosaccharides for induction," Bioresour. Technol., vol. 101, no. 2, pp. 717-723, 2010.

[28] K. Rocky-Salimi and Z. Hamidi-Esfahani, "Evaluation of the effect of particle size, aeration rate and harvest time on the production of cellulase by Trichoderma reesei QM9414 using response surface methodology," Food Bioprod. Process., vol. 88, no. 1, pp. 61-66, 2010.

[29] F. G. de Siqueira et al., "The potential of agro-industrial residues for production of holocellulase from filamentous fungi," Int. Biodeterior. Biodegrad., vol. 64, no. 1, pp. 20-26, 2010.

[30] G. L. Miller, "Use of Dinitrosalicylic Acid Reagent for Determination of Reducing Sugar," Anal. Chem., vol. 31, no. 3, pp. 426-428, 1959 


\title{
ACTIVATION ENERGY FOR PYROLYSIS OF MACADAMIA SHELLS EMPLOYING NON- ISOTHERMAL ISOCONVERSIONAL METHODS
}

\author{
Bonilla-Páez, Javier Alejandro ${ }^{1}$ \\ López, Camilo Andrés ${ }^{1}$ \\ Hernández, Laura Carolina ${ }^{1}$
}

${ }^{1}$ Universidad ECCI, Grupo de Investigación de Aprovechamiento Tecnológico de Materiales y Energía GIATME

jbonillap@ecci.edu.co

\section{THEMATIC AREA}

Biomass, Bioenergy and Biofuels

\begin{abstract}
The potential of Macadamia (Macadamia tetraphylla) Shells as feedstock in pyrolysis process is shown in the current study. By employing the non-isothermal isoconversional methods of Flynn-Wall-Ozawa and Starink, the activation energy of Colombian macadamia shells as a function of the degree of conversion throughout its pyrolysis process, was studied as potential waste to obtain biofuels. The macadamia shells were subjected to thermogravimetric analyses between $25{ }^{\circ} \mathrm{C}$ and $500{ }^{\circ} \mathrm{C}$ for three heating rates $10 \mathrm{~K} / \mathrm{min}, 20 \mathrm{~K} / \mathrm{min}$, and $30 \mathrm{~K} / \mathrm{min}$ in order to calculate the activation energy for several degrees of conversion. Then, the models were applied to build the isoconversional straight lines for each conversion degree. Results show that the higher degree of conversion, the higher activation energy, which ranged from $150 \mathrm{~kJ} /$ $\mathrm{mol}$ to $200 \mathrm{~kJ} / \mathrm{mol}$.
\end{abstract}

Keywords: isothermal isoconversional methods, activation energy, macadamia shell, pyrolysis, gasification. 


\section{INTRODUCTION}

The increment in global energy demand, coupled with the depletion of fossil resources, has led to research into novel renewable energy technologies, which do not cause a negative impact on the environment [1]-[4]. Then, operations based on thermochemical processes of biomass [5]-[10] (drying, torrefaction, pyrolysis, and gasification) arise as cutting-edge processes to obtain fuels by-using urban raw material from industrial and agricultural waste, conferring them an additional profit.

A residual biomass with great potential to be used in thermochemical processes is the macadamia shells [11]-[13]. Macadamia is a native tree from Australia, New Caledonia, and Indonesia [14]. The worldwide production of macadamia is close to 44,000 metric tons. $86 \%$ of nut yield is concentrated in countries such as Australia, South Africa, the United States, and Malawi, with Australia being the main producer with approximately 14,100 metric tons [15]. With the increment in the macadamia production, an issue has been generated because of the nut processing industry, since each ton of processed macadamia produces $700 \mathrm{~kg}$ of waste shell [16]. These shells are a residual lignocellulosic biomass with a high content of lignin. The colombian macadamia shell is composed of Cellulose by $26 \%$ $\mathrm{m} / \mathrm{m}$, hemicellulose by $17.8 \% \mathrm{~m} / \mathrm{m}$, and lignin by 40.1 $\% \mathrm{~m} / \mathrm{m}[17]$.

Pyrolysis and gasification are alternative processes to handle this waste, because they are carbon neutral and the obtained products can be used in power plants or refined to obtain biofuels [5], [18]-[20]. These processes are based on the conversion of raw material in an oxygen-absent environment. The characteristics of the products depend on the oxidizing agent, the size of the reactor, the type of biomass, the pressure, and the temperature [21].

The pyrolysis of biomass is carried out in a range of temperatures from 600 to $950 \mathrm{~K}$ [22], [23], being temperatures above $1300 \mathrm{~K}$ gasification [5]. The usage of air-steam mixtures as an oxidizing agent has evidenced an autothermic gasification, generating syngas with a higher calorific value between $4-6 \mathrm{MJ} / \mathrm{m} 3$ [24], [25].On the other hand, findings show that the use of oxygen as an oxidizing agent produces a syngas with a higher calorific value compared to that obtained by using only air [24]. Therefore, it is possible to improve the gas quality by using oxygen-vapor blends avoiding the external heating.
Conventionally, the reaction kinetics during gasification is governed by the gasification agent, the pressure and the temperature of the system [21]. In order to evaluate and model these thermal processes, it is essential to know the kinetics of the involved reactions. However, during the process of depolymerization of the biomass material, it is important to highlight that the cellulose, hemicellulose and lignin molecules do not degrade at the same temperature [26]. This means that the kinetic parameters such as the pre-exponential factor, the activation energy, or the reaction order, can no longer be estimated as independent of the temperature. Thus, it is important to explain these kinetic parameters by employing non-isothermal models, whose changes of the residual mass are monitored via thermogravimetric analyses.

\section{Kinetic models}

The reaction kinetics usually can be described as an Arrhenius model

$$
\frac{d \alpha}{d t}=A \cdot \exp \left(\frac{-E_{a}}{R T}\right) \cdot f(\alpha)
$$

Where $a$ is the fraction of devolatilized biomass or degree of conversion [27], $t$ is time, $A$ is the preexponential factor, $E_{a}$ is the activation energy, $T$ is the temperature, and $f(a)$ is a particular function known as the reaction model, which describes the dependence of the reaction rate on the devolatilized fraction $a$ as

$$
\alpha=\frac{m_{i}-m}{m_{i}-m_{f}}
$$

Where $m$ is the working residual mass, $m_{i}$ and $m_{f}$ correspond to the initial and final masses.

Then, heating rate $\beta=d T / d t$,

$$
\frac{d \alpha}{d T}=\frac{A}{\beta} \cdot \exp \left(\frac{-E_{a}}{R T}\right) \cdot f(\alpha) .
$$

Then, solving the equation for $a$, and specifying the functions 


$$
\int_{0}^{\alpha} \frac{d \alpha}{f(\alpha)} \text { and } p\left(\frac{E_{a}}{R T}\right)=\frac{R}{E_{a}} \int_{T_{0}}^{T} \exp \left(\frac{-E_{a}}{R T}\right)
$$

, it is obtained

$$
g(\alpha)=\frac{A E_{a}}{\beta R} p\left(\frac{E_{a}}{R T}\right)
$$

or

$$
\ln [g(\alpha)]=\ln \left[\frac{A E_{a}}{R}\right]-\ln [\beta]+\ln \left[p\left(\frac{E_{a}}{R T}\right)\right]
$$

\section{Flynn-Wall-Ozawa Model (FWO)}

Ozawa [28] proposed that, at a specific reaction progress $a, g(a)$ is constant for different tests at different heating rates. So,

$$
\frac{A E_{a}}{\beta_{1} R} p\left(\frac{E_{a}}{R T_{1}}\right)=\frac{A E_{a}}{\beta_{2} R} p\left(\frac{E_{a}}{R T_{2}}\right)=\cdots
$$

By using Doyle's approximation [29], $\ln (p)=2.315-$ $0.4567 \mathrm{E}_{\mathrm{a}} / \mathrm{RT}$, inside the beside expressions,

$$
-\ln \beta_{1}-0.4567 \frac{E_{a}}{R T_{1}}=-\ln \beta_{2}-0.4567 \frac{E_{a}}{R T_{2}}=\cdots
$$

Flynn and Wall [30], [31] proposed a modification of the Ozawa model to finally obtain

$$
\ln \beta_{i}=\ln \left(\frac{A E_{a}}{R g(\alpha)}\right)-5.331-1.052 \frac{E_{a}}{R T_{i}}
$$

It is important to highlight that a graphic of $\mathrm{T}^{-1} \mathrm{Vs}$ $\ln (\beta)$ for a specific value of a obtained from different thermogravimetry tests, results in a straight line whose slope is $-1.052 \mathrm{E}_{\mathrm{a}} / \mathrm{R}$.

\section{Starink Model}

In order to find an expression to $p\left(E_{a} / R T\right)$, Kissinger [32] proposed to integrate by parts and to truncate the series by considering $E_{a} / R T>>1$, so

$$
p\left(\frac{E_{a}}{R T}\right)=\left(\frac{R T}{E_{a}}\right)^{2} \exp \left(-\frac{E_{a}}{R T}\right)
$$

Then, solving for a constant fraction of a

$$
\ln \left(\frac{\beta}{T^{2}}\right)=C-\frac{E_{a}}{R T}
$$

By generalizing Kissinger and FWO

$$
\ln \left(\frac{\beta}{T S}\right)=C-B \frac{E_{a}}{R T}
$$

According to Starink [33], [34] method, the values for $S$ and $B$ are 1.92 and 1.0008 respectively. Note that every line built on the plane $\ln \left(\beta / T^{1.92}\right) v^{-1} T^{-1}$, has a slope $-1.0008 E_{a} / R$.

\section{METHODOLOGY}

Samples of Colombian macadamia shells were milled under the ASTM E1757 standard [35] and sieved in a No. 200 sieve $(75 \mu \mathrm{m})$ under the ASTM EN15149-2 standard.

Thermogravimetric tests were carried out on the stipulations of ASTM E-1131 under non-isothermal conditions using a Mettler Toledo TGA 2 XP1 equipment. The tests were performed by taking respective samples of the biomass as shown in Table 1, subjecting them to three constant heating rates 10,20 , and $30 \mathrm{~K} /$ min from a temperature of $303 \mathrm{~K}$ to $773 \mathrm{~K}$ in an inert environment (nitrogen $99.99 \%$ ) at a flow rate of $50 \mathrm{~mL} /$ min. To confirm the measured results, every test was repeated three times.

Table 1. Operational variables for thermogravimetric analysis

\begin{tabular}{|c|c|c|}
\hline Test & m_0 ( $\mathbf{m g})$ & $\boldsymbol{\beta}(\mathbf{K} / \mathbf{m i n})$ \\
\hline 1 & 15.42 & 10 \\
\hline 2 & 18.61 & 20 \\
\hline 3 & 16.40 & 30 \\
\hline \multicolumn{2}{|c|}{ m_0 and $\beta$ refers to the initial weight and the heating rate. } \\
\hline
\end{tabular}




\section{RESULTS AND DISCUSSION}

Figure 1 shows the degree of conversion a of the macadamia shells for three heating rates. Thus, three zones are detailed in Figure 1, where each one explains the stages of the thermochemical process of conversion. Drying zone (303 to $373 \mathrm{~K}$ ) is the first one where vaporization of water occurs. In the zone 2 (373 to $473 \mathrm{~K}$ ) is common to find low volatilized mass due to the low interaction of lignin and cellulose [36]. For the zone 3 (473 to $673 \mathrm{~K}$ ) is found the greatest amount of volatilized mass due to the decomposition of cellulose and hemicellulose [37].

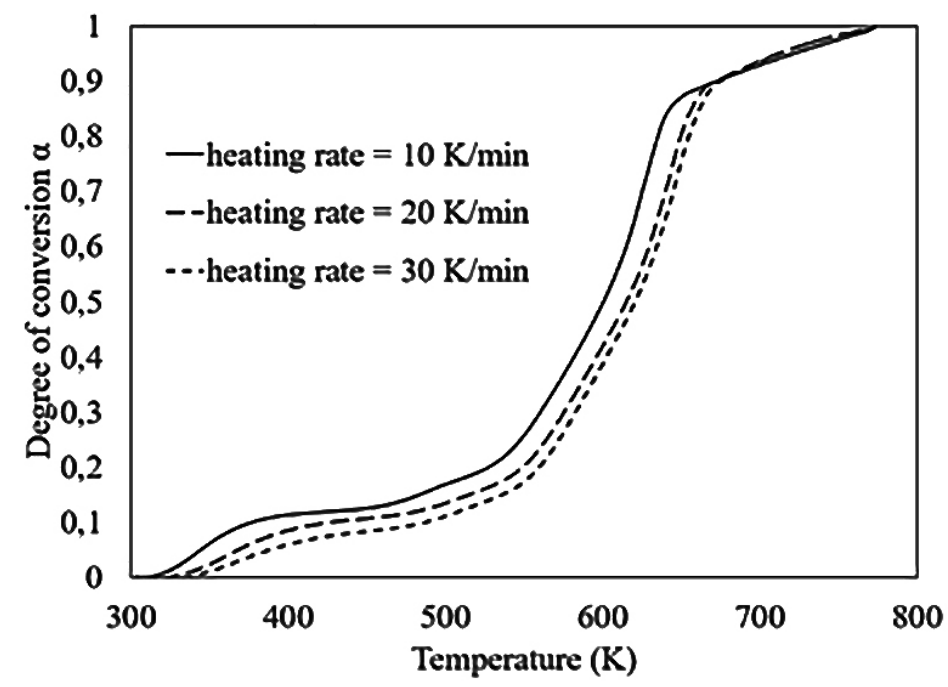

Figure 1. Degree of conversion vs Temperature.

To determine the kinetic decomposition of the macadamia shell occurring in the pyrolysis process, the current study is based on the TGA analyzes by using non-isothermal isoconversional methods FWO and Starink which are recommended in [38], [39]. Comparing $\ln (\beta)$ vs $T^{-1}$ for FWO (Figure 2$)$ and $\ln \left(\beta / T^{1.92}\right)$ vs $T^{-1}$ for Starink (Figure 3), isoconversional lines are obtained allowing to determine the activation energy for each degree of conversion. Both methods generate straight lines with a fair coefficient of determination $\mathrm{R}^{2}$ (higher to 0.95) for every degree of conversion.

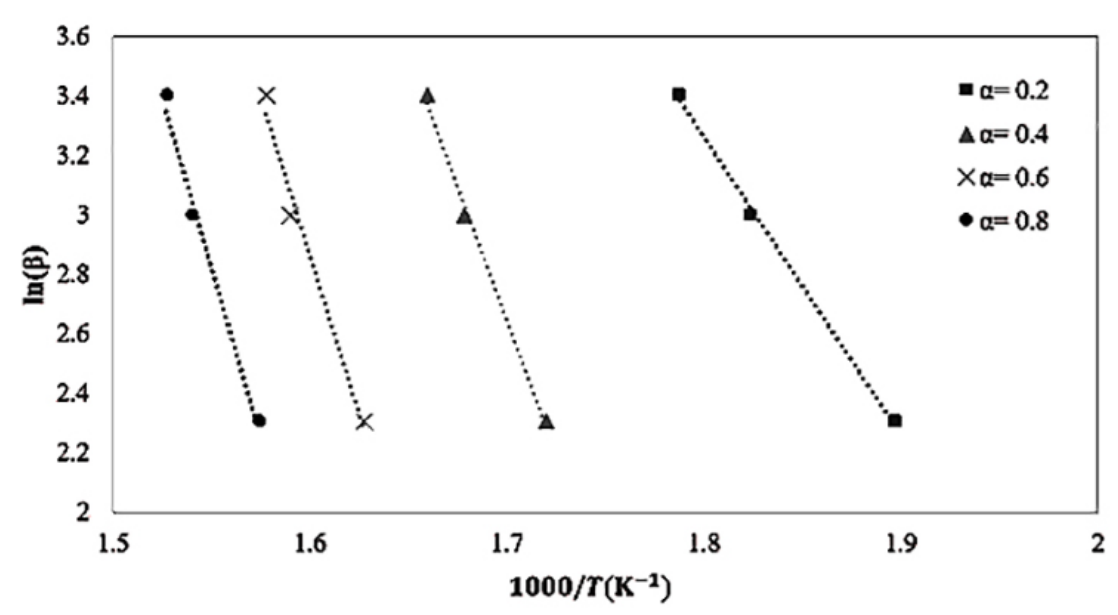

Figure 2 Isoconversional lines of MS at different degrees of conversion derived from FWO method

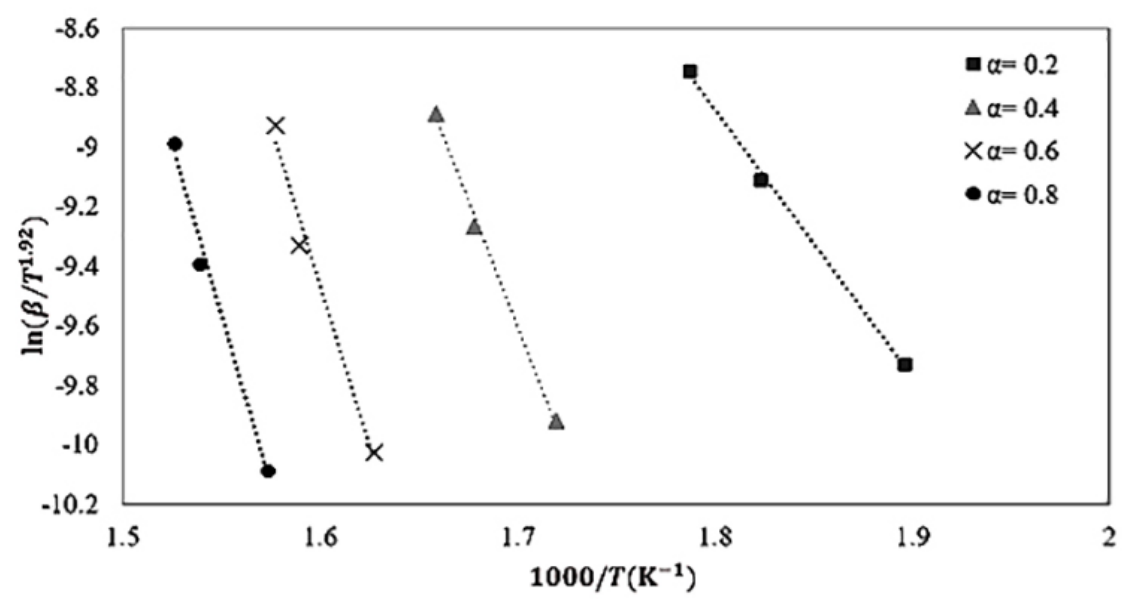

Figure 3 Isoconversional lines of MS at different degrees of conversion derived from Starink method

Figure 4 shows the different energies of activation found for the two isoconversional methods mentioned for conversion degrees from 0.05 to 0.85 . Further, the lines show the energies of activation are similar in both models. For throughout pyrolysis process, calculating the average of the activation energy would not be adequate since the pyrolysis process of this kind of solids presents complex heterogeneous kinetic mechanisms that vary with temperature because of the different bonds among hemicellulose, cellulose and lignin composites as mentioned in [40].

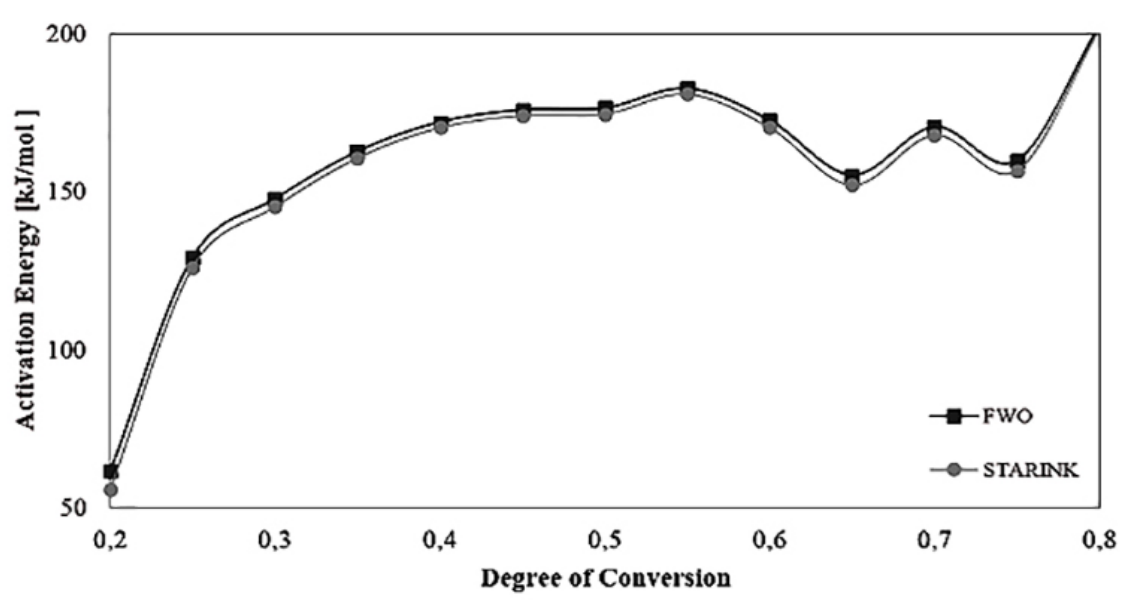

Figure 4 Activation energy of MS for several conversion degrees for FWO and Starink methods

\section{CONCLUSIONS}

The activation energy for the two non-isothermal isoconversional methods increases according to the increase of the degree of conversion is likelihood to the high content of cellulose, lignin, and complex chains bonded as occurred in previous studies mentioned in the current study. The FOW and Starink methods present similar findings related to their activation energy 
because they are integral methods based on a correction factor in their formulas, making the difference on the activation energy computation less than $3 \%$. Furthermore, the increase in the activation energy is strongly attached to the interaction of lignin with the other biochemical components as show in several studies [37], [41]-[43]. The higher temperature, the greater percentage of the residual mass of lignin is present in the sample thus the higher energy for decomposition of the lignin chains during the pyrolysis temperature zone.

\section{ACKNOWLEDGMENTS}

Authors want to state their gratefulness to Universidad ECCI for their financial support to this project.

\section{REFERENCES}

[1] EIA, "International Energy Outlook 2017 Overview," U.S. Energy Inf. Adm., vol. IEO2017, no. 2017, p. 143, 2017.

[2] U. S. E. I. Administration, "Annual Energy Outlook 2018 with projections to 2050," J. Phys. A Math. Theor., vol. 44, no. 8, pp. 1-64, 2018.

[3] EIA, "Short-Term Energy Outlook ( STEO ) Forecast highlights," US EIA - Short-Term Energy Outlook, no. April 2017, pp. 1-48, 2018.

[4] M. Guo, W. Song, and J. Buhain, "Bioenergy and biofuels: History, status, and perspective," Renewable and Sustainable Energy Reviews. 2015.

[5] A. Molino, S. Chianese, and D. Musmarra, "Biomass gasification technology: The state of the art overview," J. Energy Chem., vol. 25, no. 1, pp. 10-25, 2016.

[6] M. J. C. van der Stelt, H. Gerhauser, J. H. A. Kiel, and K. J. Ptasinski, "Biomass upgrading by torrefaction for the production of biofuels: A review," Biomass and Bioenergy, vol. 35, no. 9, pp. 3748-3762, 2011.

[7] B. Acharya, A. Dutta, and J. Minaret, "Review on comparative study of dry and wet torrefaction," Sustain. Energy Technol. Assessments, vol. 12, pp. 26-37, 2015.

[8] D. Nhuchhen, P. Basu, and B. Acharya, "A Comprehensive Review on Biomass Torrefaction," Int. J. Renew. Energy Biofuels, vol. 2014, pp. 1-56, 2014.

[9] M. J. Prins, K. J. Ptasinski, and F. J. J. G. Jans- sen, "More efficient biomass gasification via torrefaction," Energy, vol. 31, no. 15, pp. 3458-3470, 2006.

[10] G. Gordillo and K. Annamalai, "Adiabatic fixed bed gasification of dairy biomass with air and steam," Fuel, vol. 89, no. 2, pp. 384-391, 2010.

[11] M. A. Nagao and H. H. Hirae, "Macadamia: Cultivation and physiology," CRC. Crit. Rev. Plant Sci., vol. 10, no. 5, pp. 441-470, 1992.

[12] T. P. Xavier, T. S. Lira, M. A. Schettino, and M. A. S. Barrozo, "A study of pyrolysis of Macadamia Nut Shell: Parametric sensitivity analysis of the IPR model," Brazilian J. Chem. Eng., vol. 33, no. 1, pp. 115-122, 2016.

[13] M. Venkatachalan and S. K. Sathe, "Chemical composition of selected edible nut seeds," J. Agric. Food Chem., vol. 54, no. 13, pp. 4705-4714, 2006.

[14] A. J. Moreno-Pérez, A. Sánchez-García, J. J. Salas, R. Garcés, and E. Martínez-Force, "Acyl-ACP thioesterases from macadamia (Macadamia tetraphyIla) nuts: Cloning, characterization and their impact on oil composition," Plant Physiol. Biochem., vol. 49, no. 1, pp. 82-87, 2011.

[15] S. L. B. Navarro and C. E. C. Rodrigues, "Macadamia oil extraction methods and uses for the defatted meal byproduct," Trends Food Sci. Technol., vol. 54, pp. 148-154, 2016.

[16] G. E. J. Poinern, G. Senanayake, N. Shah, X. N. Thi-Le, G. M. Parkinson, and D. Fawcett, "Adsorption of the aurocyanide, Au (CN)2- complex on granular activated carbons derived from macadamia nut shells - A preliminary study," Miner. Eng., vol. 24, no. 15, pp. 1694-1702, 2011.

[17] D. b. martinez, "Impacto del pre-tratamiento de la biomasa," 2013.

[18] D. Mohan, C. U. Pittman, and P. H. Steele, "Pyrolysis of wood/biomass for bio-oil: A critical review," Energy and Fuels, vol. 20, no. 3, pp. 848-889, 2006.

[19] G. LV, S. Wu, and R. Lou, "Kinetic Study of the Thermal Decomposition of Hemicellulose Isolated From Corn Stalk," BioResources, vol. 5, no. 2, pp. 1281 1291, 2010.

[20] L. He, J. Yang, and D. Chen, "Hydrogen from Biomass: Advances in Thermochemical Processes," Renew. Hydrog. Technol. Prod. Purification, Storage, Appl. Saf., pp. 111-133, 2013.

[21] C. Y. Li, J. Y. Wu, C. Chavasint, S. Sampattagul, 
T. Kiatsiriroat, and R. Z. Wang, "Multi-criteria optimization for a biomass gasification-integrated combined cooling, heating, and power system based on life-cycle assessment."

[22] M. M. Ramirez-Corredores, "Pathways and Mechanisms of Fast Pyrolysis: Impact on Catalyst Research," Role Catal. Sustain. Prod. Bio-Fuels Bio-Chemicals, pp. 161-216, 2013.

[23] S. Zhang, Y. Yan, T. Li, and Z. Ren, "Upgrading of liquid fuel from the pyrolysis of biomass," Bioresour. Technol., vol. 96, no. 5, pp. 545-550, 2005.

[24] J. Bonilla, "ADIABATIC FIXED-BED GASIFICATION OF COLOMBIAN COFFEE HUSK USING AIRSTEAM BLENDS FOR PARTIAL OXIDATION .," pp. 1-26.

[25] K. Sandeep and S. Dasappa, "First and second law thermodynamic analysis of air and oxy-steam biomass gasification," Int. J. Hydrogen Energy, vol. 39, no. 34, pp. 19474-19484, 2014.

[26] H. Yang, R. Yan, H. Chen, D. H. Lee, and C. Zheng, "Characteristics of hemicellulose, cellulose and lignin pyrolysis," Fuel, vol. 86, no. 12-13, pp. 1781-1788, 2007.

[27] S. Vyazovkin, Isoconversional Kinetics of Thermally Stimulated Processes. 2015.

[28] T. Ozawa, "A New Method of Analyzing Thermogravimetric Data," Bull. Chem. Soc. Jpn., vol. 38, no. 11, pp. 1881-1886, 1965.

[29] C. D. Doyle, "Estimating isothermal life from thermogravimetric data," J. Appl. Polym. Sci., vol. 6, no. 24, pp. 639-642, 1962.

[30] J. Flynn and L. A. Wall, "A quick, Direct Method for the Determination of Activation Energy from Thermogravimetric Data," J. Polym. Sci. Part C Polym. Lett., vol. 4, no. 5, pp. 323-328, 1966.

[31] V. Mamleev, S. Bourbigot, M. Le Bras, and J. Lefebvre, "Three Model-Free Methods for Calculating of Activation Energy in TG," J. Therm. Anal. Calorim., vol. 78, pp. 1009-1027, 2004.

[32] H. E. Kissinger, "Reaction Kinetics in Differential Thermal Analysis," Anal. Chem., vol. 29, no. 11, pp. 1702-1706, 1957.

[33] M. J. Starink, "A new method for the derivation of activation energies from experiments performed at constant heating rate," Thermochim. Acta, vol. 288, no. 1-2, pp. 97-104, 1996.

[34] M. J. Starink, "Activation energy determination for linear heating experiments: Deviations due to neglecting the low temperature end of the temperature integral," J. Mater. Sci., vol. 42, no. 2, pp. 483-489, 2007.

[35] ASTM, "ASTM E1757 - 01 Standard Practice for Preparation of Biomass for Compositional Analysis," vol. 01, no. Reapproved 2015, pp. 18-21, 2015.

[36] K. Raveendran, A. Ganesh, and K. C. Khilar, "Pyrolysis characteristics of biomass and biomass components," Fuel, vol. 75, no. 8, pp. 987-998, 1996.

[37] H. Yang, R. Yan, H. Chen, D. H. Lee, and C. Zheng, "Characteristics of hemicellulose, cellulose and lignin pyrolysis," Fuel, vol. 86, no. 12-13, pp. 1781-1788, 2007.

[38] S. Vyazovkin, K. Chrissafis, M. L. Di Lorenzo, N. Koga, M. Pijolat, B. Roduit, N. Sbirrazzuoli, and J. J. Suñol, "ICTAC Kinetics Committee recommendations for collecting experimental thermal analysis data for kinetic computations," Thermochim. Acta, vol. 590, pp. 1-23, 2014.

[39] S. Vyazovkin, A. K. Burnham, J. M. Criado, L. A. Pérez-Maqueda, C. Popescu, and N. Sbirrazzuoli, "ICTAC Kinetics Committee recommendations for performing kinetic computations on thermal analysis data," Thermochim. Acta, vol. 520, no. 1-2, pp. 1-19, 2011.

[40] X. Yuan, T. He, H. Cao, and Q. Yuan, "Cattle manure pyrolysis: kinetic and thermodynamic analysis with isoconversional methods," Renew. Energy, vol. 107, pp. 489-496, 2017.

[41] S. D. Stefanidis, K. G. Kalogiannis, E. F. Iliopoulou, C. M. Michailof, P. A. Pilavachi, and A. A. Lappas, "A study of lignocellulosic biomass pyrolysis via the pyrolysis of cellulose, hemicellulose and lignin," J. Anal. Appl. Pyrolysis, vol. 105, pp. 143-150, 2014.

[42] A. V. Bridgwater, "Review of fast pyrolysis of biomass and product upgrading," Biomass and Bioenergy, vol. 38, pp. 68-94, 2012.

[43] M. Balat, "Mechanisms of thermochemical biomass conversion processes. Part 1: Reactions of pyrolysis," Energy Sources, Part A Recover. Util. Environ. Eff., vol. 30, no. 7, pp. 620-635, 2008. 


\title{
GENERACIÓN CATALÍTICA DE HIDRÓGENO A PARTIR DE BIODONANTES
}

\author{
Mayorga Betancourt, Manuel Alejandro ${ }^{1}$ \\ Perdomo Morales, Laura Daniela ${ }^{1}$ \\ López Santamaría, Camilo Andrés ${ }^{3}$ \\ Vargas Sáenz, Julio Cesar ${ }^{1}$ \\ Narváez Rincón, Paulo Cesar ${ }^{1}$ \\ Cadavid Estrada, Juan Guillermo ${ }^{1}$ \\ ${ }^{1}$ Universidad Nacional de Colombia, Departamento de Ingeniería Química, \\ Grupo de Investigación en Procesos Químicos y Bioquímicos \\ ${ }^{2}$ Universidad ECCI, Grupo de Investigación en Aprovechamiento Tecnológico \\ de Materiales y Energía, GIATME \\ mamayorgab@unal.edu.co
}

\section{ÁREA TEMÁTICA}

Biomasa, Bioenergía y Biocombustibles

\section{RESUMEN}

Industrialmente muchos procesos, incluidos los energéticos, requieren el manejo de gas hidrógeno presurizado lo que implica un gran riesgo dada la facilidad en la producción de fugas y la naturaleza combustible del mismo; sin embargo, una opción alternativa permite el uso de un donante para la generación de hidrógeno in situ (ya sea por transferencia o reformado catalítico), en lugar de emplear hidrógeno molecular. Esta opción requiere inicialmente una adecuada elección de un donante de hidrógeno, dado que la producción dependerá de las características físicas, químicas, biológicas y económicas de los posibles candidatos. De acuerdo con lo anterior en el presente trabajo se proponen un conjunto de alternativas definidas a partir de compuestos orgánicos de diferente grupo funcional, lo que alimenta un algoritmo de decisión multicriterio con los conjuntos de características y compuestos, obteniendo como resultado que el etanol y el ácido fórmico son los más promisorios, esta conclusión se logra a partir de un análisis termodinámico y diferentes consideraciones realizadas. Una vez seleccionados los candidatos se evalúa la acción de diferentes catalizadores metálicos y la relación molar fase activa-donante en la obtención de hidrógeno molecular en atmosfera inerte de Nitrógeno; empleando un reactor de alta presión (hasta 1000 psi) con una chaqueta de calentamiento y aislamiento térmico (hasta $500{ }^{\circ} \mathrm{C}$ ) los análisis incluyeron el estudio de los sistemas más promisiones a partir de calorimetría diferencial de Barrido a alta presión (DSC HP) con una rampa de $10{ }^{\circ} \mathrm{C} / \mathrm{min}$. Para realizar el análisis de la producción de hidrógeno se empleó cromatografía de gases, identificando que a $200^{\circ} \mathrm{C}$ y 50 bar el sistema que más genera hidrógeno es el de Pt/C sobre ácido fórmico.

Palabras claves: Biodonante, Generación In Situ, Transferencia Catalítica, Etanol, Ácido fórmico. 


\section{INTRODUCCIÓN}

El hidrógeno molecular, es una materia prima de alta importancia tanto para la industria química como para la del petróleo, principalmente por su positiva economía atómica [1]. El hidrógeno se obtiene principalmente de hidrocarburos y/o del agua, por medio de descomposición, mediante la aplicación de energía que puede ser térmica, química o eléctrica, también se produce por la oxidación parcial de hidrocarburos y otros métodos que pueden ser el proceso vapor- hierro del gas de agua, del gas pobre, la separación del gas en horno de coque y las corrientes de gas sintético de refinería [2]. Cerca del $90 \%$ de hidrógeno producido comercialmente se obtiene mediante reformado de gas natural o de fracciones de nafta, y lo que resta se obtiene por gasificación de carbón y electrolisis de agua [3]. Estos procesos no son amigables con el medio ambiente ya que dependen de materias primas fósiles y no renovables, por lo cual se han considerado otras rutas para la obtención de hidrógeno como su producción a partir de biomasa, mediante procesos bioquímicos como fermentación y biodigestión [4], otra alternativa son los procesos foto catalíticos que se han desarrollado para la producción de hidrógeno.

Por su alta difusividad, el hidrogeno posee una alta accesibilidad en estructuras moleculares, esta ventaja también genera que sea gas altamente inflamable y peligroso, por lo que el manejo seguro se convierte en un asunto de extremada importancia [1]. Además de la alta difusividad, la baja densidad del hidrogeno conlleva a que los costos de almacenamiento y transporte sean elevados [5] así mismo es necesario considerar que el hidrogeno gaseoso posee una baja solubilidad tanto en fase acuosa como orgánica haciendo que se requieran altas presiones para su empleo; Sin embargo, la difícil manipulación del hidrógeno gaseoso y las grandes cantidades requeridas, suponen un costo elevado de infraestructura a escala industrial, lo que genera una barrera económica para el desarrollo de un procesos sostenibles con esta materia prima como los que se producen en las biorrefinerías, especialmente en las etapas iniciales [6]. Una opción altamente estudiada que podría evitar los problemas asociados a la accesibilidad y solubilidad del hidrógeno requerido para el hidrotratamiento es la producción directa del hidrogeno en los sitios activos del catalizador, permitiendo un proceso con una atmósfera inerte y una presión de trabajo más baja, siendo esta una posibilidad de generar el hidrógeno in situ, en lugar de alimentarlo al reactor o de la aplicación respectiva.

Una alternativa evaluada para los procesos de hidrogenación de compuestos orgánicos es la transfe- rencia de hidrogeno desde un donador a un aceptor, presentando sustanciales ventajas respecto a los procesos que emplean hidrógeno molecular [7], dado que se emplean condiciones más moderadas para el desarrollo del proceso; Adicionalmente es posible mejorar la homogeneidad de la biomasa alimentada si esta se disuelve en solventes próticos polares (p.e. metanol, etanol, dietilenglicol) [8].

Después de la deshidrogenación y descomposición, los solventes donantes de hidrógeno fácilmente transfieren esta molécula in situ; es necesario llevar un control sobre el proceso de deshidrogenación/descomposición puesto que estas operaciones por lo general conllevan a la obtención de subproductos indeseables, lo cual puede llevar a un incremento importante en la presión del sistema lo que afecta las condiciones de operación [1].

La deshidrogenación puede obtenerse a partir de reformado en fase acuosa (APR) o por transferencia catalítica de hidrógeno (CTH); la primera opción exige la presencia de agua a altas condiciones de temperatura y presión, mientras que la segunda necesita una sustancia que done el hidrógeno a un aceptor, es decir un donante, generalmente un solvente, que transfiere el hidrógeno [7].

Con el fin de superar las limitaciones definidas durante la producción de hidrógeno a partir de biomasa, (biohidrógeno), se propone, estudiar el uso de biodonantes capaces de generar hidrógeno in situ mediante la hidrogenación por transferencia catalítica $(\mathrm{CTH})$, cuyo almacenamiento y transporte es mucho más económico que el del hidrógeno molecular [9]. En la transferencia catalítica de hidrógeno (CTH), el donante de hidrógeno se debe descomponer catalítica o térmicamente en hidrógeno molecular, óxidos de carbono e hidrocarburos ligeros; una fuente renovable de materia prima se encuentra en las corrientes de biorrefinerías, dado que sus productos en muchos casos son corrientes oxigenadas como alcoholes, aldehídos y ácidos carboxílicos, por ejemplo metanol, etanol, ácido fórmico y glicerol, incluso compuestos aromáticos condensados, algunos alcanos y aminas [12].

Muchos de los solventes que pueden ser donantes de hidrógeno se producen en mayor medida a partir de rutas que emplean como materias primas recursos fósiles como es el caso del metanol y ácido fórmico. [13].

Dado que en el hidroprocesamiento de la biomasa se emplean altas presiones, una ventaja de usar solventes donadores de hidrógeno es operar a presiones más bajas; Así mimo el donante hace más 
efectiva la estabilización de la descomposición primaria de los productos, previniendo carbonización y coquización, mejorando la selectividad. Durante la elección del donante es necesario considerar que el compuesto contenga enlaces móviles carbono-hidrógeno, deshidrogene fácilmente y tenga alta capacidad de solvatación [14]. De acuerdo con Hwang [10], el efecto de solvatación del donante hace que el catalizador mantenga su actividad y selectividad por un mayor periodo de tiempo; Sin embargo, es necesario tener en cuenta la cantidad de donante, ya que un exceso del mismo podría interactuar directamente con la superficie para deshidrogenar ocupando todos los sitios activos dando así como resultado la disminución del mejoramiento de la hidroconversión selectiva de los ácidos grasos [11].

\section{MATERIALES Y MÉTODOS}

\section{Selección de Donantes}

En primera instancia se establecen los criterios para la selección del donante, para ello se realiza un análisis termodinámico que permite hacer un posterior análisis de decisión multicriterio que muestre la factibilidad del proceso de generación de hidrogeno.

\section{Criterios}

Como se mencionó anteriormente durante la selección del donante de hidrógeno deben considerarse aspectos propiedades físicas y químicas y su capacidad de solvatación[14]. Adicionalmente hay que considerar que el donante de hidrógeno, se conserve en fase líquida a las condiciones de operación de acuerdo a su diagrama de fase, presente una adecuada viscosidad, tenga factibilidad termodinámica de deshidrogenación y descomposición, y un apropiado ciclo catalítico. Así, se tienen en cuenta como primeros candidatos los siguientes solventes orgánicos: alcoholes, polioles, aldehidos, cetonas, ácidos carboxílicos, aromáticos policiclicos (aromáticos condensados), aminas y alcanos.

\section{Decisión Multicrierio}

Una vez se enlistan todas las posibles familias de donantes, se realiza un análisis multicriterio (Multi-Criteria Decision Analysis -MCDA), para la toma de decisiones. La aplicación de los métodos multicriterio es una herramienta de ingeniería que permite desarrollar fácilmente la toma de decisiones considerando diferentes análisis y lo que conlleva a la optimización de parámetros.
El Método MACBETH, es una aproximación a los problemas de toma de decisiones multicriterio que aplica la Teoría de Utilidad Multiatributo, MAUT, basándose en consensuar los valores de los criterios de evaluación para encontrar un criterio global. MACBE$\mathrm{TH}$ propone una escala numérica, basada en juicios semánticos sobre la diferencia de "atractivo" percibida entre pares de elementos de un conjunto que permite medir con una medida cardinal.

Según la teoría de la utilidad, cada criterio aporta una descripción parcial de la utilidad global de cada una de las alternativas, así que la utilidad global puede calcularse a partir de las utilidades parciales, usando una combinación lineal de pesos y funciones obtenidas de valoraciones de expertos, según (1):

$$
U_{i}=\sum_{j=1}^{n}\left[w_{j} f_{j}\left(C_{j}\right)\right]
$$

Donde $U_{i}$ es la utilidad de la alternativa $i, w_{i}$ es el peso del criterio $j$ ( $n$ criterios) y $f_{j}\left(C_{j}\right)$ es una función de preferencia para cada criterio j. El peso de cada criterio $\left(w_{j}\right)$ se calcula con las diferencias $a_{j k}$ entre el criterio $j$ y el criterio $k$ según lo presenta la ecuación (2):

$$
w_{j}=\frac{\frac{\sum_{j=1}^{n} a_{j k}-\sum_{j=0}^{k-1} a_{j k}}{\sum_{j=1}^{n} a_{j k}}}{\sum_{j=1}^{n} \frac{\sum_{j=1}^{n} a_{j k}-\sum_{j=0}^{k-1} a_{j k}}{\sum_{j=1}^{n} a_{j k}}}
$$

Obtenidos los pesos y la función para cada criterio, con la Ecuación 4 se determina la utilidad, $\bigcup_{i}$, de cada alternativa i y se clasifica de mayor a menor el conjunto de alternativas. Es esta clasificación final la que se utiliza para la toma de decisiones [15].

Para la evaluación se propusieron ocho alternativas para los donantes: alcoholes, polioles, aldehidos, cetonas, ácidos carboxílicos, aromáticos policíclicos, aminas y alcanos. Y se establecieron 5 criterios: Disponibilidad, Costo, Origen Renovable, Productos de descomposición y Toxicidad.

\section{Análisis Termodinámico}

De cada uno de los grupos funcionales establecidos se eligió un donante representativo de acuerdo a la revisión bibliográfica realizada. Para cada donante postulado se plantearon posibles reacciones de des- 
composición, dentro de las cuales se debe resaltar la generación de hidrógeno. Luego, a cada reacción se le calculó la constante de equilibrio, $\mathrm{K}$, entre $20^{\circ} \mathrm{C}$ y 800 $\mathrm{K}$, que para una temperatura de operación, $\mathrm{T}$, puede calcularse mediante la expresión (3):

$$
K=\exp \left[\frac{\Delta H_{0}^{o}}{R T_{0}}\left(1-\frac{T_{0}}{T}\right)-\frac{\Delta G_{0}^{o}}{R T_{0}}+\int_{T_{0}}^{T} \frac{\Delta c_{P}^{o}}{R} \frac{d T}{T}-\frac{1}{T} \int_{T_{0}}^{T} \frac{\Delta c_{P}^{o}}{R} d T\right]
$$

Donde las propiedades estándar de reacción como la energía libre de Gibbs, $\Delta G^{\circ}{ }_{0}$, y la entalpia o calor de reacción, $\Delta \mathrm{H}_{0}^{\circ}$, se encuentran a la temperatura de referencia, $T_{0}$. R es la contante universal de los gases ideales y $\Delta c^{\circ}$ es la diferencia entre los calores específicos de los productos y los reactivos de la reacción multiplicados por sus respectivos coeficientes estequiométricos. De esta manera la Energía Libre de Gibbs (estándar) de la reacción, $\Delta \mathrm{G}^{\circ}$, a la temperatura, $T$, se relaciona a través de la constante de equilibrio, $K$ por medio de la ecuación (4):

$$
\ln K=-\frac{\Delta G^{o}}{R T}
$$

La reacción es factible termodinámicamente cuando $\Delta G^{\circ}<0$, es decir la energía libre de Gibbs es negativa, lo que implica que $K>1$, y entre más alto sea este valor respecto a la temperatura, la reacción será más probable. Si $\Delta G^{\circ}=0$, entonces la reacción está en equilibrio, es decir $K=1$, mientas que la reacción química no es espontánea si $\Delta G^{\circ}>0$, o sea $0<K<1$. Realizando la gráfica de $\ln (\mathrm{k})$ Vs. $1 / \mathrm{T}$ se puede observar este comportamiento, indicando las reacciones que ocurren para cada donante, analizando entre estas la de generación de hidrógeno, que es la de interés.

\section{Selección}

Con base en un análisis global dado por lo anteriores ítems fue posible definir los donantes más apropiados para la generación de hidrógeno in situ.

\section{Parte Experimental}

\section{Materiales}

Los reactivos, grado analítico, como el ácido fórmico $(99.6 \%)$ y el etanol (99.9 \% v/v) fueron provistos por ITW Reagents- PanReac Applichem (Darmstadt, Germany). Los gases hidrógeno y nitrógeno grado 5.0 fueron entregados por LINDE (Bogotá, Colombia). Los catalizadores comerciales fueron adquiridos de Sigma-Aldrich were: 5 \%Pd/C (Reference 205680), 5 \%Pd/
y-Al2O3 (Ref. 761176), 5 \%Pt/C (Ref. 80982), 5 \%Pt/YAl2O3 (Ref. 761176). Las zeolitas ultraestabilizadas USY (Series CBV-712, 720 y 780) fue proporcionada por Zeolyst International. Los catalizadores de 1\% Pt/ USY fueron preparados por impregnación húmeda a partir de la sal de dicloruro de tetra amin platino (II) [Pt $(\mathrm{NH} 3)]$ 4Cl2. Los catalizadores fueron activados a 200 ${ }^{\circ} \mathrm{C}$ durante 2 horas en una atmosfera reducida de $30 \%$ de $\mathrm{H} 2 / \mathrm{N} 2$, a partir de un calentamiento con un rampa de $3{ }^{\circ} \mathrm{C} / \mathrm{min}$.

\section{Métodos}

Se desarrollaron tres fases: pruebas en reactor Batch, ensayos en HP DSC y análisis cromatográfico.

La primera fase correspondiente a las pruebas en el reactor Batch de $300 \mathrm{~mL}$ tuvo tres etapas: en la primera, se hicieron corridas con $200 \mathrm{~mL}$ de etanol 80 \% y $99.9 \%$ (v/v), empleando $1 \mathrm{mg} / \mathrm{g}$ de catalizador (aproximadamente $0.15 \mathrm{~g}$ ), con una rampa de calentamiento de $4{ }^{\circ} \mathrm{C} / \mathrm{min}$ aprox., $200{ }^{\circ} \mathrm{C}$, 27-40 bar (para estas condiciones de trabajo fue necesario mantener presiones mayores a 26.5 bar para asegurar el etanol en fase líquida), agitación mecánica constante de 625 RPM, la presión aumentaba por la generación de presión autógena durante el calentamiento; los catalizadores empleados fueron 1 \% Pt/CBV 712, 1 \% Pt/ CBV 720, 1\% Pt/CBV 780, 5 \%Pd/C, \%Pd/Y-Al2O3 y 5 $\% \mathrm{Pt} / \mathrm{Y}$-Al203, una vez se alcanzaba la temperatura de operación, se tomaron muestras gaseosas de $1 \mathrm{~mL}$. Durante la segunda etapa, se aumentó la proporción de catalizador/donante, es decir pasó de $0.0015 \mathrm{~mol}$ de fase activa a 0.003 molal $(0.003 \mathrm{~m}=0.03 \mathrm{~mol}$ de fase activa por kg de donante; se empleó ácido fórmico concentrado (99.6 \% ó $26.5 \mathrm{M}$ ), etanol a diferentes concentraciones $(0.45,1$ y $2 \mathrm{M})$ mientas que el resto de condiciones permanecieron constantes con los catalizadores 1 \%Pt/CBV780, 5 \%Pd/C, 5 \%Pt//Y-Al2O3. Finalmente en la tercera etapa, se hicieron corridas con mayor relación de catalizador respecto al donante (0.022, 0.014 y 0.007 m), ácido fórmico (30 \% y 99.6 $\%$ ) y etanol (30 \% y $99.9 \%$ v) con los catalizadores de $5 \% \mathrm{Pt} / \mathrm{C}$ y $5 \% \mathrm{Pd} / \mathrm{C}$, pero con la diferencia de que las muestras gaseosas se tomaron a las $8 \mathrm{~h}$ del momento de inicio de reacción.

Para cada una de las pruebas, desarrolladas en el reactor Batch, fue necesario previamente adecuar el solvente despojando el oxígeno disuelto en el líquido mediante un burbujeo de nitrógeno. Cuando se trabajó con ácido fórmico y catalizador $\mathrm{Pd} / \mathrm{C}$ se produce una reacción altamente espontánea que genera gran cantidad de hidrógeno que al entrar en contacto con 
el oxígeno puede liberar energía, de modo que en este caso el solvente ingresa al sistema a baja temperatura. La mezcla de reacción se dispuso en un vaso de boro silicato y se introduce en el reactor de alta presión que cuenta con una chaqueta de calentamiento y aislamiento térmico, y un sistema de suministro de hidrogeno y nitrógeno.

Para los ensayos se trabajó una atmósfera inerte de nitrógeno mínimo de 10 bar cuando se empleó ácido fórmico y 30 bar mínimo con etanol, dicha presión se mantuvo en un rango entre 50-60 bar, esto por acción autógena del sistema cuando este llegaba una temperatura de operación de $200{ }^{\circ} \mathrm{C}$.

De acuerdo a los resultados anteriores, fue posible iniciar con la segunda fase de selección, se eligieron los sistemas catalíticos que tuvieron el mejor comportamiento y se realizaron con ellos ensayos en el HP DSC1 Star System Mettler Toledo del laboratorio de polímeros del Laboratorio de Ingeniería Química de la Universidad Nacional de Colombia, sede Bogotá.

En un crisol de $40 \mu \mathrm{L}$ se colocó el catalizador junto con el donante de hidrógeno (etanol o ácido fórmico) empleando una relación de $7 \mathrm{mmol}$ de fase activa por $\mathrm{kg}$ de donante. Se mantuvo una atmosfera inerte de 50 bar de N2 con una rampa de calentamiento de $10^{\circ} \mathrm{C} /$ min, desde $25^{\circ} \mathrm{C}$ hasta $220^{\circ} \mathrm{C}$ en el caso de etanol o de $280^{\circ} \mathrm{C}$ en el caso de ácido fórmico. Al descargar se pesó el contenido del crisol y se tomó una muestra gaseosa para un análisis de gases en un Cromatrografo de Gases.

Para la fase final, el análisis de las muestras gaseosas se dio mediante un cromatrografo de gases empleando un cromatógrafo Hewlett Packard serie 5890 (serie A), para la identificación y cuantificación de hidrógeno gaseoso (además de $\mathrm{CO}, \mathrm{CH} 4, \mathrm{C} 2 \mathrm{H} 4, \mathrm{~N} 2$ and 02) se empleó una columna empacada de tamiz molecular (Supelco 80/100 mole sieve 13X column 10' x $1 / 8$ " S.S. -Acero Inoxidable-). El arrastre se dio con un flujo de $12 \mathrm{ml} \mathrm{He} / \mathrm{min}$. A 20 psi. La muestra gaseosa se inyectó $0.1 \mathrm{~mL}$.

\section{RESULTADOS Y ANÁLISIS DE RESULTADOS}

\section{Selección de Donantes}

\section{Decision Multicrierio}

Se definieron los pesos $\left(w_{i}\right)$ para cada uno de los cinco criterios establecidos, estos resultados son ne- cesarios para la construcción del MAUT. Fue necesario hacer una comparación y establecer relaciones de influencia o peso entre las variables de entrada (origen renovable, productos de descomposición, costo, disponibilidad y toxicidad), considerando variables técnicas; Por ejemplo, durante la deshidrogenación y descomposición de donantes además de generar hidrógeno, también se generan subproductos: si los donantes son alcoholes y polioles se produce monóxido de carbono y alcanos, mientras que si son aldehídos y cetonas se libera monóxido y alquenos, y si son ácidos carboxílicos la descomposición libera dióxido de carbono y alquenos. Es necesario considerar que la producción de alquenos es indeseable pues este subproducto consume hidrógeno para saturarse a alcanos, lo que reduciría la producción de hidrogeno;

Los productos de descomposición de cada una de las familias son:

- Alcoholes: $\mathrm{CO}+\mathrm{H}_{2}+\mathrm{C}_{\mathrm{n}} \mathrm{H}_{2 \mathrm{n}+2}$ (monóxido de carbono, hidrógeno y alcanos)

- Polioles: $\mathrm{CO}+\mathrm{H}_{2}+\mathrm{C}_{\mathrm{n}} \mathrm{H}_{2 \mathrm{n}+2}$ (monóxido de carbono, hidrógeno y alcanos)

- Aldehídos y Cetonas: $\mathrm{CO}+\mathrm{H}_{2}+\mathrm{C}_{\mathrm{n}} \mathrm{H}_{2 \mathrm{n}}$ (monóxido de carbono, hidrógeno y alquenos)

- Ácidos Carboxílicos: $\mathrm{CO}_{2}+\mathrm{H}_{2}+\mathrm{C}_{\mathrm{n}} \mathrm{H}_{2 \mathrm{n}}$ (dióxido de carbono, hidrógeno y alquenos)

- Homólogos de Aromáticos condensados: $\mathrm{H}_{2}+$ $\mathrm{C}_{10} \mathrm{H}_{8}$ (hidrógeno y naftaleno)

- Aminas: $\mathrm{R}-\mathrm{C} \equiv \mathrm{N}+\mathrm{H}_{2}$ (nitrilos e hidrógeno)

- Alcanos: $\mathrm{H}_{2}+\mathrm{C}_{\mathrm{n}} \mathrm{H}_{2 \mathrm{n}}$ (hidrógeno y alquenos)

Estos resultados se ven en la Tabla 1:

Tabla 1. Calificación de diferencias entre criterios.

\begin{tabular}{|c|c|c|c|c|c|c|c|}
$\begin{array}{c}\text { Dife- } \\
\text { rencia }\end{array}$ & $\begin{array}{c}\text { Extre- } \\
\text { ma }\end{array}$ & $\begin{array}{c}\text { Muy } \\
\text { grande }\end{array}$ & Grande & Media & $\begin{array}{c}\text { Peque- } \\
\text { ña }\end{array}$ & $\begin{array}{c}\text { Muy } \\
\text { peque- } \\
\text { ña }\end{array}$ & $\begin{array}{l}\text { Insigni- } \\
\text { ficante }\end{array}$ \\
$\begin{array}{c}\text { Califica- } \\
\text { ción }\end{array}$ & 20 & 17 & 14 & 11 & 8 & 5 & 2 \\
\hline
\end{tabular}

A partir de estos resultados fue posible elaborar la matriz MAUT, presentada en la Tabla 2 donde se establece la diferencia entre el criterio fila y el criterio columna, para calcular el peso asignado, $\mathrm{w}_{\mathrm{j}}$, para cada criterio según la Ecuación 2.

Tabla 2. Calculo del peso asignado a cada criterio.

\begin{tabular}{|c|c|c|c|c|c|c|c|c|}
\hline $\begin{array}{c}\text { Crite- } \\
\text { rio }\end{array}$ & $\mathrm{j}$ & 1 & 2 & 3 & 4 & 5 & 6 & $\Sigma$ \\
\hline $\begin{array}{l}\text { Origen } \\
\text { Reno- } \\
\text { vable }\end{array}$ & 1 & - & 14 & 11 & 8 & 14 & 14 & 61 \\
\hline
\end{tabular}




\begin{tabular}{|c|c|c|c|c|c|c|c|c|}
\hline $\begin{array}{c}\text { Crite- } \\
\text { rio } \\
\end{array}$ & j & 1 & 2 & 3 & 4 & 5 & 6 & $\Sigma$ \\
\hline $\begin{array}{l}\text { Pro- } \\
\text { ductos } \\
\text { de } \\
\text { des- } \\
\text { com- } \\
\text { posi- } \\
\text { ción }\end{array}$ & 2 & - & - & 17 & 17 & 2 & 14 & 50 \\
\hline Costo & 3 & - & - & - & 5 & 14 & 17 & 36 \\
\hline $\begin{array}{l}\text { Dispo- } \\
\text { nibili- } \\
\text { dad }\end{array}$ & 4 & - & - & - & - & 17 & 14 & 31 \\
\hline $\begin{array}{l}\text { Toxici- } \\
\text { dad }\end{array}$ & 5 & - & - & - & - & - & 20 & 20 \\
\hline Otros & 6 & - & - & - & - & - & - & 0 \\
\hline
\end{tabular}

\begin{tabular}{|c|c|c|c|c|c|}
\hline Criterio & j & $\Sigma$ & Dif. & Rel. & $w_{\text {_j }}$ \\
\hline $\begin{array}{c}\text { Origen Re- } \\
\text { novable }\end{array}$ & 1 & 61 & 11 & 1.0000 & 0.3081 \\
\hline $\begin{array}{c}\text { Productos } \\
\text { de des- } \\
\text { composi- } \\
\text { ción }\end{array}$ & 2 & 50 & 14 & 0.8197 & 0.2525 \\
\hline Costo & 3 & 36 & 5 & 0.5902 & 0.1818 \\
\hline $\begin{array}{l}\text { Disponibi- } \\
\text { lidad }\end{array}$ & 4 & 31 & 11 & 0.5082 & 0.1566 \\
\hline Toxicidad & 5 & 20 & 20 & 0.3279 & 0.1010 \\
\hline$\Sigma$ & 6 & & 61 & 3.2459 & 1.0000 \\
\hline
\end{tabular}

Por el método Macbeth se calcula la utilidad a partir de la calificación sobre 10 por cada criterio j de cada una de las alternativas i, según la Ecuación 1. La tabla 3, presenta los resultados de la evaluación de cada uno de los criterios, donde se vislumbran como donantes promisorios los alcoholes y el ácido fórmico, único ácido orgánico que no se descompone en alquenos, sino $\mathrm{H}_{2}$ y $\mathrm{CO}_{2}$. Respecto a los alcoholes, se dispone ampliamente de etanol obtenido por vía biotecnológica a partir de la fermentación de carbohidratos.

Tabla 3. Calculo de la utilidad global para cada alternativa.

\begin{tabular}{|c|c|c|c|c|c|c|}
\multirow{2}{*}{ Alternativa, $\mathrm{i}$} & \multicolumn{7}{|c|}{ Criterio, j. } & \multirow{2}{*}{ U_i } \\
\cline { 2 - 7 } Alcoholes & 10 & 10 & 7 & 8 & 9 & 9.0404 \\
\hline Polioles & 8 & 9 & 8 & 8 & 9 & 8.3535 \\
\hline Aldehidos & 8 & 6 & 5 & 5 & 7 & 6.3788 \\
\hline Cetonas & 7 & 6 & 5 & 5 & 8 & 6.1717 \\
\hline $\begin{array}{c}\text { Acidos Car- } \\
\text { boxillicos }\end{array}$ & 9 & 9 & 6 & 8 & 8 & 8.1970 \\
\hline $\begin{array}{c}\text { Aromáticos } \\
\text { Condensados }\end{array}$ & 6 & 4 & 7 & 8 & 4 & 5.7879 \\
\hline Aminas & 5 & 6 & 7 & 7 & 5 & 5.9293 \\
\hline Alcanos & 3 & 5 & 9 & 9 & 7 & 5.9394 \\
\hline
\end{tabular}

De acuerdo al anterior análisis multicriterio se observa que las alternativas que tiene una utilidad global sobre 10 mayor a 8 en orden descendente son: Alcoho- les, polioles y ácidos carboxílicos. Dentro de estas familias seleccionadas se tiene en cuenta los siguientes compuestos:

- Alcoholes: Etanol, metanol, isobutanol, isopropanol (los alcoholes terciarios y secundarios liberan $\mathrm{H}_{2}$ más fácilmente).

- Polioles: Glicerina, etilenglicol, propilenglicol.

- Ácidos Carboxílicos: Ácido fórmico, ácido acético

De los alcoholes se elige el etanol ya que se genera por la fermentación de azucares, un proceso ya conocido y estandarizado, usado principalmente en la industria de bebidas, lo que es una ventaja competitiva en cuanto a la disponibilidad de otros alcoholes. Respecto a los polioles se toma decisión por la glicerina debido a que se obtiene en buenas cantidades como subproducto en la industria de los jabones y del biodiésel éster. Frente a los ácidos carboxílicos se tiene que el ácido fórmico en su descomposición a hidrógeno se descarboxila, es decir produce hidrógeno y agua, mientras que los ácidos de más carbonos generan hidrocarburos, preferencialmente alquenos.

\section{Análisis Termodinámico}

Las posibles reacciones de descomposición tanto para el ácido fórmico, el etanol y la glicerina se presentan en la Tabla 4:

Tabla 4. Reacciones de descomposición para donantes promisorios.

\begin{tabular}{|c|c|}
\hline $\begin{array}{l}\text { Descarboxilación (deshidrogena- } \\
\text { ción) del ácido fórmico (DCXAF) }\end{array}$ & $\mathrm{HCOOH} \rightarrow \mathrm{CO}_{2}+\mathrm{H}_{2}$ \\
\hline $\begin{array}{l}\text { Descarbonilación (deshidrata- } \\
\text { ción) del ácido fórmico (DCNAF) }\end{array}$ & $\mathrm{HCOOH} \rightarrow \mathrm{CO}+\mathrm{H}_{2} \mathrm{O}$ \\
\hline Deshidratación de etanol (DWE) & $\mathrm{CH}_{3} \mathrm{CH}_{2} \mathrm{OH} \rightarrow \mathrm{CH}_{2}=\mathrm{CH}_{2}+\mathrm{H}_{2} \mathrm{O}$ \\
\hline $\begin{array}{c}\text { Deshidrogenación de etanol } \\
\text { (DHE) }\end{array}$ & $\mathrm{CH}_{3} \mathrm{CH}_{2} \mathrm{OH} \rightarrow \mathrm{CH}_{3} \mathrm{CHO}+\mathrm{H}_{2}$ \\
\hline Metanación de etanol (ME) & $\mathrm{CH}_{3} \mathrm{CH}_{2} \mathrm{OH} \rightarrow \mathrm{CO}+\mathrm{CH}_{4}+\mathrm{H}_{2}$ \\
\hline Eterificación del etanol (EE) & $\begin{aligned} 2 \mathrm{CH}_{3} \mathrm{CH}_{2} \mathrm{OH} & \rightarrow \mathrm{CH}_{3} \mathrm{CH}_{2} \mathrm{OCH}_{2} \mathrm{CH}_{3} \\
& +\mathrm{H}_{2} \mathrm{O}\end{aligned}$ \\
\hline $\begin{array}{l}\text { Deshidrogenación de glicerina } \\
\text { (DHG) por APR }\end{array}$ & $\begin{array}{c}\mathrm{CH}_{2} \mathrm{OHCHOHCH} \\
4 \mathrm{H}_{2}\end{array}$ \\
\hline $\begin{array}{l}\text { Deshidratación de glicerina } \\
\text { (DWG) }\end{array}$ & $\begin{array}{c}\mathrm{CH}_{2} \mathrm{OHCHOHCH}{ }_{2} \mathrm{OH} \rightarrow \mathrm{CH}_{2}=\mathrm{CH}- \\
\mathrm{CHO}+2 \mathrm{H}_{2} \mathrm{O}\end{array}$ \\
\hline
\end{tabular}


Para las reacciones mostradas en la Tabla 4, se haIlaron las constantes de equilibrio como una función de la temperatura y la energía libre de Gibbs estándar de acuerdo a las Ecuaciones 3 y 4, las propiedades usadas son presentadas en la Tabla 5.

Tabla 5. Propiedades para las especies químicas que participan en las reacciones.

\begin{tabular}{|c|c|c|c|c|c|c|c|}
\hline \multirow{2}{*}{ Especie } & \multirow{2}{*}{$\underset{\mathrm{J} / \mathrm{mol}}{\Delta \mathrm{G}^{\circ}}$} & \multirow{2}{*}{$\underset{\mathrm{J} / \mathrm{mol}}{\Delta \mathrm{H}_{\mathrm{f}}^{\circ}}$} & \multicolumn{5}{|c|}{$c^{0}{ }_{p} / R=a_{0}+a_{1} T+a_{2} T^{2}+a_{3} T^{3}+a_{4} T^{4}$} \\
\hline & & & $a_{0}$ & $a_{1}$ & $a_{2}$ & $a_{3}$ & $a_{4}$ \\
\hline Ácido Fórmico & -351230.00 & -378860.00 & 3.809 & 1.57E-03 & 3.59E-05 & $-4.41 E-08$ & 1.67E-11 \\
\hline Dióxido de Carbono & -394380.00 & -393510.00 & 3.259 & 1.36E-03 & $1.50 \mathrm{E}-05$ & $-2.37 \mathrm{E}-08$ & $1.06 \mathrm{E}-11$ \\
\hline Hidrógeno & 0.00 & 0.00 & 2.883 & 3.68E-03 & $-7.72 \mathrm{E}-06$ & $6.92 \mathrm{E}-09$ & $-2.13 E-12$ \\
\hline Agua & -228420.00 & -241810.00 & 4.395 & $-4.19 \mathrm{E}-03$ & $1.41 \mathrm{E}-05$ & $-1.56 \mathrm{E}-08$ & $6.32 \mathrm{E}-12$ \\
\hline $\begin{array}{c}\text { Monóxido de Car- } \\
\text { bono }\end{array}$ & -137160.00 & -110530.00 & 3.912 & $-3.91 \mathrm{E}-03$ & 1.18E-05 & $-1.30 \mathrm{E}-08$ & 5.15E-12 \\
\hline Etanol & -167730.00 & -234950.00 & 4.396 & $6.28 \mathrm{E}-04$ & 5.55E-05 & $-7.02 \mathrm{E}-08$ & 2.69E-11 \\
\hline Etileno & 68480.00 & 52500.00 & 4.221 & $-8.78 \mathrm{E}-03$ & $5.71 \mathrm{E}-05$ & $-6.73 \mathrm{E}-08$ & 2.51E-11 \\
\hline Acetaldehido & -128860.00 & -166190.00 & 1.693 & 1.80E-02 & $-6.16 \mathrm{E}-06$ & $0.00 \mathrm{E}+00$ & $0.00 \mathrm{E}+00$ \\
\hline Metano & -50.45 & -74.52 & 4.568 & $-8.98 \mathrm{E}-03$ & $3.63 \mathrm{E}-05$ & $-3.41 \mathrm{E}-08$ & 1.09E-11 \\
\hline Dietileter & -120700.00 & -250800.00 & 4.612 & $3.75 E-02$ & $-1.87 E-05$ & 1.32E-08 & $-6.98 E-12$ \\
\hline Glicerina & -461060.00 & -577900.00 & 1.727 & 4.69E-02 & 2.81E-05 & $6.42 \mathrm{E}-09$ & $0.00 \mathrm{E}+00$ \\
\hline Acroleína & -85830.00 & -103370.00 & 3.114 & 1.74E-02 & 8.00E-06 & $-2.00 E-08$ & 6.00E-12 \\
\hline$\triangle \mathrm{DCXAF}$ & -43150.00 & -14650.00 & 2.333 & 3.47E-03 & $-2.86 \mathrm{E}-05$ & $2.73 \mathrm{E}-08$ & $-8.29 E-12$ \\
\hline$\triangle \mathrm{DCNAF}$ & -14350.00 & 26520.00 & 4.498 & $-9.67 \mathrm{E}-03$ & $-1.00 \mathrm{E}-05$ & 1.54E-08 & $-5.25 E-12$ \\
\hline$\triangle \mathrm{DWE}$ & 7790.00 & 45640.00 & 4.220 & $-1.36 \mathrm{E}-02$ & 1.56E-05 & $-1.27 \mathrm{E}-08$ & 4.58E-12 \\
\hline$\triangle \mathrm{DHE}$ & 38870.00 & 68760.00 & 0.180 & 2.10E-02 & $-6.93 E-05$ & 7.72E-08 & $-2.90 E-11$ \\
\hline$\triangle \mathrm{ME}$ & 30519.55 & 124345.48 & 6.967 & $-9.84 \mathrm{E}-03$ & $-1.51 E-05$ & 3.01E-08 & $-1.29 \mathrm{E}-11$ \\
\hline$\triangle \mathrm{EE}$ & -13660.00 & -22710.00 & 0.215 & 3.21E-02 & $-1.16 \mathrm{E}-04$ & 1.38E-07 & $-5.44 E-11$ \\
\hline$\triangle \mathrm{DHG}$ & 49580.00 & 246310.00 & 21.541 & $-4.39 E-02$ & $-2.36 \mathrm{E}-05$ & $-1.78 \mathrm{E}-08$ & 6.93E-12 \\
\hline$\triangle \mathrm{DWG}$ & -81610.00 & -9090.00 & 10.177 & $-3.79 E-02$ & 7.96E-06 & -5.77E-08 & $1.86 \mathrm{E}-11$ \\
\hline
\end{tabular}

La factibilidad termodinámica de las anteriores reacciones se analiza en los perfiles térmicos de las constantes de equilibrio para el intervalo entre 300 a $800 \mathrm{~K}$ como se aprecia en la Figura 1. En el caso del ácido fórmico se puede observar que tanto la deshidrogenación (DCX) como la deshidratación (DCN) son factibles, con la diferencia de que la primera siendo exotérmica se ve desfavorecida con el aumento de la temperatura y la reacción deseada para la producción de hidrógeno, siempre es más favorable que la segunda que es endotérmica.
Para el etanol, la única reacción exotérmica es la eterificación, que es factible en todo el intervalo de temperaturas elegido; por otra parte la metanación, siendo la reacción necesaria para la generación de hidrógeno, solo es factible después de los $120^{\circ} \mathrm{C}$, donde prevalece respecto a las otras tres reacciones de descomposición; la deshidrogenación se favorece después de $100{ }^{\circ} \mathrm{C}$, pero en competencia con la deshidratación, a la que solo supera después de $330^{\circ} \mathrm{C}$.

El análisis térmico señala que la donación de hidrógeno es totalmente espontanea por la descarboxila- 
ción del ácido fórmico y que en la glicerina esta reacción se da sólo después de $100{ }^{\circ} \mathrm{C}$; Adicionalmente, la descarboxilación de la glicerina supera a la del ácido fórmico solo en temperaturas mayores a $190^{\circ} \mathrm{C}$.
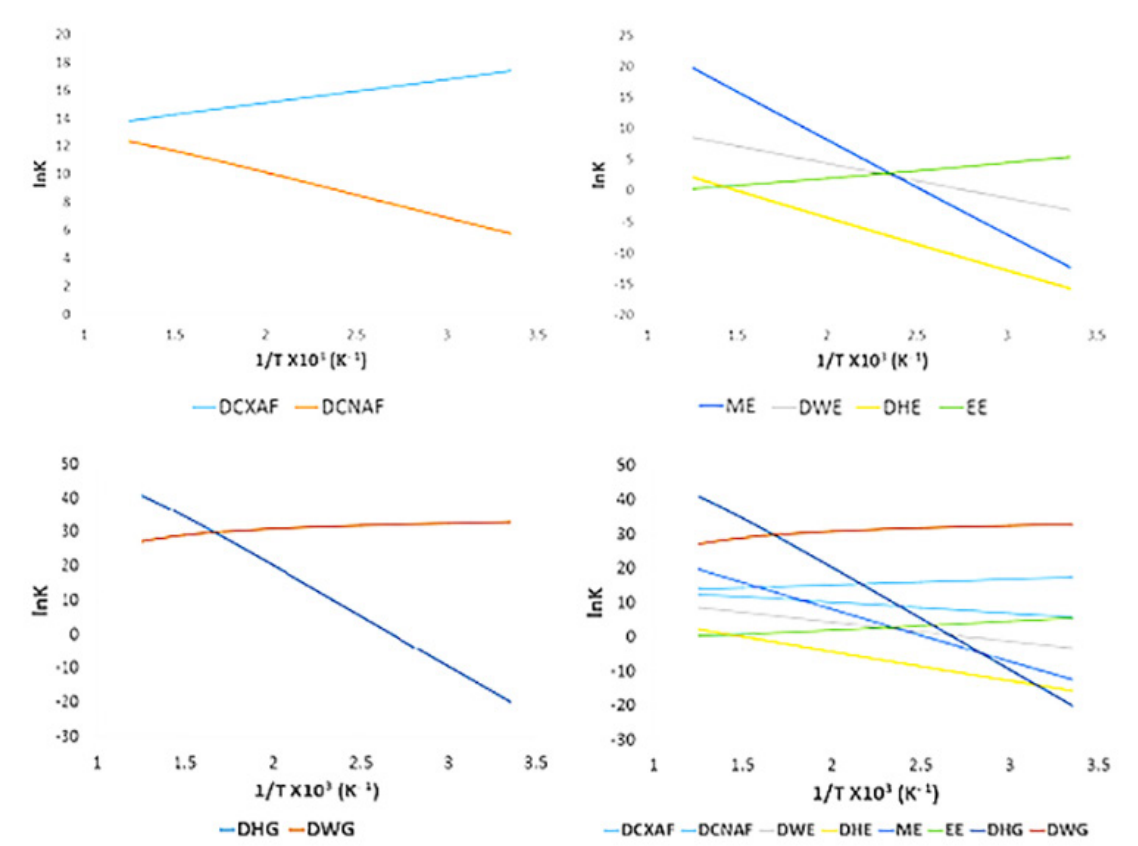

Figura 1. Perfil térmico de la constante de equilibrio en las reacciones de descomposición para ácido fórmico (izquierda arriba), etanol (derecha arriba), glicerina (izquierda abajo) y todos (derecha abajo).

\section{Selección}

El ácido fórmico es uno de los mayores subproductos de los procesos de biorrefinería lo que lo convierte en uno de los donadores más promisorios puesto que además de sus propiedades únicas como: la no toxicidad, densidad energética favorable, biodegradabilidad, reactividad, costo, seguridad de almacenamiento; la facilidad de síntesis química lo hace tener alta disponibilidad como materia prima.[16]. [17]. Por otra parte el etanol que también es un producto de biorrefinería importantes es generado principalmente por fermentación de la biomasa, es usado primordialmente como solventes en la industria química y carburante, sustituto parcial de la gasolina lo que hace que su disponibilidad como materia prima se vea reducida.

Dado que el catalizador será quien controle la selectividad en cada una de las descomposiciones factibles, es importante consultar el diagrama de Volcano (Figura 2) para generación de hidrógeno. Esto permite elección del catalizador más apropiado. Por ejemplo, respecto a la descarboxilación del ácido fórmico el diagrama de volcano indica que, respecto a los metales de transición, los catalizadores más apropiados para dicha reacción son $\mathrm{Ru}, \mathrm{Rh}, \mathrm{Pd}$, Pt e Ir.

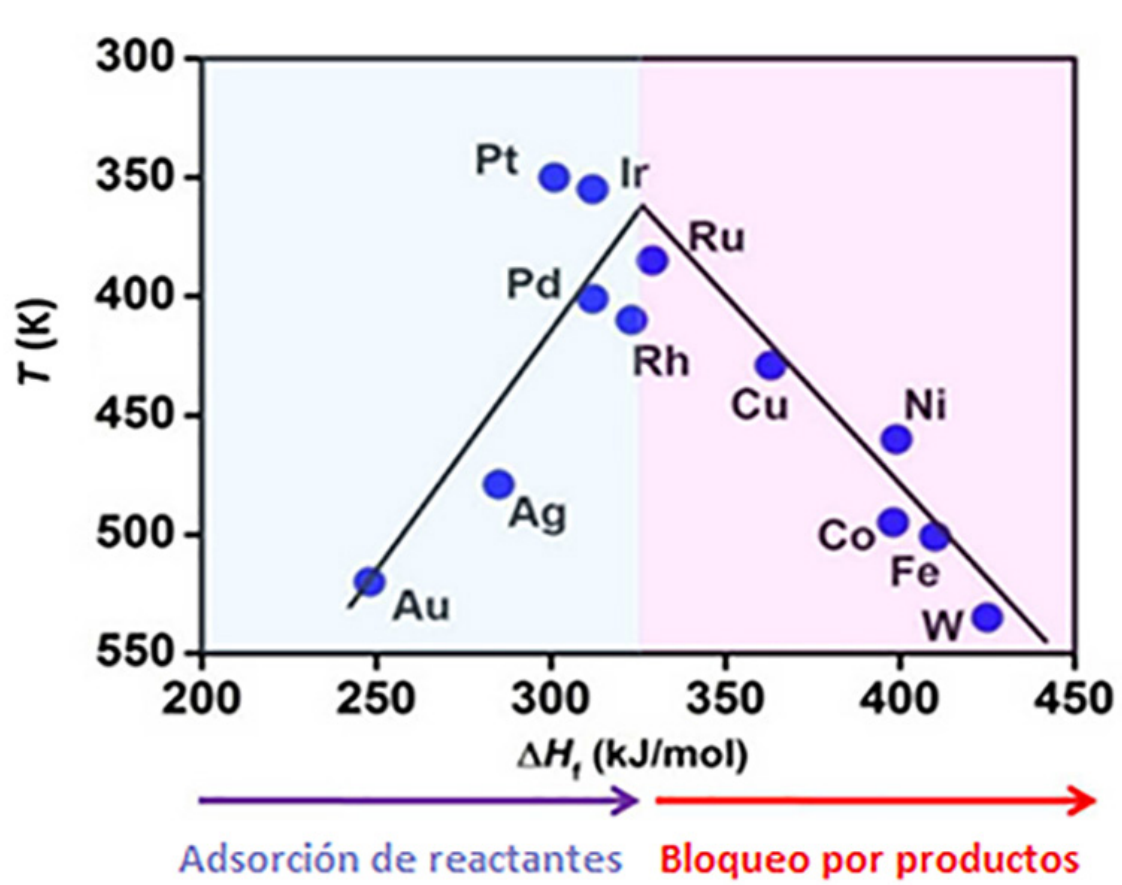

Figura 2. Diagrama de Volcano para la descomposición del ácido fórmico por descarboxilación sobre metales de transición. Adaptado de [16].

De acuerdo con lo anterior, los catalizadores más simples y fáciles de preparar, aunque de alto costo, son los metálicos reducidos soportados ya sea en carbón, alúmina o zeolita: Pt, Pd, Rh y Ru. Otros catalizadores como bisulfuros, carburos o fosfuros (mono o di) metálicos pueden ser menos costosos pero más complejos de preparar o carecer de mejor estabilidad.

\section{Parte Experimental}

\section{Reactor Batch}

En los ensayos de la primera etapa, los cromatogramas indicaron que la prueba que al cabo de la primera media hora de reacción generó la mayor cantidad de hidrógeno fue donde se empleó etanol 80 \% (v/v) con $1 \%$ Pt/CBV 780, resultado que está consignado en la

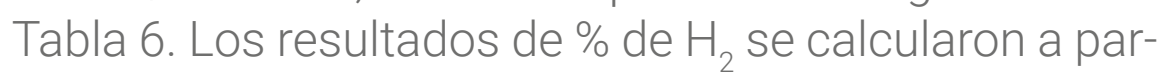
tir de la curva de calibración efectuada para cada valor de área determinado.

Tabla 6. Resultados Corridas Primera Etapa en Batch $200{ }^{\circ} \mathrm{C}$, 625 RPM, >26. 5 bar.

\begin{tabular}{|c|c|c|c|c|}
\hline Catalizador & Donante & $\begin{array}{c}\text { FA/ } \\
\text { Donante }\end{array}$ & $\begin{array}{l}\text { Área } \\
\text { [mV.s] }\end{array}$ & $\% \mathrm{H}_{2}$ \\
\hline 1 \% Pt/USY (CBV 712) & Etanol $80 \%$ & $1 \mathrm{mg} / \mathrm{g}$ & 2.806 & 0.43 \\
\hline $1 \%$ Pt/USY (CBV 720) & Etanol $80 \%$ & $1 \mathrm{mg} / \mathrm{g}$ & 0.139 & 0.02 \\
\hline $1 \%$ Pt/USY (CBV 780) & Etanol $80 \%$ & $1 \mathrm{mg} / \mathrm{g}$ & 6.375 & 0.96 \\
\hline $5 \% \mathrm{Pd} / \mathrm{C}$ & Etanol $80 \%$ & $0.0015 \mathrm{~m}$ & 3.401 & 0.52 \\
\hline $5 \% \mathrm{Pd} / \mathrm{Al} 203$ & Etanol $80 \%$ & $0.0015 \mathrm{~m}$ & 0.593 & 0.09 \\
\hline $5 \% \mathrm{Pt} / \mathrm{Al} 203$ & Etanol $99.9 \%$ & $0.0015 \mathrm{~m}$ & 0.569 & 0.09 \\
\hline
\end{tabular}


De acuerdo con los resultados de la segunda etapa, se observa una notable mejoría en comparación con la anterior debido al aumento de la carga de catalizador respecto al donante como se puede ver en la Tabla 7. Se observa que al aumentar la concentración del donante y de la fase activa el porcentaje de producción de hidrogeno aumenta. En este caso se resalta el escenario de fórmico / catalizador $5 \% \mathrm{Pd} / \mathrm{C}$ y el del etanol/ $5 \% \mathrm{Pt} / \mathrm{A} 2 \mathrm{IO} 3$.

Tabla 7. Resultados Corridas Segunda Etapa en Batch $200{ }^{\circ} \mathrm{C}$, 625 RPM.

\begin{tabular}{|c|c|c|c|c|}
\multicolumn{1}{c|}{ Catalizador } & Donante & $\begin{array}{c}\text { FA/ } \\
\text { Donante }\end{array}$ & $\begin{array}{c}\text { Área } \\
{[\mathrm{mV} . \mathrm{s}]}\end{array}$ & $\% \mathrm{H}_{2}$ \\
\hline $5 \% \mathrm{Pd} / \mathrm{C}$ & $\begin{array}{c}\text { Fórmico } 99.6 \% \\
(26.5 \mathrm{M})\end{array}$ & $0.003 \mathrm{~m}$ & 2.139 & 0.33 \\
\hline $5 \% \mathrm{Pd} / \mathrm{C}$ & Etanol $2 \mathrm{M}$ & $0.027 \mathrm{~m}$ & 5.685 & 0.86 \\
\hline $1 \% \mathrm{Pt} /$ Zeolitas USY & Etanol $0.45 \mathrm{M}$ & $0.150 \mathrm{~m}$ & 10.26 & 1.53 \\
\hline $5 \% \mathrm{Pt} / \mathrm{Al} 2 \mathrm{O} 3$ & Etanol $1 \mathrm{M}$ & $0.150 \mathrm{~m}$ & 58.641 & 7.80 \\
\hline $5 \% \mathrm{Pd} / \mathrm{C}$ & Fórmico $2 \mathrm{M}$ & $0.150 \mathrm{~m}$ & 85.904 & 10.83 \\
\hline
\end{tabular}

Para la tercera etapa se obtuvieron notablemente mayores atmosferas de hidrógeno que en las dos anteriores, como se puede apreciar en la Tabla 8.

Tabla 8. Resultados Corridas Tercera Etapa en Batch $200{ }^{\circ} \mathrm{C}$, 625 RPM.

\begin{tabular}{|c|c|c|c|c|}
\hline Catalizador & Donante & $\begin{array}{c}\text { Área máx } \mathrm{H}_{2} \\
{[\mathrm{mV} \text {.s] }}\end{array}$ & $\% \mathrm{H}_{2}$ & $\begin{array}{l}\text { Otros } \\
\text { Gases }\end{array}$ \\
\hline $5 \% \mathrm{Pd} / \mathrm{C}$ & $\begin{array}{c}\text { Ácido fórmico 99.6\%, } \\
0.022 \text { m }\end{array}$ & 241.177 & 35.9 & $\mathrm{CO}$ \\
\hline $5 \% \mathrm{Pt} / \mathrm{C}$ & $\begin{array}{c}\text { Ácido fórmico 99.6\%, } \\
0.007 \text { m }\end{array}$ & 215.302 & 30.4 & $\mathrm{CO}$ \\
\hline $5 \% \mathrm{Pt} / \mathrm{C}$ & $\begin{array}{c}\text { Ácido fórmico 30\%, } \\
0.007 \mathrm{~m}\end{array}$ & 85.670 & 10.7 & $\mathrm{CO}$ \\
\hline $5 \% \mathrm{Pt} / \mathrm{C}$ & Etanol 99.9\% $0.007 \mathrm{~m}$ & 23.572 & 3.4 & $\mathrm{CO}, \mathrm{CH}_{4}$ \\
\hline $5 \% \mathrm{Pt} / \mathrm{C}$ & Etanol 30\%, $0.007 \mathrm{~m}$ & 44.234 & 5.4 & $\mathrm{CH}_{4}$ \\
\hline $5 \% \mathrm{Pt} / \mathrm{C}$ & $\begin{array}{l}\text { Ácido fórmico 30\%, } \\
\text { iso-octano, } 0.007 \text { m }\end{array}$ & 193.300 & 26.0 & $\begin{array}{c}\mathrm{CO}, \mathrm{CH}_{4^{\prime}} \\
\text { otro }\end{array}$ \\
\hline $5 \% \mathrm{Pd} / \mathrm{C}$ & $\begin{array}{l}\text { Ácido fórmico 30\%, } \\
\text { heptano, } 0.014 \text { m }\end{array}$ & 249.938 & 37.9 & $\mathrm{CO}$ \\
\hline $5 \% \mathrm{Pd} / \mathrm{C}$ & $\begin{array}{l}\text { Ácido fórmico 30\%, } \\
\text { hexano, } 0.021 \mathrm{~m}\end{array}$ & 234.001 & 34.3 & $\mathrm{CO}$ \\
\hline $5 \% \mathrm{Pt} / \mathrm{C}$ & $\begin{array}{c}\text { Ácido fórmico 99.6\%, } \\
0.007 \text { m }\end{array}$ & 252.325 & 38.4 & $\mathrm{CO}$ \\
\hline $5 \% \mathrm{Pt} / \mathrm{C}$ & $\begin{array}{c}\text { Ácido Fórmico 5\%, } \\
0.007 \text { m }\end{array}$ & 12.400 & 1.9 & $\mathrm{CO}$ \\
\hline
\end{tabular}

Se observa que las relaciones catalizador/donante son menores que los de a segunda etapa, sin embargo los tiempos de muestreo fueron mayores, lo que da paso a una mayor conversión y por ende a un mejoramiento de la cantidad de hidrógeno generado. El emplear el ácido fórmico puro o diluido en solventes orgánicos mejora la generación de hidrógeno, la catálisis el Pt/C es levemente superior a la del Pd/C y no es necesario trabajar con relaciones mayores a $0.07 \mathrm{~m}$ pues no se observa un cambio significativo. El cromatograma presentado en la Figura 3 permite establecer el área y así el porcentaje de hidrógeno generado como se observa en el primer pico, el cual está invertido debido a que el hidrógeno tiene una menor conductividad térmica que el carrier, en este caso el helio.

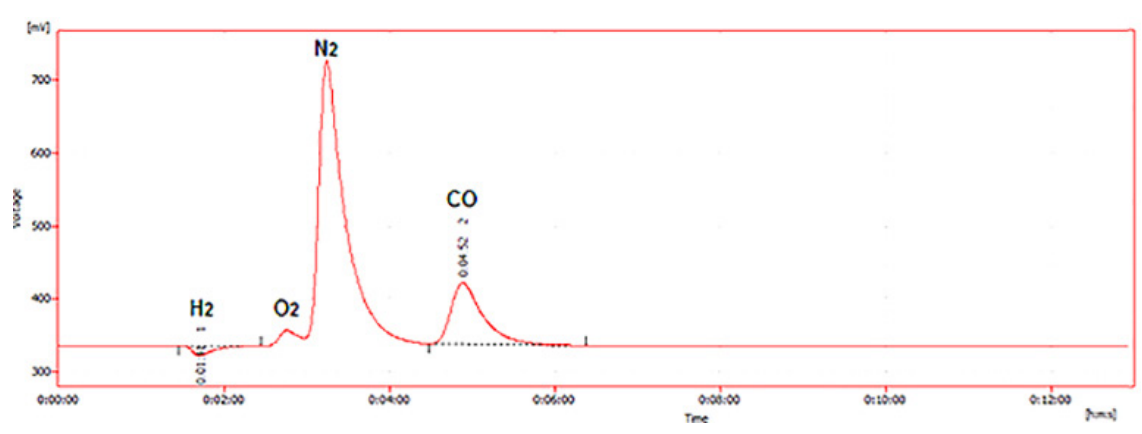

Figura 3. Cromatograma para la muestra gaseosa del ensayo ácido fórmico $30 \%$, con heptano y $5 \% \mathrm{Pd} / \mathrm{C}$.

\section{Ensayos HP DSC}

Los catalizadores de mejor comportamiento en las anteriores pruebas (5\% Pd/C, $5 \% \mathrm{Pt} / \mathrm{C}$ y $1 \% \mathrm{Pt} / \mathrm{CBV}$ 780) fueron evaluados con etanol y ácido fórmico. En la Figura 4 se puede observar de manera comparativa los termogramas para la descomposición del etanol, en los tres casos se observa un pico endotérmico con el catalizador de $5 \% \mathrm{Pt} / \mathrm{C}$, a una temperatura alrededor de los $90^{\circ} \mathrm{C}$; mientras que con los otros dos catalizadores ocurre cerca de los $205^{\circ} \mathrm{C}$. Aparentemente se ve una tendencia hacia un pico exotérmico cuando se emplea $5 \% \mathrm{Pt} / \mathrm{C}$ y el sistema sobrepasa los $190{ }^{\circ} \mathrm{C}$.

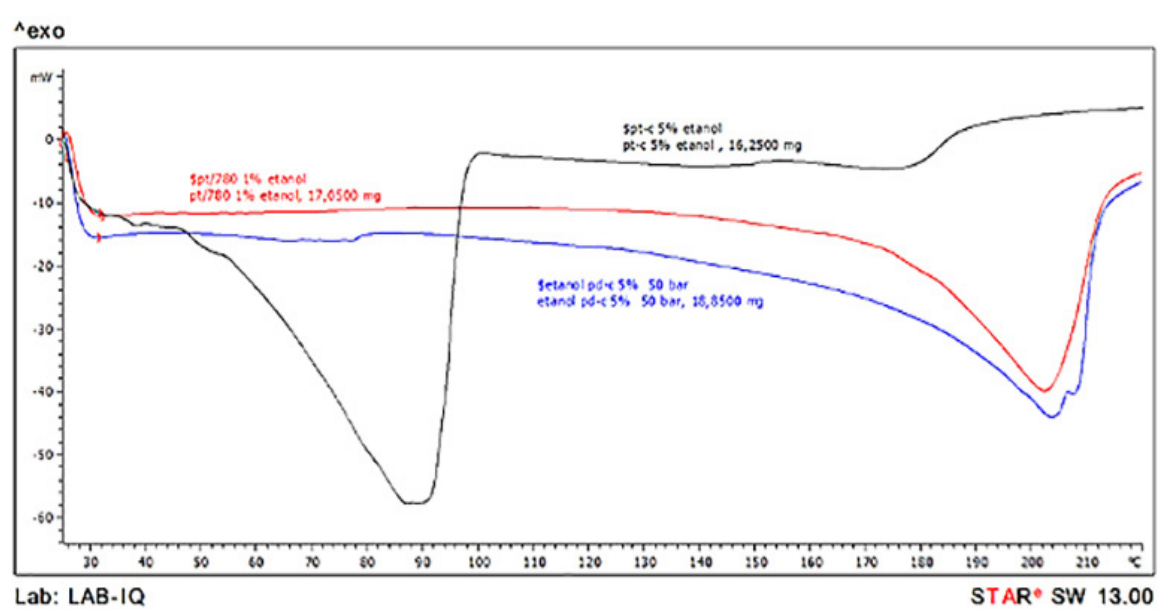

Figura 4. Termograma DSC HP para pruebas con etanol a 50 bar $\mathrm{N}_{2}, 10^{\circ} \mathrm{C} / \mathrm{min}$.

La Figura 5 muestra la descomposición del ácido fórmico de manera comparativa con los tres cataliza- 
dores evaluados. Cuando se emplea el catalizador de $1 \%$ Pt/CBV 780 se observa un pico exotérmico alrededor de los $100{ }^{\circ} \mathrm{C}$ lo que indica una descomposición del mismo, mientras que el pico endotérmico se encuentra en temperaturas cercanas a los $240{ }^{\circ} \mathrm{C}$. En el caso de $5 \% \mathrm{Pt} / \mathrm{C}$ se ve ven dos pequeños picos exotérmicos entre 40 y $60{ }^{\circ} \mathrm{C}$, y el endotérmico cercano a los $200{ }^{\circ} \mathrm{C}$. Finalmente en el caso del 5\%Pd/C no se observa un pico exotérmico, sino un pico endotérmico alrededor de los $220^{\circ} \mathrm{C}$.

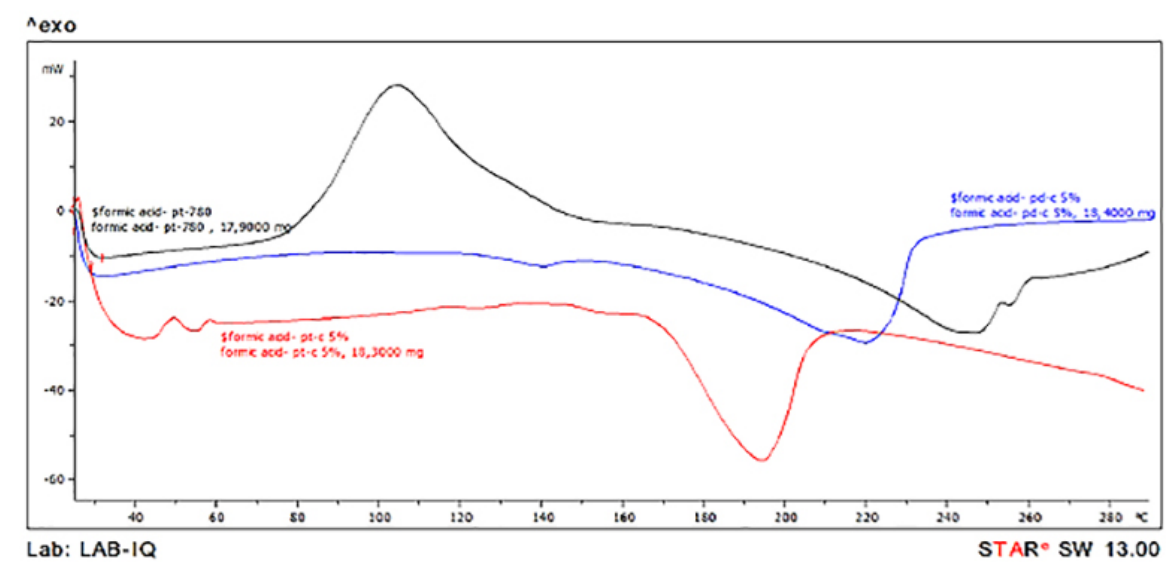

Figura 5. Termograma DSC HP para pruebas con ácido fórmico a 50 bar $\mathrm{N}_{2}, 10^{\circ} \mathrm{C} / \mathrm{min}$.

El análisis de composición de hidrógeno de las muestras gaseosas para el caso del ácido fórmico indican una mayor presencia en el caso del $5 \% \mathrm{Pt} / \mathrm{C}$ $(0.61 \%)$, respecto al $1 \% \mathrm{Pt} / \mathrm{C}(0.41 \%)$ y al $5 \% \mathrm{Pd} / \mathrm{C}$ $(0.15 \%)$

\section{CONCLUSIONES}

El algoritmo multicriterio MACBETH permitió identificar y elegir donantes óptimos para el proceso de deshidrogenación, mostrando que las mejores familias para la generación hidrógeno in situ sostenible de son: los alcoholes, polioles y ácidos carboxílicos.

A los principales exponentes de cada una de estas familias se les realizó un análisis de factibilidad termodinámica para la reacciones catalíticas de deshidrogenación, de esta manera se evaluaron los compuestos biodonantes de hidrógeno; dentro del conjunto construido de candidatos se eligieron el ácido fórmico y el etanol. Ambos compuestos cumplieron criterios técnicos, energéticos, económicos y productivos. Al realizar la evaluación de dichos donantes modificando las condiciones del catalizador el ácido fórmico presentó una leve ventaja, puesto que éste no satura el sistema de hidrogeniones que envenenen al catalizador.

De acuerdo a las pruebas realizadas, los ensayos realizados con ácido fórmico al 99.6 \% empleando como catalizador $5 \%$ Pt/C, en una relación de $7 \mathrm{mmol}$ de Pt por cada kg de ácido fórmico, fueron los que presentaron mejores resultados hacia la producción de hidrogeno. El comportamiento del sistema 5 \% Pd/C es semejante pero requiere de mayor carga del mismo respecto al fórmico. El sistema de ácido fórmico con 1 \% Pt/CBV 780 también presentó buen comportamiento por lo cual se sugiere una segunda evaluación. Aun cuando el sistema que emplea ácido fórmico genera más hidrógeno que el que emplea etanol, el producto líquido remanente presenta un valor ácido muy alto lo cual puede ser un inconveniente para el tratamiento de subproductos.

\section{AGRADECIMIENTOS}

A la Dirección de Investigación y Extensión de la Sede de Bogotá y a la Vicedecanatura de Investigación y Extensión de la Facultad de Ingeniería, ambas de la Universidad Nacional de Colombia, por el financiamiento y gestión para la ejecución de recursos (proyecto de código 37622 de Hermes), según lo otorgado por la Convocatoria Nacional para Proyectos de Fortalecimiento de la Investigación, Creación e Innovación 2016-2018 (segundo corte) de la Universidad Nacional de Colombia.

\section{REFERENCIAS}

[1] A. Toledano, L. Serrano, J. Labidi, A. Pineda, A. M. Balu, and R. Luque, "Heterogeneously Catalysed Mild Hydrogenolytic Depolymerisation of Lignin Under Microwave Irradiation with Hydrogen-Donating Solvents," ChemCatChem, vol. 5, no. 4, pp. 977-985, 2013.

[2] G. T. Austin, Manual de Procesos Químicos en la Industria, 1a (En Esp. México, 1988.

[3] V. Martínez-Merino, M. J. Gil, and A. Cornejo, "Biomass Sources for Hydrogen Production," in Renewable Hydrogen Technologies, Elsevier, 2013, pp. 87-110.

[4] L. M. Gandía, G. Arzamendi, and P. M. Diéguez, "Renewable Hydrogen Energy," in Renewable Hydrogen Technologies, Elsevier, 2013, pp. 1-17.

[5] I. Gandarias, S. G. Fernández, M. El Doukkali, J. Requies, and P. L. Arias, "Physicochemical Study of Glycerol Hydrogenolysis Over a Ni-Cu/Al203 Catalyst Using Formic Acid as the Hydrogen Source," Top. Catal., vol. 56, no. 11, pp. 995-1007, 2013. 
[6] M. J. Gilkey and B. Xu, "Heterogeneous Catalytic Transfer Hydrogenation as an Effective Pathway in Biomass Upgrading," ACS Catal., vol. 6, no. 3, pp. 14201436, 2016.

[7] I. Gandarias, P. L. Arias, J. Requies, M. El Doukkali, and M. B. Güemez, "Liquid-phase glycerol hydrogenolysis to 1,2-propanediol under nitrogen pressure using 2-propanol as hydrogen source," J. Catal., vol. 282, no. 1, pp. 237-247, 2011.

[8] E. Furimsky, "Hydroprocessing challenges in biofuels production," Catal. Today, vol. 217, pp. 13-56, 2013.

[9] X. Jin, "Catalytic Conversion of Biomass-Derived Polyols to Value-Added Chemicals : Catalysis and Kinetics Xin Jin Catalytic Conversion of Biomass-Derived Polyols to Value-Added Chemicals : Catalysis and Kinetics," 2014.

[10] K. Hwang, I. Choi, H. Choi, J. Han, K. Lee, and J. Lee, "Bio fuel production from crude Jatropha oil; addition effect of formic acid as an in-situ hydrogen source," FUEL, vol. 174, pp. 107-113, 2016.

[11] Y. Yang, Q. Wang, H. Chen, and X. Zhang, "Enhancing selective hydroconversion of $\mathrm{C} 18$ fatty acids into hydrocarbons by hydrogen-donors," FUEL, vol. 133, pp. 241-244, 2014.
[12] M. M. Ramirez-Corredores, "Pathways and Mechanisms of Fast Pyrolysis: Impact on Catalyst Research," Role Catal. Sustain. Prod. Bio-Fuels Bio-Chemicals, pp. 161-216, 2013.

[13] M. Kleinert, J. R. Gasson, and T. Barth, "Optimizing solvolysis conditions for integrated depolymerisation and hydrodeoxygenation of lignin to produce liquid biofuel," J. Anal. Appl. Pyrolysis, vol. 85, no. 1-2, pp. 108-117, 2009.

[14] K. Jacobson, K. C. Maheria, and A. Kumar Dalai, "Bio-oil valorization: A review," Renew. Sustain. Energy Rev., vol. 23, pp. 91-106, 2013.

[15] O. Y. Suárez Palacios, "Producción y Modelamiento de Gliceril-esteres como plastificantes del PVC," 2011.

[16] X. Liu, S. Li, Y. Liu, and Y. Cao, "Formic acid: A versatile renewable reagent for green and sustainable chemical synthesis," Chinese J. Catal., vol. 36, no. 9, pp. 1461-1475, 2015.

[17] F. Jin, J. Yun, G. Li, A. Kishita, K. Tohji, and H. Enomoto, "Hydrothermal conversion of carbohydrate biomass into formic acid at mild temperatures," Green Chem., vol. 10, no. 6, pp. 612-615, 2008. 


\title{
HIDROGENACIÓN DE ACEITE DE PALMA POR TRANSFERENCIA CATALÍTICA
}

\author{
Mayorga Betancourt, Manuel Alejandro ${ }^{12}$ \\ Castellanos Niño, Carlos Julio ${ }^{1}$ \\ Albarracín Norena, Ana María ${ }^{1}$ \\ Suarez Palacios, Oscar Yesid ${ }^{1}$ \\ Cadavid Estrada, Juan Guillermo ${ }^{1}$ \\ Narváez Rincón, Paulo Cesar ${ }^{1}$

\begin{abstract}
1 Universidad Nacional de Colombia, Departamento de Ingeniería Química, Grupo de Investigación en Procesos Químicos y Bioquímicos de Materiales y Energía, GIATME mamayorgab@unal.edu.co
\end{abstract} \\ 2 Universidad ECCI, Grupo de Investigación en Aprovechamiento Tecnológico
}

\section{ÁREA TEMÁTICA}

Biomasa, Bioenergía y Biocombustibles

\section{RESUMEN}

La producción mundial de biocombustibles ha aumentado en las últimas décadas dado que su utilización permite mitigar la huella de carbono y disminuir la dependencia hacia los combustibles fósiles. Los biocarburantes que pueden reemplazar el diésel fósil son: el biodiesel, el diésel renovable o el diésel Fischer-Tropsch, actualmente, el biodiésel (éster) es el más producido en todo el mundo; sin embargo, presenta inconvenientes de estabilidad de almacenamiento, problemas de mezclado con el diésel fósil e incompatibilidad mecánica. El diésel renovable (biodiésel no éster) carece de estas desventajas, pero su producción requiere el manejo de gas hidrógeno en condiciones de alta presión, lo que plantea un alto grado de peligrosidad en el almacenamiento de esta materia prima, dado el carácter combustible del hidrogeno. Como alternativa para eliminar este problema se plantea la generación in situ de hidrógeno a partir de diferentes donantes, lo que permitirá la producción de diésel renovable de forma segura empleando como materias primas aceite de palma, el donante elegido y un catalizador que realice la deshidrogenación del donante y la transesterificación de los aceites Se evaluaron varios catalizadores de metales nobles como Pt y Pd soportados en carbono, alúmina y zeolita. A través de análisis termogravimétricos (DSC, TGA y STA) y ensayos en un reactor Batch a $200{ }^{\circ} \mathrm{C}, 50$ bar tanto en una atmósfera reductora (hidrógeno) como inerte (nitrógeno) con el donante en una relación de $7 \mathrm{mmol}$ de fase activa por kg del mismo. Se encontró que los catalizadores de $\mathrm{Pd} / \mathrm{C}$, Pt/C y Pt/USY generan la cantidad requerida de hidrógeno a partir del ácido fórmico para alcanzar la conversión y selectividad adecuadas.

Palabras claves: Diésel renovable; Transferencia catalítica; hidrogenación, aceite de palma; Generación de hidrógeno in situ 


\section{INTRODUCCIÓN}

En el marco de los tratados y convenios mundiales para la reducción de emisiones de gases de efecto invernadero, la limitación de los recursos fósiles y la crisis energética, la investigación en procesos para la obtención de biocombustibles han mejorado gradualmente su sostenibilidad.

Para el reemplazo del diésel fósil, el primer paso fue producir esteres de aceites, empleando como materia prima aceite vegetal (biomasa) en lugar de crudo para producir biodiésel éster a través de una transesterificación [1],[2],[3]. Este proceso ocurre bajo condiciones moderadas de temperatura y presión, pero el producto obtenido tiene una muy limitada compatibilidad con los motores convenciones debido a que su naturaleza química (esteres grasos con oxígeno) tiene propiedades funcionales diferentes a la del diésel (hidrocarburos sin oxígeno) [4],[5].

Para contrarrestar los efectos negativos del biodiesel éster la investigación se centró en generar un biodiesel con hidrocarburos saturados empleando hidrotratamiento de aceites vegetales a través de un proceso catalítico [6],[7],[8],[9],[10],[11]. Este proceso emplea gas hidrógeno a alta presión con un consumo intensivo de energía, donde el 90 \% del hidrógeno proviene de fuentes fósiles [12],[13],[14].

Para que el proceso de biodiésel por hidrotratamiento sea lo más sostenible posible, reduciendo el consumo energético y eliminando las dificultades asociadas al manejo de hidrógeno gaseoso es posible reducir la presión de operación; Esta condición requiere generar el hidrogeno in situ para conservar las condiciones de reacción [15],[16]. La generación de hidrogeno puede lograrse mediante reformando en fase acuosa (APR) o mediante hidrogenación por transferencia catalítica $(\mathrm{CTH})$; la primera opción requiere la presencia de agua en condiciones intensas de temperatura y presión; mientras que la segunda requiere una sustancia que dona hidrógeno a un aceptor, es decir, un donante, generalmente un disolvente, que transfiere hidrógeno [17].

En el caso de CTH, el donante, que actúa como una fuente de hidrógeno, debe ser descompuesto catalíticamente y/o térmicamente en hidrógeno molecular, óxidos de carbono e hidrocarburos ligeros, para no confundirse con una simple deshidrogenación. Es deseable que dicho donante sea renovable, es decir sea plataforma o corriente de biorrefinería, en muchos casos se emplean donantes oxigenados como: alcoholes, aldehídos, cetonas y ácidos carboxílicos (por ejemplo, metanol, etanol, ácido fórmico y glicerol), incluidos los compuestos aromáticos condensados, algunos alcanos y aminas [18]; estos disolventes son relativamente más baratos que el hidrógeno molecular [19].

La fase activa del catalizador utilizado en estos procesos es generalmente un metal soportado, que puede ser un metal noble reducido, un sulfuro (o un fosfuro o carburo) metálico o bimetálico. El soporte más utilizado en alúmina o carbono activado. Los metales nobles son los más fáciles de preparar (a diferencia de los fosfuros y los carburos metálicos), y no sufren de lixiviación (como los sulfuros bimetálicos). Para la producción de biodiésel no éster, de tipo diésel renovable, la desoxigenación del aceite de palma con generación de hidrógeno in situ requiere un catalizador que sea capaz de transferir hidrógeno del donante al triglicérido para que sea hidrogenado, se someta a hidrogenólisis y finalmente sea desoxigenado.

Hwang et al. (2016) [20] estudiaron el efecto de la adición de una solución al 30 \% de ácido fórmico, como fuente de hidrógeno para la producción de biocombustible a partir de aceite crudo de jatropha por desoxigenación catalítica sobre $\mathrm{Pd} / \mathrm{C}$ en un reactor por lotes. Se encontró que la mezcla reactiva con ácido fórmico generó una mayor conversión del aceite $(99.5 \%$ ) y mayor selectividad (97\%) hacia hidrocarburos lineales (principalmente C15 a C17), que en los casos en los que no hubo mezcla o se adicionó agua. Adicionalmente al emplear ácido fórmico se tuvo una mayor resistencia a la desactivación inicial que sufre el catalizador.

Aun cuando en años recientes se han llevado a cabo un gran número de investigaciones para desarrollar el proceso de hidrotratamiento, la gran mayoría se han enfocado en el efecto de nuevos catalizadores y parámetros sobre el proceso de desoxigenación [21]. Poca atención se ha puesto en el efecto de los aditivos y solventes sobre el hidroprocesamento de aceites, especialmente en la ruta de la HDO [22].

Es de esperarse que el uso de donantes de hidrógeno en el hidrotratamiento de aceite de palma, presente los siguientes beneficios con respecto a los procesos anteriores: facilitará el empleo seguro del hidrógeno al generarlo in situ, ya que el origen, la disponibilidad y manejo de dicho gas es un aspecto crítico para que el hidroprocesamiento sea sostenible; mejorará la selectividad hacia la HDO; moderará las condiciones de operación (presión) y aumentará la estabilidad del catalizador usado [23]. 


\section{MATERIALES Y MÉTODOS}

\section{Materiales}

El aceite de palma RBD (Refinado, Blanqueado y Desodorizado) grado comestible fue provisto por Integrasas S.A.S (Bogotá, D.C. Colombia). El índice de acidez de este aceite se determinó como $0.19 \mathrm{mg}$ $\mathrm{KOH} / \mathrm{g}$ de acuerdo a la ASTM D-664. El alcohol etílico $(99.9 \%$ v/v) y el ácido fórmico (99.6 \%) en grado analítico fueron obtenidos de ITW Reagents- PanReac AppliChem (Darmstadt, Germany). Los gases de $\mathrm{N}_{2}$ $\mathrm{e}_{2}$ grado 5.0 fueron proporcionados por Linde (Bogotá, D.C., Colombia). Los estándares de referencia que incluye el n-hexano, n-pentadecano, n-hexadecano, n-heptadecano, n-octadecano y la tripalmitina de pureza mayor al 99, fue comprada de Sigma Aldrich - Merck (St Louis, MO). Mientras que la tricaprina usada como estándar interno fue obtenida desde Fluka (Buchs, Switzerland)

\section{Catalizadores}

Los catalizadores comerciales adquiridos a Sigma-Aldrich fueron: 5 \% Pd/C (Referencia 205680), $5 \%$ $\mathrm{Pd} / \mathrm{Y}-\mathrm{Al}_{2} \mathrm{O}_{3}$ (Ref. 761176), 1 \% Pt/C (Ref. 205923), 3 \% Pt/C (Ref. 237558), 5 \% Pt/C (Ref. 80982), 10 \% Pt/C

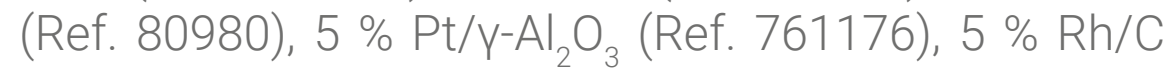
(Ref. 206164), $5 \%$ Rh/ $/{ }^{-} \mathrm{Al}_{2} \mathrm{O}_{3}$ (Ref. 83720), $5 \% \mathrm{Ru} / \mathrm{C}$ (Ref. 84031) y $5 \%$ Ru/Y- $-\mathrm{Al}_{2} \mathrm{O}_{3}$ (Ref. 84032).

Las zeolitas USY (CBV-780), H- $\beta$ (cp811c-300) y ZSM-5 (CBV-3024e) fueron provistas por Zeolyst International. La zeolita USY tiene una humedad de $4.37 \%$, la $\mathrm{H}-\beta$ de $8.19 \%$ y la ZSM- 5 de $5.57 \%$.

El catalizador de $1 \%$ de platino soportado en cada una de las tres zeolitas fue preparado por impregnación húmeda a partir de la sal de dicloruro de tetramino platino (II) $\left[\mathrm{Pt}\left(\mathrm{NH}_{3}\right)\right]_{4} \mathrm{Cl}_{2}$.

Estos catalizadores fueron activados a $200{ }^{\circ} \mathrm{C}$ durante 2 horas en una atmosfera reductora de $30 \%$ de $\mathrm{H}_{2} / \mathrm{N}_{2}$. El calentamiento se dio desde $20^{\circ} \mathrm{C}$ con una rampa de $2{ }^{\circ} \mathrm{C} / \mathrm{min}$.

\section{Procedimiento}

Las pruebas para evaluar el rendimiento de cada sistema catalítico (de catorce) con respecto a la desoxigenación del aceite de palma se llevaron a cabo en un analizador térmico simultáneo (STA). Ambos termogramas podrían obtenerse para el flujo de calor (calorimétrico, DSC) como masa (gravimétrico, TGA) al mismo tiempo para una atmósfera de hidrógeno (100 \%) a alta presión (50 bar) de $25^{\circ} \mathrm{C}$ a $290^{\circ} \mathrm{C}$ utilizando un calentamiento con una rampa de $10{ }^{\circ} \mathrm{C} / \mathrm{min}$. En un crisol de $40 \mu \mathrm{l}$ como muestra se colocaron $15 \mathrm{mg}$ de catalizador con $30 \mathrm{mg}$ de aceite de palma y en otro crisol $15 \mathrm{mg}$ de catalizador como referencia. Al final de la carrera se pesaron y analizaron los productos obtenidos por GC e IR.

De acuerdo con bibliografía previa, los sistemas catalíticos que presentaron un mejor rendimiento en la deshidrogenación de donantes fueron seleccionados para realizar una calorimetría diferencial de barrido a alta presión en el sistema HP DSC 1 Star Mettler Toledo. En un crisol de $100 \mu \mathrm{L}$ se colocaron el catalizador, el donante de hidrógeno (ácido fórmico o etanol) y el aceite de palma; para esto, las proporciones fueron de $7 \mathrm{mmol}$ de fase activa por kg de etanol o ácido fórmico y de 48.72 moles de donante por kg de aceite de palma, $200 \%$ en exceso porque la proporción de $\mathrm{H}_{2}$ /aceite debería ser de 3 a 5 veces más alta que la teórica requerida [24]; un exceso podría saturar la superficie ocupando todos los sitios activos y afectando la hidroconversión selectiva de los ácidos grasos [21].

Las condiciones de operación de la prueba fueron idénticas a las del STA, excepto en que en esta ultima la atmósfera se mantiene inerte. Cuando se emplea etanol como donante solo toma hasta $220^{\circ} \mathrm{C}$, mientras que la del ácido fórmico a hasta $280^{\circ} \mathrm{C}$, lo cual sucede por restricción de la presión de operación (50 bares)) para mantener la fase del solvente como líquida. Al final de la operación, se pesaron y analizaron los productos obtenidos.

Finalmente, los sistemas que al usar un donante en lugar de hidrógeno gaseoso mostraron un comportamiento similar en el termograma del DSC se escalaron; Para esto, se empleó un reactor discontinuo de $300 \mathrm{ml}$ (Figura 1), que puede presurizarse hasta 1000 psi y calentarse hasta $500{ }^{\circ} \mathrm{C}$, pero solo se cargaron $80 \mathrm{cc}$ garantizando una adecuada agitación. Las relaciones manejadas en el HP DSC se mantuvieron con una agitación magnética de 625 rpm y un tiempo de reacción de 8 h. Al final, la carga del reactor se pesó, se separó y se purificó para realizar un análisis de los gases generados. 


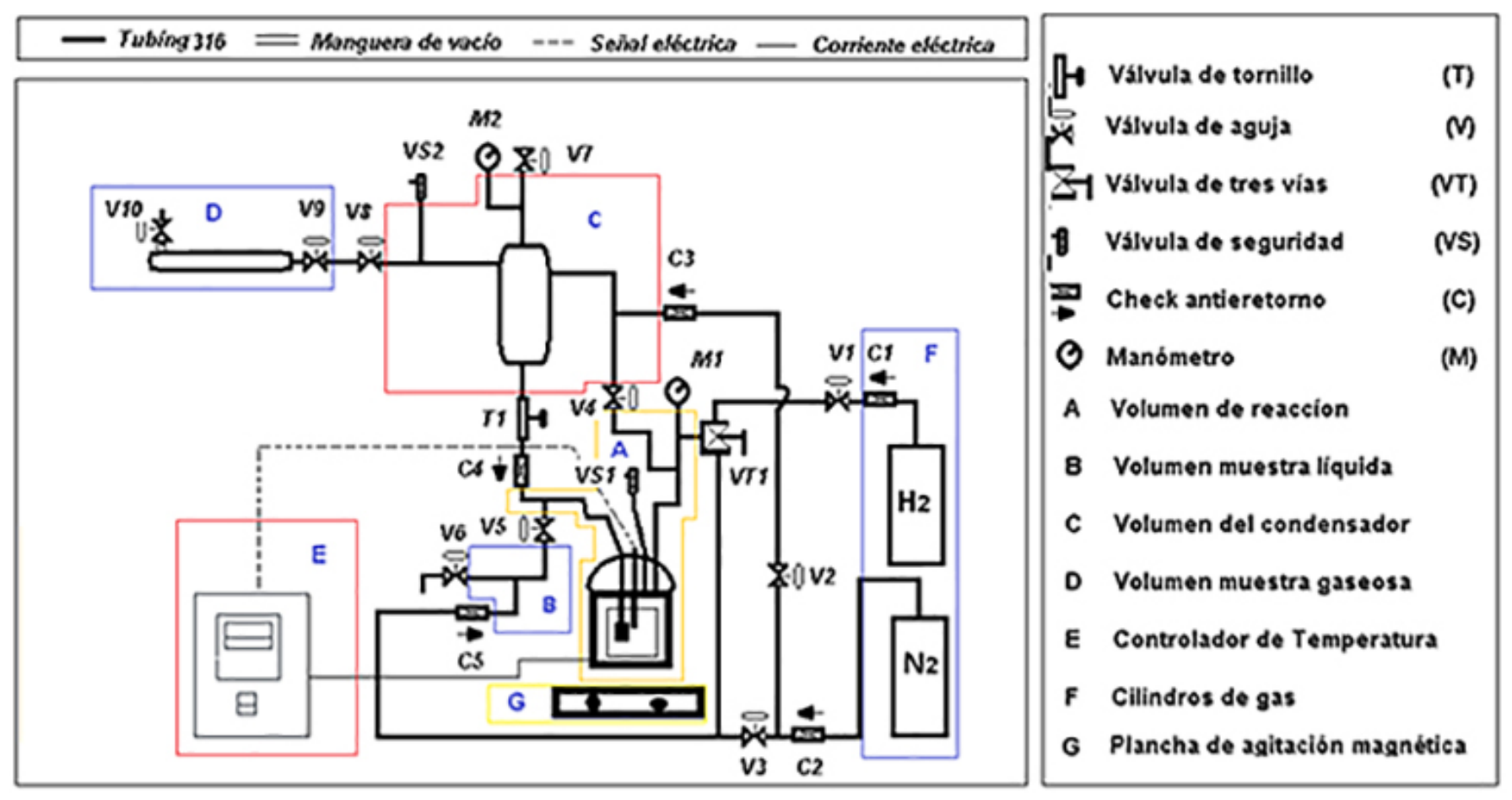

Figura 1. Sistema de Reacción.

El reactor fue cargado con una relación de masa tal que se garantice un exceso del $200 \%$ (3 veces la estequiométrica de $16.24 \mathrm{~mol} / \mathrm{kg}$ de aceite de palma) es decir de $48.72 \mathrm{~mol}$ de donante $/ \mathrm{kg}$ de aceite de palma o $2.24 \mathrm{~g}$ de donante/g de aceite de palma (ya que el etanol y el ácido fórmico tienen prácticamente la misma masa molar de $46 \mathrm{~g} / \mathrm{mol}$ ) se empleó una relación de catalizador con respecto al donante de $0.007 \mathrm{~mol}$ de fase activa por cada kg de donante.

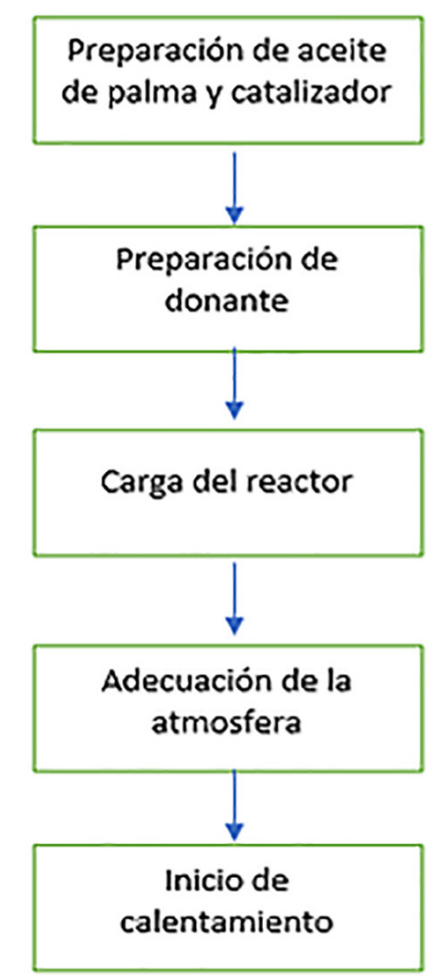

Figura 2. Arranque del Sistema

En la Figura 2, se presenta un esquema del arranque del sistema, donde cada una de las etapas se describe a continuación:
Preparación de aceite y catalizador: a temperatura ambiente, el aceite de Palma, se encuentra en estado sólido, por lo cual es necesario calentarlo hasta que se fusione y se procede a burbujear con nitrógeno durante un minuto. Después el aceite se envasó en un beaker para ponerlo en el congelador, de modo que vuelva a conservar una consistencia sólida. Cuando la mayor parte del aceite es sólida, se adiciona el catalizador y se ingresa nuevamente a la nevera para que todo el aceite solidifique.

Preparación de donante: El donante se midió volumétricamente con una probeta, en la cual es necesario burbujear nitrógeno

Cargar el reactor: es necesario cargar el vaso de borosilicato, allí introduce el agitador, el donante líquido y el aceite con el catalizador en estado sólido.

Adecuación de la atmosfera: El sistema general se purga 5 veces con nitrógeno (con una presión de 50 bar y desfogue.) Finalmente es necesario mantener una atmosfera de Nitrógeno con presión de 20 bar.

Inicio de calentamiento: se realizó calentamiento por medio de conducción mediante resistencia eléctrica, controlada con parámetros PID, (set point de 200 ${ }^{\circ} \mathrm{C}$.)

Cuando el sistema alcanza los $200{ }^{\circ} \mathrm{C}$, se activa la agitación y se inicia el tiempo de reacción de 8 horas.

Posteriormente es necesario desmontar el reactor una vez su temperatura ha disminuido hasta alcanzar temperatura ambiente. En la Figura 3 se muestra el diagrama de flujo de proceso que consta de las siguientes actividades: 
Toma de muestra gaseosa: se debe emplear el toma muestra del sistema para recolectar gas en una jeringa y de ese modo posteriormente realizar una cuantificación mediante análisis cromatográfico.

Apertura del reactor: Es necesario desfogar el sistema para que llegue a presión atmosférica y después realizar la apertura con el fin de sacar el vaso que contiene los productos obtenidos

Vaciar el condensador: Finalmentese realiza la purga del condensador para retirar el líquido que se hubiera evaporado en la reacción.

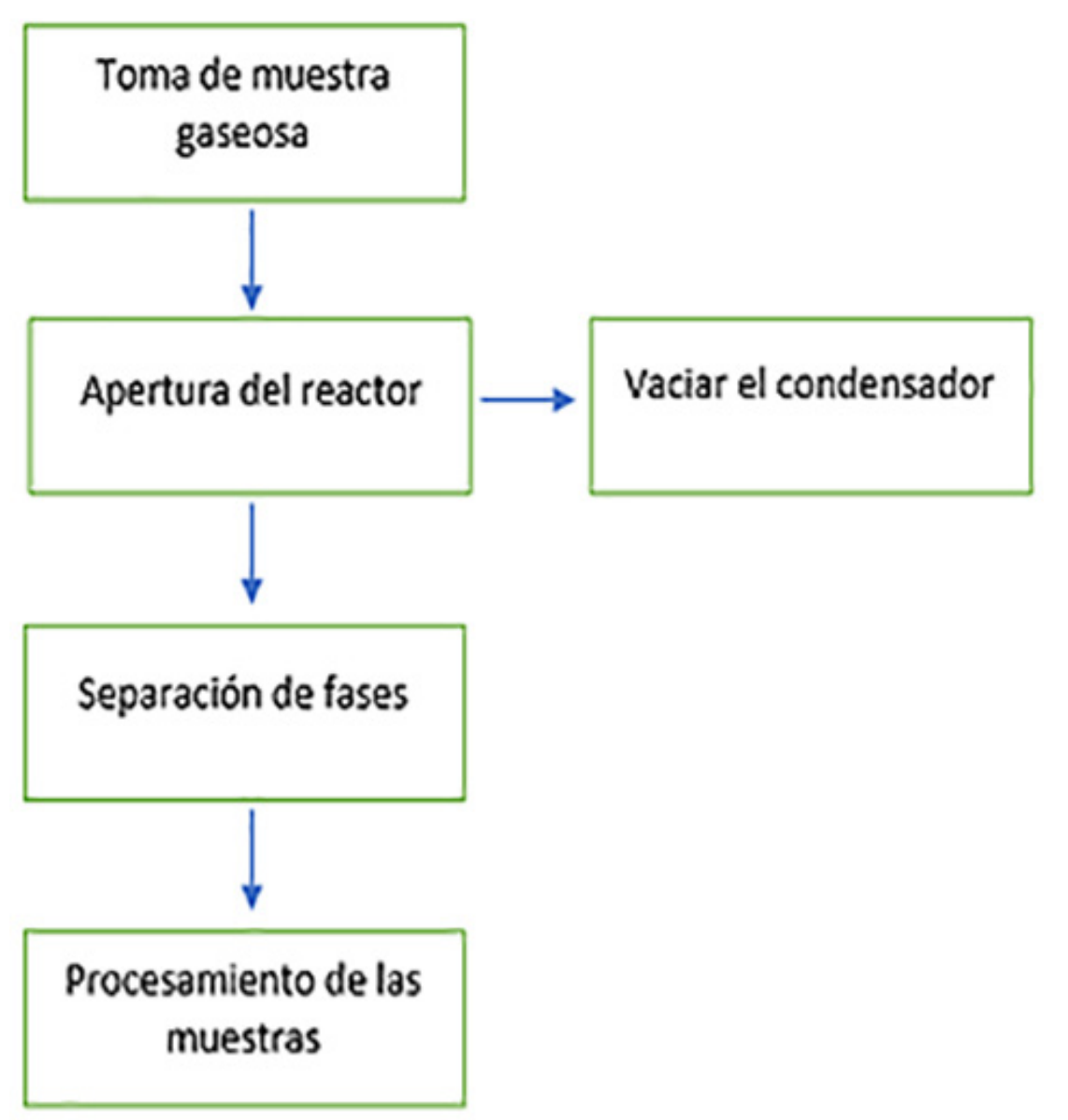

Figura 3. Desmonte del Sistema.

Separación de fases: Dentro del sistema se presentan fase liquida y sólida en diferentes etapas del proceso, las la fase sólida debe retirarse mediante una microespatula para de ese modo hacer una separación del remanente líquido.

Procesamiento de muestras: Es necesario realizar una separación del catalizador, contenido en las muestras, después se les mide acidez y con ello se decide la preparación que deben tener para realizar análisis cromatográfico.

El procedimiento y reactivos para separación de catalizador depende del tipo de catalizador y donante que se haya empleado, como se muestra en la Tabla 1.
Tabla 1. Separación del catalizador

\begin{tabular}{|c|c|c|c|}
\hline \multirow{2}{*}{ Catalizador } & \multirow{2}{*}{ Proceso } & \multicolumn{2}{|c|}{ Donante } \\
\cline { 3 - 4 } & Ácido fórmico & Etanol \\
\hline \multirow{4}{*}{ Pt/C } & $\begin{array}{c}\text { lavado de } \\
\text { muestras }\end{array}$ & agua & NA \\
\cline { 2 - 4 } & $\begin{array}{c}\text { separación de } \\
\text { catalizador }\end{array}$ & Etanol caliente & Etanol caliente \\
\hline \multirow{4}{*}{ Pd/C } & $\begin{array}{c}\text { lavado de } \\
\text { muestras }\end{array}$ & agua & NA \\
\cline { 2 - 4 } & $\begin{array}{c}\text { separación de } \\
\text { catalizador }\end{array}$ & Hexano caliente & Hexano caliente \\
\hline
\end{tabular}

La Figura 4 presenta el protocolo para el diagrama de flujo para realizar la preparación y alistamiento de las muestras, donde las operaciones requeridas se detallan más adelante.

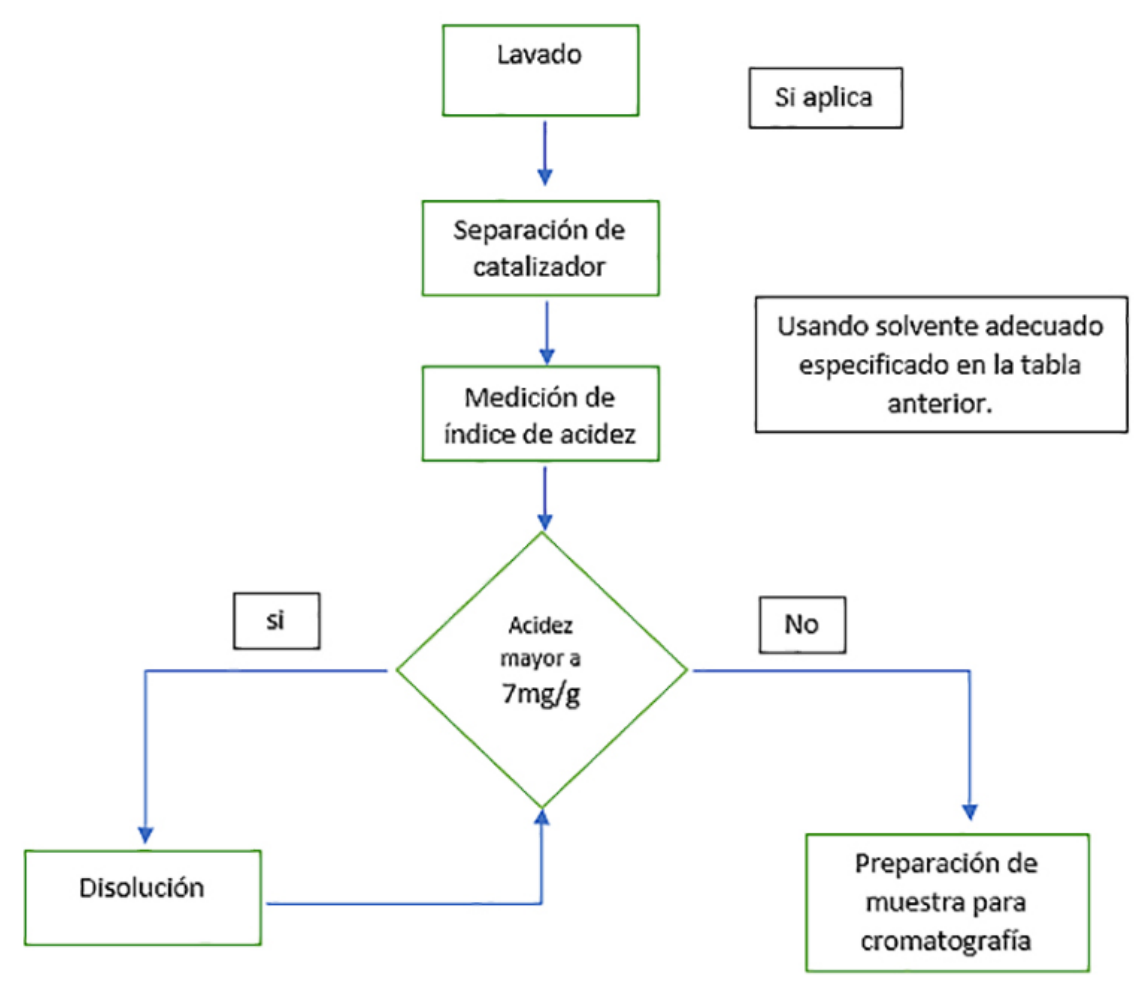

Figura 4. Preparación de muestras.

Lavado: el lavado se realiza para disminuir la acidez, por lo cual se le realiza a los productos de la reacción de ácido fórmico.

Separación del catalizador: Según el catalizador se realiza una separación con diferente solvente, pues el hexano genera solubilidad con el Pt/C y la grasa, con se genera una solución liquida de catalizador, grasa y solvente.

Medición de índice de acidez: Es necesario solubilizar la muestra tomada, esto se hace en un medio de etanol y se titula con un hidróxido de sodio dado que para pasar la muestra al cromatrografo se requiere un límite de acidez 


\section{Análisis}

Los productos obtenidos en el STA y DSC HP se separaron y se purificaron por filtración (filtro de 0.42 um) y centrifugación (6000 rpm por 10 minutos) utilizando n-hexano como disolvente.

Para analizar la presencia de compuestos oxigenados como alcoholes, aldehídos, cetonas y ácidos carboxílicos se empleó infrarrojo (IR) con el equipo Bruker. Para ver el contenido de hidrocarburos producidos como alcanos normales C-15 a C18, así como la conversión de aceite de palma, las muestras (líquidos y sólidos) se analizaron fuera de línea mediante un equipo de cromatografía de gases (CG) Agilent 6820 (Agilent Technologies Co. Ltd., Shanghai, China) con un detector de ionización de llama (FID), una precolumna de sílice fundida $(0,3 \mathrm{mx} 0,53 \mathrm{~mm})$ y una columna capilar de sílice fundida SUPELCO SGE HT-5 (12 mx 0,53 mm x 0,15 mm) (SGE International Pty. Ltd., Victoria, Australia). Se agregó tricaprina (estándar interno) y las muestras se almacenaron a $-2{ }^{\circ} \mathrm{C}$ usando un equipo equipado. Se inyectaron manualmente muestras de $1 \mu \mathrm{L}$. Después de $1 \mathrm{~min}$. de estabilización a $140^{\circ} \mathrm{C}$, la temperatura del horno se programó para aumentar de $140{ }^{\circ} \mathrm{C}$ a $380{ }^{\circ} \mathrm{C}$ a $20^{\circ} \mathrm{C} / \mathrm{min}$ y permanecer a $380^{\circ} \mathrm{C}$ durante $10 \mathrm{~min}$. El inyector fue de $350^{\circ} \mathrm{C}$, y el detector fue de $390{ }^{\circ} \mathrm{C}$. Cada carrera duró $23 \mathrm{~min}$. El gas portador fue nitrógeno con un caudal de $6 \mathrm{ml} / \mathrm{min}$. y una relación de división de 50: 1. Los flujos de $\mathrm{H}_{2}$ y aire seco fueron de 40 y $450 \mathrm{ml}$ / min. respectivamente. La adquisición y el procesamiento de datos se lograron con el programa Cerity (Agilent Technologies Co. Ltd., Shanghai, China).

En cuanto al análisis de gases, se hizo utilizando el cromatógrafo de la serie 5890 de Hewlett Packard (serie A). Para la identificación y cuantificación de gas de hidrógeno (además de $\mathrm{CO}, \mathrm{CH}_{4^{\prime}} \mathrm{C}_{2} \mathrm{H}_{4^{\prime}} \mathrm{N}_{2}$ y $\mathrm{O}_{2}$ ) se tiene un tamiz molecular de $5 \mathrm{~A}$ empaquetado en una columna (Tamiz de 80/100 moles Supelco 80/100 columna 10 'x 1/8 "SS - Acero inoxidable -) con detector de conductividad térmica (TCD). La adquisición y procesamiento de datos se realizó con el programa Clarity Lite. El gas portador fue helio con un flujo de $12 \mathrm{ml} / \mathrm{min}$. a 20 psi de presión. La temperatura del horno, del inyector y del detector es de $30^{\circ} \mathrm{C}, 100^{\circ} \mathrm{C}$ y $150^{\circ}$ Las muestras gaseosas a inyectar fueron de 0,1 ml (100 L). Para el dióxido de carbono, $\mathrm{CO}_{2}$, el equipo fue Hewlett Packard 5890 Serie II, con una columna Rt-QPLOT capilar (30 mx 0,53 $\mathrm{mm}$ ). Detector TCD. El gas portador es He a $16 \mathrm{~mL} / \mathrm{min}$.

La inyección y el detector fueron de $100{ }^{\circ} \mathrm{C}$ y $150^{\circ} \mathrm{C}$ respectivamente.

Aquellos catalizadores que cumplieron ambas funciones (generan hidrógeno del donante y desoxigenan el aceite) de manera exitosa con conversión y selectividad adecuadas, se caracterizaron mediante las siguientes técnicas: Difracción de rayos X (DRX); las áreas de superficie específica, los volúmenes de poros totales y la distribución del tamaño de los poros se midieron mediante una técnica de sorción de nitrógeno; la morfología y el tamaño de partícula de los catalizadores reducidos se examinaron mediante microscopía electrónica de barrido. Para los catalizadores soportados en zeolita, se realizó una prueba de acidez efectiva.

\section{RESULTADOS Y ANÁLISIS DE RESULTADOS}

\section{STA Vs. HP DSC}

Los catalizadores que tuvieron mejor selectividad y conversión en los ensayos del STA fueron el $5 \% \mathrm{Pd} / \mathrm{C}$ y 5 \% Pt/C (además de 1 \% Pt/CBV-780). Con estos se procedió a realizar ensayos en el HP DSC reemplazando el gas de hidrógeno por una atmósfera inerte de nitrógeno con un donante de hidrógeno, como ácido fórmico o etanol. Los termogramas mostraron el pico de fusión para el aceite de palma en la misma posición e intensidad que en la STA, pero los picos exotérmicos sufrieron un retraso en la temperatura como se puede ver en la Figura 5 para el 5 \% de Pd/C con fórmico ácido. El primer pico exotérmico atribuido a la hidrogenación antes de que ocurriera a $70{ }^{\circ} \mathrm{C}$ ahora ocurre ligeramente a $100^{\circ} \mathrm{C}$. Este retraso puede deberse primero al hecho de que el hidrógeno primero debe generarse y luego usarse en la reacción posterior, lo que genera un agotamiento de los sitios activos para llevar a cabo las hidrogenaciones. Las pruebas con etanol y $5 \%$ de catalizador de Pt/C mostraron una menor actividad con respecto a la hidrogenación, ya que en este caso los dos picos anteriores no son pronunciados.

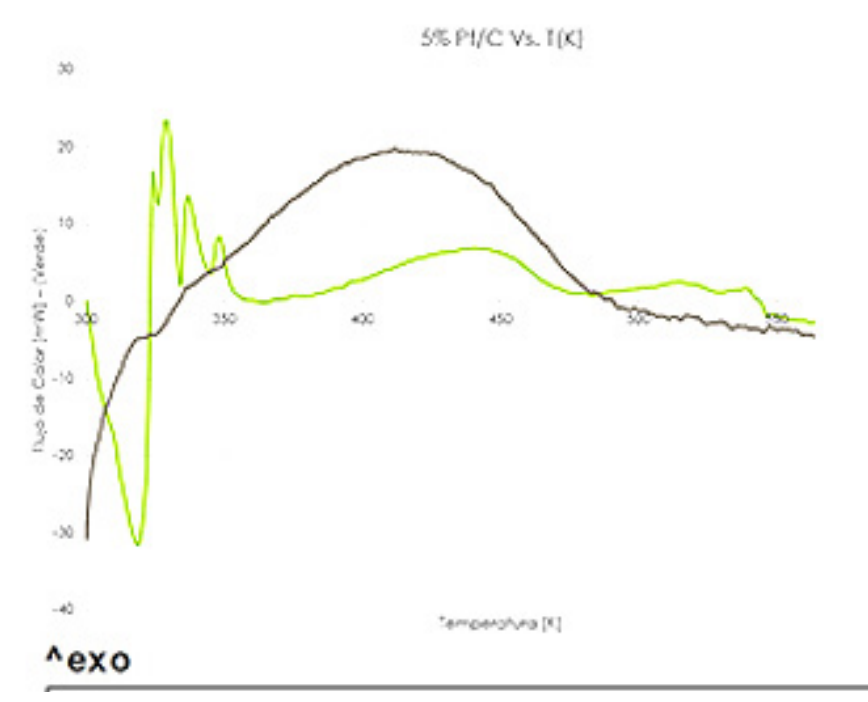

Figura 5. Termogramas de hidrotratamiento de aceite de palma con: $\mathrm{H}_{2}$ gaseoso en STA (arriba) y donantes -etanol y ácido fórmico- (abajo) en HP DSC, ambos para catalizadores de 5 \% Pt/C y $5 \% \mathrm{Pd} / \mathrm{C}$. 
El análisis de los productos con GC mostró en el último caso una baja selectividad a los hidrocarburos, alta conversión y muy alta producción de esteres etílicos de ácidos grasos (FAEE's) y alcoholes grasos como puede verse en la Figura 6, respecto al ensayo en el STA, aunque de menor intensidad. Esto se da porque se produce transeserificación entre los triglicéridos y el etanol, y porque la ruta para la HDO se da incompleta quedando en un intermedio como el alcohol graso por la carencia de hidrógeno o falta de tiempo de reacción. También se presenta un favorecimiento a la ruta de la descarbonilación.
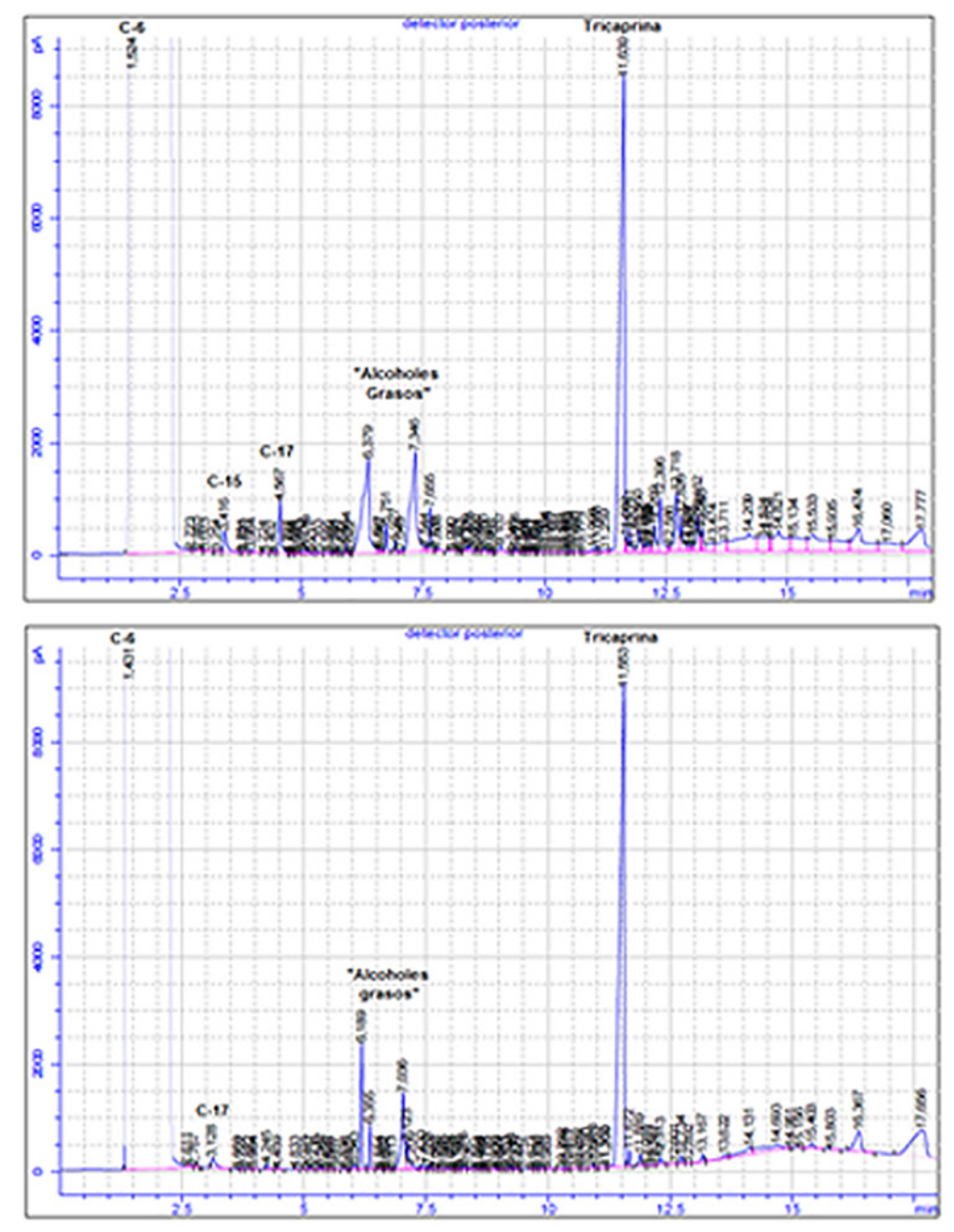

Figura 6. Cromatogramas de hidrotratamiento de aceite de palma con: $\mathrm{H}_{2}$ gaseoso - 5 \% Pt/C en STA (arriba) y ácido fórmico - 5\% Pd/C (abajo) en HP DSC.

El GC sobre la muestra de la fase gaseosa generada en el HP DSC muestra $0.37 \%$ de $\mathrm{H}_{2}$ para ácido fórmico con $5 \% \mathrm{Pd} / \mathrm{C}$ y $0.39 \%$ de $\mathrm{H}_{2}$ para etanol con $10 \% \mathrm{Pt} / \mathrm{C}$, para los cuales en ambos casos es similar.

\section{Pruebas en reactor Batch}

En los ensayos realizados con ácido fórmico hubo una producción notable de hidrógeno como se observa en los cromatogramas de muestras gaseosas (Figura 7), así como en el aumento registrado de alrededor del 80 \% en la presión autógena del sistema. El primer pico está de acuerdo con el hidrógeno y se invierte debido a su menor conductividad térmica con respecto al helio.
En orden, el resto de los picos son: oxígeno, nitrógeno y monóxido de carbono.

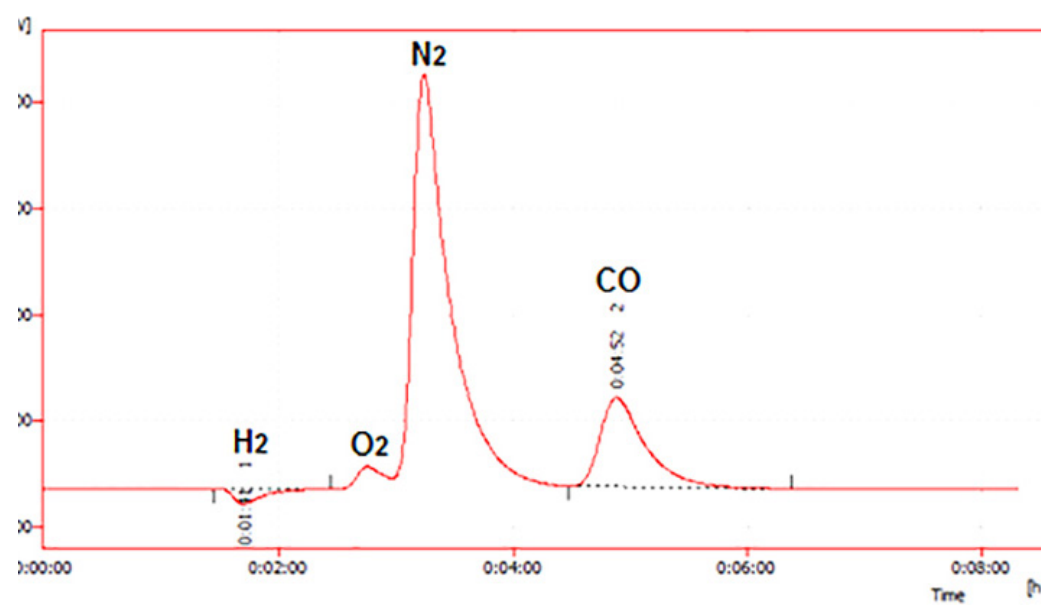

Figura 7. Cromatograma de hidrotratamiento in situ de aceite de palma con ácido fórmico y $5 \% \mathrm{Pd} / \mathrm{C}$.

En el caso de usar etanol como donante, la generación de hidrógeno es menor. De manera comparativa, podemos ver la Tabla 2 con los once ensayos con respecto al análisis de la fase gaseosa.

Tabla 2. Corridas en reactor Batch.

\begin{tabular}{|c|c|c|c|c|c|c|c|}
\hline \multirow[b]{2}{*}{ No. } & \multirow[b]{2}{*}{$\left|\begin{array}{c}\text { Sistema } \\
\text { Cataliti- } \\
\text { co }\end{array}\right|$} & \multirow[b]{2}{*}{ Donante } & \multicolumn{2}{|c|}{ Fase Gaseosa } & \multicolumn{3}{|c|}{ Fase Líquida } \\
\hline & & & $\% \mathrm{H}_{2}$ & Gases & Selec- & $\begin{array}{l}\text { Con- } \\
\text { ver- } \\
\text { sión } \\
\end{array}$ & $\begin{array}{c}\text { Alcoholes } \\
\text { grasos y } \\
\text { FAEEs } \\
\end{array}$ \\
\hline 1 & $5 \% \mathrm{Pd} / \mathrm{C}$ & \begin{tabular}{|c} 
Ácido fórmi- \\
co $99.6 \%$, \\
0.022 m \\
\end{tabular} & 35.9 & $\mathrm{CO}$ & Media & Media & Media \\
\hline 2 & $5 \% \mathrm{Pt} / \mathrm{C}$ & $\begin{array}{c}\text { Ácido fórmi- } \\
\text { co } 99.6 \% \text {, } \\
0.007 \text { m }\end{array}$ & 30.4 & $\mathrm{CO}$ & Media & Media & Media \\
\hline 3 & $5 \% \mathrm{Pt} / \mathrm{C}$ & $\begin{array}{c}\text { Ácido fór- } \\
\text { mico } 30 \% \text {, } \\
0.007 \text { m } \\
\end{array}$ & 10.7 & $\mathrm{CO}$ & Media & Media & Media \\
\hline 4 & $5 \% \mathrm{Pt} / \mathrm{C}$ & $\begin{array}{l}\text { Etanol } 99.9 \\
\%, 0.007 \mathrm{~m} \\
\end{array}$ & 3.4 & $\mathrm{CO}, \mathrm{CH}_{4}$ & Baja & Alta & Alta \\
\hline 5 & $5 \% \mathrm{Pt} / \mathrm{C}$ & $\begin{array}{c}\text { Etanol } 30 \% \text {, } \\
0.007 \mathrm{~m}\end{array}$ & 5.4 & $\mathrm{CH}_{4}$ & Baja & Baja & Baja \\
\hline 6 & $5 \% \mathrm{Pt} / \mathrm{C}$ & $\begin{array}{c}\text { Ácido fór- } \\
\text { mico } 30 \% \text {, } \\
\text { iso-octano } \\
0.007 \text { m }\end{array}$ & 26.0 & $\begin{array}{c}\mathrm{CO}, \mathrm{CH}_{4^{\prime}} \\
\text { otros }\end{array}$ & Media & Media & Media \\
\hline 7 & $5 \% \mathrm{Pd} / \mathrm{C}$ & $\begin{array}{l}\text { Ácido fór- } \\
\text { mico } 30 \% \text {, } \\
\text { heptano } \\
0.014 \text { m }\end{array}$ & 37.9 & $\mathrm{CO}$ & Media & Media & Media \\
\hline 8 & $5 \% \mathrm{Pd} / \mathrm{C}$ & $\begin{array}{c}\text { Ácido fór- } \\
\text { mico } 30 \\
\% \text {, hexano } \\
0.021 \text { m }\end{array}$ & 34.3 & $\mathrm{CO}$ & Media & Media & Media \\
\hline 9 & $5 \% \mathrm{Pt} / \mathrm{C}$ & $\begin{array}{l}\text { Ácido fór- } \\
\text { mico } 5 \text { \%, } \\
0.007 \text { m }\end{array}$ & 1.9 & $\mathrm{CO}$ & Media & Baja & Alta \\
\hline 10 & $5 \% \mathrm{Pt} / \mathrm{C}$ & \begin{tabular}{|c} 
Ácido fórmi- \\
co $99.6 \%$, \\
0.007 m \\
\end{tabular} & 38.4 & $\mathrm{CO}$ & Media & Media & Media \\
\hline 11 & $5 \% \mathrm{Pt} / \mathrm{C}$ & $30 \%$ H2/N2 & 24.16 & - & Alta & Alta & Baja \\
\hline
\end{tabular}

Nota: La "m" significa molal que en este caso es moles de fase activa por kg de donante (ácido fórmico o etanol). 
En cuanto a la fase líquida y/o sólida al final de cada serie, el análisis por GC indicó que la conversión y la selectividad a FAEE's y alcoholes grasos es muy alta cuando se usa etanol al $99.9 \%$ (v). La producción de hidrocarburos en este caso es principalmente a C18, pero si el alcohol se diluye, entonces es a C17 y la conversión y selectividad a FAEE's y alcoholes grasos también es baja. Significa que la presencia de agua desfavorece la hidrodeoxigenación, mejorando la descarbonilación y la descarboxilación debido a la menor presencia de hidrógeno generado. Cuando el camino es la hidrodeoxigenación, una especie intermedia son los alcoholes grasos. Respecto al uso de ácido fórmico como donante se observa un atmosfera con una alta concentración de hidrógeno lo que conduce a favorecer la vía de la hidrodeoxigenación. Al usar solventes orgánicos la conversión tiende a desarrollarse por las otras dos rutas por el aumento en la presencia de monóxido de carbono. Además, el uso de ácido fórmico muy concentrado (99.6\%) conduce a saturar y envenenar la superficie del catalizador para realizar el hidrotratamiento con el alto contenido de hidrógeno generado, de modo que la conversión por hidrodesoxigenación es baja. El uso de solvente genera una leve mejoría en la selectividad a hidrocarburos, pero también a especies intermedias, al tiempo que una leve disminución de la conversión.

En la Figura 8 se puede observar un cromatograma para la fase líquida de la corrida de aceite de palma con etanol al $30 \%(\mathrm{v} / \mathrm{v})$ y $5 \%$ Pt/C en una relación $0.007 \mathrm{~m}$, con exceso del $200 \%$. Los picos importantes entre el n-hexano y la tricaprina parecieran ser alcoholes grasos, pero una cromatografía GC-MS arrojó que son esteres etílicos de ácidos grasos (FAEE's), lo que indicó que en el caso del etanol, se desarrolló una principalmente una transesterificación con una pequeño hidrotratamiento.
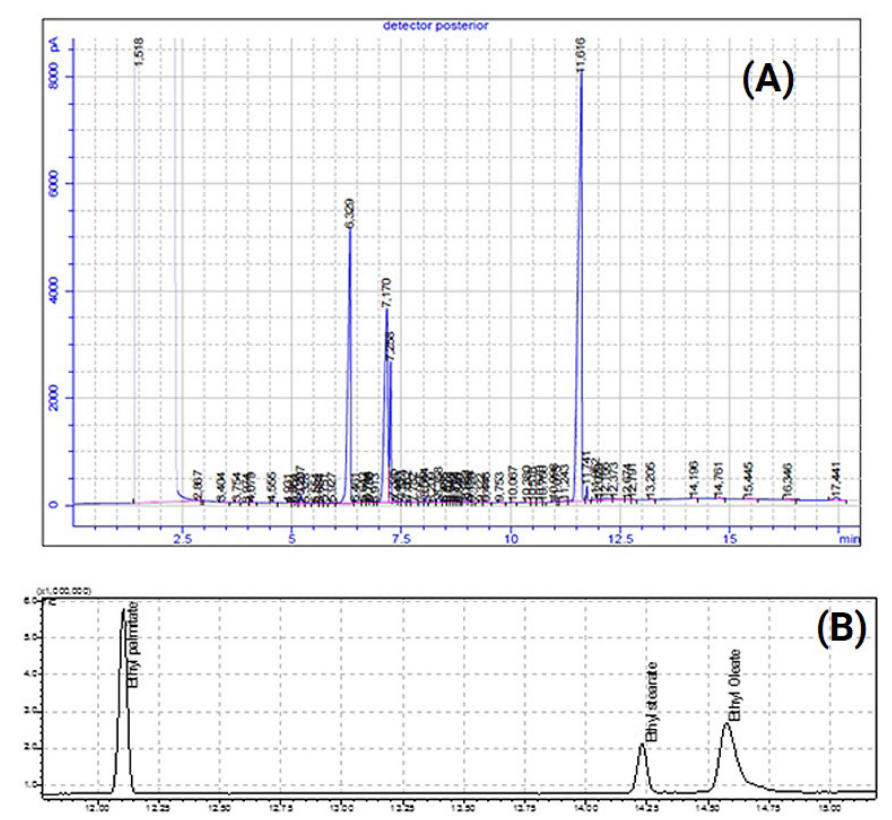

Figura 8. Cromatogramas de hidrotratamiento in situ de aceite de palma con etanol $99.9 \%$ (v/v) y $5 \%$ Pt/C: Con detector TCD (A) con detector MS (B).

\section{CONCLUSIONES}

Para el hidrotratamiento del aceite de palma, los catalizadores de metales nobles más prometedores son Pd y Pt soportados en C o zeolita USY (CBV 780), porque tienen la mejor selectividad y conversión a hidrocarburos, FAEE's y alcoholes grasos. Cuando el hidrógeno es administrado por un donante como ácido fórmico se observa que la generación de hidrógeno es mayor que con etanol, pero el catalizador tiende a saturarse para el hidrotratamiento posterior, por lo que la ruta para la desoxigenación no es la hidrodeoxigenación, por este motivo es necesario diluirlo. Para el caso del etanol es lo opuesto, ya que la vía principal para la desoxigenación de los ácidos grasos más concentrada es la hidrodeoxigenación, que se administra cuando el alcohol tiene poca agua, de modo que se produce una gran cantidad de FAEE's y alcoholes grasos.

\section{AGRADECIMIENTOS}

A la Dirección de Investigación y Extensión de la Sede de Bogotá y a la Vicedecanatura de Investigación y Extensión de la Facultad de Ingeniería, ambas de la Universidad Nacional de Colombia, por el financiamiento y gestión para la ejecución de recursos (proyecto de código 37622 de Hermes), según lo otorgado por la Convocatoria Nacional para Proyectos de Fortalecimiento de la Investigación, Creación e Innovación 2016-2018 (segundo corte) de la Universidad Nacional de Colombia.

\section{REFERENCIAS}

[1] R. Arslan and Y. Ulusoy, "Utilization of waste cooking oil as an alternatuve fuel for Turkey," in 5th International Conference on Renewable Energy Research and Applications, ICRERA 2016, 2016, vol. 5, pp. 149-152.

[2] S. Dewang, Suriani, S. Hadriani, E. S. Lestari, Banu, and Diana, "Production from Callophyllum Inophyllum $L$ using Catalyst and Time Variations for Stirring in," in 6th International Conference on Renewable Energy Research and Applications, ICRERA 2017, 2017, vol. 5, pp. 734-738.

[3] A. Hidayat and M. A. Adnan, "Free Fatty Acid Removal on Sludge of Palm Oil using Heterogeneous Solid Catalyst Derived from Palm Empty Fruit Bunch," Int. J. Renew. Energy Res., vol. 8, no. 2, pp. 986-993, 2018.

[4] E. Bernard, "Biodiesel : Los aspectos mecánicos en los vehículos," 2014. 
[5] X. Wang, Y. Ge, L. Yu, and X. Feng, "Comparison of combustion characteristics and brake thermal efficiency of a heavy-duty diesel engine fueled with diesel and biodiesel at high altitude," Fuel, vol. 107, pp. 852858, 2013.

[6] L. P. Lindfors, "High Quality Transportation Fuels From Renewable Feedstock," in XXIst World Energy Congress Montreal, 2010, pp. 1-12.

[7] H. Aatola, M. Larmi, T. Sarjovaara, and S. Mikkonen, "Hydrotreated Vegetable Oil (HVO) as a Renewable Diesel Fuel: Trade-off between NOx, Particulate Emission, and Fuel Consumption of a Heavy Duty Engine. SAE Technical Paper 2008-01-2500," SAE Tech. Pap., no. 724, p. 12, 2008.

[8] R. Sotelo-boyás, F. Trejo-zárraga, and F. D. J. Hernández-loyo, "Hydroconversion of Triglycerides into Green Liquid Fuels," in Hydrogenation, InTech, Ed. 2012, pp. 187-216.

[9] T. Khammasan and N. Tippayawong, "Light Liquid Fuel from Catalytic Cracking of Beef Tallow with ZSM-5," Int. J. Renew. Energy Res., vol. 8, no. 1, pp. 407-413, 2018.

[10] S. Jamilatun and A. Budiman, "Non-Catalytic Slow Pyrolysis of Spirulina Platensis Residue for Production of Liquid Biofuel," Int. J. Renew. Energy Res., vol. 7, no. 4, pp. 1901-1908, 2017.

[11] A. Budiman and P. Mulyono, "Silica-Alumina Based Catalytic Cracking of Bio-Oil Using Double Series Reactor," Int. J. Energy Res., vol. 8, no. 1, pp. 414-420, 2018.

[12] V. Martínez-Merino, M. J. Gil, and A. Cornejo, "Biomass Sources for Hydrogen Production," in Renewable Hydrogen Technologies, Elsevier, 2013, pp. 87-110.

[13] O. Bilgin, "Evaluation of hydrogen energy production of mining waste waters and pools," in 4th International Conference on Renewable Energy Research and Applications, ICRERA 2015, 2015, vol. 4, pp. 557561.

[14] S. Mohapatra, "Hydrogen Production Technologies with Specific Reference to Biomass," Int. J. Renew. Energy Res., vol. 2, no. 3, pp. 416-420, 2012.

[15] L. Ce, O. Ni, and C. Lee, "Hydrogen production from oxidative steam reforming of ethanol on pyro- chlore-type metal oxide ," in 1th International Conference on Renewable Energy Research and Applications, ICRERA 2012, 2012, pp. 9-11.

[16] O. Nakagoe, Y. Furukawa, and S. Tanabe, "Hydrogen production from steam reforming of woody biomass with cobalt catalyst," in 1th International Conference on Renewable Energy Research and Applications, ICRERA 2012, 2012, pp. 2-5.

[17] I. Gandarias, P. L. Arias, J. Requies, M. El Doukkali, and M. B. Güemez, "Liquid-phase glycerol hydrogenolysis to 1,2-propanediol under nitrogen pressure using 2-propanol as hydrogen source," J. Catal., vol. 282, no. 1, pp. 237-247, 2011.

[18] M. M. Ramirez-Corredores, "Pathways and Mechanisms of Fast Pyrolysis: Impact on Catalyst Research," Role Catal. Sustain. Prod. Bio-Fuels Bio-Chemicals, pp. 161-216, 2013.

[19] X. Jin, "Catalytic Conversion of Biomass-Derived Polyols to Value-Added Chemicals : Catalysis and Kinetics Xin Jin Catalytic Conversion of Biomass-Derived Polyols to Value-Added Chemicals : Catalysis and Kinetics," 2014.

[20] K. Hwang, I. Choi, H. Choi, J. Han, K. Lee, and J. Lee, "Bio fuel production from crude Jatropha oil; addition effect of formic acid as an in-situ hydrogen source," FUEL, vol. 174, pp. 107-113, 2016.

[21] E. Santillan-jimenez and M. Crocker, "Catalytic deoxygenation of fatty acids and their derivatives to hydrocarbon fuels via decarboxylation / decarbonylation," J. Chem. Technol. Biotechnol., no. February, pp. 1-10, 2012.

[22] Y. Yang, Q. Wang, H. Chen, and X. Zhang, "Enhancing selective hydroconversion of $\mathrm{C} 18$ fatty acids into hydrocarbons by hydrogen-donors," FUEL, vol. 133, pp. 241-244, 2014.

[23] M. J. Gilkey and B. Xu, "Heterogeneous Catalytic Transfer Hydrogenation as an Effective Pathway in Biomass Upgrading," ACS Catal., vol. 6, no. 3, pp. 14201436, 2016.

[24] A. Srifa, K. Faungnawakij, V. Itthibenchapong, and N. Viriya-empikul, "Production of bio-hydrogenated diesel by catalytic hydrotreating of palm oil over NiMoS2/c-Al203 catalys," Bioresour. Technol., vol. 158, pp. 81-90, 2014. 


\title{
ACCIÓN CATALÍTICA DE METALES NOBLES EN EL HIDROTRATAMIENTO DE ACEITE DE PALMA
}

\author{
Mayorga Betancourt, Manuel Alejandro ${ }^{12}$ \\ González Carmona, Jair Orlando ${ }^{12}$ \\ Martínez Saavedra, José Mateo ${ }^{3}$ \\ Trujillo, Carlos Alexander ${ }^{3}$ \\ Suarez Palacios, Oscar Yesid ${ }^{12}$ \\ Cadavid Estrada, Juan Guillermo ${ }^{12}$

\begin{abstract}
${ }^{1}$ Universidad Nacional de Colombia, Departamento de Ingeniería Química, Grupo de Investigación en Procesos Químicos y Bioquímicos 2 Universidad ECCI, Grupo de Investigación en Aprovechamiento Tecnológico de Materiales y Energía, GIATME

${ }^{3}$ Universidad Nacional de Colombia, Departamento de Química, Grupo de Investigación Laboratorio de Catálisis Heterogénea, LCH mamayorgab@unal.edu.co
\end{abstract}

\section{ÁREA TEMÁTICA}

Biomasa, Bioenergía y Biocombustibles

\section{RESUMEN}

El estudio de catalizadores heterogéneos para transformar aceites vegetales en combustibles se encuentra en auge, dada la escasez de combustibles de origen fósil. Para fortalecer el conocimiento en este campo, el hydrocracking no isotérmico de aceite de palma se llevó a cabo sobre diferentes catalizadores soportados, usando un analizador térmico simultáneo de alta presión (STA-HP), una técnica nunca antes usada para este propósito. Se evaluaron Pt, Ru, Rh, y Pd, como fases metálicas y carbón activado, $\mathrm{Y}^{-} \mathrm{Al}_{2} \mathrm{O}_{3}$ y zeolitas USY como soportes. Las curvas DSC y los termogramas permitieron evidenciar tres picos principales, atribuidos a reacciones de hidrogenación, y desoxigenación principalmente, que ocurren de manera secuencial. Los productos de la reacción fueron recuperados y analizados en un cromatógrafo de gases, lo cual nos permitió evaluar la actividad y selectividad de cada catalizador. También, los productos fueron caracterizados por espectroscopia IR, lo cual nos permitió evidenciar las desapariciones de dobles enlaces $\mathrm{C}=\mathrm{C}$ y $\mathrm{C}=\mathrm{O}$. Los resultados muestran que catalizadores con fases metálicas Pt y Pd soportados en USY y en C respectivamente presentan el mejor comportamiento en cuanto a conversión y selectividad en el hidrotratamiento de aceite de palma.

Palabras claves: Metales nobles, Catalizadores, Hidrotratamiento, Aceite de Palma, Acción Catalítica 


\section{INTRODUCCIÓN}

Uno de los principales inconvenientes que se presentan en la generación de biodiesel (FAME) a partir de un alcohol, como el metanol, y un aceite, es el grupo carbonilo presente en el compuesto final, ya que por este enlace $\mathrm{C}=\mathrm{O}$, el biodiesel posee una baja estabilidad oxidativa además de su grado de saturación en la cadena de carbonos y el nivel de antioxidantes naturales presentes en la materia prima [1]. A lo largo de la oxidación se generan una serie de cambios en términos de sus propiedades; principalmente aumentando el índice de acidez y una disminución en el contenido de metilésteres [2].

Por esta razón, diferentes autores han presentado al hidrogeno como un adecuado sustituto del metanol como materia prima, ya que este permite la desoxigenación, es decir la remoción del oxígeno presente en los triglicéridos, y a su vez la hidrogenación de las insaturaciones presentes, lo que se realizaría por un hidroproceso en lugar de una transesterificación. El resultado es un biocombustible con la misma composición química del diésel fósil (excepto la fracción de aromáticos) y por ende con propiedades funcionales similares lo que permite la sustitución total del ACPM [3].

El éxito de un hidroprocesamiento de una biomasa para obtener el producto con las características deseadas estriba en la adecuada selección del catalizador, ya que este incide no solamente en la cinética de la conversión, sino que su accionar direcciona el mecanismo de reacción que determina una selectividad y conversión determinada; además para la comprensión más detallada del proceso de producción de diésel renovable (también llamado green diesel) como un biodiésel de tipo no éster, se ha realizado estudios sobre los mecanismos de reacción y el accionar catalítico.

En general los catalizadores empleados se puede agrupar en 4 grupos: los más conocidos por usarse a nivel industrial en la desulfuración del crudo son los bimetálicos sulfurados de $\mathrm{Ni}$, Mo y W, los cuales tienen el problema de lixiviarse al emplear biomasas [4], [5]; Ios fosfuros y carburos metálicos presentan una importante selectividad pero su preparación es compleja y dispendiosa; los óxidos, sales, poliácidos y PILS (materiales arcillosos microporosos) muchos de ellos residuos sólidos del procesamiento termoquímico de biomasas tienen bajo desempeño por su baja área específica activa a pesar de su bajísimo costo; y finalmente los metálicos reducidos los que pueden tener un costo elevado pero que son los más simples, adquiribles y fáciles de preparar teniendo un adecuado comportamiento [6].
Dentro de los catalizadores metálicos reducidos como Co, Pd, Pt, Ni, Rh, Mo y Ru la desoxigenación durante el hidrotratamiento es favorecida por descarboxilación y descarbonilación, siendo el cobalto el compuesto que presenta la mayor actividad catalítica; mientras que el uso de $\mathrm{Pd}$, Pt y $\mathrm{Ni}$, promueve fuertemente la reacción de metanación, aumentando el consumo de hidrógeno. Por otra parte, la ruta de la hidrodesoxigenación se ve favorecida principalmente por metales como $\mathrm{V}$, Fe y $\mathrm{W}$ que presentan una especial afinidad ya que reducen las condiciones de temperatura, aumentando la conversión y mejorando la selectividad hacia los alcanos saturados que constituyen el producto final; estudios comparativos que describen cada metal como favorece una u otra ruta han sido escasos en cuanto a compilación [7].

De acuerdo a lo anterior, se pretende brindar una mayor idea sobre los cambios tanto físicos como químicos que ocurren en la reacción de aceite de palma con hidrogeno gaseoso a 50 bar de presión, bajo diferentes catalizadores dentro del grupo de los metales nobles reducidos como Pt, $\mathrm{Pd}$, Rh y Ru soportados en carbón activado, $\mathrm{y}^{-} \mathrm{Al}_{2} \mathrm{O}_{3}$ y zeolitas ultraestabilizadas tipo Y (USY Con una perspectiva comparativa entre estos catalizadores, se busca establecer el paso a paso de la reacción registrada por medio de un analizador termino simultaneo (STA) y caracterizando las muestras obtenidas por medio de cromografía GC y espectroscopia IR. Para esto, el equipo permite analizar de manera continua tanto el cambio de energía como el másico de la muestra problema a lo largo de la reacción, logrando correlacionarlos y fundamentar el fenómeno presente en cada pico de energía.

\section{MATERIALES Y MÉTODOS}

\section{Reactivos}

El hidrógeno gaseoso empleado en este estudio fue grado analítico proporcionado por Linde (Bogotá, D.C., Colombia), y el aceite de palma refinado por Integrasas S.A.S (Bogotá, D.C. Colombia). El valor ácido de este aceite cuantificado fue de $0.19 \mathrm{mg} \mathrm{KOH} / \mathrm{g}$ (ASTM D-664). Los estándares como el n-hexano, n-pentadecano, n-hexadecano, n-heptadecano, n-octadecano y la tripalmitina de pureza mayor al $99 \%$, fueron provisto por Sigma Aldrich - Merck (St Louis, MO). Se empleó como estándar interno tricaprina usada de referencia Fluka (Buchs, Switzerland) 


\section{Catalizadores}

Para éste estudio se utilizaron catalizadores comerciales de Pd, Pt, Rh, y Ru soportados en carbón activado y $\mathrm{Y}-\mathrm{Al}_{2} \mathrm{O}_{3}$, a saber: $5 \% \mathrm{Pd} / \mathrm{C}, 5 \% \mathrm{Pd} / \mathrm{Y}-\mathrm{Al}_{2} \mathrm{O}_{3}, 1 \%$ $\mathrm{Pt} / \mathrm{C}, 3 \% \mathrm{Pt} / \mathrm{C}, 5 \% \mathrm{Pt} / \mathrm{C}, 10 \% \mathrm{Pt} / \mathrm{C}, 5 \% \mathrm{Pt} / \mathrm{Y}-\mathrm{Al}_{2} \mathrm{O}_{3}, 5 \%$ $\mathrm{Rh} / \mathrm{C}, 5 \% \mathrm{Rh} / \mathrm{Y}-\mathrm{Al}_{2} \mathrm{O}_{3}, 5 \% \mathrm{Ru} / \mathrm{C}$ y $5 \% \mathrm{Ru} / \mathrm{Y}-\mathrm{Al}_{2} \mathrm{O}_{3}$. Todos de referencia Sigma Aldrich - Merck Las zeolita USY (CBV-780) la proporcionó Zeolyst International. La zeolita USY tiene una humedad de $4.37 \%$.

Además se utilizó Pt soportado al 1 \% en zeolita CBV780 adquirida por zeolyst. El platino fue soportado sobre la zeolita por impregnación húmeda, usando dicloruro de tetra-amin platino (II) como sal precursora, sintetizada en el laboratorio a partir de Pt metálico.

\section{Procedimiento}

Se utilizó un analizador térmico simultáneo (STA) de la empresa LINSEIS, dispuesto en el laboratorio de catálisis heterogénea (LCH) del Departamento de Química de la Facultad de Ciencias de la Universidad Nacional de Colombia (ver Figura 1). Este equipo permite medir tanto el flujo de calor (DSC) como los cambios de peso (TGA) en un material como función tanto de la temperatura como del tiempo a una atmósfera controlada además de trabajar a altas presiones [8].

Como primer paso se debe activar el catalizador, para esto, en los dos crisoles de $40 \mu \mathrm{L}$ (R: Reference y S: Sample), se dispuso de $15 \mathrm{mg}$ de catalizador y se colocaron en el soporte del equipo. Por medio de una bomba de vacío conectada a la salida del gas, se lleva el sistema a una presión de 2,6 mbar. Una vez se llega a la presión deseada se empieza calentar el equipo a una rampa de $2{ }^{\circ} \mathrm{C} / \mathrm{min}$ hasta una temperatura de 300 ${ }^{\circ} \mathrm{C}$. Al terminar la rampa de calentamiento, se procede a apagar la bomba de vacío y a abrir la válvula que da paso al hidrógeno en el sistema, se define un flujo de entrada de 0,4 I/min hasta que el sistema se enfríe a $30-40{ }^{\circ} \mathrm{C}$.

Para la activación del catalizador, la fase metálica del catalizador fue activada en el analizador térmico simultáneo antes de iniciar la reacción. El procedimiento fue basado en el trabajo de M. K. Oudenhuijzen et al., quien Ilama la metodología autoreducción [9]. El procedimiento constó en pesar 20 mg de catalizador en un crisol de aluminio de 40 microlitros y llevarla al STAHP donde la muestra se sometió a condiciones de vacío, y se calentó a una rata de $2{ }^{\circ} \mathrm{C} / \mathrm{min}$ hasta $300{ }^{\circ} \mathrm{C}$ con el propósito que el agua adsorbida en los soportes sea desalojada. Una vez alcanzada la temperatura máxima se dejó pasar $1 \mathrm{l} / \mathrm{min}$ de hidrógeno hasta que el sistema alcanzara temperatura ambiente.
La reacción no isotérmica se inicia una vez activado el catalizador, sobre éste se adicionaron entre 30-40 mg de aceite de palma y se tapó el crisol de aluminio de muestra (S), sin hacer sello. Una vez activado el catalizador, se procede a colocar $30 \mathrm{mg}$ de aceite de palma en el crisol de muestra (S). Ambos crisoles se deben tapar antes de disponerlos de nuevo en el equipo Para la carga de la muestra, tal como se ve en el cuadro verde de la Figura 1, el equipo consta de un soporte donde se colocan los dos crisoles, el de la muestra (S) y la referencia (R). Una vez colocados en su respectivo espacio se procede a presionar el sistema hasta 50 bar por medio de un flujo de hidrógeno de $20 \mathrm{l} / \mathrm{min}$. Al llegar a la presión se define una rampa de calentamiento de $10{ }^{\circ} \mathrm{C} / \mathrm{min}$ hasta la temperatura que desee (en este caso de $290^{\circ} \mathrm{C}$ ). Paralelamente se cambia el flujo de hidrógeno a 0,4 l/min con el objetivo de arrastrar cualquier sólido que pueda retenerse en la balanza.

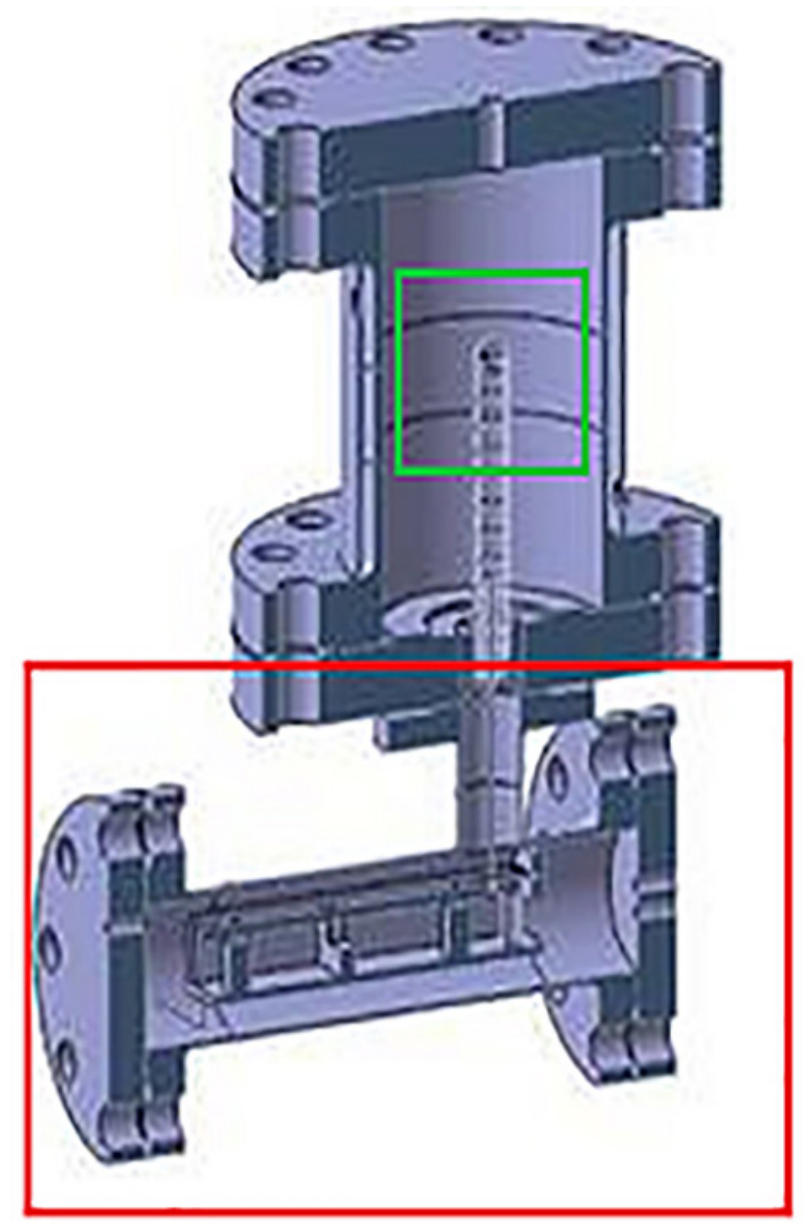

Figura 1. Interior del STA (El cuadro verde consta del soporte para ambos crisoles y el recuadro rojo permite visualizar el interior de la balanza)

\section{Análisis}

Una vez terminada la corrida se pesan los dos crisoles para conocer la masa final en cada uno de ellos. Luego el crisol de muestra se coloca en $3 \mathrm{~mL}$ de n-hexano. Se lleva a $40{ }^{\circ} \mathrm{C}$ con ultrasonido durante 
20 min. para solubilizar la muestra en el solvente. Se toman aproximadamente $0.1 \mathrm{~g}$ de la muestra para el análisis IR con el equipo Bruker con el fin de observar presencia de compuestos oxigenados.

Al resto de la muestra se le adicionan alrededor de 10 mg de tricaprina para proceder a realizar el análisis cromatográfico respectivo. Si se observa algo de turbiedad se procede a realizar centrifugación (6000 rpm por 10 min.) y filtración $(0.42 \mu \mathrm{m})$. Posteriormente se inyecta manualmente $1 \mu \mathrm{L}$ de esta muestra en el cromatógrafo de gases, Agilent 6820 (Agilent Technologies Co. Ltd., Shanghai, China), con el fin de identificar y cuantificar los hidrocarburos producidos como cadenas lineales n-C15 a n-C18, también la cantidad de aceite de palma para determinar conversión, el equipo cuenta con un detector de ionización de llama (FID), una precolumna de sílice fundida $(0,3 \mathrm{mx} 0,53 \mathrm{~mm})$ y una columna capilar de sílice fundida SUPELCO SGE HT-5 (12 mx 0,53 mm x 0,15 mm) (SGE International Pty . Ltd., Victoria, Australia); el método es el siguiente: Después de 1 min. se estabiliza la temperatura a $140{ }^{\circ} \mathrm{C}$, la temperatura del horno aumentó desde 140 ${ }^{\circ} \mathrm{C}$ con una rampa de $20{ }^{\circ} \mathrm{C} / \mathrm{min}$. hasta $380{ }^{\circ} \mathrm{C}$, y permaneciendo en esta última durante $10 \mathrm{~min}$. la temperatura del inyector fue de $350{ }^{\circ} \mathrm{C}$, y la del detector de $390^{\circ} \mathrm{C}$. Cada test duró 23 min. El gas portador fue nitrógeno con un caudal de $6 \mathrm{ml} / \mathrm{min}$. y un Split de 50: 1 . Los flujos de $\mathrm{H}_{2}$ y aire seco fueron de 40 y $450 \mathrm{ml} / \mathrm{min}$. respectivamente. La adquisición y el procesamiento de datos se lograron con el programa Cerity (Agilent Technologies Co. Ltd., Shanghai, China).

\section{RESULTADOS Y ANÁLISIS DE RESULTADOS}

En todos los termogramas para el flujo de calor, se observa el primer pico correspondiente a la fusión del aceite de palma, que es endotérmico desde $35^{\circ} \mathrm{C}$ hasta $40^{\circ} \mathrm{C}$ aproximadamente con una entalpía de alrededor de $80 \mathrm{~kJ} / \mathrm{mol}$, lo que concuerda con lo que informó el proveedor. También en estos se vio el segundo pico de naturaleza exotérmica, la diferencia radica en la altura, área y posición (en la evolución de la temperatura), que varían de acuerdo con cada catalizador; este pico se atribuye a la hidrogenación de triglicéridos para la saturación. Un tercer pico, también exotérmico, más intenso, muestra una hidrogenólisis de los triglicéridos saturados para generar ácidos grasos y propano debido a la hidrogenación que hace una ruptura posterior de ellos. Estos tres picos son claramente definidos en el caso de Pd/C y Pt/USY (CBV780) como se muestra en la Figura 1. Otros picos subsiguientes son exotérmicos y más pequeños, representan la desoxigenación de los ácidos grasos para obtener hidrocarburos; no se sabe si corresponden a hidrodeoxigenación, descarbonilación o descarboxilación. Si aparecen picos posteriores a temperaturas superiores a $300{ }^{\circ} \mathrm{C}$, pueden significar la ruptura y la isomerización de los hidrocarburos generados.

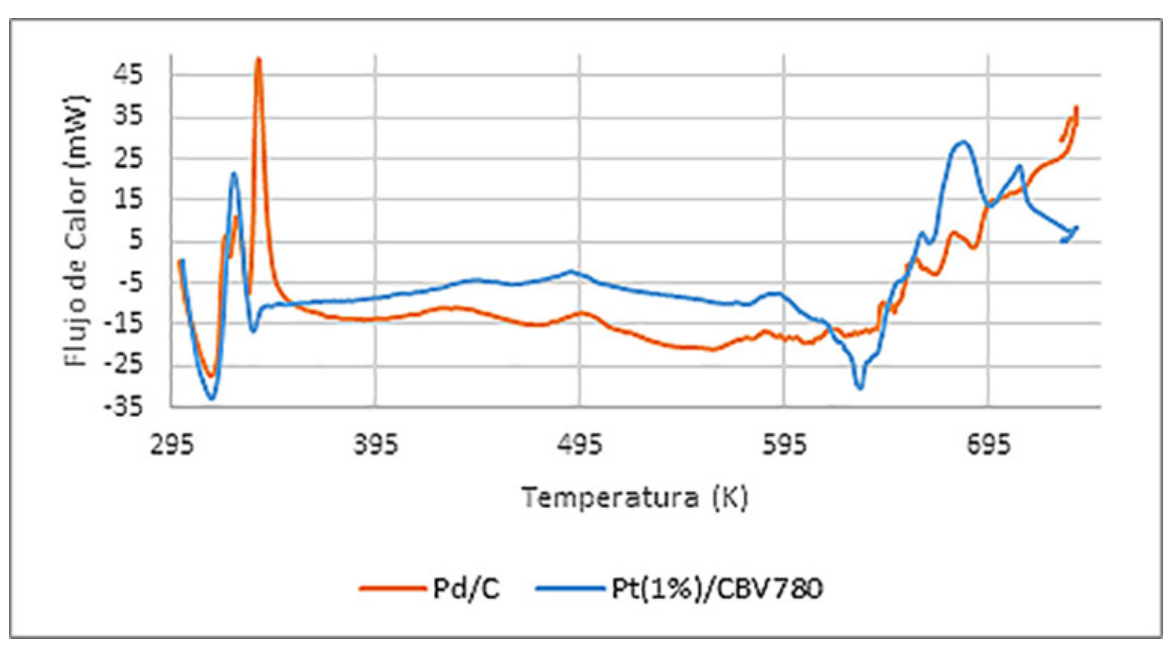

Figura 2. Termograma de Flujo de Calor (DSC) a 50 bar para $\mathrm{Pd} / \mathrm{C}$ y $\mathrm{Pt} / \mathrm{USY}$.

Con respecto a los termogramas de cambio de masa, inicialmente se puede observar un aumento de masa porque el triglicérido está saturado con hidrógenos que aumentan de peso, pero luego de alrededor de $200{ }^{\circ} \mathrm{C}$, la masa que cae suavemente debido al gas propano es generada por la hidrogenólisis y se producen gases, tales como óxidos de carbono durante la desoxigenación. Luego, a $300{ }^{\circ} \mathrm{C}$, la caída de masa es vertiginosa porque las fracciones de hidrocarburos de los gases ligeros generados por ruptura, como el metano. Todo esto se puede ver en la Figura 3 para el caso del Pd/C, sin embargo, este comportamiento es similar para los otros catalizadores, y la diferencia principal está en el retraso de cada una de las etapas del mecanismo de hidrotratamiento.

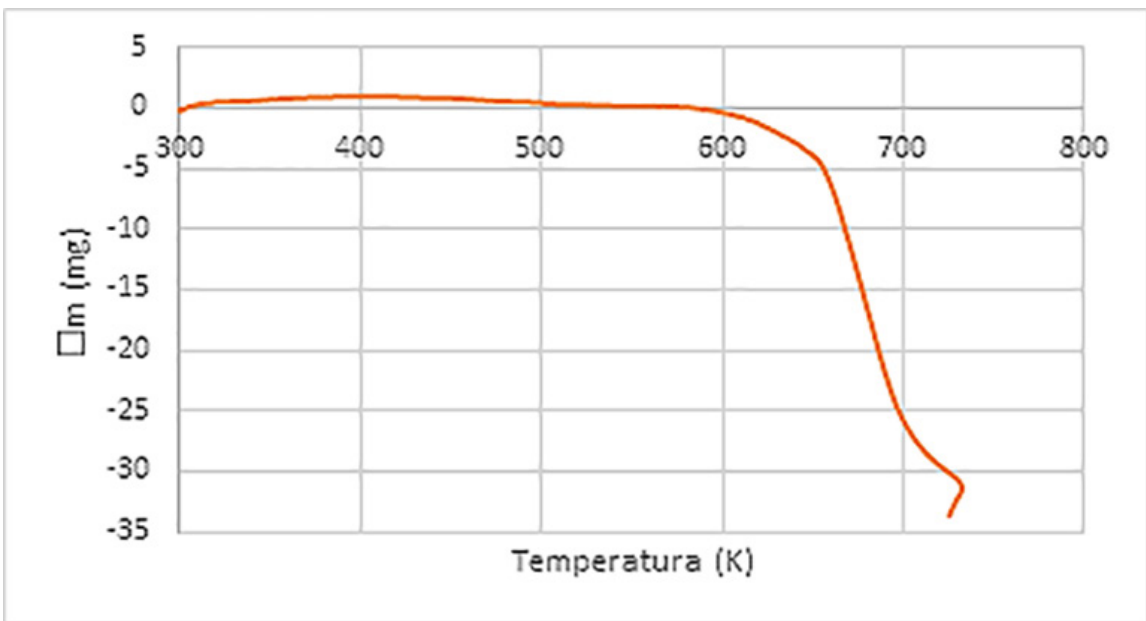

Figura 3. Termograma de cambio de masa (TGA) a 50 bar para $\mathrm{Pd} / \mathrm{C}$. 
El análisis de GC mostró que la mejor selectividad (al hidrocarburo C-15 a C-18) y la conversión, así como una alta generación de alcoholes grasos con el catalizador Pt/USY (ver Figura 4), mientras que los catalizadores soportados en alúmina tienen una conversión baja, a diferencia de las que están soportadas en carbono que tienen una conversión más alta (excepto las de Pt y Pd).

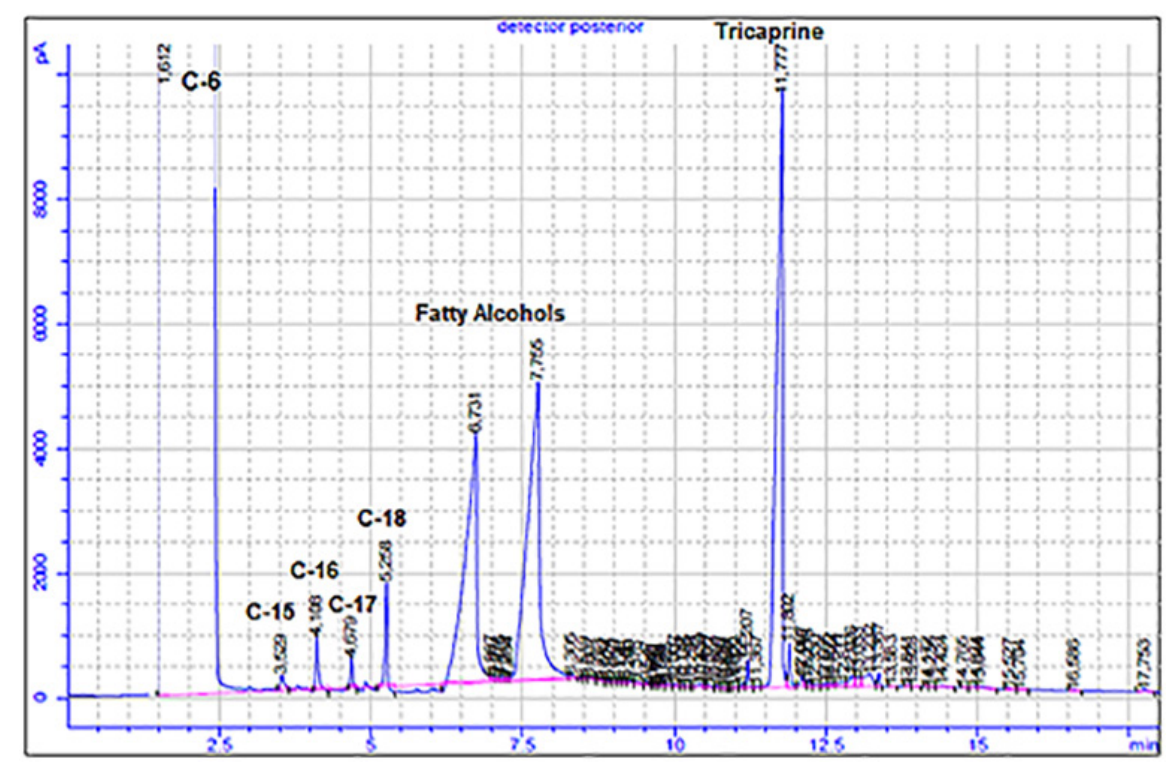

Figura 4. Cromatograma del hidrotratamiento de aceite de palma con 1 \% Pt/USY (CBV-780).

En términos generales, se analiza que a medida que hay menos conversión, parece que se detecta una mayor presencia de alcoholes grasos, lo cual es razonable ya que es un intermediario hacia la generación de hidrocarburos. Un resumen cualitativo del comportamiento de cada uno de los 10 once sistemas catalíticos en cuanto a selectividad a hidrocarburos (productos de interés), conversión y generación de alcoholes grasos, se recoge en la Tabla 1.

Tabla 1. Propiedades de cada catalizador en el hidrotratamiento de aceite de palma.

\begin{tabular}{|c|c|c|c|}
\multicolumn{1}{|c|}{ Catalizador } & Selectividad & Conversión & $\begin{array}{c}\text { Alcoholes } \\
\text { grasos }\end{array}$ \\
\hline $5 \% \mathrm{Pd} / \mathrm{Y}-\mathrm{Al}_{2} \mathrm{O}_{3}$ & Alto & Medio & Alto \\
\hline $5 \% \mathrm{Pt} / \mathrm{Y}-\mathrm{Al}_{2} \mathrm{O}_{3}$ & Medio & Bajo & Medio \\
\hline $5 \% \mathrm{Rh} / \mathrm{Y}-\mathrm{Al}_{2} \mathrm{O}_{3}$ & Medio & Bajo & Alto \\
\hline $5 \% \mathrm{Ru} / \mathrm{Y}-\mathrm{Al}_{2} \mathrm{O}_{3}$ & Bajo & Muy Bajo & Medio \\
\hline $5 \% \mathrm{Pd} / \mathrm{C}$ & Medio & Alto & Alto \\
\hline $5 \% \mathrm{Pt} / \mathrm{C}$ & Alto & Medio & Bajo \\
\hline $5 \% \mathrm{Rh} / \mathrm{C}$ & Alto & Medio & Alto \\
\hline $5 \% \mathrm{Ru} / \mathrm{C}$ & Medio & Alto & Alto \\
\hline $1 \% \mathrm{Pt} / \mathrm{C}$ & Muy Alto & Bajo & Medio \\
\hline $1 \% \mathrm{Pt} / \mathrm{USY}(\mathrm{CBV}$ & Muy Alto & Muy Alto & Muy Alto \\
\hline 780$)$ & & &
\end{tabular}

\section{CONCLUSIONES}

Se observó que a una temperatura entre los 200 ${ }^{\circ} \mathrm{C}$ y los $290{ }^{\circ} \mathrm{C}$ gran parte, tanto de la desoxigenación como la hidrogenación, han ocurrido sin implicar ruptura térmica (cracking), logrando cadenas de carbono desde n-pentadecano hasta n-octadecano, y algunos intermedios como aparentemente alcoholes grasos. Con respecto al catalizador, de acuerdo con la caracterización del producto y los termogramas observados, los catalizadores que presentaron una alta conversión y selectividad fueron Pd/C y Pt/USY (CBV-780).

\section{AGRADECIMIENTOS}

A la Dirección de Investigación y Extensión de la Sede de Bogotá y a la Vicedecanatura de Investigación y Extensión de la Facultad de Ingeniería, ambas de la Universidad Nacional de Colombia, por el financiamiento y gestión para la ejecución de recursos (proyecto de código 37622 de Hermes), según lo otorgado por la Convocatoria Nacional para Proyectos de Fortalecimiento de la Investigación, Creación e Innovación 2016-2018 (segundo corte) de la Universidad Nacional de Colombia. También agradecemos a Laboratorio de Catálisis Heterogénea (LCH) del Departamento de Química de la Facultad de Ciencias de la Universidad Nacional por su valioso apoyo por facilitarnos el acceso y uso del STA.

\section{REFERENCIAS}

[1] L. P. Lindfors, "High Quality Transportation Fuels From Renewable Feedstock," in XXIst World Energy Congress Montreal, 2010, pp. 1-12.

[2] G. Knothe, "Biodiesel and renewable diesel: A comparison," Prog. Energy Combust. Sci., vol. 36, no. 3, pp. 364-373, 2010.

[3] H. Aatola, M. Larmi, T. Sarjovaara, and S. Mikkonen, "Hydrotreated Vegetable Oil (HVO) as a Renewable Diesel Fuel: Trade-off between NOx, Particulate Emission, and Fuel Consumption of a Heavy Duty Engine. SAE Technical Paper 2008-01-2500," SAE Tech. Pap., no. 724, p. 12, 2008.

[4] S. Brillouet, E. Baltag, S. Brunet, and F. Richard, "Applied Catalysis B : Environmental Deoxygenation of decanoic acid and its main intermediates over unpromoted and promoted sulfided catalysts," "Applied Catal. B, Environ., vol. 148-149, pp. 201-211, 2014. 
[5] M. Toba, Y. Abe, H. Kuramochi, M. Osako, T. Mochizuki, and Y. Yoshimura, "Hydrodeoxygenation of waste vegetable oil over sulfide catalysts," Catal. Today, vol. 164, no. 1, pp. 533-537, 2011.

[6] A. Srifa, K. Faungnawakij, V. Itthibenchapong, and N. Viriya-empikul, "Production of bio-hydrogenated diesel by catalytic hydrotreating of palm oil over NiMoS2/c-Al203 catalys," Bioresour. Technol., vol. 158, pp. 81-90, 2014.

[7] A. Srifa, K. Faungnawakij, V. Itthibenchapong, and S. Assabumrungrat, "Roles of monometallic catalysts in hydrodeoxygenation of palm oil to green diesel," Chem. Eng. J., vol. 278, pp. 249-258, 2015.
[8] Linseis, "Simultaneous Thermal Analysis - STA (TGA/DSC)," 2018. [Online]. Available: http://www.linseis.com/en/our-products/simultaneous-thermogravimetry/.

[9] M. K. Oudenhuijzen, P. J. Kooyman, B. Tappel, J. A. Van Bokhoven, and D. C. Koningsberger, "Understanding the influence of the pretreatment procedure on platinum particle size and particle-size distribution for SiO2impregnated with [Pt2+(NH3)4](NO3-)2: A combination of HRTEM, mass spectrometry, and quick EXAFS," J. Catal., vol. 205, no. 1, pp. 135-146, 2002. 


\title{
DISEÑO Y CONSTRUCCIÓN DE UN PIROLIZADOR A ESCALA LABORATORIO PARA LA OBTENCIÓN DE COMBUSTIBLE.
}

\author{
Bernal Bermúdez, Andrés David ${ }^{1}$ \\ Blanco Gómez, María Alejandra ${ }^{1}$ \\ Malagón Romero, Dionisio Humberto ${ }^{1}$
}

\begin{abstract}
Universidad Santo Tomas, Semillero en energía y termo fluidos andres.bernalb@usantotomas.edu.co; mariablanco@usantotomas.edu.co; dionisiomalagon@ usantotomas.edu.co.
\end{abstract}

\section{ÁREA TEMÁTICA}

Biomasa, Bioenergía y Biocombustibles

\section{RESUMEN}

Actualmente tanto el petróleo, el carbón y el gas natural son fuentes agotables de energía, ya que se ha estimado que las reservas de petróleo disponibles durarán aproximadamente 50 años [1]. A partir de lo anterior, llegará el momento en el que deban ser reemplazados, es por esto que se investigan varios procesos donde se puedan aprovechar los residuos producidos y convertirlos en energía [2]. Las rutas de transformación termoquímica como: la combustión, pirolisis y gasificación, son altamente empleadas para el aprovechamiento de biomasa o materia prima; específicamente en este trabajo se emplea la pirolisis de polietileno que contiene una alta energía por unidad de masa; llegando a tener un poder calorífico de $43 \mathrm{MJ} / \mathrm{kg}$ en comparación con el diésel que tiene 44,94 MJ/Kg [3]. Para llevar a cabo este proceso, se diseñó y construyó un pirolizador partiendo de una investigación exhaustiva acerca del proceso y comparando los parámetros técnicos de diferentes equipos comerciales para así realizar una posterior generación de ideas; esto llevo a un diseño conceptual y posteriormente uno en detalle teniendo como referencia los parámetros básicos de funcionamiento como temperatura, tamaño del equipo, velocidad de la rampa de calentamiento, entre otros. Una vez realizada la construcción, se desarrollaron diferentes pruebas para encontrar los parámetros sobre los cuales se obtienen combustibles, entre ellos, la temperatura de operación con diferentes rampas de calentamiento y mayor tiempo de sostenimiento sobre $400{ }^{\circ} \mathrm{C}$, además de sellos no porosos que garanticen hermeticidad. Actualmente el equipo opera en los laboratorios de la Universidad Santo Tomás generando conocimiento acerca de "plásticos y combustibles" a los estudiantes de ingeniería mecánica y procesos a fines.

Palabras claves: Pirolisis, plásticos, diseño mecánico, biocombustibles. 


\section{INTRODUCCIÓN}

La humanidad está en constante desarrollo e industrialización, lo cual requiere la utilización de los recursos disponibles para la obtención de energía. Para el año 2015 el 81,7 \% de la energía obtenida se obtuvo a partir de combustibles fósiles [4] y se ha estimado que las reservas de petróleo disponibles durarán aproximadamente 50 años manteniendo la producción del 2017 (851.000 barriles por día), lo cual complica aún más la situación de los combustibles fósiles y su uso a través de los años [5].

En Bogotá, solo en el sector público distrital en el año 2016 se desecharon 1878,24 toneladas al año de basura aprovechable, de las cuales el 7,04 \%, es decir, unas 132,22 toneladas correspondían sólo a plástico [6], esto sin contar el material proveniente de uso domiciliario; así, se puede evidenciar la cantidad de plástico que representa una oportunidad de materia prima reciclada para el posterior aprovechamiento en la generación de combustibles líquidos como Bio-oíl, Oíl y Diésel de pirolisis una vez terminada la vida útil para el uso que fue creado.

Debido a esto, una forma de obtener nuevos combustibles que sean más económicos, por medio de la pirolisis y aprovechando materiales derivados del petróleo, como el caso de HDPE (High Density Polyethylene) y LDPE (Low Density Polyethylene), por sus siglas en inglés, a partir del cual se obtienen combustibles líquidos que llegan a tener un poder calorífico superior a $43 \mathrm{MJ} / \mathrm{kg}$ en comparación con el diésel que tiene $44,94 \mathrm{MJ} / \mathrm{Kg}[7]$.

Con miras a lograr el aprovechamiento de los desperdicios plásticos que se generan, el Semillero de Energía y Termofluidos a través de la financiación por parte de la Universidad Santo Tomás, decidió diseñar y construir un pirolizador que permite que distintas materias primas puedan ser sometidas a pirolisis y a partir de ellas obtener una gama de combustibles con potencial energético para ser utilizados como sustitutos de los petroquímicos; aunque en este proyecto se considera como materia prima el polietileno, la versatilidad del equipo permitirá emplearlo con diferentes materias primas.

\section{MATERIALES Y MÉTODOS}

Para la construcción del pirolizador se inició con un diseño conceptual, el cual permite determinar bajo que parámetros se están construyendo los distintos equipos que llevan a cabo el proceso de pirolisis y que compañías los fabrican; dentro del diseño conceptual se generaron los requerimientos del cliente que desencadenaron en especificaciones de ingeniería, estas últimas debían ser medibles y se debía alcanzar en el diseño final del equipo.

Mediante la herramienta Quality Function Deployment, (QFD) se determinaron las relaciones que existen entre los requerimientos del cliente y las especificaciones de ingeniería, guiando así, el cumplimiento del diseño con respecto a los requerimientos; también, se calificaron las diferentes opciones de equipos comerciales y patentes con respecto a lo que necesitaba el cliente actual, para así evidenciar en qué medida estos equipos cumplían con los requerimientos, esto se puede evidenciar de manera general en la Figura 1.

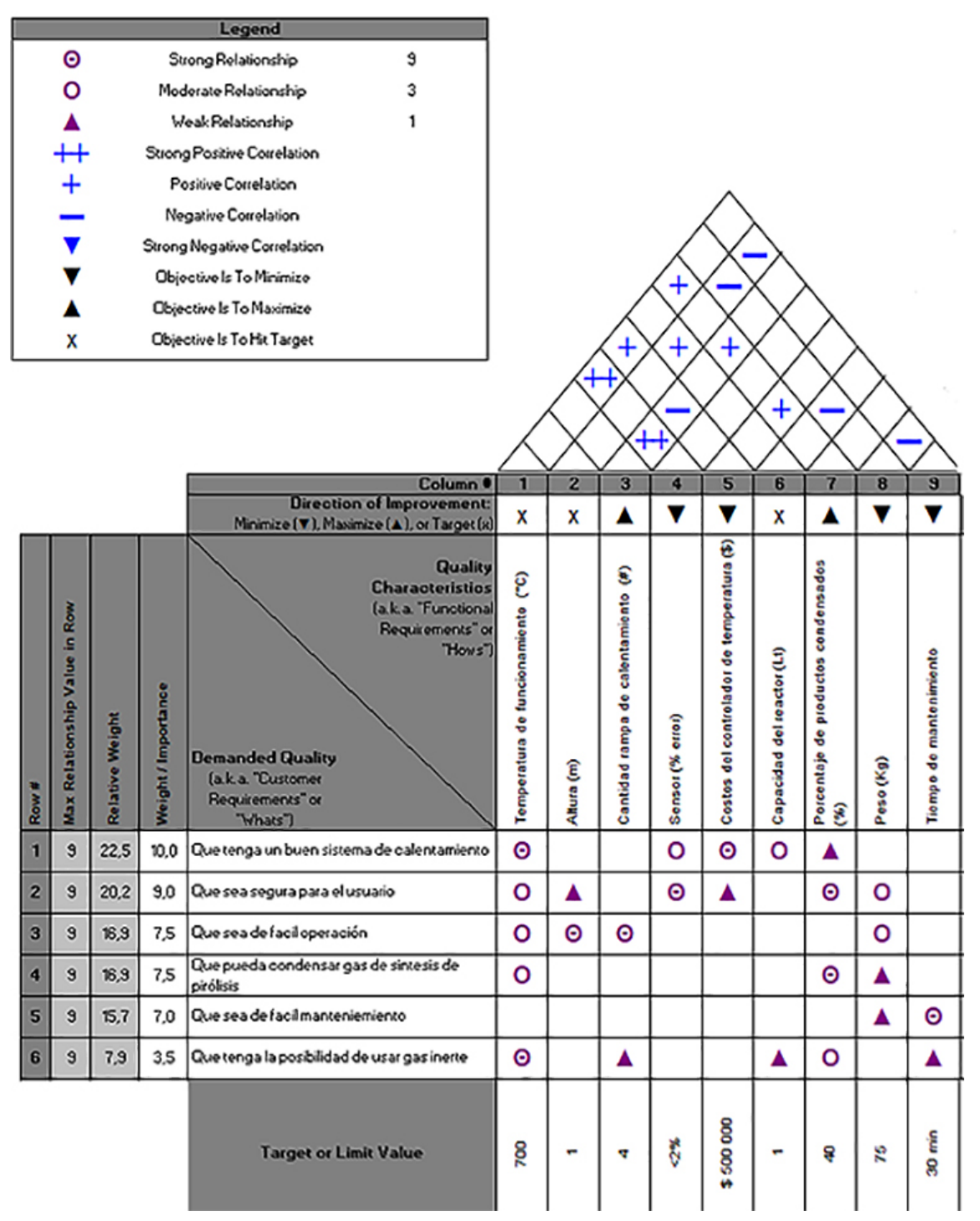

Figura 1 Esquema general QFD

De la realización del QFD se generaron distintas alternativas que satisfacían los requerimientos del cliente, mediante un diagrama de Pugh, se calificaron las alternativas generadas por el diseñador y se seleccionó la que mejor puntaje, de esta manera se obtuvo el diseño final para su posterior construcción.

Una vez construido el pirolizador, se realizaron pruebas para determinar el correcto funcionamiento del 
equipo, integridad, posibles fugas y las oportunidades de mejora, para esto se realizaron pruebas hidrostáticas medidas por el manómetro en la tapa superior y de calentamiento máximo medido por la termocupla interna.

Posteriormente se realizaron pruebas de hermeticidad y funcionamiento del controlador, eesta prueba consiste en revisar el comportamiento del controlador PID para regular las rampas de calentamiento necesarias y el tiempo de sostenimiento deseado por el usuario, para ello se planteó un programa que enviara la señal a la resistencia para que llegara a $350^{\circ} \mathrm{C}$ en $35 \mathrm{~min}$ y sostuviera $30 \mathrm{~min}$, posteriormente subiera a $450{ }^{\circ} \mathrm{C}$ en 10 min y mantuviera 20 min y finalmente llegara a $700{ }^{\circ} \mathrm{C}$ en 15 min y mantuviera 30 min; estas pruebas se realizaron con polietileno de alta densidad, polietileno de baja densidad, polipropileno y una mezcla; estas materias primas se obtuvieron a partir de la recolección de bolsas de supermercado, botellas de detergentes, jabón líquido y tapas de botellas de gaseosa, como se muestra en la Figura 2, esto con el fin de llenar la capacidad del reactor de 1 litro.
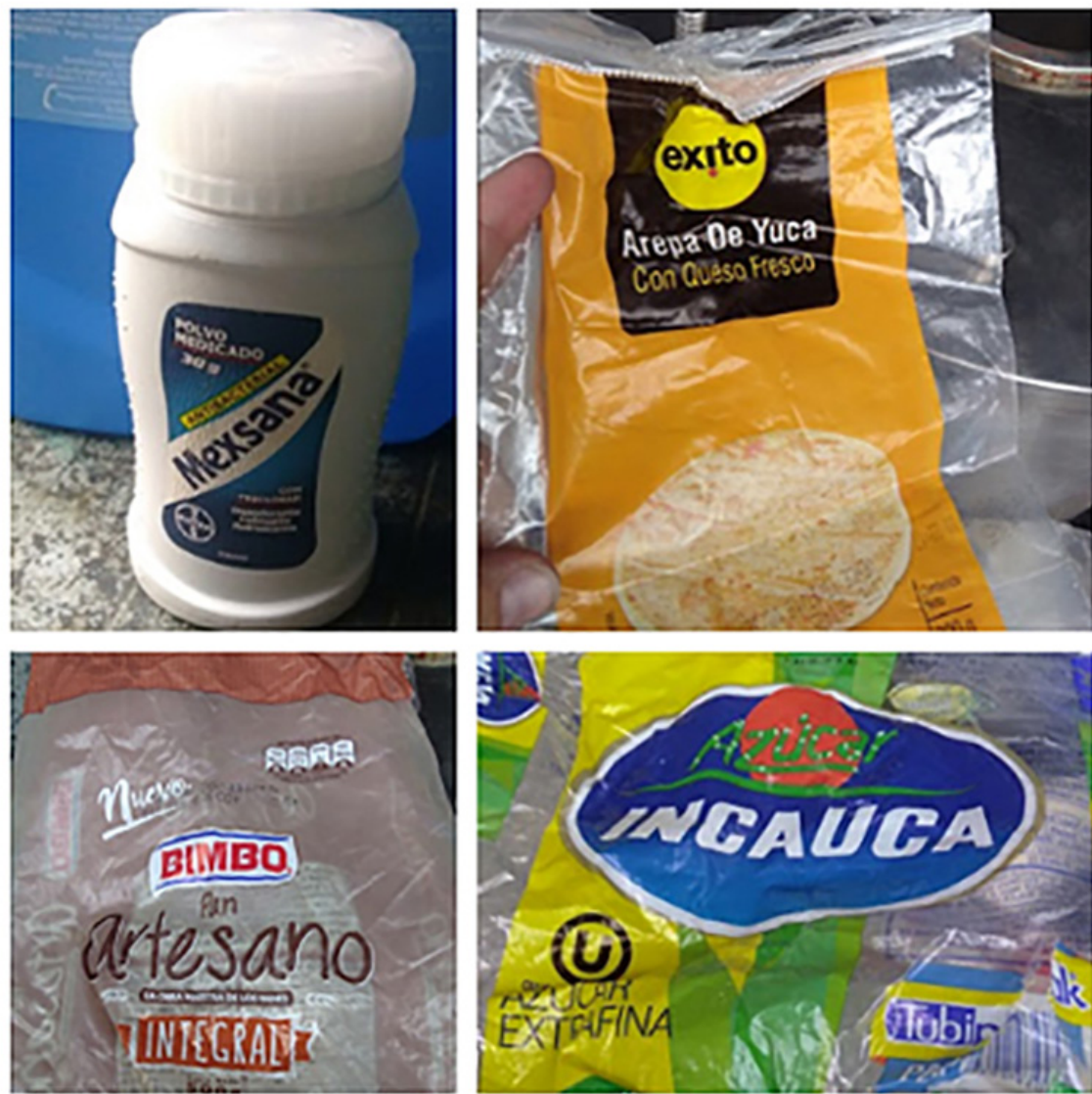

Figura 2 Materia prima.

\section{RESULTADOS Y ANÁLISIS DE RESULTADOS}

El equipo tiene la capacidad de alcanzar $700^{\circ} \mathrm{C}$ ya que cuenta con una resistencia eléctrica de 1,6 KW, esto lo hace un equipo apto para llevar a cabo el pro- ceso de pirolisis, posee una capacidad de 1 litro con alimentación tipo Batch en acero inoxidable 316, este material es el material más utilizado en reactores sometidos a gases tóxicos a altas temperaturas; como se muestra en la Figura 3, cuenta con una caja eléctrica en la cual el sistema de control es dado por un controlador PID, este permite tener un rango amplio de temperatura y rampas de calentamiento, además de facilitar la operación.

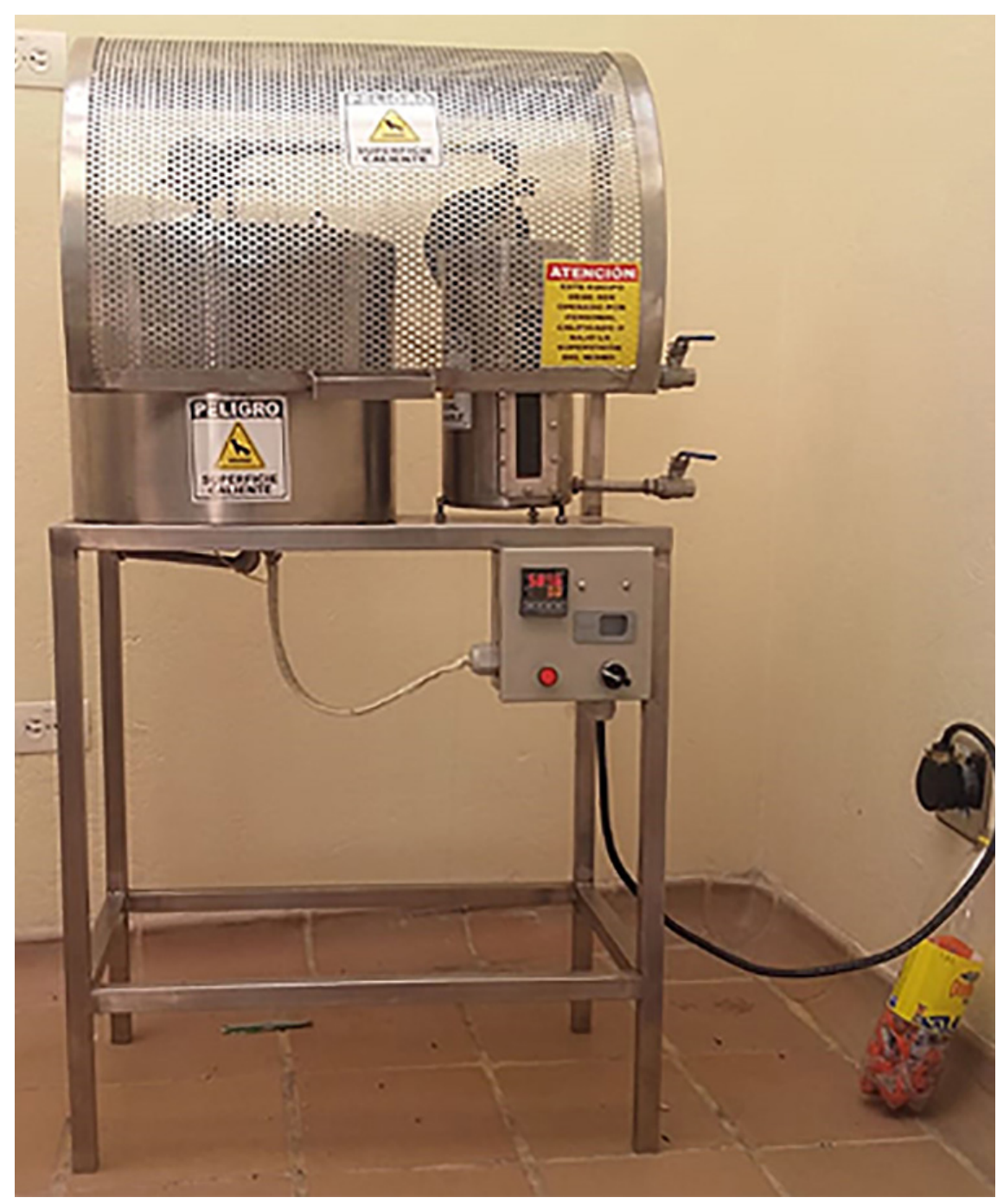

Figura 3 Pirolizador

La prueba de presión hidrostática permitió evidenciar la integridad del equipo y el correcto funcionamiento de la tubería, durante la prueba el equipo alcanzó una presión de 100 Psi obteniendo resultados favorables debido a que el equipo no presentó ninguna fuga a medida que aumentaba su presión durante 1 hora y demostró que el equipo puede trabajar con presión positiva en caso de ser requerida, esto sin sobrepasar la realizada en la prueba, siguiendo el código ASME Boiler and pressure Vessel Code Secction VIII Rules for Construcción of Pressure Vessel.

La prueba de temperatura se llevó acabo con el equipo vacío y con carga hasta la temperatura de 800 ${ }^{\circ} \mathrm{C}$, se utilizó esta temperatura para comprobar el correcto funcionamiento del equipo y como método de seguridad por si la inercia térmica afectaba la tempe- 
ratura máxima establecida para el proceso de $700{ }^{\circ} \mathrm{C}$; no se presentó ningún problema estructural ni en las uniones soldadas, la inercia térmica no presento cambios relevantes.

Para las pruebas de hermeticidad se usaron dos tipos de sellos diferentes, el primero, un sello de fibra de manta cerámica que soporta hasta $1200{ }^{\circ} \mathrm{C}$ sin dañarse y el segundo de silicona roja de alta temperatura: inicialmente el sello de fibra de manta cerámica sufrió una dilatación alrededor de $600{ }^{\circ} \mathrm{C}$, lo que hizo que sus poros se expandieran y de esta manera permitieran la salida de la mayoría del gas de pirolisis; con respecto al sello de silicona, se garantiza la hermeticidad hasta $700{ }^{\circ} \mathrm{C}$, sin embargo, ya que su degradación y deformación comienza entre 350 y $400{ }^{\circ} \mathrm{C}$ no es posible su uso en más de tres pruebas ya que el sello se cristaliza y rompe completamente abriendo paso al gas de pirolisis.

En las pruebas realizadas con los diferentes tipos de plástico se obtuvieron productos cerosos debido a las rampas de calentamiento usadas, estas iban enfocadas al funcionamiento mecánico del equipo y no a la obtención de líquidos, aunque se evidencia que el equipo es capaz de hacer la transformación termoquímica sin mayor problema, fugas o comprometiendo su estructura interna o externa; los sensores y el filtro funcionaron correctamente.

\section{CONCLUSIONES}

Se diseñó y construyó un equipo pirolizador con parámetros de operación similares a los del mercado actual, funcional, ergonómico y con la posibilidad de manejar distintas fuentes de materia prima, dirigido a los estudiantes de la Universidad Santo Tomás.

Mediante la metodología QFD y con base en la bibliografía revisada, se lograron establecer los requerimientos del cliente y las especificaciones de inge- niería, esto soportó el diseño en detalle y la posterior construcción del equipo.

El equipo fue puesto en funcionamiento en diferentes condiciones y locaciones, demostrando la versatilidad para la instalación y producción de combustibles mediante el proceso de pirolisis, así como el buen desempeño mecánico y térmico.

\section{REFERENCIAS}

[1] World Energy Conusil, "World Energy Resources," World Energy Counsil, 2016. [Online]. Available: http://www.springerlink.com/index/10.1007/978-3-642-56342-3.

[2] G. Joshi, J. K. Pandey, S. Rana, and D. S. Rawat, "Challenges and opportunities for the application of biofuel," Renew. Sustain. Energy Rev., vol. 79, no. March, pp. 850-866, 2017.

[3] A. K. Panda, "Studies on process optimization for production of liquid fuels from waste plastics," no. July 2011, 2011.

[4] International Energy Agency, "WORLD ENERGY BALANCES: AN OVERVIEW Global trends," p. 21, 2017.

[5] Worl Energy Council, "World Energy Resources Oil | 2016," p. 91, 2016.

[6] Secretaria Disrital De Ambiente, "Porcentaje de generación de residuos aprovechables por tipo de material en el sector público Distrital.," 2016.

[7] A. K. Panda, "Studies on process optimization for production of liquid fuels from waste plastics," 2011.

[8] S. D. Anuar Sharuddin, F. Abnisa, W. M. A. Wan Daud, and M. K. Aroua, "A review on pyrolysis of plastic wastes," Energy Convers. Manag., vol. 115, pp. 308326, 2016. 


\title{
TRATAMIENTO DE ACEITES USADOS DE MOTOR DIÉSEL PARA SU EVALUACIÓN COMO POSIBLE COMPUESTO REUTILIZABLE EN DIFERENTES PROCESOS DEL CENTRO DE TECNOLOGÍAS DEL TRANSPORTE DEL SENA
}

\author{
Lozano, Daniel ${ }^{1}$ \\ Páez, Adriana ${ }^{2}$ \\ Cuesta, Diana²
}

\begin{abstract}
SENA-Centro de tecnologías del transporte, Tecnologías y Sistemas de Transporte: Semillero de Investigación (CTT)

${ }^{2}$ Fundación Universidad América, Investigación en energías alternativas (FUA) dalozanor@sena.edu.co
\end{abstract}

\section{ÁREA TEMÁTICA}

Biomasa, Bioenergía y Biocombustibles

\section{RESUMEN}

A nivel Colombia, el consumo de lubricantes se estima en 39.6 millones de galones al año de los cuales solo el 21 \% tienen una disposición final adecuada, lo que conlleva a efectos a largo plazo sobre el medio ambiente, como en las fuentes hídricas en donde un litro de aceite lubricante usado puede contaminar tres (3) litros de agua dada su baja biodegradabilidad, además está considerado como un residuo peligroso según el convenio de Basilea. Sin embargo, si el lubricante residual tiene un manejo adecuado puede ser un recurso muy valioso debido a su composición química la cual está constituida por una base aceite (producto de refinación del crudo) que esta entre una composición del 71.5 al $96.2 \%$ del total de lubricante usado de motor. Actualmente para la recuperación de esta base aceite se emplean métodos físico-químicos como acido-arcilla, extracción con solvente, destilación al vacío, hidrotratamiento, etc. La mayoría de estos procedimientos generan residuos peligrosos por lo cual en los últimos años se ha buscado la utilización de métodos alternativos que reduzcan los riesgos ambientales u optimicen los procedimientos utilizados actualmente. Este trabajo tiene como objetivo el re-aprovechamiento de los aceites usados en los programas de formación en técnico en motores diésel del centro de tecnologías del transporte del SENA mediante la reducción de contaminantes tales como nitratos, óxidos, hollín y sulfatos a partir de la utilización de métodos físico-químicos y biológicos con el fin de evaluar su efectividad y conveniencia ambiental y que desde una evaluación a escala laboratorio esta investigación pueda tener un impacto en el re-aprovechamiento de residuos peligrosos como lo es el aceite lubricante usado de motor. En los resultados obtenidos se puede visualizar una reducción de hasta $97 \%$ de los contaminantes.

Palabras claves: Aceites lubricantes usados, Bacterias sulfato-reductoras, acidificación, reutilización de residuos peligrosos, eficiencia energética. 


\section{INTRODUCCIÓN}

La utilización de fuentes fósiles tales como el crudo, el petróleo y el gas, los cuales constituyen aproximadamente el $85 \%$ de la canasta energética utilizados para suplir la demanda energética a nivel mundial [1] y nacional genera una serie de implicaciones que corresponden a: primero la disminución de los recursos naturales no renovables, segundo generar una dependencia energética al no contar con los recursos naturales suficientes que satisfagan la demanda energética interna de cada país y por último pero no menos importante contribuir a la disminución de los gases efecto invernadero (GEI) generados por los procesos de combustión de las fuentes fósiles antes mencionadas. Los impactos mencionados se reflejan en la obtención de energía, el desarrollo económico y tecnológico de Colombia; principalmente del sector transporte que se cataloga como el principal consumidor de energía con una participación del 40.32\% [2] de la energía total consumida; utilizando como principal fuente energética el petróleo y sus derivados (gasolina extra y corriente $39.76 \%$, ACPM $37.63 \%$, Kerosene y jet fuel $9.65 \%$ y fuel oíl $1.37 \%$ ) [3]. Como consecuencia de la utilización de combustibles fósiles para la generación de energía, el sector transporte tiene una contribución respecto a la emisión de GEl de un valor de $72.5 \mathrm{Mt}$ ). Una alternativa para mitigar los efectos negativos que se generan por el uso excesivo de las fuentes fósiles además de contribuir con la generación de conocimiento y tecnología para afrontar las nuevas tecnologías mundiales que se derivan de estas problemáticas es la reutilización de residuos con un alto potencial energético como lo es el caso de los aceites lubricantes usados que al ser tratados correctamente pueden aprovecharse como un combustible alternativo o una base para la formulación de nuevos lubricantes.

Los tratamientos actuales realizados para recuperar el aceite usado son tres [4]:

1. Reprocesar el aceite usado, este proceso es utilizado para modificar las características del residuo de tal manera que sea adecuado para el proceso de combustión; es decir que se utilice como combustible en el quemador del motor.

2. La recuperación del aceite consiste en el proceso de degradación del aceite para utilizarlo como lubricante industrial.

3. Por último, encontramos el refınado, que hace referencia a la conversión del residuo en un producto de características similares y comparables al aceite lubricante virgen.
A continuación se presenta un diagrama que específica algunas de las técnicas más usadas en el tratamiento de aceites de motor usado, tanto para la utilización del aceite tratado ya sea como aceite lubricante como para generar energía [5].

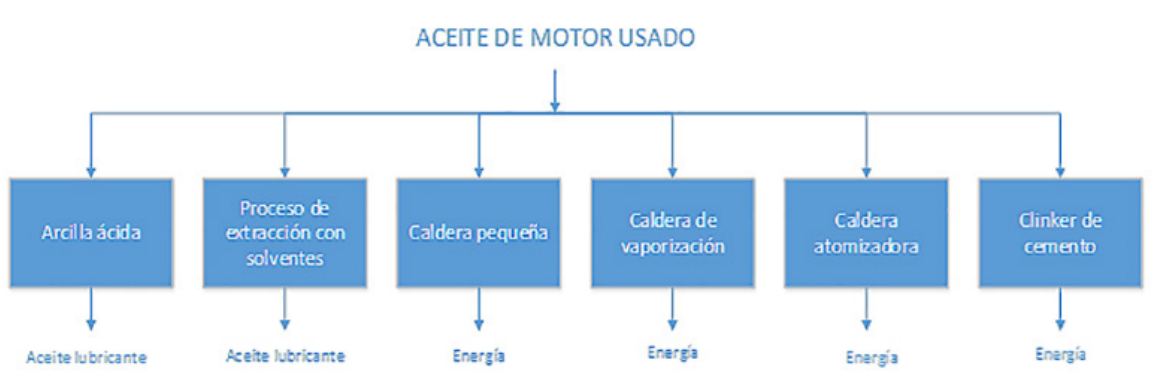

Figura 1. Tratamientos para los aceites de motor usados

En términos ambientales, el proceso de arcilla ácida genera lodos ácidos altamente contaminantes, debido a la adición de ácido sulfúrico que separa las fases aceitosas y acuosas. El proceso de extracción con solventes requiere el uso de una mezcla de solventes químicos además de requerir energía para realizar un proceso de destilación al vacío para recuperar la fase aceite. Los procesos que interfieren con los diferentes tipos de calderas generan un serie de gases contaminantes $\left(\mathrm{CO}, \mathrm{CO}_{2}, \mathrm{SO}_{x^{\prime}} \mathrm{NO}_{x^{\prime}}, \mathrm{PM}-10\right)$ debido a la concentración de metales pesados que se encuentra en el aceite usado de motor; esta técnica corresponde a la mezcla de una proporción del aceite usado con el combustible crudo para producir energía por el proceso de combustión; por último, encontramos la metodología referente al uso del aceite usado como combustible a temperaturas extremadamente altas $\left(1500-2000{ }^{\circ} \mathrm{C}\right)$ con un tiempo de reacción de 10-12 s en Clinker de cemento generando un requerimiento energético muy alto para alcanzar estas temperaturas de reacción.

Como se puede observar en la descripción anterior los métodos usados actualmente para la reutilización del aceite, ya sea como aceite lubricante o para la generación de energía, tienen una serie de impactos ambientales, tanto en el proceso de tratamiento como en la utilización final de esta materia prima cuando el tratamiento es incompleto; de acuerdo a la falta de sostenibilidad en términos ambientales se pretende realizar un tratamiento biológico y hacer una comparación con los tratamientos físico y/o químicos por medio del contacto del aceite con una sustancia alcalina seguido del contacto con medios adsorbentes como lo es el carbón activado y diferentes tipos de zeolitas, para seleccionar aquellos métodos que generen los menores impactos ambientales, y así definir la ruta de tratamiento a seguir y contribuir con la minimización de vertimientos, gases efecto invernadero y efectos perjudiciales en la salud. 
Para el alcance de este proyecto se emplearon aceites derivados de los procesos de formación en el centro de tecnologías del transporte a los cuales por medio de tratamientos físicos, químicos y biológicos se les busca mejorar características físicas y químicas. Algunos tratamientos utilizados en la actualidad son; acido-arcilla, extracción con solvente, calentamiento por caldera, Clinker de sementó, Extracción por solventes con adsorción y Bio-remediación [6]. Debido a términos económicos y de rendimiento de cada uno de los métodos para la reducción de contaminantes (>70 \%) se seleccionaron los métodos de ácido-arcilla y bio-remediación a partir de cepas de bacterias sulfato-reductoras que tienen la capacidad de remover componentes azufrados y metales pesados, mediante procesos intracelulares y extracelulares [7].

\section{MATERIALES Y MÉTODOS}

El desarrollo del proyecto está dividido en tres etapas las cuales son; (1) Recolección y muestreo inicial del aceite lubricante usado; (2) Tratamiento físico y químico a partir del método acido-arcilla y (3) Tratamiento Biológico a partir de Bacterias sulfato reductoras. La recolección del aceite lubricante usado se realizó en el centro de tecnologías del transporte (CTT) en la ciudad de Bogotá, finalizada su recolección estos son llevados a los laboratorios de Biotecnología y Nanotecnología de Tecnoparque nodo Bogotá para la ejecución de los procesos de tratamiento debido a que cuentan con los equipos e instalaciones para su realización. Se envía una muestra de $500 \mathrm{ml}$ del aceite recolectado al laboratorio de SGS Colombia para identificar parámetros de Oxidación, Agua, Nitratos, volátiles y Hollín por medio de la norma ASTM E 2412.

La segunda etapa se realizó a partir de una filtración inicial en donde se busca remover contaminantes solidos gruesos por medio de un sistema compuesto por un embudo Buhner, matraz kitasato de 500 ml, papel filtro de celulosa y una bomba de vacío de 0,78 atm. El siguiente paso es el calentamiento de la muestra para la reducción de agua y volátiles a una temperatura de $170{ }^{\circ} \mathrm{C}$ durante 15 minutos en una plancha de calentamiento, la muestra se deja enfriar hasta los $40-45^{\circ} \mathrm{C}$ y se adiciona el ácido al $10 \% \mathrm{v} / \mathrm{v}$ y se mezcla durante 20 minutos. El aceite se deja sedimentar por 24 horas y se filtra luego se neutraliza para ajustar el pH adicionándole $4 \%$ en peso del aceite de cal hidratada y se agita durante 10 minutos para finalmente dejarlo sedimentar durante 24 horas [8] y se filtran las impurezas residuales.
Para el tratamiento Biológico se recolectaron diez muestras de agua y lodo termales provenientes de las "piscinas azufradas del Nilo", localizadas en Agua de Dios, Cundinamarca, Colombia; el muestreo se llevó a cabo según la norma técnica colombiana NTC-ISO 5667-3 [9], por lo que las muestras fueron mantenidas a $4{ }^{\circ} \mathrm{C}$ hasta el momento de su uso. Con el propósito de aumentar la población de bacterias reductoras de sulfatos en las muestras, se prepararon $1000 \mathrm{~mL}$ de medio de cultivo Postgate $\mathrm{C}$ modificado [7], de tal manera que $50 \mathrm{~mL}$ de cada muestra fueron añadidos a $100 \mathrm{~mL}$ de medio de cultivo, las mezclas se incubaron bajo condiciones de anaerobiosis en shaker a $150 \mathrm{rpm}$ y $37^{\circ} \mathrm{C}$ durante 15 días. El aislamiento de bacterias se realizó según la técnica de siembra por extensión en superficie de $0.4 \mathrm{~mL}$ de las mezclas incubadas anteriormente, sobre medio de cultivo solidificado con agar granulado; las cepas se mantuvieron bajo condiciones de anaerobiosis en incubadora a $37^{\circ} \mathrm{C}$ durante 20 días y su morfología se identificó mediante Coloración de Gram. El tratamiento biológico de los aceites usados se ejecutó en 3 matraces de erlenmeyer de $500 \mathrm{~mL}$; los matraces se completaron con diferentes proporciones de medio de cultivo, inóculo de la cepa seleccionada (B) y aceite lubricante usado de motor Diésel (25\%, 50 $\%, 75 \%$ ) hasta el volumen de control (450 mL), los experimentos se mantuvieron durante 29 días bajo condiciones de anaerobiosis en shaker a $150 \mathrm{rpm}$ y $37^{\circ} \mathrm{C}$. Se caracterizaron tres muestras tratadas de ALU y un blanco sin tratamiento en el laboratorio SGS, evaluando las mismas características del muestreo inicial.

\section{RESULTADOS Y ANÁLISIS DE RESULTADOS}

Se recolectaron un total de 20 litros de aceite lubricante usado de motor diésel los cuales fueron caracterizados a partir del envío de una muestra de $500 \mathrm{ml}$ a los laboratorios de SGS en donde se analizaron parámetros como oxidación, nitración, hollín, sulfatación, glicol, agua, combustible y residuo de carbón. Lo anterior se puede visualizar en la tabla 1.

Tabla 1. Caracterización inicial

\begin{tabular}{|c|c|}
\hline PARAMETRO & MUESTRA INICIAL \\
\hline OXIDACIÓN (A/0.1 mm) & 21 \\
\hline NITRACIÓN (A/0.1 mm) & 9 \\
\hline HOLLIN (A/0.1 mm) & 20 \\
\hline SULFATACIÓN (A/0.1 mm) & 17 \\
\hline Glicol (\%) & 0 \\
\hline Agua (\%) & 1,5 \\
\hline Combustible (\%) & 5,83 \\
\hline Residuo de carbón & 1,29 \\
\hline
\end{tabular}


Los parámetros como nitración, hollín, agua y combustible son producto de la combustión incompleta dentro del motor lo cual se debe a fallas internas o a un exceso de diésel lo cual puede generar corrosión en las partes móviles disminuyendo la lubricación del aceite y acelerando su degradación debido al aumento de viscosidad y a la generación de lodos y sedimentos [10].

La oxidación esta referenciada sobre la degradación del aceite debido a que el equipo en su uso normal sufre desgaste en sus piezas internas lo cual se mezcla con el aceite generando una degradación acelerada del mismo debido a que algunos metales como el cobre y el hierro son catalizadores de las reacciones oxidativas del lubricante. Adicionalmente el aceite presenta contenidos altos de hollín [1], estos producen una coloración oscura en el aceite y esto a su vez indica fallas en el motor, como bajas eficiencias de producción y mala inyección.

Debido a estas características encontradas durante la caracterización inicial es necesario realizar procedimientos de pre-tratamiento físico y químico para acondicionar el aceite lubricante usado para ser tratado por métodos biológicos ya que a los niveles que se encuentra actualmente pueden afectar el rendimiento y la supervivencia de las bacterias sulfato reductoras. El aceite recolectado en la etapa inicial es filtrado a una velocidad de $100 \mathrm{ml} / \mathrm{h}$ y posteriormente calentado hasta los $170{ }^{\circ} \mathrm{C}$ para realizar el proceso de acidificación por medio de ácido sulfúrico al $10 \%$ v/v. En la figura 2 se presentan los resultados obtenidos durante este procedimiento y se compara frente a la caracterización inicial.

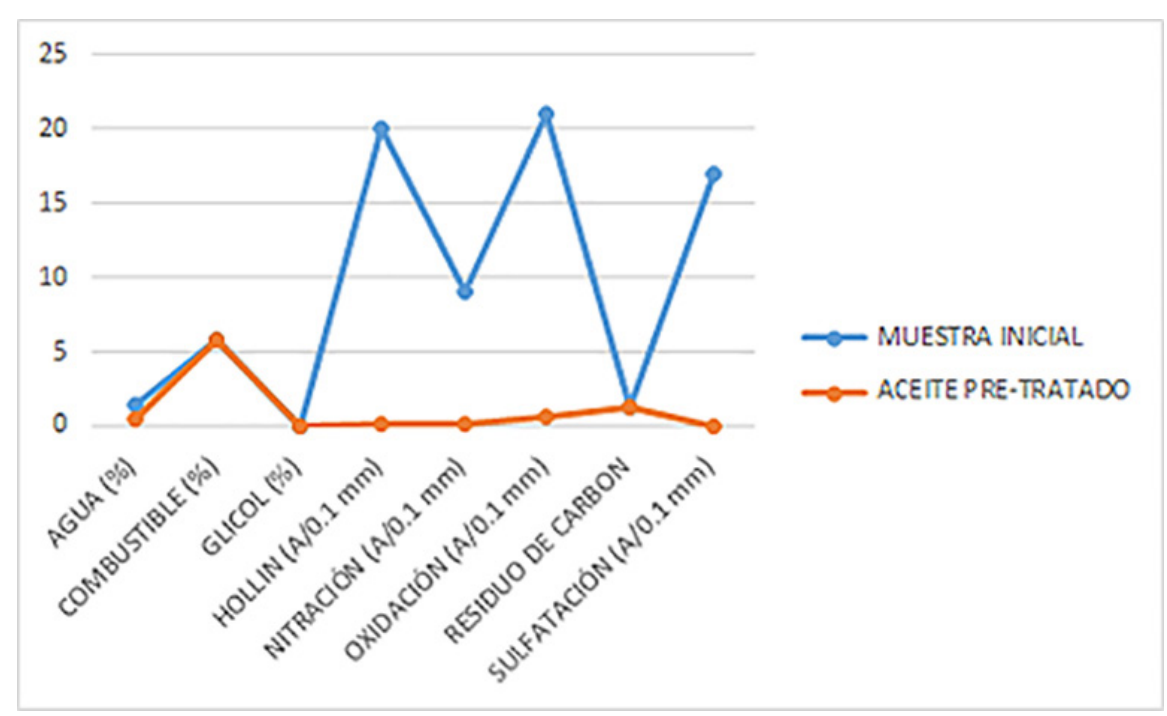

Figura 2. Caracterización inicial vs Caracterización Aceite pretratado

Como se puede visualizar en la gráfica \#1 hay una reducción en parámetros como oxidación (97\%), Nitración (98\%), hollín (99\%), Sulfatación (99\%) y agua (68\%) esto se debe a la reacción que tiene lugar entre los iones metálicos derivados del desgaste de las piezas del motor con el ácido sulfúrico lo cual genera sulfatos insolubles que son removidos durante los procesos de sedimentación y filtración, adicional, el calentamiento por encima de los $100{ }^{\circ} \mathrm{C}$ al inicio del pretratamiento genera una remoción de agua debido a que la temperatura está por encima de su punto de ebullición.

Finalizado el acondicionamiento del aceite se procede a realizar el tratamiento biológico a partir de bacterias sulfato reductor. Se inicia por la siembra de las diez muestras inciales, de las cuales solo dos $(B, D)$ se adaptaron perfectamente a las condiciones impuestas de temperatura $\left(37^{\circ} \mathrm{C}\right)$, anaerobiosis y medio de cultivo (Postgate C); luego de hacer la tinción de Gram, se determinó de que se trataban de bacilos Gram negativos y que además generaban sulfuro de hidrógeno, demostrado en el experimento de sulfuro de plomo al formar precipitado negro. Las bacterias mesofilas Gram negativas son uno de los tres grupos de bacterias sulfato reductoras y tienen características parecidas de crecimiento a las cepas salvajes aisladas, por lo cual estas cepas tienen una alta probabilidad de ser bacterias sulfato reductoras.

A los diez días de iniciado el tratamiento de aceite lubricante usado con la cepa B, se empezó a evidenciar una serie de precipitados blancos en el fondo de los Erlenmeyer, que disminuían al aumentar la concentración de ALU; una parte de este precipitado puede provenir del medio cultivo el cual contiene una serie de metales como hierro, magnesio, potasio, sodio y estos pueden precipitarse con el sulfuro de hidrógeno pero otra parte proviene del aceite, de los metales presentes allí y como el experimento de $25 \%$ de inoculo contenía más aceite y menos volumen de medio, indica que si se están precipitando elementos del ALU al poseer mayor cantidad de precipitado que sus contrapartes.

Tabla 2. Caracterización aceite pre-tratado vs Caracterización con tratamientos Biológicos

\begin{tabular}{|c|c|c|c|c|}
\hline $\begin{array}{c}\text { PARAME- } \\
\text { TRO (ASTM } \\
\text { E2412) }\end{array}$ & $\begin{array}{c}\text { ACEITE } \\
\text { USADO SIN } \\
\text { TRATAR }\end{array}$ & $\begin{array}{c}\text { ACEITE } \\
\text { USADO TRA- } \\
\text { TADO (25\%) }\end{array}$ & $\begin{array}{c}\text { ACEITE } \\
\text { USADO TRA- } \\
\text { TADO (50\%) }\end{array}$ & $\begin{array}{c}\text { ACEITE } \\
\text { USADO TRA- } \\
\text { TADO (75\%) }\end{array}$ \\
\hline $\begin{array}{c}\text { Oxidación } \\
\text { A/0.1 mm }\end{array}$ & 0.63 & 0.61 & 0.31 & 0.05 \\
\hline $\begin{array}{c}\text { Nitración } \\
\text { A/0.1 mm }\end{array}$ & 0.14 & 0.41 & 0.15 & 0.04 \\
\hline $\begin{array}{c}\text { Hollín A/0.1 } \\
\text { mm }\end{array}$ & 0.21 & 0.24 & 0.12 & 0.05 \\
\hline $\begin{array}{c}\text { Sulfatación } \\
\text { A/0.1 mm }\end{array}$ & 0.05 & 0.00 & 0.00 & 0.00 \\
\hline Glicol \% & 0.00 & 0.00 & 0.35 & 0.00 \\
\hline Agua\% & 0.48 & 2.48 & 4.98 & 3.73 \\
\hline
\end{tabular}


\begin{tabular}{|l|l|l|l|l}
\hline PARAME- & ACEITE & ACEITE & ACEITE & ACEITE
\end{tabular}

TRO (ASTM USADO SIN USADO TRA-USADO TRA-USADO TRA\begin{tabular}{l|l|l|l|l|} 
E2412) & TRATAR & TADO (25\%) & TADO (50\%) & TADO (75\%) \\
\hline
\end{tabular}

\begin{tabular}{|c|c|c|c|c|}
\hline $\begin{array}{c}\text { Combustible } \\
\%\end{array}$ & 5.83 & 3.62 & 2.40 & 1.90 \\
\hline $\begin{array}{c}\text { Residuo de } \\
\text { carbón Con- } \\
\text { radson }\end{array}$ & 1.29 & 1.28 & 1.32 & 1.28 \\
\hline
\end{tabular}

Los resultados de la caracterización del aceite Tabla 2, muestran una disminución en todos los parámetros medidos a excepción del porcentaje de humedad por parte del tratamiento 3, obteniendo un mejor rendimiento medio por parámetro de $81 \%$ de reducción, le sigue el experimento 2 con $49 \%$. El experimento 1 (25 \%) elevo los parámetros de nitración, hollín y no disminuyo la oxidación, esto se debe a que el exceso de sulfuro de hidrogeno presente en los primeros dos experimentos, pudo generar reacciones secundarias o estos experimentos al tener una capa más delgada de aceite, el sulfuro de hidrógeno pudo atravesarla y no reaccionar con los compuestos azufrados, oxigenados y nitrogenados, a diferencia del tercer experimento donde se producía menos gas y la capa de aceite era mayor. El porcentaje de combustible presento una reducción apreciable en los tres experimentos, sobre todo en el último, donde se disminuyó en un $67 \%$. Las bacterias sulfato reductoras son utilizadas en procesos de bioremediación de suelos y aguas con hidrocarburos, entonces esta cepa podría degradar volátiles presentes, aunque podría afectar la base lubricante del aceite al degradarla.

\section{CONCLUSIONES}

La caracterización inicial muestra un nivel avanzado de contaminación del aceite lubricante usado, algunos parámetros como oxidación, hollín, sulfatación y agua son los más relevantes debido a que su presencia indica el estado de degradación del aceite producto de fallas internas y desgaste del motor al igual que combustiones incompletas. El pre-tratamiento químico-físico utilizado para reducir las características anteriormente mencionadas y poder re-utilizar el aceite tiene un rendimiento promedio del $97 \%$ debido a las reacciones de precipitación generadas por la interacción entre el ácido sulfúrico y los iones metálicos, este acondicionamiento permite realizar la re-refinación del aceite a partir de bacterias sulfato reductoras que generan una reducción media del $81 \%$ de los contaminantes presentes en el aceite pretratado pero aumenta el contenido del agua del mismo debido al medio utilizado para el crecimiento de la bacteria. El aceite obtenido posee parámetros que lo hacen apto para la utilización como una base lubricante [11] la cual puede ser mezclada con otros lubricantes para su utilización en motores diésel. La utilización de métodos biológicos para mejorar el nivel de re-refinación del aceite posee una alta conveniencia ambiental debido a que la generación de lodos residuales es nula por lo cual se puede considerar como una alternativa frente a los métodos utilizados convencionalmente, sin embargo, se recomienda la revisión de otras características como metales pesados y el contenido de agua después de realizar los tratamientos.

\section{REFERENCIAS}

[1] D. A, B. M.A y K. M, «Diesel Fuel From Waste Lubricating Oil by Pyrolitic Distillation,» Petroleum Science and Technology, vol. 33, n² 2, pp. 129-138, 2015.

[2] MINISTERIO DE AMBIENTE, VIVIENDA Y DESARROLLO TERRITORIAL, «Manual Técnico para el Manejo,» Bogota, 2005.

[3] H. G. Anza Cruz, P. D. Orantes Calleja, R. González Herrera y A. Ruíz Marín, «BIORREMEDIACIÓN DE SUELOS CONTAMINADOS CON ACEITE AUTOMOTRIZ USADOS MEDIANTE SISTEMA DE BIOPILAS,» ESPACIO I+D, vol. 5, nº 12, p. 2, 2016.

[4] M. A. Al-Ghouti y L. Al-Atoum, «Virgin and recycled engine oil differentiation: A spectroscopic study,» Journal of Environmental Management, vol. 90, no 1 , pp. 187-195, 2009.

[5] V. Kanokkantapong, W. Kiatkittipong, Panyapinyop, P. Wongsuchoto y P. Pavasant, «Used lubricating oil management options based on life cycle thinking,» Resources, conservation and recycling, vol. V, $n^{0}$ 53, pp. 294-299, 2009.

[6] E. Delgado, J. Parra, L. Aguilar y D. Guevara, «COMBUSTIBLES ALTERNATIVOS A PARTIR DE ACEITES,» Avances en investigación e ingenieria , $n^{\circ}$ 6, pp. 110-115, 2007.

[7] T. D.F., T. P.G y M. M.Hattingh, «Enumeration, isolation and identification of sulphate-reducing bacteria of anaerobic digestion,» Water Research, vol. II, n 7, pp. 505-513, 1968.

[8] C. Stan, C. Andreescu y M. Toma, «Some aspects of the regeneration of used motor oil,» Procedia Manunfacturing, $n^{\circ} 22$, pp. 709-713, 2018.

[9] International Organization for Standardization, Water quality -- Sampling -- Part 3: Preservation and handling of water samples, 5, 2018. 
[10] A.-G. Mohammad y A. LinaAl, «Virgin and recycled engine oil differentiation: A spectroscopic study,» Journal of Environmental Management, vol. 90, no 1, pp. 187-195, 2009.

[11] O. Arpa, R. Yumrutas y Z. Argunhan, «Experimental investigation of the effects of diesel-like fuel obtained from waste lubrication oil on engine perfor- mance and exhaust emission,» Fuel Processing Technology, vol. 91, nº 10, pp. 1241-1249, 2010.

[12] Asociación Colombiana del petroleo, Panorama general del aceite lubricante usado, Bogota, 2016.

[13] E. Muñoz, D. Montoya y A. Muñoz, «PLANTEAMIENTO Y SOLUCIÓN DE LA PROBLEMATICA DE LOS USADOS EN COLOMBIA,» Medellin, 2017. 


\title{
EVALUACIÓN DE LA CALIDAD DE ENERGÍA EN SISTEMAS FOTOVOLTAICOS MEDIANTE INTELIGENCIA COMPUTACIONAL
}

\author{
Fuentes Velandia, Juan de Dios ${ }^{1}$ \\ Orjuela Cañón, Álvaro David ${ }^{2}$ \\ Tangarife Escobar, Héctor Iván ${ }^{1}$ \\ ${ }^{1}$ Servicio Nacional de Aprendizaje, SENA, Grupo de investigación GICEMET \\ 2 Universidad Antonio Nariño, UAN, Grupo de investigación GIBIO \\ hitangarife@misena.edu.co
}

\begin{abstract}
ÁREA TEMÁTICA
Energías Alternativas: Energía solar, eólica, hidráulica, geotérmica y mareomotriz
\end{abstract}

\section{RESUMEN}

Este artículo pretende evaluar, parámetros relacionados con armónicos de tensión, mediante la aplicación de técnicas de procesamiento de señales para aportar en el estudio de calidad de la energía de sistemas fotovoltaicos. Se adquirieron señales de tensión durante la conexión de diferentes tipos de cargas no lineales, se realiza un análisis en frecuencia para caracterización, se clasifican las cargas estudiadas mediante redes neuronales de aprendizaje supervisado. A manera de comparación, se toma información de la red eléctrica convencional que sirve como referencia para el análisis del sistema. Se identifican tres tipos de cargas dentro de la normativa relacionada con THD (Distorsión Armónica Total) inferior al 5 \%. Este fenómeno también es observado cuando la energía es tomada de la red eléctrica convencional, sin embargo, cuando se conecta cargas inductivas al sistema FV se excede el $5 \%$ de THD en donde la red neuronal indica que el sistema no cumple con los parámetros de la normativa. Se concluye que la red neuronal está en capacidad de determinar si el sistema cumple o no con la normatividad que rige la calidad de la energía eléctrica a partir de la evaluación del THD, esto permite entregar diagnósticos acertados a especialistas en el área. El proyecto hace parte de la línea de investigación en procesamiento digital de señal e inteligencia computacional aplicada del grupo de investigación GIBIO de la Universidad Antonio Nariño, implementado en el sistema fotovoltaico de SENA CMM.

Palabras claves: Calidad de energía, sistemas fotovoltaicos, redes neuronales, aprendizaje supervisado. 


\section{INTRODUCCIÓN}

Los sistemas fotovoltaicos han ampliado las formas de generación de energía en el mundo, hacen parte de una forma ecológicamente limpia que ha permitido reducir la dependencia de los combustibles fósiles [1]. La novedad radica en la capacidad de tomar la radiación solar transformarla en energía eléctrica de corriente directa (DC) y, mediante inversores ser convertida a corriente alterna, para ser adaptada a la red eléctrica de servicio público y así ser utilizada en hogares e industrias.

Las horas de brillo solar sobre los paneles, el tipo, cantidad de módulos y orientación son los principales factores que proporcionan condiciones óptimas en relación a cantidad de energía y potencia nominal generada [2].

Algunos trabajos notables realizados en Colombia son: el de la Institución Educativa Martinica en la zona rural de Montería, el cual cuenta con una instalación de 16 paneles solares que garantizan luz durante 24 horas para facilitar el acceso a internet y encendido de ventiladores [3]. En la misma región, el proyecto Celsia Solar, en Yumbo (Valle del Cauca), cuenta con 35000 paneles que proporcionan 9,8 MW cerca de 16,5 MW año [4].

El proyecto considera el uso de los paneles solares ubicados en el Servicio Nacional de Aprendizaje, SENA, complejo sur, Bogotá. La planta solar dispone de cuatro secciones y están divididas en 145 módulos, con una capacidad total de 20,45 kW pico. Cada sección solar va conectada a un inversor monofásico que convierte la corriente directa DC entregada por los paneles a corriente eléctrica alterna $A C$, para ser inyectada a la red eléctrica del edificio del complejo sur.

Existe normatividad que rige algunas características en lo que se refiere a los sistemas fotovoltaicos y se menciona en la norma NTC 4405, que apunta a la eficiencia energética y la evaluación de misma en este tipo de sistemas [5]. También existen normativas que siguen parámetros internacionales determinados por el estándar IEEE 519 [6], donde se toman como referencia la Distorsión Armónica Total (DAT) o THD (del inglés, Total Harmonic Distortion).

Por tanto, el objetivo del proyecto es proporcionar herramientas alternativas para evaluar la calidad de energía eléctrica mediante de técnicas de procesamiento de señales e inteligencia computacional para determinar si los sistemas cumplen o no con los parámetros proporcionados por las normativas.

\section{MATERIALES Y MÉTODOS}

Se implementaron 4 fases: acondicionamiento, adquisición, procesamiento y clasificación, a partir del sistema fotovoltaico se realiza la recolección de datos de señales de tensión. Posteriormente, se realiza un análisis en frecuencia de las señales obtenidas mediante la transformada de Fourier. La Figura 1 describe las fases en el orden establecido.

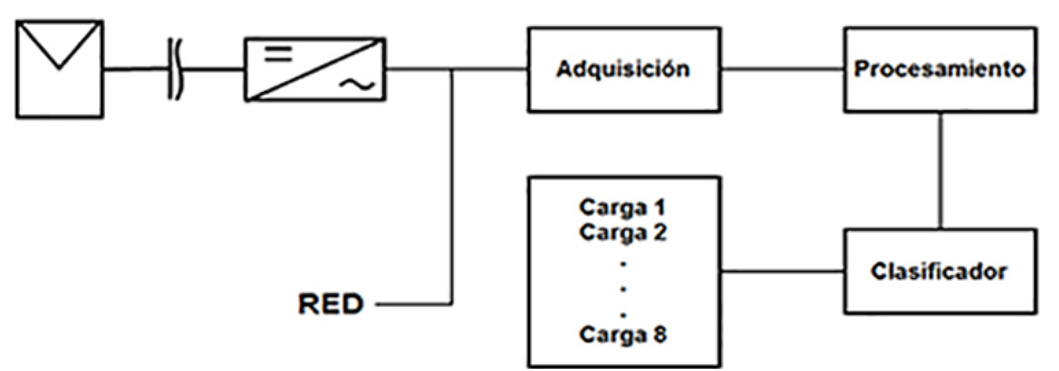

Figura. 1. Diagrama de bloques metodológico.

\section{Acondicionamiento y adquisición de señales}

Para implementar la conversión Analógica-Digital se utilizó una tarjeta Arduino UNO, un transformador para reducir el voltaje de la red eléctrica de $120 \mathrm{Vrms}$ a 12 Vrms y agregarle un nivel de offset de entrada de 2,5 V DC para realizar la adquisición. Finalmente, se obtienen las señales de tensión, representadas en vectores de 100000 muestras, almacenándolos en archivos en formato texto.

\section{Cargas usadas para muestreo de señal}

Se toman diferentes cargas no lineales, porque son ampliamente usadas en estudios de distorsión armónica por su comportamiento [7]. Para establecer un parámetro de referencia, se toman 50 adquisiciones sin ninguna carga. Posteriormente, se toman 20 adquisiciones con siete cargas diferentes para observar su efecto en cada uno de los sistemas. Esto permite establecer las ocho (8) clases, determinadas por las combinaciones de las tres cargas establecidas como base Tabla 1.

Tabla 1. Clasificación de muestras

\begin{tabular}{|c|c|c|} 
Clase & Tipo & \# Muestras \\
\hline Clase 1 & Sin Carga & 50 muestras \\
\hline Clase 2 & Bombilla ahorradora & 20 muestras \\
\hline Clase 3 & Bombilla Led & 20 muestras \\
\hline Clase 4 & Bombilla ahorradora + Bombilla Led & 20 muestras \\
\hline Clase 5 & Motor + Bombilla ahorradora & 20 muestras \\
\hline Clase 6 & Motor + Bombilla Led & 20 muestras \\
\hline Clase 7 & Motor & 20 muestras \\
\hline Clase 8 & Motor + Bombilla ahorradora + Bombilla Led & 20 muestras \\
\hline
\end{tabular}




\section{Procesamiento de las señales}

A partir de las señales de tensión adquiridas, se realiza un estudio en análisis de frecuencia para cada uno de los segmentos obtenidos en la fase anterior. El sistema de adquisición implementado con Arduino, adquiere 1666 muestras por segundo. De acuerdo al teorema de Nyquist, el ancho de banda de dichas señales de tensión estará en la banda de cero y $833 \mathrm{~Hz}$ [8].

\section{Entrenamiento de la RN y clasificación de las señales}

El objetivo de la red neuronal es poder determinar el tipo de carga que ha sido conectada al sistema a partir de la información en frecuencia. Para esto, es necesario presentar la información de las 15 características a la entrada e indicarle a la red la salida de acuerdo al tipo de carga a la cual corresponden dichas características.

Para la aplicación y entrenamiento de la red neuronal se realizó una validación cruzada [9]. La base de datos se divide en folds para mostrar la generalización del aprendizaje. El conjunto de muestras se dividió en 5 folds: cuatro de ellos para entrenamiento de la red y uno para validar el entrenamiento. Fueron establecidos nueve casos, estos se dieron de acuerdo a las combinaciones de las características, información de energía e información de picos de las subbandas estudiadas.

Se plantean diferentes escenarios para determinar la clasificación de las ocho clases, FV-Energías, FV-Picos, FV-Energías-Picos, RED-Energías, RED-Picos, RED-Energías-Picos, FV-RED-Energías, FV-RED-Picos, FV-RED-Energías-Picos.

\section{RESULTADOS Y ANÁLISIS DE RESULTADOS}

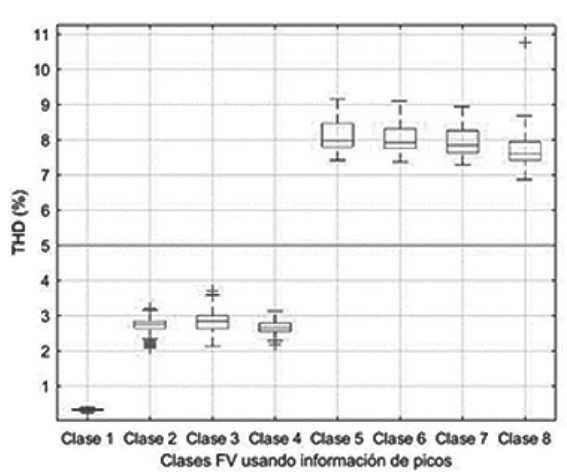

a)

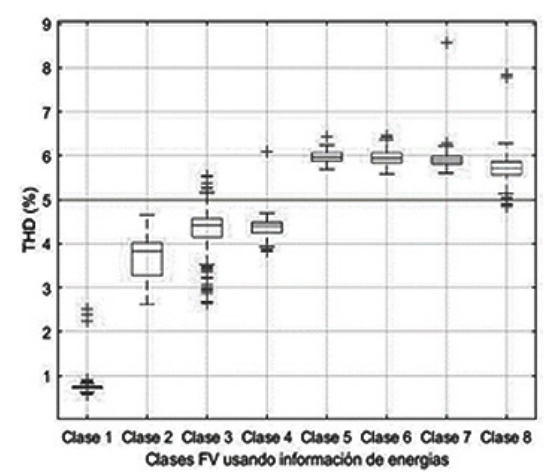

b)
Figura. 2. THD para características basadas en información de a) Picos y b) energías.
Acorde a la Figura 2a, para la clase 1 los valores están concentrados por debajo de una THD de $1 \%$, con algunos valores atípicos entre el 2 y $3 \%$. Las clases 2, 3 y 4 se encuentran en su mayoría con valores dentro de la norma, donde para la clase 3 tiene valores atípicos por encima del $5 \%$. Finalmente, para este escenario las clases 5 a 8 muestran los valores del THD por encima del máximo permitido por la norma, concentrándose entre el 5,5 y el 6,5 \%. Esto quiere decir que cuando se conecta el motor, solo o en combinación con las otras cargas Tabla 1, genera una distorsión armónica total que está ligeramente por fuera de la norma. Acorde a la figura $2 \mathrm{~b}$ se presenta un comportamiento similar tanto en picos como en energías.
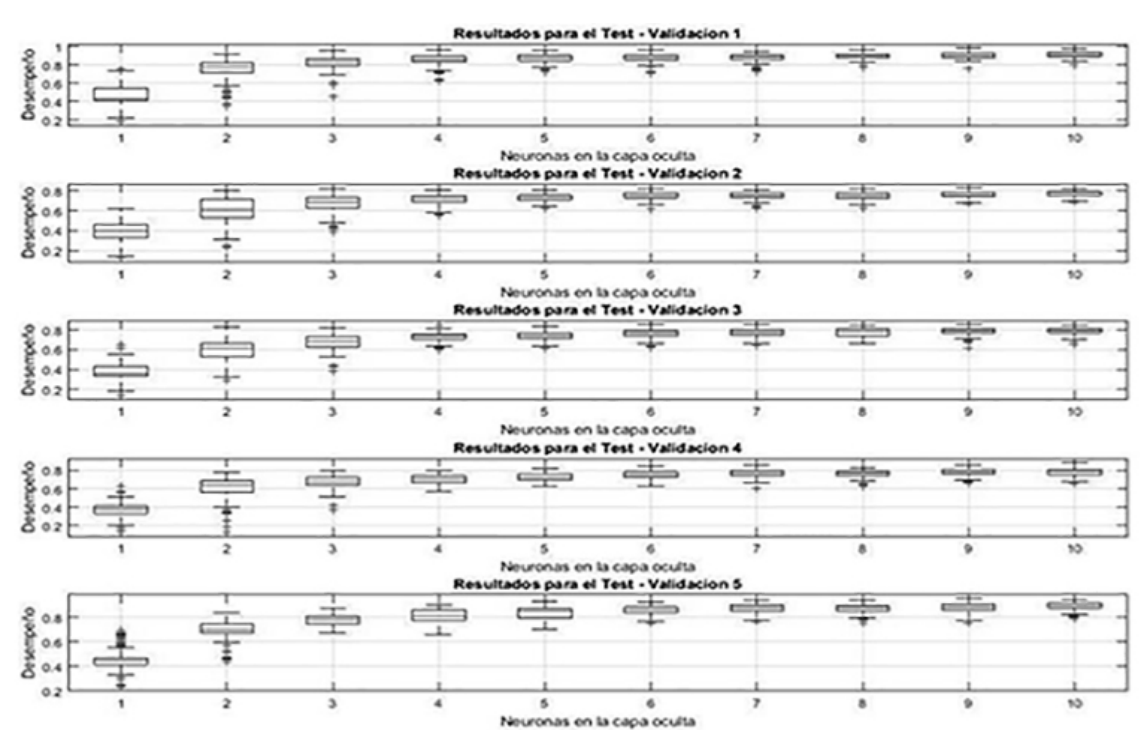

Figura 3. Resultados para clasificación de energías del sistema FV.

Se puede observar que para todos los folds, que las arquitecturas con cinco neuronas son suficientes para obtener buenos resultados Fig. 3, pues con más neuronas los resultados se estabilizan. Además, existe consistencia para los 100 experimentos realizados representados por las inicializaciones, obteniendo resultados alrededor y por encima del 80 \% de clasificación para todos los folds.

\section{CONCLUSIONES}

Los sistemas de supervisión pueden impactar positivamente la calidad de energía en sistema fotovoltaicos, ya que facilitan la toma de decisiones y ayudan a mantener los sistemas dentro de las normativas.

La calidad de energía eléctrica se ve afectada durante la conexión de cargas no lineales, el THD sobrepasa los umbrales definidos por las normativas, cargas lineales no afectan el sistema, muestran un THD inferior 
al $5 \%$. La calidad de la energía no se ve afectada cuando la señal procede de la red convencional.

Cuando se comparan las técnicas para obtención de características, basadas en Energías y en Picos, es posible observar que las primeras ofrecen información de THD menores para cuando se analiza el sistema FV comparado con la segunda técnica. Cuando la energía se toma de la red convencional el efecto es inverso, es decir, la información tomada de las Energías produce mayores valores de THD.

\section{AGRADECIMIENTOS}

Especial agradecimiento a la Universidad Antonio Nariño, por su aval para el desarrollo del proyecto y al Servicio Nacional de Aprendizaje, por permitir realizar las pruebas y estudios en el sistema fotovoltaico.

\section{REFERENCIAS BIBLIOGRÁFICAS}

[1] K. Hakuta, H. Masaki, M. Nagura, N. Umeyama, and K. Nagai, "Evaluation of Various Photovoltaic Power Generation Systems," Inst. Electr. Electron. Eng. IEEEXplore, no. 2015 IEEE International Telecommunications Energy Conference (INTELEC), pp. 1-4, 2015.

[2] O. I. Adekol, A. M. Almaktoof, and A. K. Raji, "Design of a Smart Inverter System for Photovoltaic Systems Application," IEEEXplore, no. 2016 International
Conference on the Industrial and Commercial Use of Energy (ICUE), pp. 310-217, 2015.

[3] A. Alcaldia de monteria, "Primer colegio con energía solar en el país," 2017. .

[4] E. Celsia Solar grupo Argos, "Empezó a generar energía Celsia Solar Yumbo, primera granja fotovoltaica de Colombia," 1, 2017.

[5] I. Instituto Colombiano de Normas Técnicas and I. Instituto de Ciencias Nucleares y Energías Alternativas, "Evaluación de la eficiencia de los sistemas solares fotovoltaicos y sus componentes. NTC 4405," Icontec Internacional. p. 7, 1998.

[6] I. IEEE Power Engineering society, "IEEE Recommended Practices and Requirement for Harmonic Control in Electrical Power Systems STD IEEE-519-1992." p. 101, 1992.

[7] M. Barajas and B. Sánchez, "Contaminación armónica producida por cargas no lineales de baja potencia: modelo matemático y casos prácticos," Scielo, pp. 189-198, 2010.

[8] V. R. Franca, M. A. Filho, and K. Carneiro De Oliveira, "Analysis of Power Quality for Photovoltaic Systems Connected to the Grid," IEEEXplore, p. 5, 2016.

[9] M. Kubat, "Neural networks: a comprehensive foundation by Simon Haykin, Macmillan, 1994, ISBN 0-02-352781-7.," The Knowledge Engineering Review, vol. 13, no. 4. p. S0269888998214044, 1999 


\title{
DISEÑO Y CONSTRUCCIÓN DE UN REACTOR DE CAVITACIÓN HIDRODINÁMICA PARA LA PRODUCCIÓN DE BIODIESEL
}

\author{
Gómez, Luis-Clavijo, Andrés ${ }^{1}$ \\ Malagón, Dionisio ${ }^{1}$ \\ 1 Universidad Santo Tomás, Semillero energía fluidos \\ luisgomezm@usantotomas.edu.co, andresclavijo@usantotomas.edu.co, dionisiomalagon@ \\ usantotomas.edu.co
}

\begin{abstract}
ÁREA TEMÁTICA
\end{abstract}
Biomasa, Bioenergía y Biocombustibles

\begin{abstract}
RESUMEN
Durante los últimos años, la demanda de biocombustibles a nivel global ha generado que la producción de estos sea una alternativa para reemplazar los combustibles fósiles que se han utilizado por muchos años; situación que ha desembocado en un impacto ambiental con respecto a la contaminación que estos generan. Por eso, este proyecto va enfocado en la investigación, desarrollo e implementación de nuevas tecnologías para la producción de biodiesel por medio de procesos tecnológicos que se han estudiado previamente. De esta manera, se procedió a realizar la caracterización y diseño conceptual de un equipo para la obtención de biodiesel por medio del proceso de cavitación hidrodinámica, a partir de la revisión bibliográfica de equipos similares "placa orificio" y "cavitadores hidrodinámicos" de laboratorio, se diseñó y dimensionó un reactor de hidrocavitación piloto para este equipo determinado a partir de la información recolectada. Teniendo en cuenta los datos proporcionados acerca de estos equipos y procesos similares, se procedió a realizar el diseño de detalle del equipo contemplando como factor importante las principales características que este debe poseer para realizar dicho proceso. Dentro de los principales componentes como se aclaró anteriormente está el reactor hidrodinámico y específicamente la electrobomba que se requiere y utilizara para el funcionamiento del equipo, debido a que esta brindara la energía suficiente para aumentar la presión del fluido y así por consiguiente este logre experimentar la caída de presión suficiente dentro del reactor para así generar el fenómeno de cavitación. La realización de este proyecto trae consigo el desarrollo y estudio de esta tecnología, que permitirá el aprovechamiento de residuos de aceites vegetales para la producción de biodiesel y además aportará a la fomentación de nuevos procesos para la producción del mismo.
\end{abstract}

Palabras claves: Cavitación hidrodinámica, biodiesel, placa orificio, reactor, diseño. 


\section{INTRODUCCIÓN}

A nivel global la producción de biocombustibles se ha convertido en una alternativa para reemplazar a los combustibles de origen fósil que se han empleado por casi 100 años. Gracias a lo anterior se ha logrado ampliar la participación de las energías alternativas en la canasta energética global, así como reducir localmente las emisiones de gases derivados de los combustibles fósiles [1]. Para el caso particular Colombiano, con la implementación del uso obligatorio de biodiesel en automotores, la producción de biodiesel se elevó hasta un orden de casi medio millón de toneladas[2]. Lo anterior ha conllevado a la creciente necesidad de producir en mayores cantidades el biodiesel incrementando el cultivo de palma, siendo esta la principal materia prima para la producción de biodiesel en Colombia.

Las tecnologías de intensificación de reacción particularmente en la producción de Biodiesel, son insipientes en el país tanto desde el punto de vista industrial como desde el punto de vista científico. El apropiar dichas tecnologías propenderá en el incremento de la competitividad de las empresas productoras de Biodiesel, así como en el sector energético y de hidrocarburos directamente beneficiados. El anterior beneficio redundará directamente en el cumplimiento de la metas de producción de Biodiesel de calidad [6], diversificación de materias primas, tiempos de reacción más cortos y consumos energéticos menores que sistemas tradicionales que ya han sido probados tanto en laboratorio[7], [8], [9] como escalados a nivel industrial[10], [11],[12]. El desarrollo de este tipo de tecnologías de punta a nivel mundial en sectores tan neurálgicos para el país como lo son los biocombustibles [13], [14], fomentará el desarrollo e inmersión de tecnología nacional de calidad e innovación en proceso productivos en el sector energético.

\section{Cavitación}

La cavitación puede ser definida como la ruptura de un medio liquido por la reducción de la presión local. El cambio drástico de presión produce un cambio de fase en el líquido, dando como resultado el crecimiento de burbujas de vapor saturado que al acercase a regiones de alta presión colapsan y liberan una alta energía [15] en donde las condiciones locales de presión y temperatura por el efecto transitorio de colapso pueden llegar generar impactos con presiones de miles de atmósferas y alcanzar temperaturas de miles de Kelvin [11]. La dinámica del proceso de nucleación (generación de las burbujas) y colapso, está altamente influenciado por las condiciones locales del flujo, su configuración y las propiedades físicas de este, provocando distintos tipos de cavitación a diferentes regímenes.

\section{Agentes favorables para la generación de cavitación}

Dentro de los factores que favorecen la cavitación se pueden mencionar[15],[21]:

Cambios bruscos o severos de geometría pueden generar un incremento de la velocidad cortante local resultando esto en caídas de presión. Esto se da por ejemplo en restricciones como orificios, venturis, o también debido geometrías que inducen alta curvatura en las líneas de corriente.

La cavitación también puede ocurrir en flujos cortantes debido a la gran turbulencia y por fluctuaciones de presión. La naturaleza de algunos flujos inestables, como el golpe de ariete puede resultar en una fuerte aceleración del fluido y consecuentemente en la producción instantánea de bajas presiones en algunos puntos en el flujo conduciendo a la cavitación.

\section{Biodiesel}

El biodiesel es, definido por la ASTM, como un combustible alternativo para motores diésel, que consiste en los ésteres de ácidos grasos obtenidos por la reacción de transesterificación entre los aceites vegetales o grasas animales y un alcohol [16], [17].

Así mismo, el biodiesel como combustible posee enormes ventajas tales como su disponibilidad a partir de materia prima renovable, alta eficiencia en combustión, y bajo contenido de emisiones en sulfuros y aromáticos [18]. Debido a ello, es una alternativa económica, renovable [19].

\section{MATERIALES Y MÉTODOS}

Durante la realización de este proyecto se debe tener en cuenta la realización de una metodología de diseño que sea desarrollada de acuerdo a la problemática establecida, en este caso es la realización y diseño de un equipo de laboratorio que permita la producción de biodiesel a partir del fenómeno de cavitación hidrodinámica.

Dentro de esta metodología se debe considerar e incluir parámetros importantes como especificaciones 
de diseño, las cuales nos permiten conocer los requerimientos planteados por el cliente para su posterior análisis y determinación sobre las características que este debe poseer. Luego de esto y a partir de la literatura consultada sobre artículos científicos relacionados y desarrollados acerca de la problemática planteada, se lleva a cabo el desarrollo de las posibles alternativas y propuestas sobre el diseño de este. Tomando en base la información recolectada y caracterización de esta, se realiza el diseño conceptual del equipo, el cual debe ser presentado como posible solución al cliente.

Avalada y aprobada la solución se procede a desarrollar el diseño de detalle del equipo para su posterior fabricación. Este paso incluye la realización de los cálculos necesarios para determinar algunas características de este. Dentro de los cálculos que se deben realizar; esta la comprobación del espesor de pared necesaria de la tubería. También se deben incluir los cálculos de las pérdidas generadas dentro del sistema para determinar así la potencia mínima requerida por la electrobomba, de esta manera garantizar el correcto funcionamiento del equipo.

Finalmente definido y aprobado el diseño de detalle, se realiza la construcción de este basado en los planos realizados.

Posteriormente se realiza la puesta en marcha de este, para realizar el análisis y evaluación del equipo para confirmar que este cumple con los objetivos planteados inicialmente.

\section{RESULTADOS Y ANÁLISIS DE RESULTADOS}

De acuerdo a la metodología planteada para el desarrollo de este proyecto a continuación se muestran los resultados obtenidos de este proyecto.

\section{Requerimientos del cliente}

Los requerimientos de diseño planteados por el cliente se muestran en la siguiente tabla.

Tabla 1. Especificaciones de diseño

\begin{tabular}{|c|c|}
\hline Tipo & Descripción \\
\hline \multirow{3}{*}{$\begin{array}{c}\text { Propiedades } \\
\text { físicas }\end{array}$} & El peso del equipo debe ser ligero y ergonómico. \\
\cline { 2 - 2 } & \begin{tabular}{c} 
El equipo debe utilizar el menor espacio posible. \\
\cline { 2 - 2 }
\end{tabular} \\
\hline
\end{tabular}

\begin{tabular}{|c|c|}
\hline Tipo & Descripción \\
\hline \multirow{3}{*}{$\begin{array}{l}\text { Tanque de } \\
\text { almacena- } \\
\text { miento. }\end{array}$} & $\begin{array}{l}\text { La capacidad del tanque del fluido debe ser de } 5 \text { It en } \\
\text { acero inoxidable. }\end{array}$ \\
\hline & $\begin{array}{c}\text { Debe contar con una válvula que permita vaciar el } \\
\text { tanque completamente para el lavado y vertimiento } \\
\text { del producto final. }\end{array}$ \\
\hline & $\begin{array}{c}\text { El tanque se debe permitir retirar del equipo para su } \\
\text { mantenimiento o cambio. }\end{array}$ \\
\hline \multirow{5}{*}{$\begin{array}{l}\text { Sistema de } \\
\text { control y } \\
\text { medición de } \\
\text { datos. }\end{array}$} & $\begin{array}{c}\text { El equipo debe contar con varios instrumentos de } \\
\text { medición que se describen a continuación: }\end{array}$ \\
\hline & Presión del fluido a la entrada y salida del reactor. \\
\hline & Temperatura del fluido. \\
\hline & $\begin{array}{l}\text { Caudalímetro para conocer el caudal y velocidad del } \\
\text { fluido. }\end{array}$ \\
\hline & $\begin{array}{l}\text { Válvula de control que permita regular el caudal del } \\
\text { fluido para realizar diferentes pruebas. }\end{array}$ \\
\hline $\begin{array}{l}\text { Fuente de } \\
\text { energía }\end{array}$ & $\begin{array}{l}\text { El equipo debe operar con línea bifásica } \\
\text { a un voltaje de } 110 .\end{array}$ \\
\hline $\begin{array}{l}\text { Automatiza- } \\
\text { ción }\end{array}$ & $\begin{array}{l}\text { El equipo debe contar con un tablero de control eléc- } \\
\text { trico que permita la manipulación y seguridad de este } \\
\text { con los respectivos elementos de control y protec- } \\
\text { ción de los componentes eléctricos del sistema. }\end{array}$ \\
\hline \multirow{3}{*}{$\begin{array}{l}\text { Mantenimien- } \\
\text { to y operación }\end{array}$} & $\begin{array}{l}\text { El mantenimiento del equipo debe ser el más fácil y } \\
\text { riguroso, esto debido a que al finalizar cada prueba se } \\
\text { debe realizar un lavado completo de este para garan- } \\
\text { tizar su correcto funcionamiento. }\end{array}$ \\
\hline & $\begin{array}{c}\text { Este debe garantizar que en el futuro no se generen } \\
\text { riesgos por suciedades que puedan alterar el proceso } \\
\text { y el buen funcionamiento de este. }\end{array}$ \\
\hline & $\begin{array}{l}\text { Su operación debe ser totalmente manual por medio } \\
\text { de un tablero de control. }\end{array}$ \\
\hline \multirow{2}{*}{$\begin{array}{l}\text { Reactor de } \\
\text { cavitación }\end{array}$} & $\begin{array}{c}\text { El reactor de hidrocavitación debe contar con un } \\
\text { sistema de conexión universal, ya sea por medio de } \\
\text { bridas, uniones u otro tipo de mecanismo. }\end{array}$ \\
\hline & $\begin{array}{c}\text { Debe permitir el intercambio de las placas orificio que } \\
\text { se utilizaran para las distintas pruebas. }\end{array}$ \\
\hline
\end{tabular}

A partir de los requerimientos del clientes planteados en la tabla 1. Se procedió a realizar el análisis de estos, los cuales nos brindaron características básicas acerca de lo que se espera del este y que se debieron tener en cuenta para el diseño, como lo es el peso, el dimensionamiento y funcionamiento de este.

\section{Diseño conceptual}

Realizando el diseño conceptual del equipo de acuerdo a la investigación detallada acerca del proceso de hidrocavitación para la producción de Biodiesel de manera experimental, se han determinado variables y características específicas de este, a partir de los requerimientos del cliente y de información suministrada de la bibliografía consultada, se determinaron las características de los componentes con los cuales el equipo contara para el desarrollo del fenómeno, entre ellos el más importante es el reactor de hidrocavitación que es donde se generara este proceso. 
A partir de esta información suministrada se determinaron algunas características de los componentes que debe poseer el equipo son los siguientes:

- Electrobomba centrifuga.

- Manómetros.

- Válvula de regulación de caudal. (Válvula de Compuerta)

- Válvula de Bypass manual de retorno del fluido al tanque. (Válvula de globo)

- Tanque de mezcla.

- Flujometro.

- Reactor de hidrocavitación.

• Tubería en acero inoxidable. ( Diámetro 1" SCH 40)

\section{Diseño del reactor}

De acuerdo a la literatura consultada se encontró información acerca del diseño y modelo de un reactor de hidrocavitación, el cual se tomó como referencia para realizar el diseño de este, como se encuentra en la literatura. Un ejemplo de esto encontramos un artículo muy interesante como lo es la "Síntesis intensificada de biodiesel utilizando reactores de cavitación hidrodinámica basados en la interesterificación de aceite de cocina usado" [22] el cual nos describe el proceso que se realizó para obtención del biodiesel a partir de aceite usado de cocina y brinda información más detallada sobre el reactor piloto que utilizaron para realizar la experimentación. A partir de la información brindada en este artículo se procedió con la caracterización y diseño de nuestro reactor de hidrocavitación, el cual funcionaria también bajo la experimentación de placas orificio instaladas dentro del reactor para la ayuda en la generación de la cavitación, así de esta manera realizar el estudio de los efectos generados por la utilización de distintas configuraciones de placas orificio. Uno de estos artículos relevantes que muestra el estudio realizado de la experimentación de cavitación hidrodinámica por medio de placas orificio es "Producción más limpia de éster metílico usando aceite de cocina de desecho derivado a partir de oleína de palma utilizando un reactor de cavitación hidrodinámica" [23].

De acuerdo a la esta información suministrada se realizó el diseño detallado de nuestro reactor con placas orificio, el cual se muestra en las figuras 1 y 2.

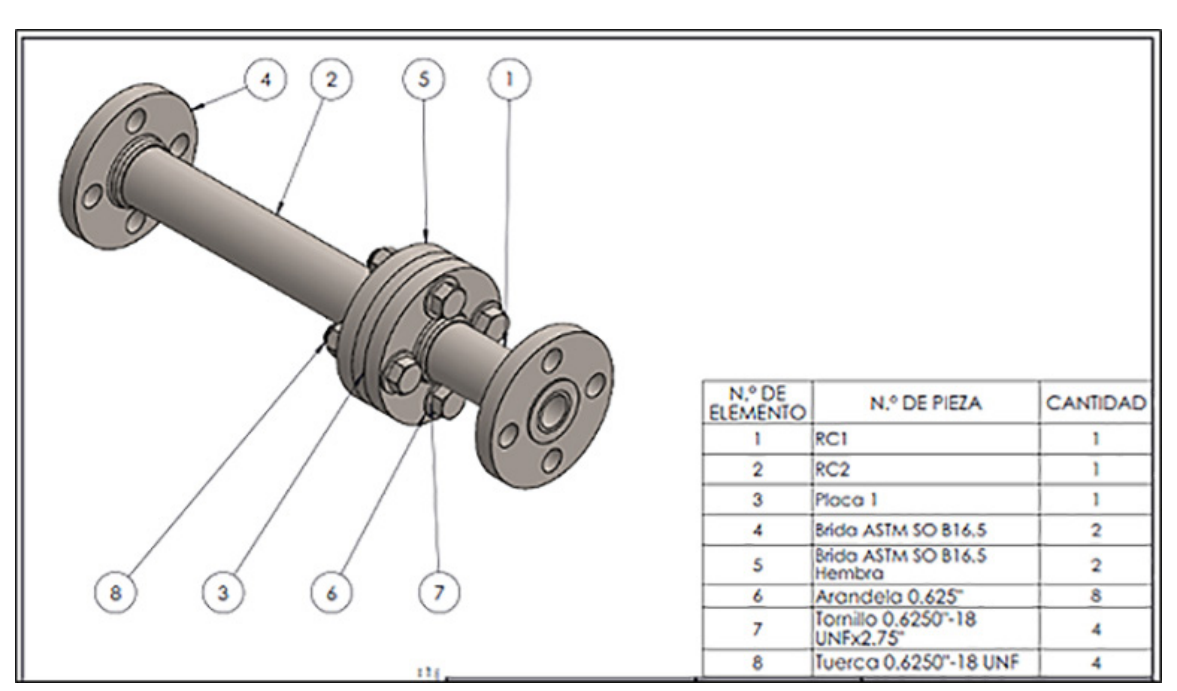

Figura 1. Diseño general del reactor de hidrocavitación

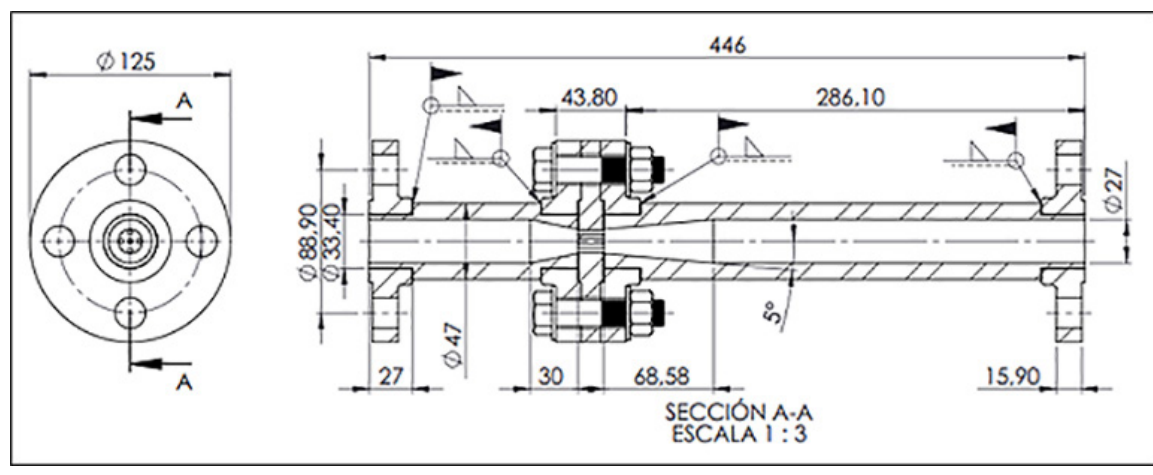

Figura 2. Dimensionamiento reactor de hidrocavitación

\section{Diseño general del equipo}

Teniendo en cuenta el diseño del reactor y los requerimientos planteados anteriormente, se procedió a realizar el diseño general del equipo, el cual podemos ver en las figuras 3 y 4.

A medida que se iba avanzando en el diseño de este, se realizaron los cálculos propuestos para verificación de que el equipo funcionara según lo planteado. En las siguientes tablas podemos ver los resultados obtenidos de estos cálculos.

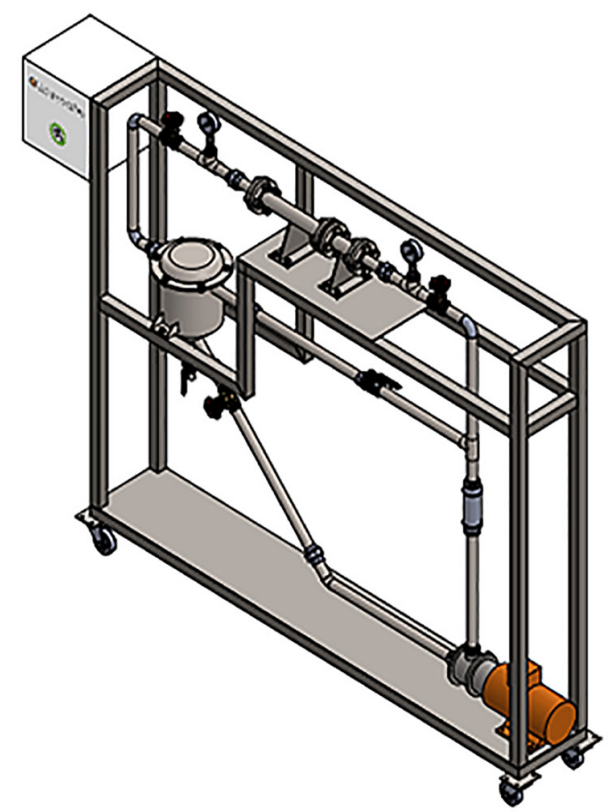

Figura 3. Diseño final del equipo de cavitación hidrodinámica 

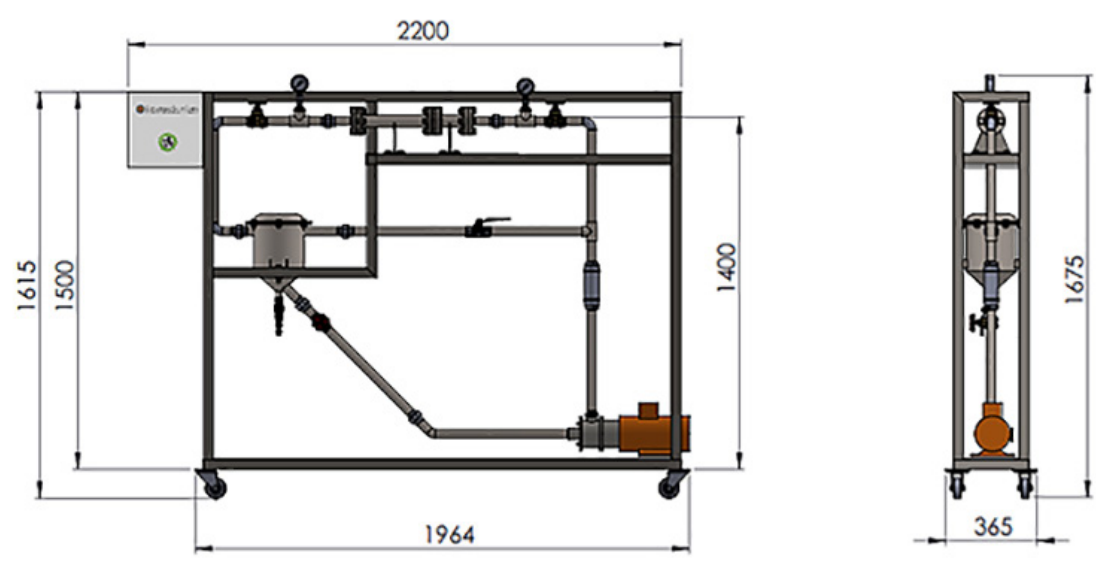

Figura 4. Dimensiones generales del equipo

Tabla 2. Valores de entrada

\begin{tabular}{|c|c|c|}
\hline \multicolumn{3}{|c|}{ Datos de entrada } \\
\hline \multicolumn{3}{|c|}{ Material tubería } \\
\hline \multicolumn{3}{|c|}{ Acero Inoxidable 304 SCH 40} \\
\hline \multicolumn{3}{|c|}{ Presión del sistema } \\
\hline $\mathrm{P}$ & 20,00 & Bar \\
\hline$P$ & 2000,00 & $\mathrm{kPa}$ \\
\hline $\mathrm{P}$ & 290,00 & PSI \\
\hline \multicolumn{3}{|c|}{ Diámetro exterior tubería } \\
\hline Do & 33,36 & $\mathrm{Mm}$ \\
\hline Do & 1,31338583 & In \\
\hline \multicolumn{3}{|c|}{ Coeficiente relación temperatura y material } \\
\hline $\mathrm{Y}$ & 0,40 & --- \\
\hline \multicolumn{3}{|c|}{ Tensión admisible del material } \\
\hline SE & 13,30 & $\mathrm{KSI}$ \\
\hline SE & 91703,50 & $\mathrm{KPa}$ \\
\hline S & 13300 & PSI \\
\hline \multicolumn{3}{|c|}{ Calibre tubo Seleccionado SCH } \\
\hline $\mathrm{t}$ & 3,38 & $\mathrm{Mm}$ \\
\hline $\mathrm{t}$ & 0,13307087 & $\ln$ \\
\hline
\end{tabular}

Tabla 3. Cálculo espesor de pared.

\begin{tabular}{|c|c|c|}
\hline \multicolumn{3}{|c|}{ Formula } \\
\hline \multicolumn{3}{|c|}{ Cálculo espesor de pared Según norma ASME B31.1 } \\
\hline \multicolumn{3}{|c|}{} \\
\hline \multicolumn{3}{|c|}{ Factor de seguridad tubería } \\
\hline \multirow{3}{|c|}{ Form } \\
\hline
\end{tabular}

Tabla 4. Presión de prueba hidrostática

Presión de prueba hidrostática "Formula de Barlow" para tubería Formula

\begin{tabular}{|c|c|c|}
\hline \multicolumn{3}{|c|}{ Formula } \\
\hline \multicolumn{3}{|c|}{} \\
\hline Ph & 2695,08393 & PSI \\
\hline Ph & 185,867857 & Bar \\
\hline \multicolumn{3}{|c|}{ Factor de seguridad tubería } \\
\hline$\psi$ & 1,30237131 & --- \\
\hline
\end{tabular}

De acuerdo a los resultados obtenidos en la tabla 3 y 4 podemos interpretar que el espesor de tubo seleccionado para el sistema no va a tener ningún inconveniente debido a que este contara con un factor de seguridad de 9,37 debido a que la presión máxima de trabajo determinada para el equipo es de 20 bar y el tubo puede trabajar a una presión máxima de 185 Bar.

Tabla 5. Valores de entrada

\begin{tabular}{|c|c|c|}
\hline \multicolumn{3}{|c|}{ Datos de entrada } \\
\hline \multicolumn{3}{|c|}{ Diámetro tubería } \\
\hline Di & 26,6 & $\mathrm{~mm}$ \\
\hline Di & 0,0266 & $\mathrm{~m}$ \\
\hline \multicolumn{3}{|c|}{ Diferencia de altura } \\
\hline $\mathrm{H}$ & 0,818 & $\mathrm{~m}$ \\
\hline \multicolumn{3}{|c|}{ Presión dentro del tanque } \\
\hline $\mathrm{P} 1-2$ & 1 & atm \\
\hline \multicolumn{3}{|c|}{ Longitud aspiración tubería } \\
\hline LS & 1,39 & $\mathrm{~m}$ \\
\hline \multicolumn{3}{|c|}{ Longitud descarga tubería } \\
\hline Ld & 2,82 & $\mathrm{~m}$ \\
\hline \multicolumn{3}{|c|}{ Caudal del fluido } \\
\hline Q & 50 & $\mathrm{It} / \mathrm{min}$ \\
\hline Q & 0,00083333 & $\mathrm{~m} 3 / \mathrm{s}$ \\
\hline \multicolumn{3}{|c|}{ Gravedad } \\
\hline G & 9,81 & $\mathrm{~m} / \mathrm{s} 2$ \\
\hline \multicolumn{3}{|c|}{ Eficiencia de bomba } \\
\hline$E$ & $90 \%$ & $\%$ \\
\hline \multicolumn{3}{|c|}{ Densidad fluido (Diesel) } \\
\hline$\Sigma$ & 921 & $\mathrm{~kg} / \mathrm{m} 3$ \\
\hline \multicolumn{3}{|c|}{ Rugosidad tubería } \\
\hline$E$ & 0,0002 & $\mathrm{~mm}$ \\
\hline \multicolumn{3}{|c|}{ Viscosidad dinámica del fluido } \\
\hline$\mu$ & 0,1215 & $\mathrm{~Pa}^{*} \mathrm{~s}$ \\
\hline \multicolumn{3}{|c|}{ Cambio de sección contracción-expansión gradual } \\
\hline D & 27 & $\mathrm{~mm}$ \\
\hline $\mathrm{D}$ & 15 & $\mathrm{~mm}$ \\
\hline \multicolumn{3}{|c|}{ Cambio de sección expansión-contracción repentina (placa orificio) } \\
\hline D & 2 & $\mathrm{Mm}$ \\
\hline $\mathrm{D}$ & 15 & $\mathrm{Mm}$ \\
\hline \# Agujeros & 9 & --- \\
\hline
\end{tabular}

Tabla 6. Cabeza y potencia mínima del equipo

\begin{tabular}{|c|c|c|}
\hline \multicolumn{3}{|c|}{ Cabeza neta requerida por la bomba } \\
\hline \multicolumn{3}{|c|}{ Formula } \\
\hline $\mathrm{hB}$ & 6,06558803 & $\mathrm{~m}$ \\
\hline \multirow{2}{*}{\multicolumn{3}{|c|}{ Potencia mínima requerida por la bomba }} \\
\hline & & \\
\hline $\mathrm{PB}$ & 0,06802037 & hp \\
\hline
\end{tabular}

Se realiza el análisis de los resultados obtenidos en la tabla 6, la cual muestra los valores de la cabeza y potencia mínima requerida por la bomba a partir de los datos determinados en la tabla 5.

Estos valores se determinan teniendo en cuenta las pérdidas generadas dentro del sistema y la diferencia de altura a la cual va a ser bombeado el fluido. Realizando este cálculo se determina que la potencia mínima de la electrobomba debe de ser aproximadamente 
de 0,07 HP, al analizar este resultado se opta por realizar una comparación con los valores de las potencias con las que trabajan las bombas de estos equipos, se encuentra que estos trabajan en un rango de $1 \mathrm{HP}-7$ HP. Se decide trabajar con una bomba dentro de este rango de potencia, debido a que se debe de tener en consideración el rango de caudales en los cuales estas bombas trabajan y le suministran la energía suficiente al fluido para lograr generar el efecto de cavitación dentro del reactor, debido a que el fluido llega a una presión determinada y esta luego debe caer por debajo de la presión de vapor del fluido para generar la cavitación.

Realizando estos cálculos y analizándolos, se determina que se trabajara con una bomba de 1,5 HP con cabezal en acero en inoxidable, esta última característica se definió así debido a que este es uno de los requerimientos del cliente. Por otro lado se decidió trabajar con esta electrobomba debido a que esta se encuentra dentro del rango de las potencias con las que trabajan los demás equipos relacionados.

A continuación en la figura 5 se muestra el equipo ya fabricado según el diseño de detalle realizado con todos sus componentes.

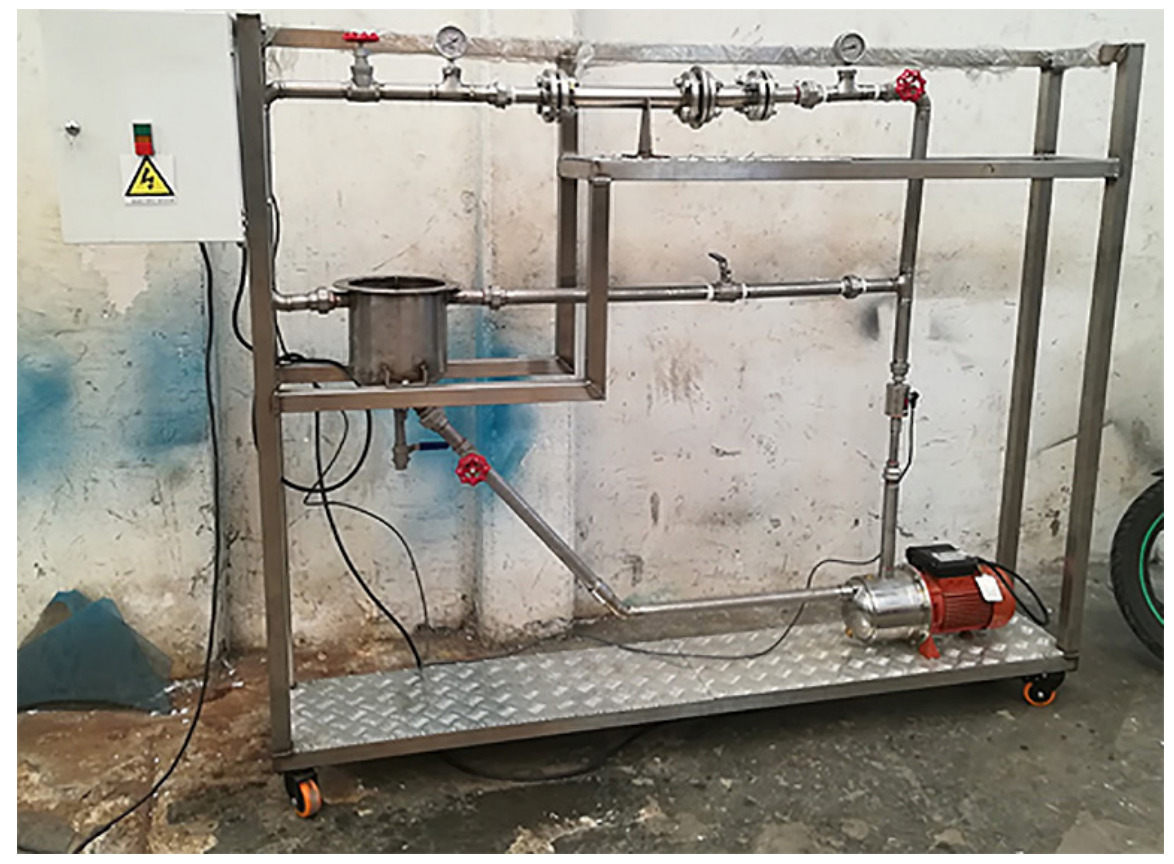

Figura 5. Equipo fabricado y puesto en marcha

\section{CONCLUSIONES}

Respecto a la investigación realizada y el desarrollo de este proyecto se determina que durante los últimos años la influencia de nuevas tecnologías para la optimización de procesos, especialmente en este caso que es la producción de biodiesel a partir de aceites vegetales, ha venido tomando mucha fuerza y se ha venido realizando por medio de nuevas alternativas. En este caso se logró cumplir con el objetivo principal que era el diseño de un equipo generador de cavitación hidrodinámica por medio de placas perforadas con diferentes configuraciones. A pesar de que teóricamente se determinó que el equipo requiere una bomba de menor capacidad, se decidió trabajar con una que estuviera dentro del rango de capacidad de los demás equipos, esto se debe a que se encontró poca información acerca de características físicas y específicas del reactor; el por qué este proceso requiere de una bomba de características específicas y no cualquier otro tipo generando así una incertidumbre grande al momento de la selección de la bomba, y valores que nos definan el punto óptimo para la generación de este proceso junto con especificaciones mucho más técnicas de este tipo de equipos de laboratorio. Sin importar la poca información encontrada sobre el diseño de estos equipos se logró desarrollar y fabricar un equipo de Cavitación hidrodinámica para las instalaciones de la universidad Santo Tomás, el cual quedara a disposición de los estudiantes para próximas investigaciones relacionadas con este tema, en las cuales posiblemente se busque la optimización y mejoramiento del equipo, realizando investigaciones más a fondo sobre estos procesos, los cuales ha demostrado ser prometedores al momento de la producción de biodiesel y otros temas que tienen un impacto ambiental positivo.

El desarrollo de este proyecto determinó que es posible realizar un equipo de estas características, con una inversión de capital no tan grande y que esto representaría la implementación e inversión en este tipo procesos dentro de la industria colombiana para generar el desarrollo de nuevas tecnologías y así de esta manera garantizar en el futuro un mejor desarrollo sostenible respecto a políticas ambientales sobre el consumo de combustibles fósiles dentro del país.

\section{REFERENCIAS BIBLIOGRÁFICAS}

[1] C. Razo, A. Astete-Miller, A. Saucedo, and C. Ludeña, "Biocombustibles y su impacto potencial en la estructura agraria, precios y empleo en América Latina," Santiago de Chile, 2007.

[2] A. Ladino and H. B. Jason, "Diseño de Reactor por Cavitación Hidrodinámica Mediante CFD para Aplicaciones de Producción de Biodiesel," Universidad de Cali, 2014.

[3] L. López, J. Bocanegra, and D. Malagón-romero, "Obtención de biodiesel por transesterificación de aceite," Ing. y Univ., vol. 19, no. 1, pp. 155-172, 2015. 
[4] R. Alarcón, D. Malagón-Romero, and A. Ladino, "Biodiesel production from waste frying oil and palm oil mixtures," Chem. Eng. Trans., vol. 57, pp. 571-576, 2017.

[5] D. Rodríguez, J. Riesco, and D. Malagon-Romero, "Production of Biodiesel from Waste Cooking Oil and Castor Oil Blends," Chem. Eng. Trans., vol. 57, pp. 679684, 2017.

[6] H. G. Romero, "Evaluación de la política de Biocombustibles en Colombia," 2012.

[7] P. R. Gogate, "Cavitational reactors for process intensification of chemical processing applications: A critical review," Chem. Eng. Process., vol. 47, pp. 515527, 2008.

[8] P. R. Gogate, R. Tayal, and A. Pandit, "Cavitation: A technology on the horizon," Curr. Sci., pp. 35-46, 2006.

[9] A. Pandit and P. R. Gogate, "A review and assessment of hydrodynamic cavitation as a technology for the future," Ultrason. Sonochemistry, vol. 12, pp. 2127, 2005.

[10] H. D. Inc., "Hydro Dynamics Inc.," Hydro Dynamics Inc., 2014.

[11] C. T. Inc., "Cavitation Technologies Inc.," Cavitation Technol. Inc., 2014.

[12] Piedmont biofuels., "Piedmont biofuels.," Piedmont biofuels., 2014.

[13] L. M. Florez, "Biocombustibles de segunda generación," Universidad Autónoma de Occidente, Cali, Colombia, 2007.
[14] U. and F. Bariloche, "PEN 2010-2030," UNAL Fund. Bariloche, 2009.

[15] J.-M. Michelle and J.-P. Franc, Fundamentals of Cavitation. 2005.

[16] J. Wang, J. Ji, Y. Li, Y. Yu, and Z. Xu, "Preparation of biodiesel with the help of ultrasonic and hydrodynamic cavitation," Ultrasonics, pp. 411-414, 2006.

[17] A. Demirbas, "Comparison of transesterification methods for production of biodiesel from vegetable oils and fats," Elsevier, vol. 49, no. 1, pp. 125-130, 2008.

[18] E. M. Nada, "The Manufacture of Biodiesel from the used vegetable oil," EISOIh, 2011.

[19] P. Castro, J. Coello, and L. Castillo, "Opciones para la producción y uso del biodiésel en el Perú," Soluciones Prácticas - ITDG, 2007.

[20] M. C. Math, S. P. Kumar, and S. V. Chetty, "Technologies for biodiesel production from used cooking oil - A review," Energy Sustain. Dev., vol. 14, no. 4, pp. 339-345, 2010.

[21] H. Incorporated and P. Eisenberg, "Cavitation."

[22] G. L. Maddikeri, P. R. Gogate, and A. B. Pandit, "Intensified synthesis of biodiesel using hydrodynamic cavitation reactors based on the interesterification of waste cooking oil," Fuel, vol. 137, pp. 285-292, 2014.

[23] L. F. Chuah, S. Yusup, A. R. Abd Aziz, A. Bokhari, and M. Z. Abdullah, "Cleaner production of methyl ester using waste cooking oil derived from palm olein using a hydrodynamic cavitation reactor," J. Clean. Prod., vol. 112, pp. 4505-4514, 2016. 
